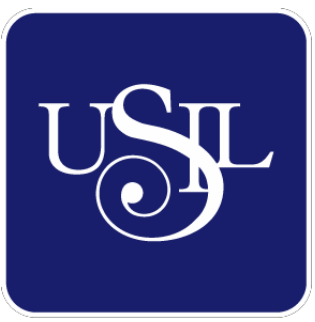

UNIVERSIDAD

SAN IGNACIO

DE LOYOLA

ESCUELA DE POSTGRADO

\title{
PLANEAMIENTO ESTRATÉGICO DE LA EMPRESA ENEL GENERACIÓN PERÚ S.A.A. PARA LOS AÑOS $2018-2023$
}

Trabajo de Investigación para optar el grado de:

PAÚL CAMINO FLORES

Maestro en Ciencias Empresariales con Mención en Gestión de Proyectos

DANIEL ALEJANDRO KANEKU ALAKAWA

Maestro en Ciencias Empresariales con Mención en Gestión del Capital Humano

GABRIELA OBREGÓN CHIU

Maestro en Ciencias Empresariales con Mención en Marketing y Gestión Comercial

Asesor:

Dr. Edmundo Rafael Casavilca Maldonado

$$
\text { Lima - Perú }
$$




\section{Resumen Ejecutivo}

En la actualidad las empresas que se sostienen y manejan al ritmo de los cambios de coyuntura nacional e internacional, se ven afectadas por la incidencia de factores tanto internos como externos, y, que afectan de manera directa el desempeño de sus operaciones, tal es el caso de la empresa generadora de energía eléctrica Enel Generación Perú SAA, principalmente la cobertura de la demanda de generación de energía eléctrica, los costos operativos. Mediante el presente Plan Estratégico se plantea incorporar y poner en marcha estrategias innovadoras, y, la aplicación de nuevas tecnologías que integre las iniciativas que pueden mitigar los principales problemas que afectarían el desempeño de la organización.

El mercado eléctrico peruano se encuentra altamente regulado. Los principales lineamientos sobre la organización y el funcionamiento del sector eléctrico peruano se establecen en la Ley de Concesiones Eléctricas y en especial en la Ley $\mathrm{N}^{\circ} 28832$, la cual asegura el desarrollo eficiente de la generación eléctrica. Los cambios en el marco regulatorio han permitido que Enel Generación Perú SAA, aumente su capacidad instalada en 130 MW desde su constitución en 1994.

Se seleccionó el sector de generación de energía debido al importante rol que juega en el crecimiento económico del Perú, especialmente por la difícil coyuntura políticoeconómica actual del país. Se decidió valorizar EGP porque se considera que es una empresa que ha evolucionado positivamente desde sus inicios y tiene el potencial de seguir creciendo.

Las acciones o iniciativas responden a los principales objetivos estratégicos:

a) Incremento de la cartera de clientes a nivel nacional.

b) Establecer procesos de mejora continua a través de la implementación de SIG como ERP.

c) Potenciar las relaciones con las comunidades donde se opera a través de los programas de RSE.

d) Calidad del servicio, tomando en cuenta la experiencia de las empresas que son del grupo Enel Generación Perú SAA.

e) Cumplir con los marcos legales y normas, basándonos en las certificaciones y acreditaciones de Seguridad y Medio ambiente ISO 14001- OHSAS 18001.

f) Productividad y eficiencia de los procesos implementando un área de desarrollo de otras fuentes de energía. 
g) Tecnología para el desarrollo de la generación de energía, implementando centrales mini-hidro.

h) Mejorar el compromiso organizativo y la satisfacción laboral.

Se ha considerado el presupuesto para la ejecución de las iniciativas en Miles de Soles, ascendiendo el costo de inversión en miles de S/. 410,929 en un horizonte de cinco años, que circunscriben la inversión en equipamiento y la construcción de un centro de capacitación y desarrollo y una central hidroeléctrica de energía renovable que permitiría la reducción de los costos de conversión de la energía y que permitiría mejorar la rentabilidad del grupo Enel Generación Perú SAA.

Se plantea que los encargados de implementar cada iniciativa sean los líderes que actualmente tienen sus cargos en cada área funcional y guardar relación con la estrategia

Se pronostica con la puesta en marcha de la ejecución del proyecto un incremento anual de $3 \%$ en los ingresos a partir del siguiente año de implementado el plan estratégico, tomando como proyección los siguientes cinco años, y teniendo como referencia los pronósticos que se fundamentan en los indicadores macroeconómicos. Para tener un enfoque con un orden lógico entre el costo de la implementación y los resultados que se buscó obtener, se presentan dos escenarios de evaluación económica, el primero denominado sin estrategia y el segundo con la implementación de la estrategia que se ha diseñado, producto de una evaluación previa. En tal sentido, los indicadores de valoración financiera, en el escenario denominado con implementación de la estrategia los resultados son positivos, reflejándose en una Tasa Interna de Retorno (TIRE) de 44\% y un Valor Actual Neto Económico (VANE) de Miles S/. 521,852.44; además, se obtendría un flujo incremental de Miles de S/. 1,402,539 en un horizonte de cinco años. Se concluye que el análisis financiero es positivo y la puesta en marcha depende de la gerencia. 


\section{Contenido}

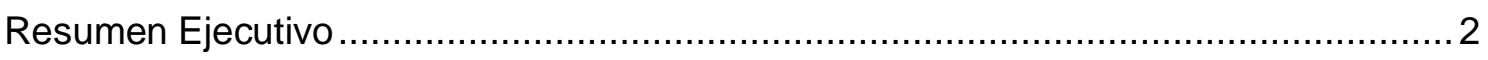

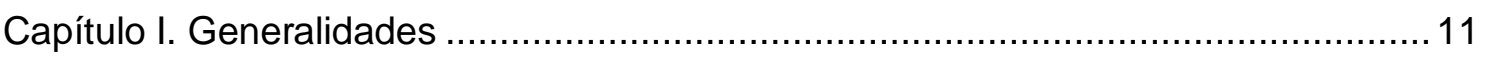

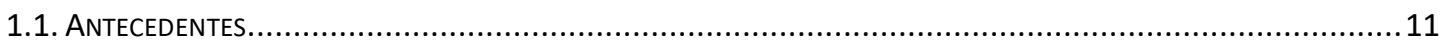

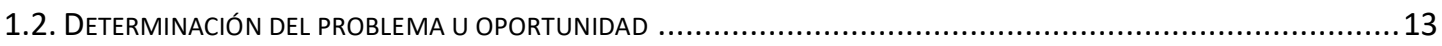

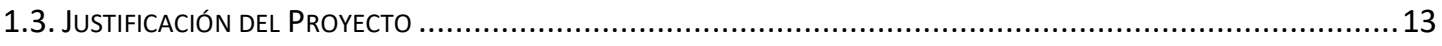

1.3.1. Justificación Empresarial................................................................................................ 13

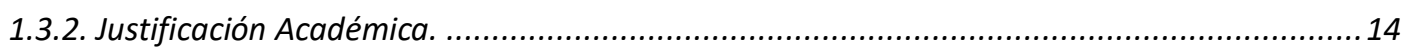

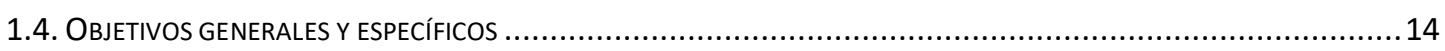

1.4.1. Objetivo General del Proyecto. ........................................................................................ 14

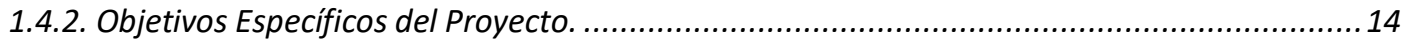

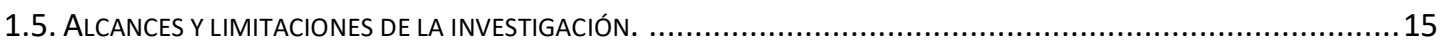

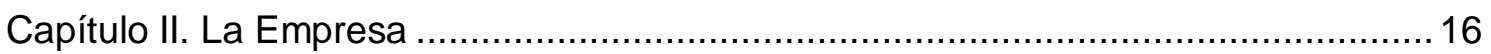

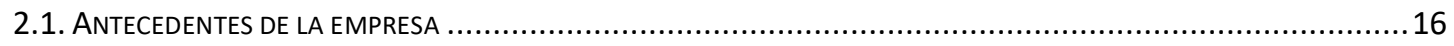

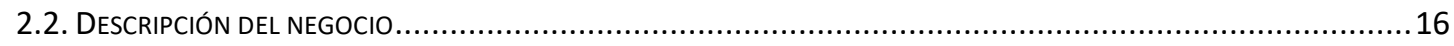

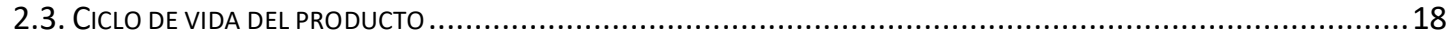

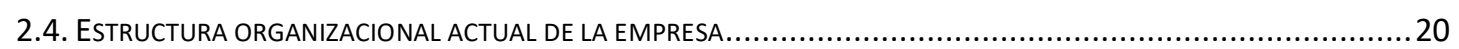

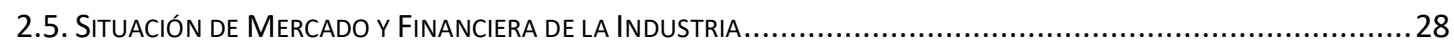

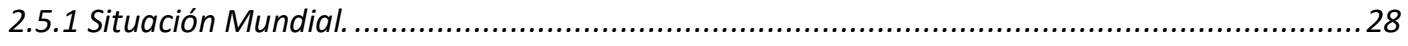

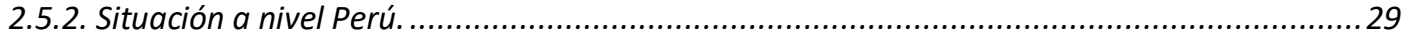

Capítulo III. Formulación de Visión, Misión y Valores de la Empresa ..........................30

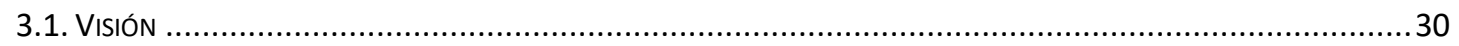

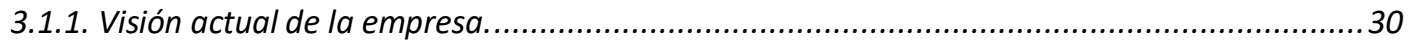

3.1.2. Análisis de la visión actual........................................................................... 30

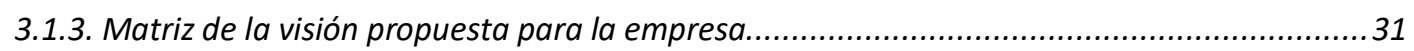

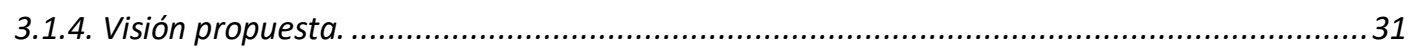

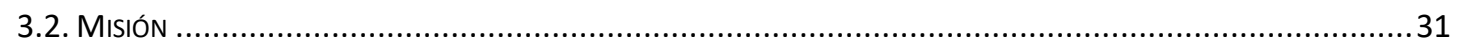

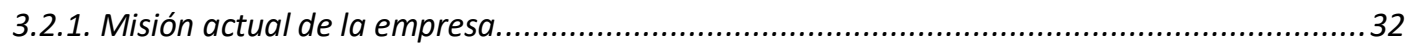

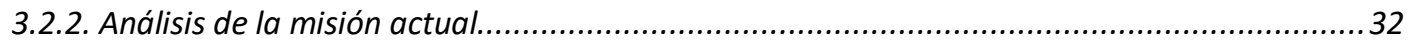

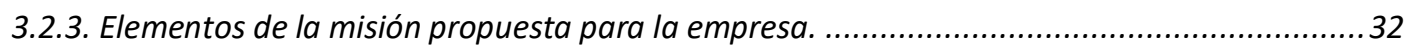

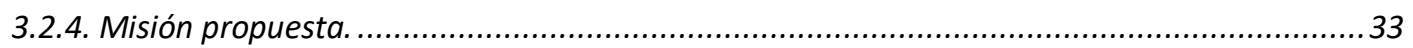

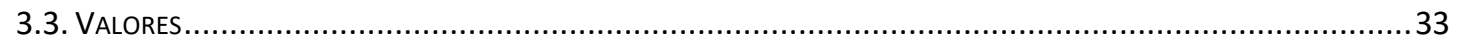

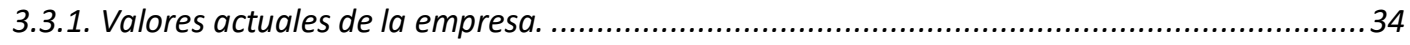

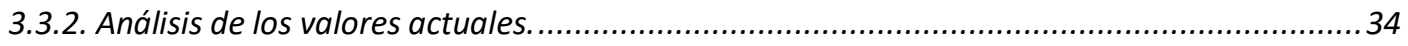

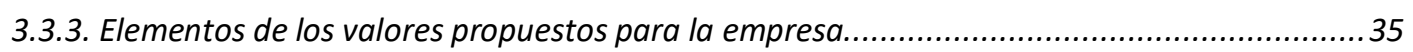


3.3.4. Valores propuestos.

3.4. AlineAmiento eStRATÉGICO DE LA VISIÓN, MISIÓn Y VALORES DE LA EMPRESA ..........................................36

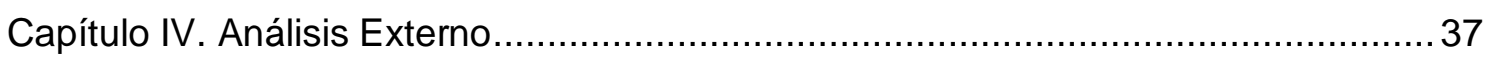

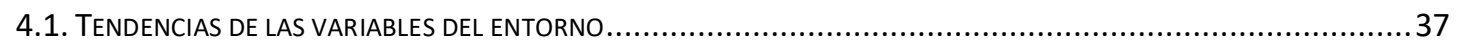

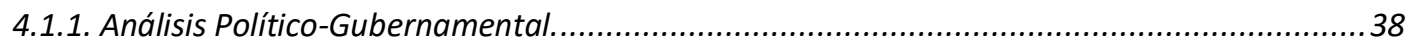

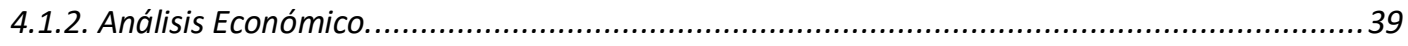

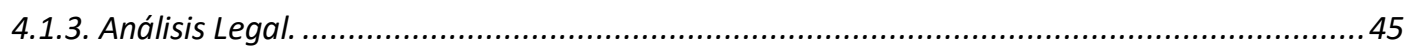

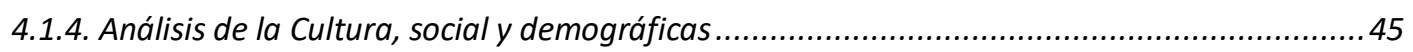

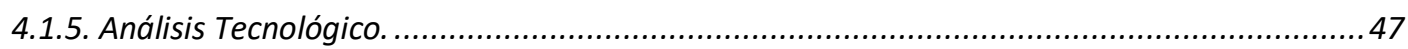

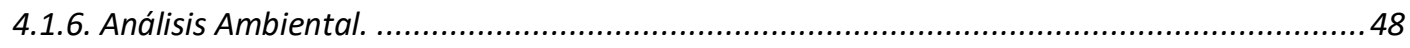

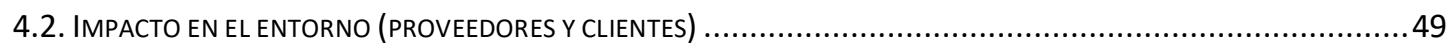

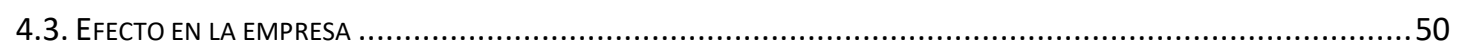

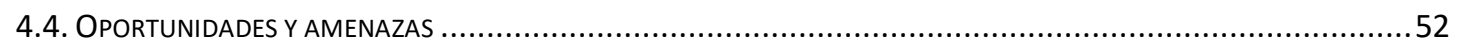

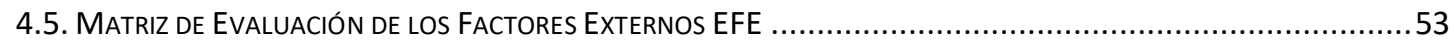

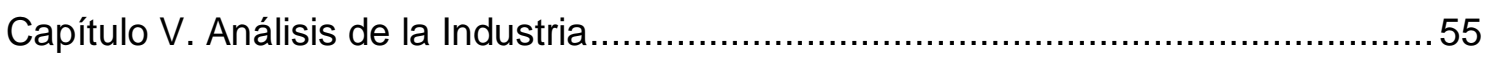

5.1. DeSCRIPCIÓN DEL MERCADO (DEMANDA) E INDUSTRIA (OFERTA) .............................................................5 55

5.2. DESCRIPCIÓN LAS CINCO FUERZAS COMPETITIVAS DE LA INDUSTRIA....................................................5 56

5.2.1Fuerza Competitiva de Porter: Poder de los Sustitutos. ...............................................5 57

5.2.2. Fuerza competitiva de Porter: Potenciales. ...........................................................5 57

5.2.3. Fuerza competitiva de Porter: Clientes.............................................................. 60

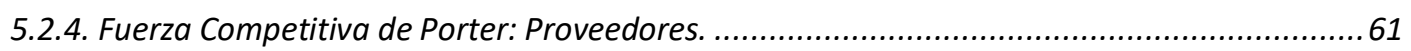

5.2.5. Fuerza Competitiva de Porter: Competencia en el mismo sector......................................61

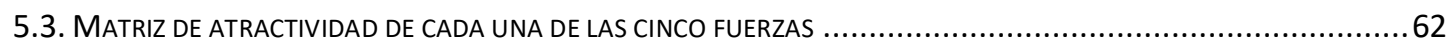

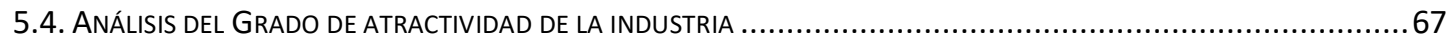

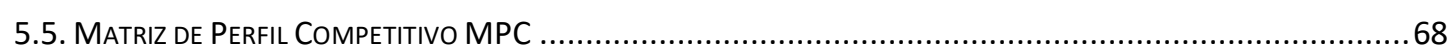

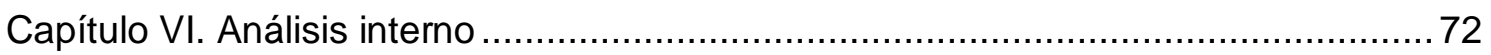

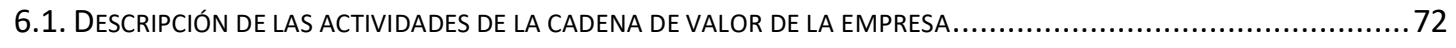

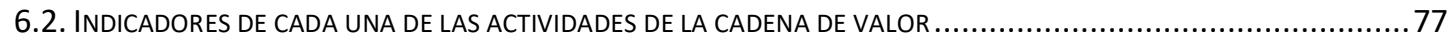

6.3. BENCHMARKING Y COMPARACIÓN CON LOS LÍDERES DE LA INDUSTRIA DE CADA UNA DE LAS ACTIVIDADES DE LA

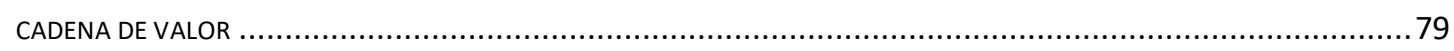

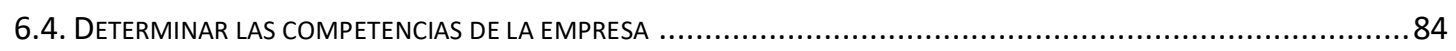

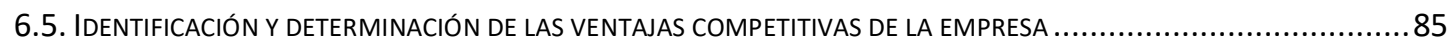

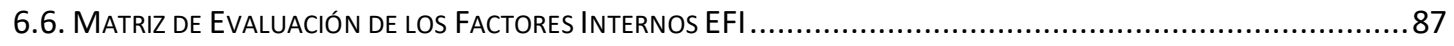

Capítulo VII. Formulación de los objetivos y diseño de las estrategias .........90

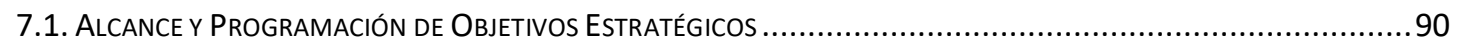




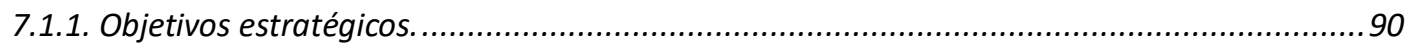

7.1.2. Análisis de los objetivos estratégicos. ................................................................ 91

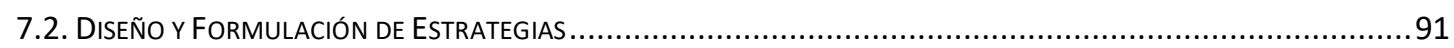

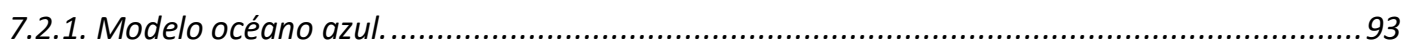

7.2.2. Matrices de formulación de estrategias...............................................................99

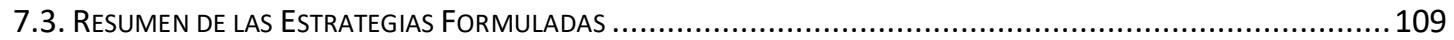

Capítulo VIII. Selección de la Estrategia ...............................................................110

8.1. Método Factores Estratégicos Claves........................................................................... 110

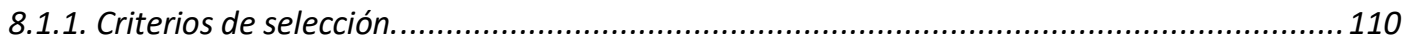

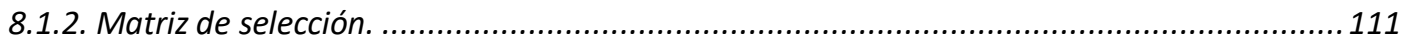

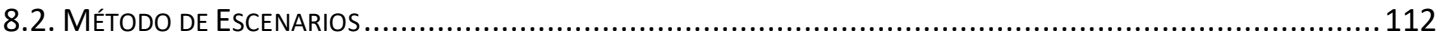

8.2.1. Descripción de escenarios considerados.................................................................. 112

8.3. Matriz de Planeación Estratégica Cuantitativa MPEC ......................................................... 118

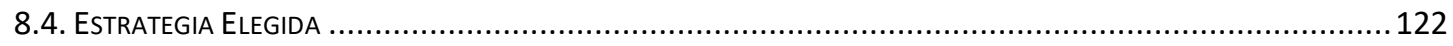

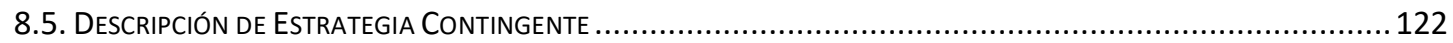

Capítulo IX. Implantación de la Estrategia ........................................................... 123

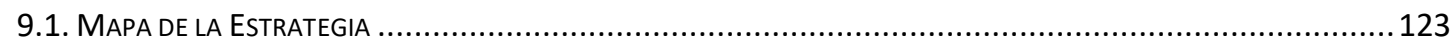

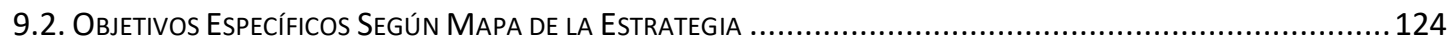

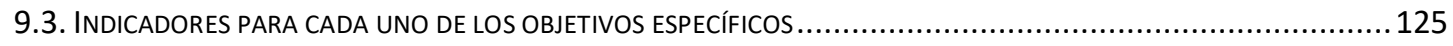

9.4. Metas Para Cada Uno de los Objetivos EsPecíficos............................................................... 127

9.5. Iniciativas (Acciones a llevar a Cabo Para Cada Uno de los Objetivos Específicos) Estrategias,

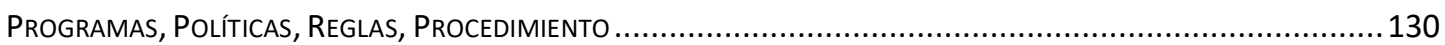

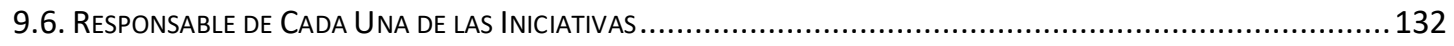

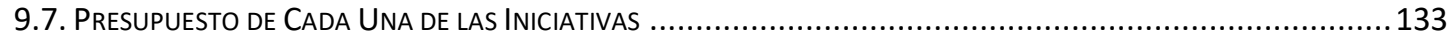

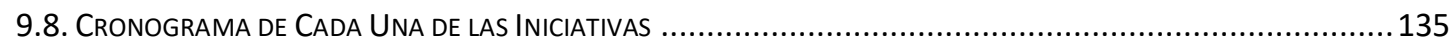

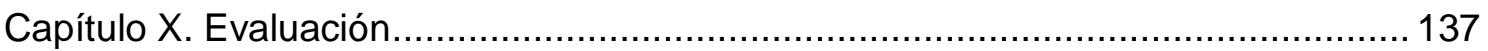

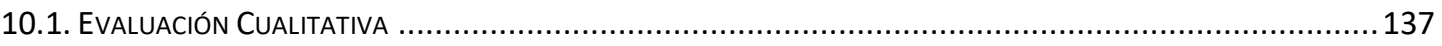

10.1.1. Criterios de Evaluación. ........................................................................... 137

10.1.2. Comparación de la Estrategia con los Criterios.................................................... 137

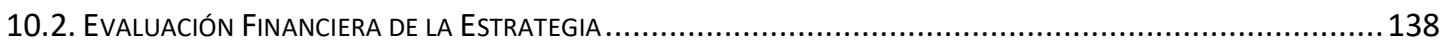

10.2.1. Proyección de Estados Financieros. (Situación Actual y con la Nueva Estrategia) ............. 138

10.2.2. Estado de Resultados. (Situación Actual y Nueva Estrategia)...................................... 140

10.2.3. Balance General. (Situación Actual y con la Nueva Estrategia) .................................. 143

10.2.4. Flujo de Efectivo. (Situación Actual y con la Nueva Estrategia) ...................................... 148

10.2.5. Evaluación Financiera. (VAN, TIR y Ratios Financieros) .............................................. 151

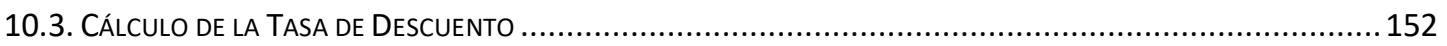


10.3.1. Costo de Oportunidad. (Ke)

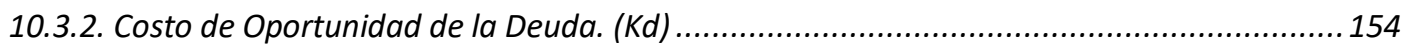

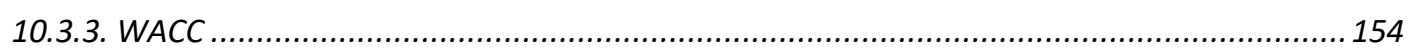

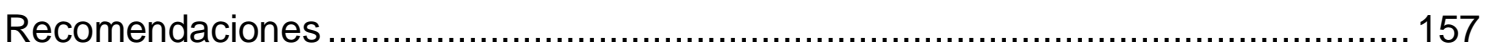

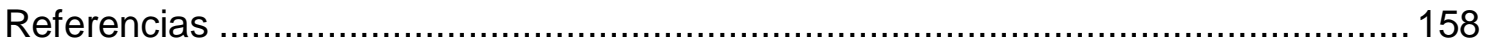

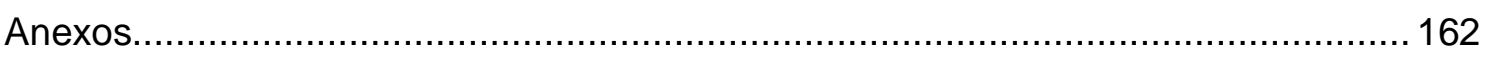




\section{Índice de tablas}

Tabla 1 Proceso de generación eléctrica por tipo de central .....................................23

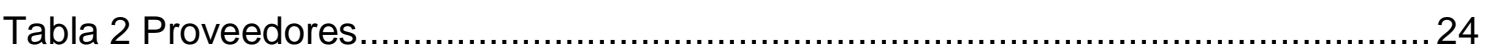

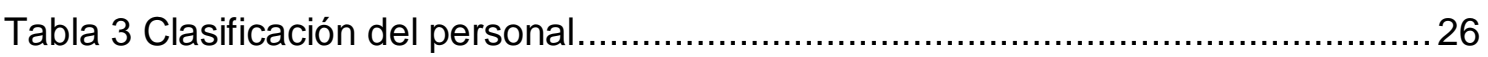

Tabla 4 Edades de la población laboral del personal de Enel. ....................................26

Tabla 5 Comparativa de salario más bajo en la empresa vs. Salario mínimo...............28

Tabla 6 Análisis Político.......................................................................................... 49

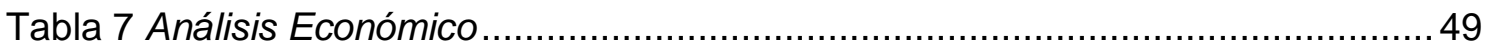

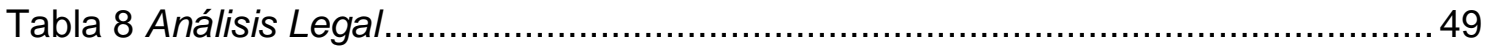

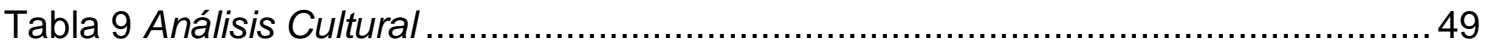

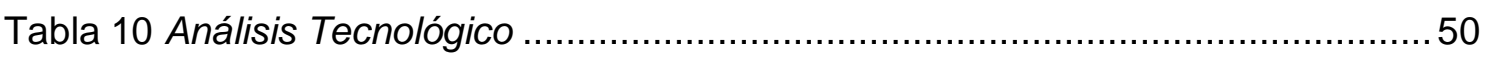

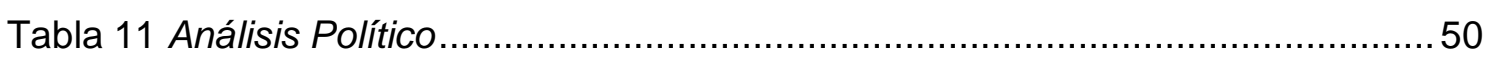

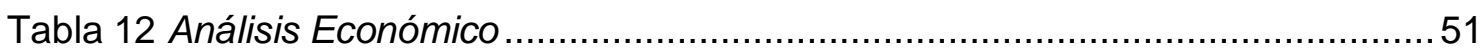

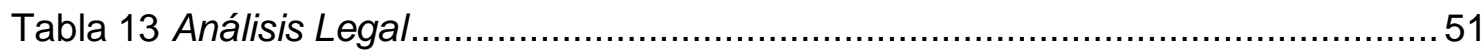

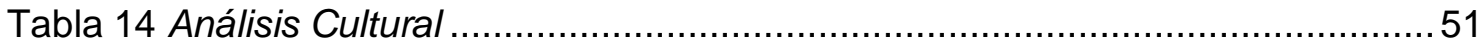

Tabla 15 Matriz EFE de Enel Generación Perú SAA................................................... 54

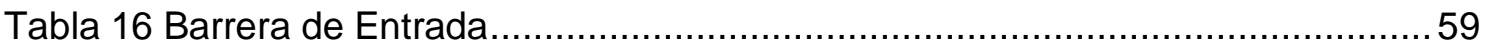

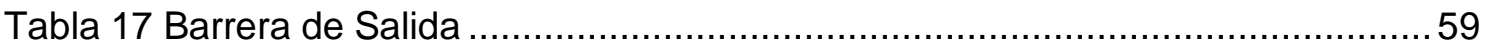

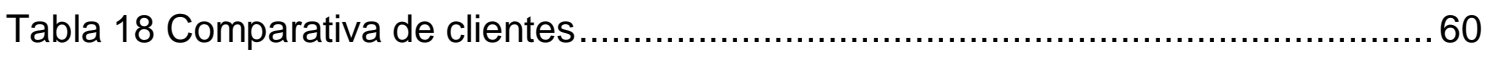

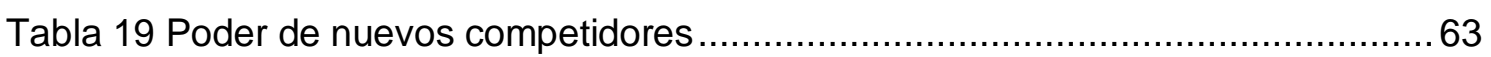

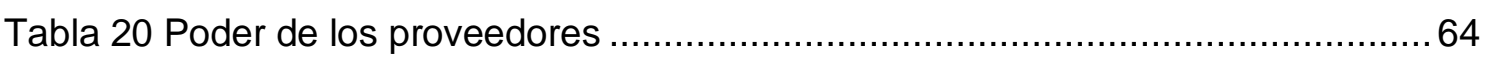

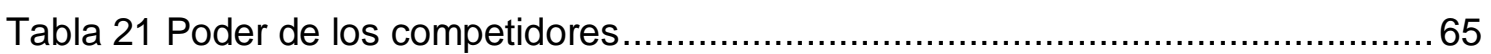

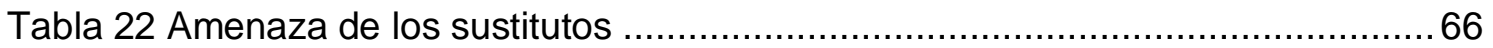

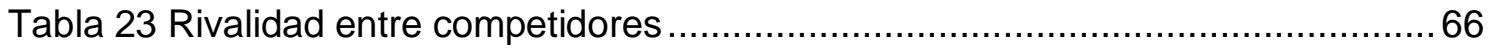

Tabla 24 Compromiso de Inversión privada 2017 - 2019 por sectores (Millones de

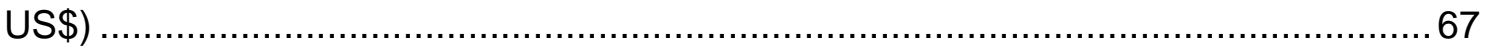

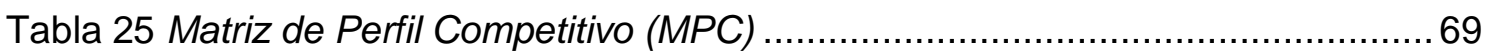

Tabla 26 Relación de Clientes Libres y Regulados de Enel Generación Perú SAA.....75

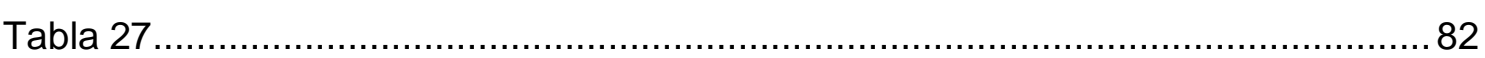

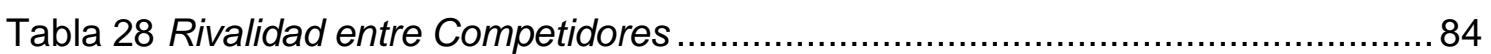

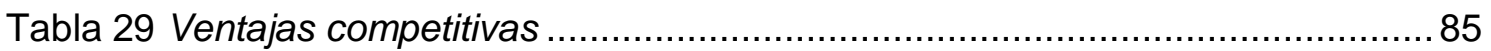

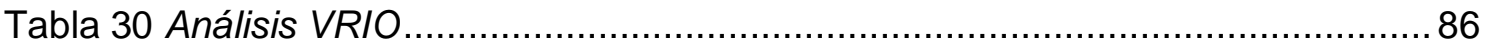

Tabla 31 Matriz de Evaluación de Factores Internos (EFI) ....................................... 88

Tabla 32 Características de las empresas de Generación ...........................................93

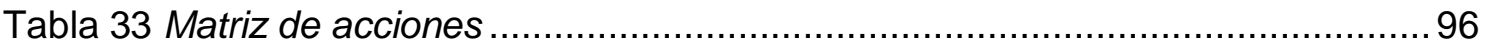




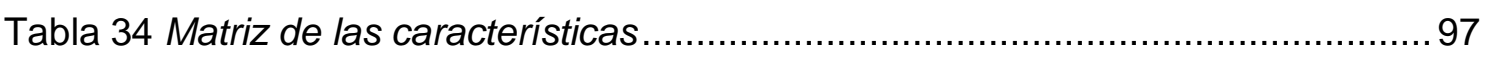

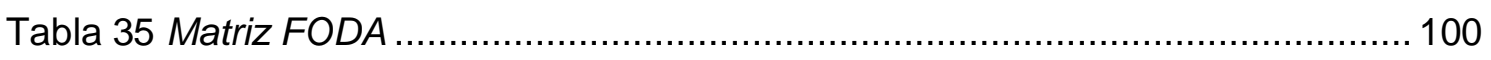

Tabla 36 Factores que constituyen las Variables de los Ejes de la Matriz PEYEA de

Enel Generación Perú SAA............................................................................. 104

Tabla 37 Matriz de Selección de la estrategia........................................................ 111

Tabla 38 Objetivos estratégicos al 2021 CEPLAN .................................................... 112

Tabla 39 Escenarios 2017-2021 ..................................................................... 114

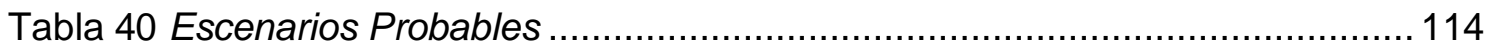

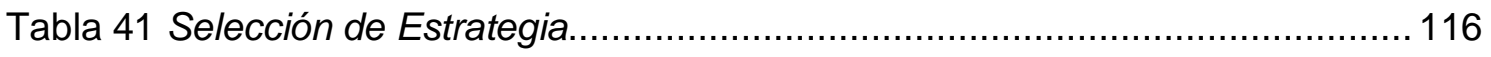

Tabla 42 Matriz de Estrategias vs. Objetivos a Largo Plazo..................................... 116

Tabla 43 Matriz Planeación Estratégica Cuantitativa MPEC .................................... 119

Tabla 44 Objetivos específicos de acuerdo con el mapa de la estrategia ................... 124

Tabla 45 Indicadores para cada objetivo específico.................................................. 126

Tabla 46 Metas Para Cada Uno de los Objetivos Específicos.................................. 129

Tabla 47 Iniciativas para cada uno de los objetivos-Perspectiva financiera y clientes 130

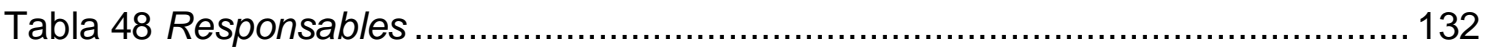

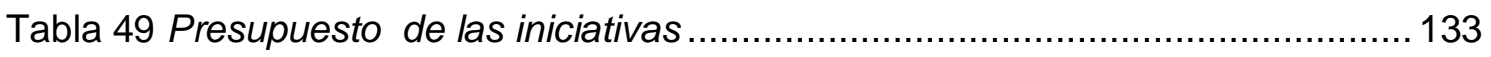

Tabla 50 Cronograma de cada una de las iniciativas .............................................. 135

Tabla 51 Análisis de Rumelt de estrategias ....................................................... 138

Tabla 52 Principales variables y supuestos ........................................................ 139

Tabla 53 Estado de Resultados: Situación Actual S/.................................................... 141

Tabla 54 Estado de Resultados: Situación Nueva Estrategia, S/. (000) ..................... 142

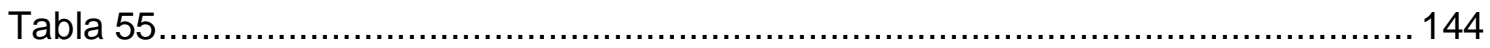

Tabla 56 Balance General: Situación con la Nueva Estrategia, S/.......................... 146

Tabla 57 Flujo de efectivo: Situación Actual, S/. ....................................................... 149

Tabla 58 Flujo de efectivo: Situación con la Nueva Estrategia, S/. - Flujo de Caja

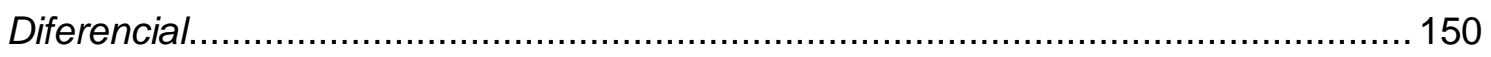

Tabla 59 Ratios financieros proyectados, Análisis Dupont y Liquidez ...................... 152

Tabla 60 Cálculo del Ke............................................................................... 153

Tabla 61 Cálculo del Kd................................................................................ 154

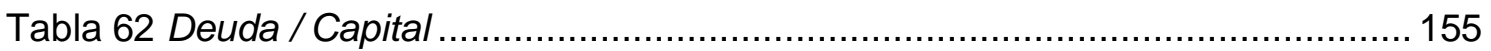

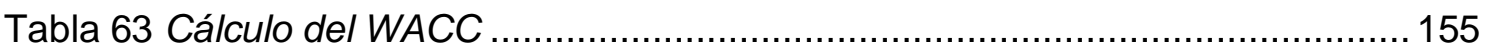




\section{Índice de Figuras}

Figura 1. Ciclo de vida servicio de Enel Generación Perú SAA..................................20

Figura 2. Organigrama Funcional de la empresa Enel Generación Perú SAA..............21

Figura 3. Matriz para formular la visión. ............................................................ 31

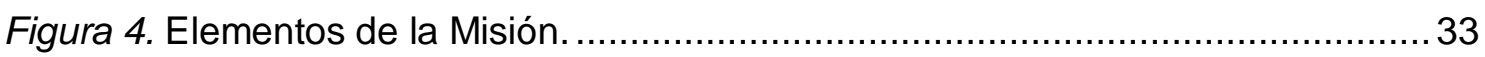

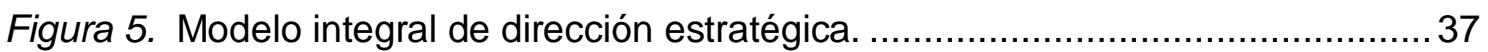

Figura 6. Variación del PBI 2000-2017. Adaptado del INEI - Gestión.......................... 39

Figura 7. Evolución y proyección de la Inflación en el Perú año 2015 - 2019. INEI ....40

Figura 8. Evolución de riesgo País de Perú 1998 - 2017. Banco Central de Reserva 41

Figura 9. Tipo de cambio promedio anual 2000-2016Fuente: BCRP.......................... 42

Figura 10. Tipo de cambio promedio anual 2000-2016Fuente: BCRP ....................... 42

Figura 11. Reducción de la Pobreza Extrema según ámbito geográfico ..................... 44

Figura 12. Reducción de la Pobreza No Extrema según ámbito geográfico ................. 44

Figura 13. Evolución número de trabajadores en el rubro de generación......................46

Figura 14. Muestra la producción acumulada por tipo de recurso a diciembre 2018 ...58

Figura 15. Muestra la producción acumulada por tipo de recurso a diciembre 2018 ...58

Figura 16. La cadena de Valor en Servicios........................................................ 72

Figura 17. Esquema de una Central Hidroeléctrica.................................................. 73

Figura 18. Esquema de una Central Térmica a Gas. ............................................... 74

Figura 19:Participación de Mercado Sector Eléctrico 2018 ....................................... 83

Figura 20. Lienzo de la empresa y sus competidores. .......................................... 95

Figura 21. Lienzo de la nueva estrategia considerada. ......................................... 98

Figura 22. Matriz PEYEA de Enel Generación Perú SAA ......................................... 106

Figura 23. Matriz Interna -Externa de Enel Generación Perú SAA............................ 107

Figura 24. Matriz BCG. ................................................................................ 108

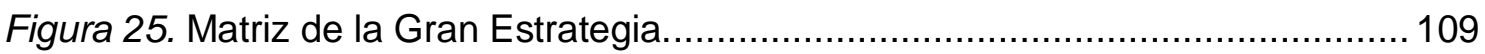

Figura 26. Mapa estratégico de Enel Generación Perú SAA................................... 124 


\section{Capítulo I. Generalidades}

\subsection{Antecedentes}

En el ámbito nacional, se ha encontrado estudios como el de Alcalde, Aquino, Duran, Núñez, \& Trelles (2017) quienes desarrollaron la investigación titulada Valor Compartido en las Empresas de Generación de Energía Eléctrica en el Perú, el objetivo ha sido describir el nivel de aplicación del valor compartido en las empresas de generación de energía eléctrica en el Perú en el año 2016. Para conseguir este objetivo, se efectuó un análisis cuantitativo. Los datos recolectados provinieron de fuentes primarias y secundarias relacionados con las siete empresas más importantes de generación de energía eléctrica en el Perú, las cuales fueron: Enel Generación Perú SAA, Engie Perú S.A., Kallpa Generación S.A., Fénix Power Perú S.A., Statkraft Perú S.A., Duke Energy Egenor S. en C por A. y Electricidad del Perú - Electroperú S.A. Los resultados de la propuesta de investigación señalaron que solo una de las organizaciones empresariales tiene conocimiento del concepto de valor compartido.

Asimismo, ninguna de las siete empresas investigadas se encontró preparada para la aplicación del valor compartido. De otro lado, solo una empresa aplicó el valor compartido de acuerdo con las tres formas propuestas por Porter y Kramer (2011). Se concluyó que cinco empresas del muestreo se ubicaban en el nivel 2 con respecto al VC con enfoque de Stakeholders. Los resultados logrados se emplearon para solventar de información y conocimiento a los actores importantes del sector de generación de energía eléctrica en el Perú.

También, es pertinente citar la investigación de Salas (2013), el propósito fue diagnosticar, analizar y proponer acciones de mejora al proceso de gestión de interrupciones imprevistas en el suministro eléctrico de baja tensión. Se realizó un diagnóstico del proceso de operaciones y gestión de dificultades presentadas en baja tensión de la compañía. Es importante destacar que dentro de los propósitos del estudio se identificaron fallas en las redes de distribución, también fue propósito reducir el costo operativo de la cuadrilla de reparaciones SAE. Se basa en una mejora de la eficiencia operativa del proceso traducida en menores niveles de fatiga física y mental, el mantenimiento de la calidad del servicio de reparación y la reducción de accidentes por manipulación de equipos y cableado eléctrico.

Balarezo Valdez, García, Catherine, \& Zambrano (2014) desarrollaron el plan estratégico denominado "Planeamiento Estratégico del Sector de Generación de Energía Eléctrica del Perú", el objetivo fue establecer que el sector de generación eléctrica del Perú sea reconocido en el país y en Sudamérica por su compromiso en satisfacer la demanda nacional cumpliendo con la Norma Técnica de Calidad del 
Servicio Eléctrico (NTCSE) a un precio competitivo, por su esfuerzo en llegar a las zonas rurales más remotas y por su responsabilidad con el medio ambiente promoviendo el uso de energías renovables.

Celis, Gutiérrez, Silva Matos, \& Torres (2012) desarrollaron la investigación titulada Plan Estratégico del Sistema de Generación Térmica de Electricidad en el Perú, el modelo estratégico proyecta una visión para el año 2030 en el que el sistema de generación térmica lidera la producción de electricidad en base a eficiencia y productividad, satisfaciendo la alta demanda nacional, desarrollando nuevos mercados con altos estándares de calidad y respetando a todos los Stakeholders. La evaluación estratégica del sistema de generación térmica de electricidad del Perú se basará en los resultados que arroje los indicadores de las diferentes perspectivas en base a los objetivos a corto plazo, además de los indicadores que darán un control cuantitativo de dicho objetivo que muestra claramente la meta deseada En el ámbito internacional, se ha encontrado el estudio del Gobierno Unidad Nacional (2011), se presentó el plan estratégico para su implementación en un horizonte de tres años en el cual se establecen las acciones y estrategias que se desarrollarán para cumplir con la misión de contribuir con el desarrollo de la nación brindando un servicio oportuno y de calidad. Los objetivos estratégicos para el desempeño de la misión fueron reducir el nivel de pérdidas, modernizar procesos de control y operación para mejorar la eficiencia administrativa, desarrollar la inversión que asegure el suministro de electricidad, impulsando y desarrollando la generación de electricidad a través de fuentes renovables y atendiendo las necesidades energéticas del pueblo hondureño en el marco del plan de nación y visión de país.

Cada una de las acciones que forman parte de las estrategias de corto y mediano plazo, serán ejecutadas por los responsables designados por las respectivas dependencias involucradas. El costo estimado del monitoreo fue de US\$70,000.00 para la compra de equipo de cómputo para la Unidad de Monitoreo y enlaces de los Planes Operativos Anuales (POAS), además de la adquisición del software que automatice la recolección de información, indicadores y POAS (Gobierno Unidad Nacional, 2011).

De acuerdo con los antecedentes citados del ámbito nacional como internacional, se puede fundamentar que el plan estratégico que se plantea a la empresa Enel Generación Perú SAA tiene un soporte científico que correlaciona de manera directa y positiva con las estrategias que se determinen a implementar posteriormente, es notable que el tema de la generación de energía eléctrica ha evolucionado de manera coyuntural donde las amenazas siempre van a estar presentes y actualmente se hace 
necesario que se apliquen estrategias que permitan mitigar las amenazas a la que se encuentra expuesta Enel Generación Perú SAA.

\subsection{Determinación del problema u oportunidad}

Internamente existen diversas debilidades en relación con la industria de generación de energía eléctrica; este tipo de empresas se encuentran expuestas a distintas amenazas, frente a ello es necesario analizar el ambiente interno/externo y determinar cuáles son las amenazas que se deben mitigar y que debilidades se deberán fortalecer. También se hizo necesario determinar la necesidad de incrementar proyectos de inversión para el desarrollo de generación eléctrica a largo plazo. Entre otros, los problemas relacionados con la gestión administrativa y operativa. Por lo tanto, se debe tomar en cuenta que la optimización de costos permite mejorar la rentabilidad de la empresa.

Ante este panorama, la empresa Enel Generación Perú SAA debe tomar medidas que sean sostenibles en el tiempo.

Enel Generación Perú SAA debe plantear acciones estratégicas que permitan la optimización y mejora de todos los procesos transversales y del core del negocio. Por otro lado, se cuenta con el respaldo del grupo corporativo al que pertenece el cual se dedica al rubro de la generación de energía eléctrica a nivel global.

\subsection{Justificación del Proyecto}

\subsubsection{Justificación Empresarial.}

La investigación y propuesta del plan de acción estratégica surge bajo la necesidad de Enel Generación Perú SAA, de desarrollar un plan estratégico que permita y ayude a la empresa a ser sostenible en sus operaciones, por lo tanto, se busca incrementar la generación de energía eléctrica que serviría para cubrir la demanda estimada con un margen de reserva promedio del mercado. En efecto, a través de la implementación de tecnología de punta se debe explotar las fuentes de energía renovables para la generación de energía eléctrica. También mediante la reducción de los costos operativos de Enel Generación Perú SAA se buscará incrementar el rendimiento financiero promedio (ROE).

El diseño del plan estratégico se convierte en un instrumento de gestión recomendable sustentado en las teorías científicas de la administración moderna, que permitirá a los gerentes y personal de Enel Generación Perú SAA, situar las decisiones en el logro de aumentar la cuota de mercado, para generar mayor rentabilidad a través del mejoramiento en el servicio que se ofrece en el rubro empresarial, buscando mayor eficacia en las metas propuestas, y mayor amplitud en la eficiencia de la gestión de los recursos económicos. Para que la empresa Enel Generación Perú SAA de generación 
eléctrica del país logre un pleno desarrollo y finalmente el éxito en el futuro es fundamental que siga creciendo, promoviendo nuevos proyectos de inversión. Posteriormente a la realización de una evaluación de tipo cualitativo y tomando en cuenta el soporte que nos entregan los expertos en el tema; por otro lado, el análisis de tipo cuantitativo se recomienda desarrollar y proponer el plan estratégico para que la Empresa Enel Generación Perú SAA enfrente de forma eficaz la volatilidad del mercado y lograr el objetivo de incrementar la rentabilidad. Por lo tanto, es necesario analizar el ambiente interno y externo que afecta a la organización.

\subsubsection{Justificación Académica.}

El panorama de la industria de generación de energía eléctrica se ha desarrollado bajo un ambiente prometedor de oportunidades que se enfocan en el desarrollo de una propuesta estratégica para aplicar los conocimientos adquiridos en la Maestría. Frente a ello se hace necesario proponer y desarrollar herramientas de tipo estratégico que permitan en corto plazo establecer una mejor ventaja competitiva a nivel empresarial, en el caso de la empresa Enel Generación Perú SAA, también es fundamental establecer cómo los factores externos a nivel país vienen afectando el proceso operativo de la empresa.

\subsection{Objetivos generales y específicos}

\subsubsection{Objetivo General del Proyecto.}

Promover el desarrollo de las energías renovables, automatizar los procesos, realizar el plan de inversión, incrementar el nivel de generación de energía (capacidad instalada), para ampliar la cobertura brindando un servicio confiable y de calidad; obteniendo un incremento en la rentabilidad para los inversionistas.

\subsubsection{Objetivos Específicos del Proyecto.}

El Plan se divide en acciones de corto y mediano plazo. Las acciones de corto plazo son las siguientes:

a) Analizar el sector de energía eléctrica en el Perú.

b) Analizar y describir los factores de incidencia del ambiente interno y externo de Enel Generación Perú SAA.

c) Seleccionar las estrategias financieras, administrativas y operativas de la empresa Enel Generación Perú SAA.

d) Planificar la implementación de las estrategias para Enel Generación Perú SAA.

e) Calcular el capital económico para la ejecución de las actividades de acuerdo al plan estratégico para Enel Generación Perú S.A.A. 
Las medidas de mediano plazo incluyen:

f) Incrementar la Creación de Valor Económico de la Empresa

g) Ejecutar el Plan de Responsabilidad Social Empresarial

h) Incrementar la Eficiencia de la Empresa con respecto a la gestión de contrataciones.

i) Desarrollar las competencias del personal y transferencia de know how.

\subsection{Alcances y limitaciones de la investigación.}

\section{Alcances}

Se utilizará la información recopilada para el desarrollo del Programa General Aplicado, proporcionada por la empresa, así como la información recolectada de las distintas fuentes secundarias, la que nos permitirá desarrollar:

El Plan Estratégico que comprenderá un periodo de 5 años, considerando como año base 2018.

Incluye a toda la Empresa.

\section{Limitaciones}

Limitación del conocimiento técnico del sector de generación.

La dificultad al acceso de la información de la empresa y de sus competidores, por parte de los integrantes del grupo por el temor de los accionistas a la divulgación de su información comercial (nuevos clientes, nuevos nichos de negocio, tecnología). Después de la elaboración del presente capítulo, concluimos que es de vital importancia la elaboración de un Método estratégico para la empresa Enel Generación Perú S.A.A, que le admita afrontar el crecimiento que viene presentando el sector al cual está dirigido 


\section{Capítulo II. La Empresa}

\subsection{Antecedentes de la empresa}

Enel Generación Perú SAA, es una empresa de capitales privados que opera en el país, ubicada en el sector de generación de energía eléctrica; y, que percibe los ingresos por venta de potencia y energía a clientes libres realizados bajo contratos, con clientes que se encuentran regulados por el ente regulador, o, a transferencia de potencia y energía en el mercado denominado spot.

Los orígenes de Enel Generación Perú S.A.A. se remontan a 1906, con el nacimiento de Empresas Eléctricas Asociadas, empresa privada dedicada a la generación, transmisión y distribución de electricidad. Posteriormente, en 1974, la mayoría absoluta del capital de dicha empresa pasó a poder del Estado, cambiando su razón social a Electro-lima S.A (BVL, 2007).

En 1994, la empresa fue separada en tres diferentes unidades de negocio: generación, transmisión y distribución. La unidad de negocio de generación fue el origen de la Empresa de Generación Eléctrica de Lima S.A. (Edegel). El control de la empresa fue transferido al sector privado en 1995, cuando el Estado vendió el 60\% del capital social al consorcio Generandes.

Enel Generación Perú SAA es la mayor compañía privada de generación de electricidad en el Perú. A la fecha cuenta con una potencia efectiva total de 1283.8 $\mathrm{MW}$, de la cual 739.4 MW corresponde a potencia hidroeléctrica y $544.4 \mathrm{MW}$ a potencia termoeléctrica.

Como empresa generadora percibe ingresos por la venta de potencia y la venta de energía, las cuales se realizan bajo contratos con clientes libres, clientes regulados o a través de transferencia de potencia y energía en el mercado spot.

Enel Generación Perú SAA forma parte del Sistema Interconectado Nacional y realiza sus operaciones conforme a lo establecido en la Ley de Concesiones Eléctricas y de acuerdo con lo indicado por el COES-Sinac. Además, cumple las normas aplicables a las actividades del sector eléctrico establecidas por el MEM y supervisadas por Osinergmin (Edegel, 2013).

\subsection{Descripción del negocio}

Enel Generación Perú SAA es una empresa privada dedicada a la generación de energía eléctrica.

\section{Enel en el mundo.}

Con presencia en 34 países y en los 5 continentes, la empresa produce energía con una capacidad instalada neta de 83 GW (Gigavatio) aproximadamente, llevando electricidad y gas a una red de 2,1 millones de $\mathrm{km}$. Con 64 millones de usuarios finales 
en el globo, la organización cuenta con una mayor base de clientes en Europa y es la principal empresa eléctrica del continente con respecto a capacidad instalada y a EBITDA declarado (Enel, 2017).

El personal del grupo Enel Generación Perú SAA es de aproximadamente 63.500 personas, de ambos sexos en el mundo entero, cuya labor se basa aplicar los valores de Responsabilidad, Innovación, Confianza y Proactividad de la empresa. Navegando hacía el mismo rumbo: ser Open Power para enfrentar algunos desafíos del mundo actual.

Enel Generación Perú SAA tiene dentro de su gestión un parque de centrales diversificadas: gestión de tipo hidráulica, termoeléctrica, nuclear, hidroeléctrica, geotérmica, fotovoltaica, eólico y otras fuentes renovables.

Enel Generación Perú SAA tiene el compromiso en el sector de las energías renovables, en la investigación y el desarrollo de nuevas tecnologías que respetan el medio ambiente.

La empresa negocia en promedio $36 \mathrm{GW}$ de su capacidad operativa instalada que proviene de las infraestructuras de tipo hídrica, eólica, geotérmica, fotovoltaica, biomasa y cogeneración en Europa, América, Asia y África dentro de las empresas que operan la energía renovable a nivel mundial. Enel Generación Perú SAA tiene mayor diversificación tecnológica (Enel, 2017).

\section{Nueva identidad corporativa.}

La nueva marca "Open Power", representa una nueva forma de dar acceso de energía a más personas, significa apertura hacia el mundo la energía a otras tecnologías, dar la posibilidad de otros usos y abrirse a nuevas alianzas.

El perfil actual de Enel Generación Perú SAA., personifica la imagen empresarial moderna de la empresa que se caracteriza por ser abierta, reactiva, flexible, líder en la transición de energía.

\section{En el Perú.}

Enel Generación Perú SAA es una empresa privada dedicada a la generación de energía eléctrica.

En Perú el grupo Enel Generación Perú SAA opera en distribución y generación eléctrica. Enel Distribución Perú es una de las primeras distribuidoras del país. Se cuenta con más de 1.3 millones de clientes y 7.7816 TWh en ventas el 2016 (Enel Generación Perú SAA, 2017).

Enel Generación Perú S.A. es una de las principales generadoras eléctricas del país con una potencia efectiva, incluida su filial Chinango, de 1,682.7 MW a diciembre 
2016. De manera posterior a su privatización, la empresa pasó a ser controlada por el grupo Enel Generación Perú SAA, compañía multinacional que posee actualmente el 35.8\% del accionariado (Apoyo \& Asociados , 2017).

Enel Generación Perú SAA es una de las mayores generadoras del país con un $13.86 \%$ del total de potencia del SEIN (Sistema Eléctrico Interconectado Nacional) en el 2016. Posee 1,682.60 MW (53.3 \% térmico; 46.7\% hidráulico) y cuenta con siete centrales hidroeléctricas y dos centrales térmicas (Enel Generación Perú SAA, 2017). Enel Generación Perú SAA realiza actividades propias de la generación y la comercialización de energía eléctrica, y mantiene presencia en el negocio de gas natural. Su producción de electricidad durante el 2016 fue de 679.58 GWh (Enel Generación Perú SAA, 2017).

La empresa opera en energías renovables a través de Enel Green Power, teniendo proyectado una inversión de casi 400 millones de dólares. Se tiene adjudicados tres megaproyectos por $332 \mathrm{MW}$ licitados en eólico $132 \mathrm{MW}$, fotovoltaico $180 \mathrm{MWp}$, e hidroeléctrico 20 MW (Enel Generación Perú SAA, 2017).

\subsection{Ciclo de vida del producto}

La etapa del ciclo de vida en el que se encuentra la empresa es de Madurez, gracias a factores de tipo tecnológico y financiero que inciden directamente en sus operaciones. La Compañía Enel Generación Perú SAA pese al enfriamiento económico en Perú proyecta mantener un crecimiento del $10 \%$ frente al año anterior y superar los $S / .300$ millones en facturación. A nivel del mercado se espera que se incremente $2.7 \%$ anualmente, por mayor atención.

Si bien es cierto han pasado 23 años desde la privatización de la compañía, el mercado peruano de generación de energía todavía debe seguir expandiéndose para poder atender la demanda de los grandes proyectos de minería, infraestructura, industria y desarrollo urbano. Por lo tanto, Enel Generación Perú SAA continuará realizando inversiones para aumentar su participación de mercado y atender a la demanda del sector.

Las entrevistas realizadas a los clientes internos, la empresa aplica estrategias operativas gestionando nuevos proyectos de energía renovable, apuntando por la tecnología limpia, de rápida ejecución e implantación de proyectos, y retornos económicos en orden con los periodos previstos y la inversión realizada estratégicamente desde un respaldo global de Enel Italia.

Debido a estos indicadores la empresa actualmente se encuentra en su fase de Madurez, en base a la información obtenida por la empresa concluimos lo siguiente: 
luego del análisis de los EEFF auditados de los últimos años se evidencia que a Compañía ha presentado una tendencia creciente de sus ingresos totales desde el periodo 2012-2016, sin embargo, al primer semestre 2017 los ingresos disminuyeron $5.75 \%$ respecto al primer semestre 2016 como consecuencia de las menores tarifas promedio de nuevos contratos con clientes libres debido a menores precios en el mercado de generación, ocasionados por la sobreoferta, a pesar del ligero incremento en el volumen de ventas (en GWh). Cabe mencionar que el desempeño de los ingresos se encuentra influenciado por la evolución de la economía, dadas las características del sector eléctrico.

Por otro lado, las ventas para el 2018 vienen creciendo, respecto al año 2017, donde al cierre del año 2018 las ventas brutas fueron de S/. 1,438,539 respecto al 2017 que fueron de $S / .1,359,781$, lo que denota que la empresa cuenta con una estabilidad económica y mantiene el crecimiento en $5.7 \%$. Debe tenerse presente que, el mercado donde se desenvuelve la empresa está en constante cambio, los ciclos de vida suelen realizarse periódicamente por efecto del continuo crecimiento del sector al ser un servicio de necesidad básica que ofrecen, las cuales pueden generar un crecimiento continuo y redefiniciones sucesivas en la etapa de madurez.

Adicionalmente se considera los siguiente:

a. Perspectivas de Desarrollo y Crecimiento de la industria al 2025

Según el INEI (2018), para el año 2025 el Perú tendría una población de 35.7 millones de habitantes aproximadamente.

Se incrementa la población urbana en $6 \%$ al 2025 (dato a 1995 - 71.2\%), debido a la migración del área rural en busca de mejores oportunidades principalmente en lo laboral, salud, educación, otros.

b. Inversión

Las modificatorias en el marco de inversiones, ha permitido establecer limitaciones a largo plazo e incentivado la inversión. Al 2015, el sector eléctrico alcanzo US\$ 2593 millones de inversiones, de los cuales $91.2 \%$ correspondió a inversiones de empresas privadas, $4.1 \%$ a inversiones de empresas públicas y $4.7 \%$ a inversiones en electrificación rural. Del total de inversiones, la actividad de generación ejecuto $71.4 \%$, transmisión $14.2 \%$ y distribución $14.4 \%$.

c. Sector Minería 
Según el Banco Central de Reserva del Perú (BCRP), el crecimiento del Producto Bruto Interno (PBI) se debe al desarrollo de la minería metálica, impulsada por la producción cuprífera de las Bambas y Cerro Verde.

Para el rubro energético es positivo ya que el sector minero tiene más del $50 \%$ de usuarios que tiene generadores de energía. Enel Generación Perú SAA se encuentra en la etapa de Madurez (Osinergmin, 2017).

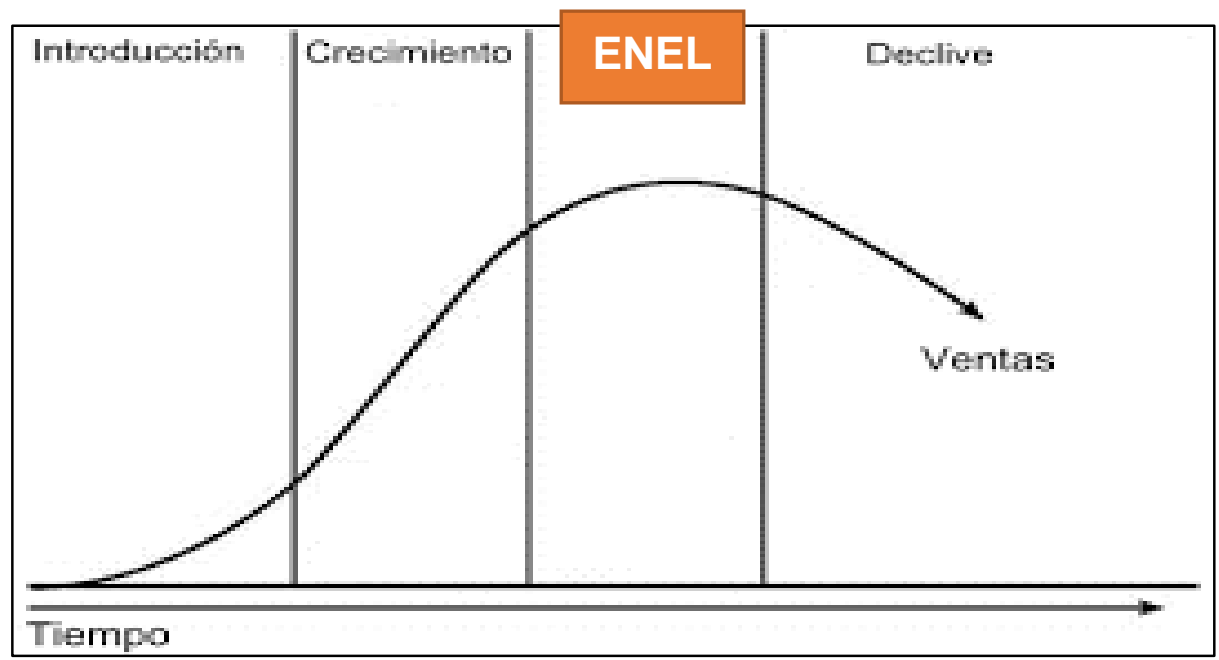

Figura 1. Ciclo de vida servicio de Enel Generación Perú SAA.

\subsection{Estructura organizacional actual de la empresa}

De acuerdo con Robbins y Judge (2012) "una estructura organizacional define el modo en que se dividen, agrupan y coordinan los trabajos de las actividades" (p. 523). Las empresas de gran dimensión utilizan diferentes formas de departamentalización. Analizando lo dicho por Robbins, una empresa del tamaño organizacional de Enel Generación Perú SAA desarrolla cada una de sus divisiones de acuerdo con sus líneas funcionales, y sus unidades de operaciones de acuerdo con los procesos. En empresas como Enel Generación Perú SAA, son los altos funcionarios quienes toman las decisiones, y los gerentes de bajo nivel sólo establecen las directivas de ellos (Robbins \& Judge, 2012).

Las organizaciones grandes se encuentran muy centralizadas, y las de organizaciones pequeñas se encuentran descentralizadas.

A continuación, en la Figura 2 se presenta el Equipo de Generación Perú SAA: 


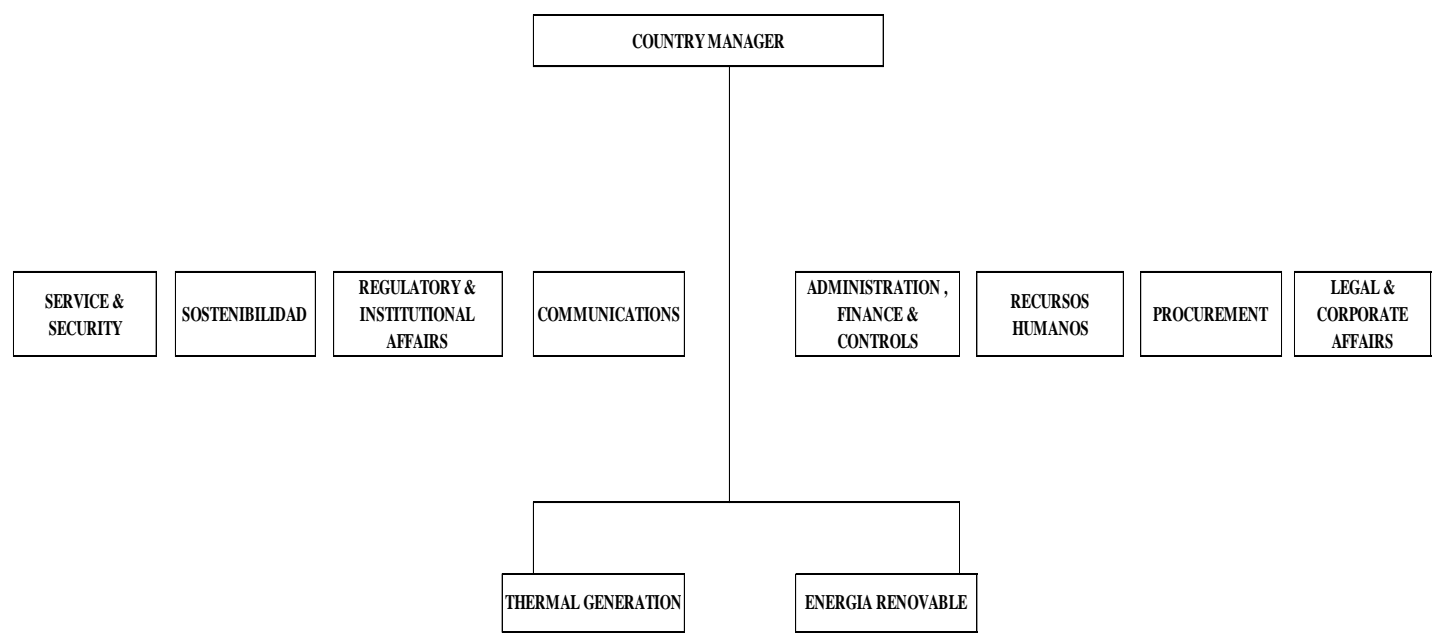

Figura 2. Organigrama Funcional de la empresa Enel Generación Perú SAA

a) José Manuel Revuelta - Country Manager

Representante de la compañía en el País, gestiona las operaciones y desarrollo del negocio de generación y distribución de energía eléctrica.

b) Leonardo Castro - Service \& Security

Responsable del control de los contratos de servicios generales, patrimonio y security transversales a las tecnologías.

c) Sostenibilidad - Rosario Arrisueño

Fortalecer las relaciones públicas con autoridades y el sector privado, diseño,

desarrollo y

gestión de programas de Responsabilidad Social promoviendo la participación activa de

las comunidades.

d) Tatiana Lozada - Regulatory and Institutional Affaris

Responsable de identificar, evaluar y gestionar los riesgos y oportunidades regulatorios

de todas las empresas del grupo Enel Generación Perú SAA.

e) Alicia Martinez - Communicatios

Responsable de la gestión de reputación y de la comunicación interna y externa de las empresas Enel Generación Perú SAA.

f) Guillermo Lozada - Administration, finance \& controls

Responsable de Administración (contabilidad), Finanzas, Relaciones com inversionistas,

tributos y planificación y control del Grupo Enel Generación Perú SAA.

g) Rocio Pachas - Recursos Humanos 
Responsable de mantener relación fuerte entre el empleador y sus colaboradores, resolviendo eventualidades que surjan y planificar programas de entrenamiento.

h) Patricia Mascaro - Procurement

Responsable de la gestión de compras y contrataciones para el Grupo Enel

Generación Perú SAA, atendiendo a los negocios de Distribución, Generación

Térmica, Renovables y Servicios.

i) Daniel Abramovich Ackerman - Legal \& corporate affairs

Responsable de todos los asuntos jurídicos (litigios, legales corporativos -

comerciales- societarios, legal ambiental, contractual, regulatorios, predial entre otros)

del Grupo Enel Generación Perú SAA.

j) Marco Raco - Thermal Generation

Administrar las operaciones y el mantenimiento de la flota de generación de energía maximizando la eficiencia operativa y los estándares de rendimiento técnico, logrando los objetivos de seguridad, seguridad, calidad, tiempo y costo siguiendo los principios de sostenibilidad del Grupo mediante la aplicación de las herramientas CSV adecuadas. Optimice los gastos de inversión y gastos de capital asignados maximizando el retorno esperado de la inversión y logre los objetivos asignados; Apoyar el desarrollo del negocio de generación de energía para optimizar la cartera de activos

k) Eugenio Calderon - Energía Renovables

Responsable de gestionar la operación y el mantenimiento de la flota de generación de energía a partir de fuentes renovables, maximizando las eficiencias operativas y los estándares de rendimiento técnico, logrando los objetivos de seguridad, medio ambiente, calidad, tiempo y costo. - Para optimizar el Opex y el Capex asignados maximizando el retorno esperado de la inversión, el EBITDA y alcanzar los objetivos asignados. - Apoyar el desarrollo del negocio de generación renovable para optimizar la cartera de activo

\section{Estructura Operacional}

Enel cuenta con cinco centrales hidroeléctricas y dos centrales termoeléctricas ubicadas en el departamento de Lima; las hidroeléctricas aprovechan las aguas de los ríos Rímac y Santa Eulalia, y, las termoeléctricas, utilizan como combustible principal el gas natural que proviene de los yacimientos de Camisea. Adicionalmente, a través de su subsidiaria Chinango S.A.C., cuenta con dos centrales hidroeléctricas ubicadas en el departamento de Junín, que aprovecha las aguas de los ríos Tarma y Tulumayo. 
Cabe resaltar, que la empresa cuenta con una concentración de sus centrales en la región central del país, zona de mayor producción de energía del Sistema Eléctrico Interconectado Nacional (SEIN).

La potencia efectiva de Enel, incluyendo a su empresa subsidiaria, es de 1.685,54 MW, donde el $54 \%$ es generado por las centrales termoeléctricas y el $46 \%$ por las centrales hidroeléctricas.

\begin{tabular}{|l|l|l|r|c|}
\hline \multirow{3}{*}{ Tipo de Central } & Empresa & Central & $\begin{array}{c}\text { Potencia } \\
\text { Efectiva } \\
\text { MW }\end{array}$ & $\begin{array}{c}\text { \% de } \\
\text { Participacion }\end{array}$ \\
\hline \multirow{3}{*}{ Hidroeléctricas } & \multirow{3}{*}{ Enel } & Huinco & 267,83 & $16 \%$ \\
\cline { 3 - 5 } & Matucana & 137,02 & $8 \%$ \\
\cline { 3 - 5 } & Callahuanca & 84,17 & $5 \%$ \\
\cline { 3 - 5 } & Moyopampa & 69,15 & $4 \%$ \\
\cline { 3 - 5 } & Huampani & 30,18 & $2 \%$ \\
\cline { 3 - 5 } & \multirow{2}{*}{ Chinango } & Yanango & 42,61 & $3 \%$ \\
\cline { 3 - 5 } & Chimay & 152,22 & $9 \%$ \\
\hline Subtotal hidroeléctricas & & $\mathbf{7 8 3 , 1 8}$ & $\mathbf{4 6 \%}$ \\
\hline \multirow{2}{*}{ Termoeléctricas } & Enel & Ventanilla & 483,77 & $29 \%$ \\
\cline { 3 - 5 } & Santa Rosa & 418,59 & $25 \%$ \\
\hline \multicolumn{2}{|l|}{ Subtotal termoeléctricas } & $\mathbf{9 0 2 , 3 6}$ & $\mathbf{5 4 \%}$ \\
\hline \multicolumn{2}{|l|}{ Total hidroeléctricas y termoeléctricas } & $\mathbf{1 . 6 8 5 , 5 4}$ & $\mathbf{1 0 0} \%$ \\
\hline
\end{tabular}

Fuente: Memoria Anual 2018, Enel Generación Perú S.A.A.

\section{Proceso Productivo}

El proceso de generación eléctrica se explica según el tipo de central que se utiliza.

Tabla 1

Proceso de generación eléctrica por tipo de central

\begin{tabular}{|c|c|}
\hline $\begin{array}{l}\text { Central } \\
\text { hidroeléctrica }\end{array}$ & $\begin{array}{l}\text { Su insumo principal es el agua, la cual es captada del caudal de los ríos y llevada } \\
\text { mediante válvulas hacia una turbina hidráulica, ello genera un movimiento de rotación } \\
\text { que se transmite a un generador unido a su eje. Luego, el generador convierte la } \\
\text { energía } \\
\text { rotatoria transmitida en energía eléctrica. }\end{array}$ \\
\hline $\begin{array}{l}\text { Central } \\
\text { termoeléctrica de } \\
\text { ciclo simple }\end{array}$ & $\begin{array}{l}\text { Su insumo principal es el gas y diesel, los cuales se queman en una caldera generando } \\
\text { el calentamiento de agua y su transformación en vapor. Este vapor permite mover las } \\
\text { palas de una turbina de vapor generando un movimiento de rotación que se transmite a } \\
\text { un } \\
\text { generador mediante su eje que posteriormente lo transforma en energía eléctrica. }\end{array}$ \\
\hline $\begin{array}{l}\text { Central } \\
\text { termoeléctrica de } \\
\text { ciclo combinado }\end{array}$ & $\begin{array}{l}\text { Su insumo principal es el gas y diesel, los cuales al mezclarse con aire en una cámara } \\
\text { de combustión hacen girar una turbina de gas unida mediante su eje a un generador. A } \\
\text { su vez, el calor de la combustión genera la transformación de agua en vapor en una } \\
\text { caldera cuya presión permite mover las palas de una turbina de vapor que se transmite } \\
\text { a un generador mediante su eje. Posteriormente, los generadores convierten la energía } \\
\text { transmitida por las turbinas en energía eléctrica. }\end{array}$ \\
\hline
\end{tabular}

Fuente: Elaboración propia, 2018. 


\section{Proveedores y contratistas}

Enel Generación Perú S.A.A. cuenta con un Sistema de Calificación de Proveedores que permite asegurar el cumplimiento de normativas en materia legal, laboral, de seguridad y de protección del medio ambiente, así como la suficiente experiencia técnica con la que cuenta cada proveedor, con ello determinan si éste es capaz de garantizar alta calidad y alto desempeño en los servicios que nos brindará.

El sistema consta de criterios y requisitos para la calificación. Los principales son:

1. Cumplir con la evaluación empresarial y ser declarado aprobado, involucrando en esta etapa lo concerniente a su situación financiera, experiencia y cumplimientos jurídicos laborales.

2. Ser declarado apto en temas asociados a la Sostenibilidad, la misma que integra aspectos relacionados a Seguridad, Derechos Humanos y Medio Ambiente.

3. Cumplir las condiciones técnicas del servicio.

Tabla 2

Proveedores

1 ANDRITZ HYDRO S.r.I Unipersonale 31.27

2 SIEMENS ENERGY, INC 20.10

3 SIEMENS S.A.C. 15.54

4 CONFIPETROL ANDINA S.A. 11.27

5 SERVICIOS GENERALES HIDRAÚLICOS Y CIVILES ARMER S.A.C. $\quad 11.23$

6 ANDRITZ HYDRO S.A.

7 CARBONELL FIGUERAS S.A.C. $\quad 8.51$

8 STORK PERU S.A.C. $\quad 7.39$

$9 \quad$ EMPRESA DE SERVICIOS MULTIPLES JM INGENIEROS E.I.R.L. $\quad 6.18$

10 WOOD GROUP PRATT \& WHITNEY INDUSTRIAL TURBINE SERVICES 6.08

Fuente: Aprovisionamiento - Enel Generación Perú.

Los proveedores estratégicos están sujetos a un monitoreo continuo a través del Vendor Rating, que es la metodología corporativa de evaluación del desempeño de los proveedores para todas las empresas del Grupo Enel. Consta de evaluaciones realizadas trimestralmente en cuatro aspectos importantes: Calidad, Puntualidad, Seguridad y Cumplimientos Jurídicos Laborales. 
Sus principales objetivos son:

- Monitoreo permanente en los servicios contratados e identificados como estratégicos.

- Tomar acciones preventivas en conjunto con los proveedores.

- Impulsar la mejora de los servicios brindados.

- El resultado de estas evaluaciones puede tener un efecto sobre su estado de calificación referido a suspensiones o facilitar el proceso de renovación de la calificación.

\section{Clientes}

Los clientes del sector eléctrico a los cuales Enel brinda su servicio se dividen en:

Clientes regulados, con demanda de potencia menor a $200 \mathrm{KW}$.

Clientes libres o no regulados, con demanda de potencia mayor a $2.500 \mathrm{KW}$.

Aquellos clientes que presentan una demanda entre los $200 \mathrm{KW}$ y $2.500 \mathrm{KW}$, pueden elegir entre ser considerados como clientes libres o regulados. Se debe resaltar que, en los últimos años, la empresa ha ganado procesos de licitación de energía que le han permitido extender el plazo de sus contratos con clientes regulados, lo que brinda una mayor predictibilidad a sus flujos futuros.

\section{Comunicación}

El personal de Enel Generación Perú S.A.A. cuentan con diversos mecanismos para denunciar conductas contrarias a los principios organizacionales: comunicación al jefe directo, denuncia a través de los sindicatos, comunicación a los servicios de auditoría interna o registro a través del canal ético por medio del portal en internet de la empresa. La confidencialidad de este registro es supervisada por la firma externa Ethicspoint, que tramita las comunicaciones hacia quien corresponda, garantizando el anonimato.

La empresa cuenta con procedimientos para la atención de pedidos y quejas de los accionistas. Estos procedimientos se aplican a los pedidos de los accionistas relacionados con información pública de la empresa, pago de beneficios o trámites varios, y a las quejas de los accionistas generados por su disconformidad en la atención de los citados pedidos. Se establece que los pedidos y las quejas pueden ser 
recibidos vía telefónica, fax, comunicación escrita, correo electrónico u otro medio; o, personalmente, en las oficinas de la empresa, previa cita.

Finalmente, para ejercer un adecuado control y estadística, se ha creado un Registro de Pedidos y Quejas de los Accionistas. Se busca que estos mecanismos sirvan para que los accionistas aporten sugerencias para mejorar el manejo de la empresa.

\subsubsection{Análisis funcional de la Organización:}

A diciembre de 2018, la plantilla de personal asciende a 285 trabajadores, de los cuales 233 son trabajadores permanentes y los 52 restantes son trabajadores con carácter temporal. Se encuentran clasificados de la siguiente manera:

Tabla 3

Clasificación del personal

\begin{tabular}{llll} 
Ejecutivos & 20 & 19 & -1 \\
Líderes y profesionales & 177 & 184 & 7 \\
Técnicos & 66 & 71 & 5 \\
\hline Administrativos & 13 & 11 & -2
\end{tabular}

Fuente: People and Organization Perú - Enel Generación Perú.

Como se puede apreciar, el número de colaboradores, en su mayoría personal técnico se ha incrementado con respecto al 2017, con el fin de cubrir posiciones en los nuevos proyectos de automatización y construcción de nuevas plantas renovables que Enel Generación Perú S.A.A viene ejecutando en este último año.

Se identifica como debilidad de la organización la falta de programas u estrategias de retención de personal, esto sumado a que en los últimos años se ha incrementado el número de empresas generadoras, distribuidoras o empresas relacionadas al sector que ofrecen mejores remuneraciones para profesionales con alta especialización o que se encuentran restringidos en el sector eléctrico.

Como resultado más del $50 \%$ de la fuerza laboral fluctúan entre los 40 a 59 años de edad, caso diferentes para las personas menores de 30 representado por un $8.4 \%$ y quienes como promedio de duración en la organización es de 2 a 3 años.

Tabla 4

Edades de la población laboral del personal de Enel.

\begin{tabular}{lll}
\hline Menores de 30 años & 8.7 & 8.4 \\
Entre 30 y 39 años & 21.0 & 22.5 \\
Entre 40 y 49 años & 28.3 & 28.4 \\
Entre 50 y 59 años & 30.1 & 29.5 \\
\hline Mayores de 59 años & 12.0 & 11.2
\end{tabular}

Fuente: People and Organization Perú - Enel Generación Perú. 


\subsubsection{Desarrollo de Personas:}

Enel Generación Perú S.A.A. es una empresa que requiere de profesionales y técnicos cada vez más especializados; debido a las condiciones cambiantes del sector, es necesario que exista una política definida de capacitación que tienda a cerrar la brecha generada entre las capacidades que tiene cada trabajador contra las capacidades requeridas para el puesto de trabajo; en este sentido vienen desarrollando programas de formación focalizados principalmente en el fortalecimiento de competencias técnicas del negocio, staff, seguridad y salud laboral, desarrollo del liderazgo, habilidades interpersonales, idioma inglés y herramientas digitales.

Entre los programas específicos que desarrollaron destacan Generación E, diseñado para impulsar el desarrollo de jóvenes profesionales identificados como alto potencial. Este programa se enfoca en potenciar las habilidades de liderazgo y el conocimiento estratégico del negocio, al mismo tiempo de elevar el nivel de exposición organizacional de los jóvenes que desarrollan proyectos de mejora multidisciplinarios. Asimismo, la organización cuenta con programa de liderazgo LIDERA, que brindar herramientas de liderazgo y gestión a todos los líderes de la compañía.

Finalmente debido a los entornos cambiantes en los que se viene viviendo, han desarrollado programas de transformación digital, que incluyen formación y experiencias digitales; así como desarrollo de proyectos en los que se impulsen los marcos de trabajo ágiles.

\subsubsection{Clima Laboral:}

Si bien la organización con el objetivo de fomentar un adecuado clima organizacional, propiciar el sentido de pertenencia, estimular el compañerismo y la integración del personal y sus familiares viene ofreciendo beneficios que superan lo exigido por las normas laborales vigentes en el Perú.

En términos generales, en los resultados de las encuestas de clima laboral se observa que la empresa ha mejorado el índice de satisfacción, lo cual refleja una evolución positiva en el clima de la organización. En la última medición de clima organizacional que se hizo en la empresa refleja que el clima organizacional de Enel Generación Perú S.A.A es del $85 \%$, lo que implica cierta satisfacción en cuanto a la motivación institucional, económica, y ambiente de trabajo. 
En comparación con otras empresas generadoras, los gastos de personal de Enel Generación Perú S.A.A son superiores al promedio de las generadoras y del salario mínimo del Perú.

Tabla 5

Comparativa de salario más bajo en la empresa vs. Salario mínimo

\begin{tabular}{llll}
\hline Año & Salario mínimo & $\begin{array}{l}\text { Salario inicial en la } \\
\text { empresa }\end{array}$ & Relación \\
\hline 2017 & 850 & 2,000 & 2.35 \\
2018 & 930 & 2,528 & 2.72 \\
\hline
\end{tabular}

Fuente: People and Organization Perú - Enel Generación Perú.

\subsection{Situación de Mercado y Financiera de la Industria}

La sociedad moderna actual, y su disposición del recurso eléctrico está potencialmente orientada a la salud y el bienestar; y a la permanencia del tiempo de vida de los recursos humanos.

Los consumos más bajos de energía se dan en los países con mayor pobreza, por otro lado, los países ricos utilizan altas cantidades de energía, esta realidad está cambiando drásticamente, se presume que, en los próximos años, se tendrá un mayor consumo de energía por parte de los países en vía de desarrollo.

\subsubsection{Situación Mundial.}

En los últimos 20 años se ha observado que, en paralelo al crecimiento económico mundial, la demanda de energía eléctrica se ha incrementado de manera sostenida. De esta manera, se pasó de consumir 11260 TWh en 1990 a 22662 TWh en 2015 A nivel de países, en 2015, la mayor producción de energía eléctrica de dio en China (5552 TWh), Estados Unidos (4402 TWh), India (1220 TWh), Rusia (1083 TWh) y Japón (1068 TWh), representando alrededor de 56\%. A nivel de Latinoamérica los principales países son Brasil (583 TWh), México (304 TWh), Argentina (144 TWh) y Venezuela (126 TWh), mientras que Perú tuvo una producción de 48 TWh.

A nivel mundial dos terceras partes de la capacidad instalada estaba conformada por centrales que empleaban combustibles fósiles, las hidroeléctricas fueron alrededor de 19\%, 6,4\% para las centrales nucleares y $7.8 \%$ para centrales solares y eólicos, la excepción fue Sudamérica, donde la hidroeléctrica represento 54\% y los combustibles fósiles 43\% (región con generación más limpia del mundo) 
En las diversas cumbres de países han permitido que se concreten acuerdos y compromisos sobre el uso de energías renovables. En la declaración sobre el cambio climático del G7, los países integrantes se comprometieron a realizar una transformación en el sector eléctrico para 2050 y acelerar a energía renovable tanto en África como en algunos países en desarrollo. Por su parte, el G20 acordó acelerar el acceso de energía renovable para mejorar la eficiencia energética (Osinergmin, 2015)

\subsubsection{Situación a nivel Perú.}

En la última década, el Perú ha registrado un crecimiento económico sostenible, lo cual ha impulsado la generación de energía eléctrica debido a que es soporte de la gran mayoría de industrias que impulsan a la economía. A nivel de región el Perú ha registrado un crecimiento de la producción per cápita, pasando de $0.6 \mathrm{MWh}$ a 1.5 MWh entre los años 1990 y 2015 (comparado a Colombia o Ecuador).

La participación de la zona centro en la producción nacional era $70 \%$, el sur $17 \%$, el norte $7 \%$ y el oriente $7 \%$, mientras que para el 2016 , la participación de la zona centro había aumentado 8 puntos porcentuales y en las otras se había reducido.

El desarrollo del Proyecto de interconexión eléctrica Perú-Ecuador a 220Kv, permite transferencia de energía entre ambos países, el cual se ha venido utilizando para suministros extraordinarios de emergencia.

Con repuesta a la estructura del sector, se cuenta con cuatro actores principales:

El mercado eléctrico: lo integran los generadores, trasmisores y distribuidores; los clientes (libres y regulados) y los organismos normativos y supervisores.

El Ministerio de Energía y Minas (Minem): define las políticas de energía del país y es la autoridad competente para el otorgamiento y caducidad de autorizaciones y concesiones para las actividades de generación, transmisión y distribución.

Osinergmin: regula y fiscaliza el cumplimiento de las normas relacionadas con las actividades de electricidad, hidrocarburos y minería, haciendo cumplir las obligaciones establecidas en los contratos de concesión.

El Comité de Operación Económico del Sistema (COES): es el operador del Sistema Eléctrico Interconectado Nacional (SEIN), coordina el despacho de las unidades de generación en función del mismo costo (Osinergmin, 2016) 


\section{Capítulo III. Formulación de Visión, Misión y Valores de la Empresa}

\subsection{Visión}

La visión permite establecer la futura dirección de una empresa, así como los cambios en el producto, mercado, clientes, y las ventajas competitivas a mejorar. Asimismo, la visión provee un marco general para la estrategia y hacia donde estará orientándose la empresa, proporcionándole de esta manera un sentido de dirección para el futuro a dónde quiere llegar y de cómo quiere verse.

Thompson y Strickland, sostienen como concepto de visión "un mapa de rutas del futuro de una compañía, de la dirección que lleva, de la posición que pretende ocupar y de las capacidades que planea desarrollar" (2011, p.5).

La visión incluye a la gerencia que amplíe el funcionamiento de la empresa, y proyecta el futuro en consideración del impacto que tiene la tecnología, la política y economía del país, asimismo, de la competitividad, clientes, el mercado, etc. Los directores deben pensar hacia donde quieren dirigir su empresa y cuáles son los cambios que requieren según la configuración en el logro de las ventajas competitivas (Thompson \& Strickland, 2011).

\subsubsection{Visión actual de la empresa.}

La visión actual de Enel Generación Perú SAA es la siguiente:

"Ser Open Power para hacer frente a algunos de los mayores desafíos del mundo". La empresa durante más de 60 años con sus operaciones ha llevado progreso a personas y comunidades de todo el mundo. Desde su fundación en el año 1962, se ha trabajado para ayudar a las personas, empresas y naciones a prosperar mediante la conexión a la electricidad, el gas y los servicios más importantes para sus necesidades.

En todo este tiempo, se han adoptado e integrado nuevas tecnologías para volver más confiable, más asequible y más sostenible nuestra energía, desde la introducción del primer contador inteligente hasta convertirse en el mayor productor mundial de energía renovable.

El desarrollo de las operaciones se ha consolidado el inicio del traslado de energía para mejorar la calidad de vida de las comunidades, empoderar a las personas, establecer nuevas asociaciones y abrir nuevas tecnologías, para hacer posible un mundo más abierto y colaborativo.

\subsubsection{Análisis de la visión actual.}

Tomando como referencia de los autores Thompson \& Strickland (2011), se analiza la visión actual de Enel Generación Perú S.A.A. 
a. Es incompleta. No concibe cual sería la orientación de la empresa o de qué manera sería su gestión en los próximos años.

b. Emplea un acento demasiado amplio. El párrafo que se presenta es muy general, permitiendo a la compañía tomar cualquier dirección; no existe un rumbo definido, salvo la sectorización a nivel general.

c. Presenta términos poco sugerentes para una visión a largo plazo. No permite motivar a los empleados ni inspira confianza sobre la dirección.

d. Genérico. No transmite una identidad propia y/o genuina.

La visión actual de Enel Generación Perú SAA es una enunciación con debilidades, no es clara en lo que quiere la organización en el largo plazo, por lo tanto, no servirá como herramienta y tampoco ayudará a formular las estrategias necesarias.

\subsubsection{Matriz de la visión propuesta para la empresa.}

La matriz de la Figura 3 desagrega la visión por cada elemento que lo conforma. Para la redacción de la visión, primero se debe plantear cada uno de los elementos y luego integrarlos en una sola expresión.
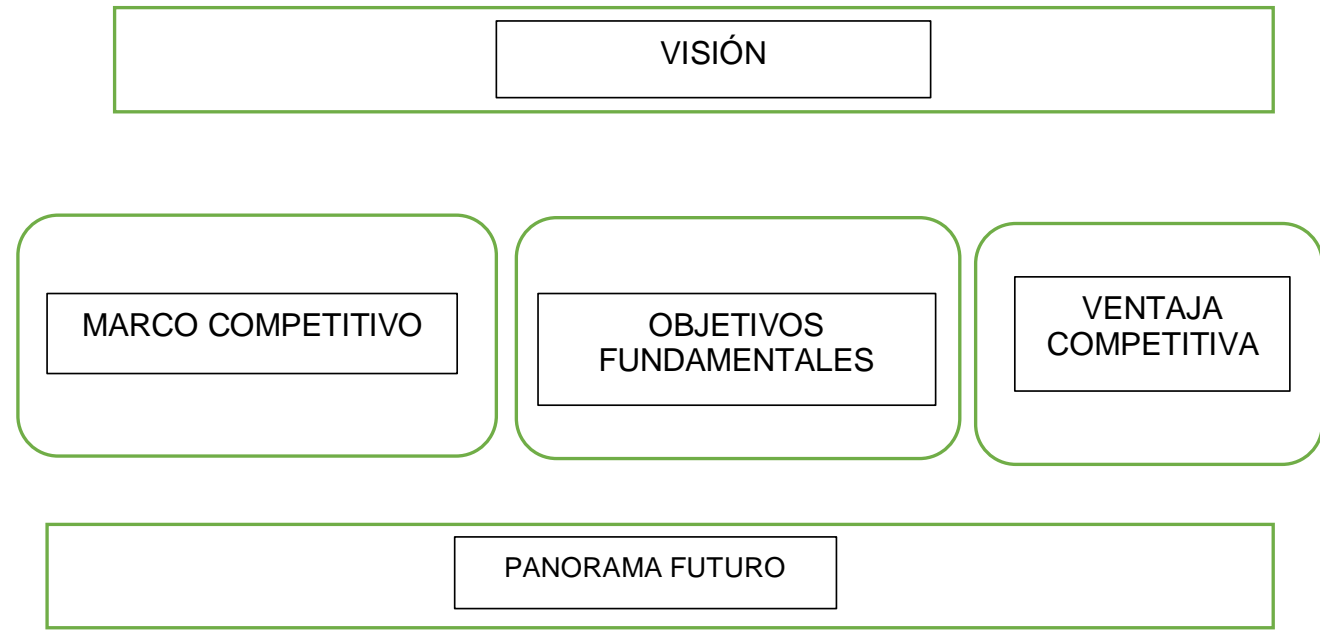

Figura 3. Matriz para formular la visión.

Tomado de "Administración estratégica: conceptos y casos (11a.ed.)", por Thompson, A., Strickland, A, J., 2011, Mc Graw-Hill.

\subsubsection{Visión propuesta.}

Visión Planteada: "Ser una empresa líder en la generación de energía segura, de calidad y sostenible".

\subsection{Misión}

La misión corresponde a la declaración perpetua de los objetivos que una organización pretende alcanzar teniendo claro cuáles son sus productos, mercados, y tipos de 
clientes, planteándose los objetivos a corto y largo plazo que influyen el mejoramiento de la comunicación.

En cuanto concepto de la misión, esta se constituye en cómo se organiza la empresa para llevar a cabo todas sus operaciones y estrategias para lograr sus metas.

\subsubsection{Misión actual de la empresa.}

Enel Generación Perú SAA tiene como misión:

"Trabajamos con el objetivo de cambiar al mundo".

La empresa busca acercar los servicios cada vez a más personas en un gran número de países, impulsando las economías locales y ampliando el acceso a la energía.

\subsubsection{Análisis de la misión actual.}

Permite colocar los elementos de la misión en el presente y en el futuro según lo establecido en la visión de la empresa. La matriz está dividida en tres columnas en donde se colocan los elementos de la misión en la primera columna, luego la situación actual para cada uno de los elementos en la segunda columna y finalmente la situación deseada para los mismos en la tercera columna. Los elementos que se plantean son los siguientes:

Clientes: No cumple, no se refleja y tampoco toma en cuenta a los clientes corporativos.

Producto / Servicio: Si cumple, hace mención la importancia de generar energía eléctrica sin afectar nuestros recursos para futuras generaciones.

Mercado: Si cumple, menciona la geografía "ámbito global" donde la empresa realiza sus actividades.

Tecnología: No cumple, no menciona que tecnología utiliza para conseguir su producto final.

Filosofía: No cumple, no hace mención sobre los estándares de calidad y acreditaciones.

Preocupación por su imagen pública: Si cumple, Hace mención el deseo de cambio de un mundo mejor.

Preocupación por sus colaboradores: No cumple, no menciona sobre los beneficios o crecimiento de sus trabajadores.

\subsubsection{Elementos de la misión propuesta para la empresa.}

Thompson \& Strickland (2011) sostiene que los elementos que debe contener una misión son los siguientes:

1. Clientes: conceptualiza de una manera general los clientes en quienes se está centrada la demanda de la empresa.

2. Los productos o servicios: Manifiesta lo que comercializa en el mercado. 
3. Competencias: organizaciones que brindan el mismo servicio en el mismo mercado.

4. Mercado: zona geográfica donde opera.

5. Tecnología: sistemas utilizados en el proceso para la elaboración de sus productos.

6. Empleados: sostenimiento de los colaboradores.

7. Filosofía: expresa la ética de la compañía.

8. Concepto propio: detalla cómo quiere darse a conocer la organización empresarial ante el público.

9. Imagen pública: manifiesta como la organización participa o atiende a la comunidad, y se preocupa del medio ambiente.

10. Desarrollo y supervivencia: manifiesta el propósito de que la organización mantenga su desarrollo a largo plazo.

Si bien no todos los elementos se encuentran presentes en la expresión de una misión, en general se busca que se incluya en su redacción la mayoría de ellos, de modo que se exprese claramente el propósito de la empresa.

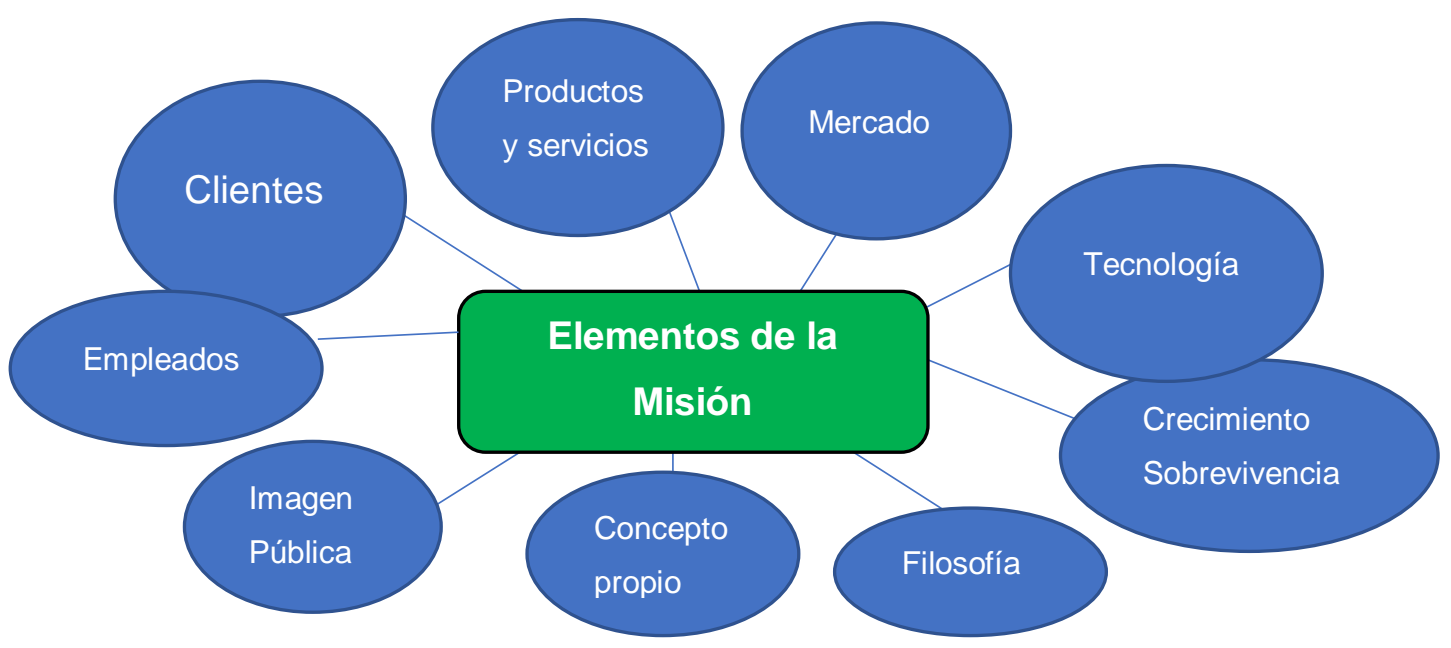

Figura 4. Elementos de la Misión.

Adaptado de Fred David, Strategic Management: Concepts \& Cases, 11th Edition, Prentice Hall, México, 2001.

\subsubsection{Misión propuesta.}

La misión propuesta para Enel Generación Perú SAA es la siguiente: "Producir energía eléctrica para el desarrollo de país, basados en el talento humano, la tecnología, la calidad y la eficiencia.

\subsection{Valores}

Thompson \& Strickland (2011) indicaron que los valores, también llamados "valores corporativos, empresariales u organizacionales", son las creencias (el credo) acerca de las conductas consideradas correctas y valiosas por la empresa. De los tres elementos mencionados, los valores son los que tienen mayor permanencia. No se 
trata de una declaración circunstancial o de conveniencia, sino de creencias básicas, esenciales, que tienen valor intrínseco.

\subsubsection{Valores actuales de la empresa.}

\section{Confianza}

Actuamos de manera competente, honesta y transparente, para ganar la confianza de nuestros compañeros, clientes y colaboradores externos, valorando las diferencias individuales.

\section{Innovación}

Vivimos y trabajamos con curiosidad, nos esforzamos por ir más allá de lo habitual y superamos nuestros temores, para abrir la energía a nuevos usos, tecnologías y personas. Aprendiendo de los errores igual que de los aciertos.

\section{Responsabilidad}

Cada uno de nosotros es responsable del éxito del grupo, a todos los niveles.

Ponemos nuestra energía al servicio de las personas para mejorar su vida y hacerla más sostenible.

\section{Proactividad}

Nos hacemos cargo de nuestro trabajo en primera persona. Interpretamos continuamente los escenarios y retos mundiales para adelantarnos a los cambios, redefiniendo las prioridades si el contexto lo requiere.

Los valores de Enel Generación Perú SAA sirven para estandarizar la cultura y filosofía del trabajo día a día, la cual influye en la atención con sus clientes. De esta manera se fortalecen sus relaciones y crecen en sus negocios. (Memoria Anual Enel Generación Perú SAA, 2017, pp 12-13)

\subsubsection{Análisis de los valores actuales.}

Según D’Alessio (2015) se deben analizar los valores instrumentales u operativos asociados a la forma de pensar y hacer las cosas con que la organización pretende afrontar las demandas de su entorno e integrar sus tensiones internas para alcanzar su visión y su misión, los cuales se ponen de manifiesto en la etapa de implementación de las estrategias de la organización. Lo que da coherencia a una organización es la claridad y consenso de sus metas y principios, o lo que es lo mismo, de sus fines y de sus valores operativos.

Los valores que plantea y profesa la empresa Enel Generación Perú SAA cumplen con los lineamientos articulados al código de ética que teóricamente el profesor D'Alessio sostiene en su enfoque teórico, por lo tanto, los valores se relacionan con el rol ético empresarial y la funcionalidad de la misión y visión de la empresa. 
En el caso de Enel Generación Perú SAA, los valores que se profesan tienen su origen en la casa matriz, la idea es fortalecer una cultura organizacional sólida basada en tres pilares importantes.

En cuanto a los valores de innovación y proactividad, los dos elementos que se plantean, involucran y grafican que la empresa pueda ubicarse en un sitio importante frente a sus competidores debe estar en constantes cambios e innovaciones. Por el lado de responsabilidad y confianza, se constituye en una estrategia que actualmente se conoce como gestión del talento humano, y en Enel Generación Perú SAA los recursos humanos se consideran como un activo principal de la empresa.

\subsubsection{Elementos de los valores propuestos para la empresa.}

D’Alessio (2015) sostiene que los valores de una organización son contemplados como las políticas directrices más relevantes: norman y se relacionan con el desempeño de sus colaboradores, y constituyen el patrón de actuación que orienta el proceso de toma de decisiones. Los valores se enfocan a la filosofía de la empresa al representar de manera clara las creencias, actitudes, tradiciones y su personalidad. Por lo tanto, los valores son indispensables para moldear los objetivos y propósitos, producir las políticas y definir las intenciones estratégicas. En el planteamiento de los valores de Enel Generación Perú SAA se abarcan los elementos que componen los valores relacionados con el compromiso externo e interno, y esforzándose en hacer lo correcto.

\subsubsection{Valores propuestos.}

Los valores que se han señalado previamente son propuestos por la empresa, los cuales se encuentran alineados a los propósitos estratégicos de la empresa. Es por ello que se mantendrán los valores actuales.

\section{Responsabilidad Ambiental}

Cumplimiento con el marco legal referente al medio ambiente.

\section{Seguridad.}

Proporcionar confianza a sus clientes, brindando un servicio ininterrumpido.

\section{Puntualidad}

Respeto por el tiempo de los demás, cumpliendo con los plazos establecidos.

\section{Perseverancia}

Constancia, dedicación y firmeza en la consecución de propósitos y metas.

\section{Colaboración}

Compromiso a fomentar el trabajo en equipo y a una incesante búsqueda de alianzas que nos permitan alcanzar el beneficio mutuo. 


\subsection{Alineamiento estratégico de la Visión, Misión y Valores de la empresa}

D’Alessio (2015) sostiene que "el alineamiento estratégico de la organización tiene como punto de partida la evaluación de las relaciones internacionales, para continuar con un planeamiento estratégico nacional" (p. 137).

La estructuración alineada de un planeamiento integral se articula hacia el cumplimiento de la misión, visión y los valores que se plantean.

Con la declaración de misión, visión y valores, se debe evaluar su eficacia para confirmar de manera simultánea por el equipo de la empresa u organización. Si no tiene una declaración de misión, visión y valores, proceda a prepararla de alguna de las siguientes maneras: se debe preparar y someterla a discusión por parte de su equipo gerencial.

Enel Generación Perú S.A.Al alinea su visión, misión y valores mediante el cumplimiento de sus Políticas de Desarrollo Sostenible mediante su Sistema de Gestión Integrado, ver figura 5, en donde se han establecido siete compromisos que están enmarcados dentro de las dimensiones económica, ambiental y social. Dichos compromisos son promovidos desde la dirección de la empresa y conciernen a todos y cada uno de los que trabajamos de la organización, y se traslada a sus contratistas y proveedores, los compromisos son:

$\checkmark$ El Buen Gobierno: Compromiso con el buen gobierno, cumplimiento de la legislación y reglamentación aplicable, y comportamiento ético.

$\checkmark$ Nuestros Accionistas: Compromiso con la creación de valor y la rentabilidad.

$\checkmark$ Nuestros Clientes: Compromiso con la calidad del servicio y la satisfacción del cliente.

$\checkmark$ Nuestra Gente: Compromiso con la salud, la seguridad y el desarrollo personal y profesional de nuestros empleados.

$\checkmark$ El Medio Ambiente: Compromiso con la protección del entorno

$\checkmark$ La Innovación y Mejora Continua: Compromiso con la eficiencia.

La Sociedad: Compromiso con el desarrollo de las sociedades en las que operamos. 


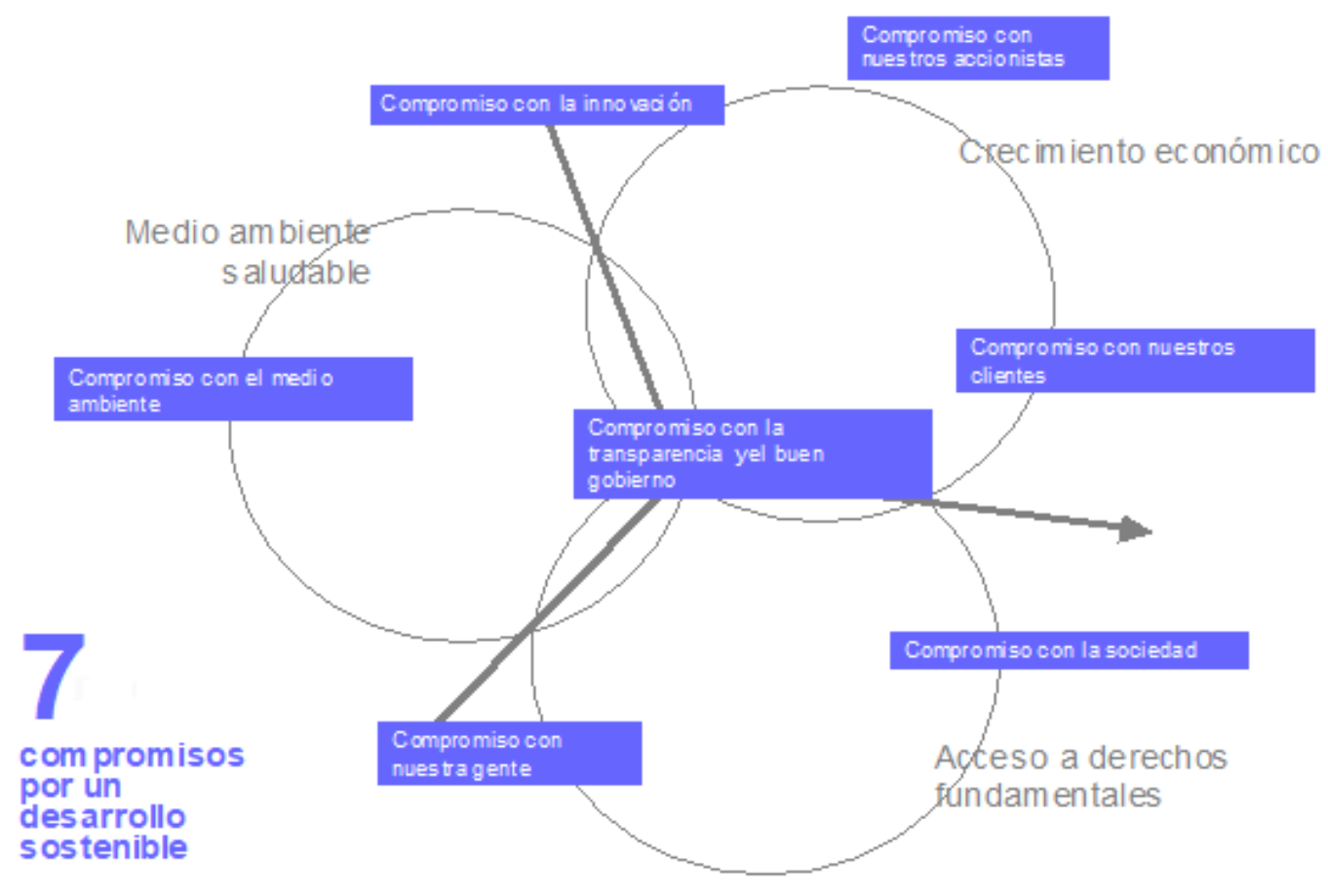

Figura 5. Modelo integral de dirección estratégica.

Adaptado de Fred David, Strategic Management: Concepts \& Cases, 11th Edition, Prentice Hall, México, 2001.

\section{Capítulo IV. Análisis Externo}

\subsection{Tendencias de las variables del entorno}

El análisis externo contempla oportunidades y amenazas que son externas a la compañía en relación al sector donde comercializan.

Para Enel Generación Perú SAA, las variables que afectan directamente son: social, económico, legal, tecnológico, políticos, geográfico e industrial.

D’Alessio menciona "la evaluación externa denominada también auditoria externa de la gestión estratégica está enfocada hacia la exploración del entorno y análisis de la industria. Este procedimiento busca identificar y evaluar las tendencias y eventos que están más allá del control inmediato de la firma" (2015, p. 31).

El análisis denota una serie de oportunidades y amenazas como factores claves de éxito, así como la situación de los competidores en el sector industrial. "El propósito de esta auditoria es ofrecer información relevante a los gerentes, tanto para iniciar el proceso conducente a la formulación de estrategias que permitan sacar ventaja de las oportunidades como para reducir el impacto de las amenazas, conocer los factores clave para tener éxito en el sector industrial y así vencer a la competencia" (D'Alessio, 2015). 


\subsubsection{Análisis Político-Gubernamental.}

El país políticamente está estable, si bien al asumir Martin Vizcarra la presidencia del Perú, los retos en materia económica son principalmente reactivar el crecimiento, generar empleo y cerrar el déficit fiscal.

Los acontecimientos que han impactado negativamente en la economía del país como: Corrupción pública por el caso Odebrecht, corrupción judicial o CNM audios y la crisis política que ha desatado.

El Perú empezó a perder su ranking de competitividad, incrementando ligeramente la pobreza, escenario que no se presenta desde el año 1990.

En el 2017 el Perú cerró con un crecimiento económico de 2.5\% y al finalizar el 2018 con un $4 \%$ de crecimiento.

Como consecuencia de dichos eventos de corrupción, se vieron afectadas grandes obras públicas y megas proyectos, no obstante, el Perú se ha mantenido firme con un óptimo control de la inflación que no supera el $2 \%$.

A la fecha el gobierno para generar mayor inversión ha puesto en marcha la activación de los diversos proyectos que quedaron paralizados a raíz de la situación del anterior gobierno.

Para el periodo 2016 - 2021, el gobierno se centraría en dos retos muy importantes a cumplir:

Erradicar la pobreza que hoy aqueja a un tercio de la población.

Lograr que la economía del Perú crezca por encima del 7\% anual durante la próxima década.

De acuerdo con el Plan Energético Nacional 2014 - 2025, se proyecta que las inversiones en la generación de energía alcancen hasta los US\$ 7.300 millones y dichas inversiones serán principalmente del sector privado. Pero, para el sector privado (nacional e internacional) es muy importante que el gobierno mantenga un marco normativo e institucional claro, predecible y legítimo sobre la base de una economía social de mercado. Asimismo, es fundamental la autonomía de los poderes del Estado y es crucial el respeto a la empresa privada. En el anexo 8 se presenta el marco legal y regulatorio del mercado eléctrico peruano (Matthew, Quintanilla Pacheco, \& Sulca Gómez, 2017).

El Gobierno plantea las siguientes estrategias como propuestas de desarrollo:

- Cambio de la matriz energética.

Contar con una estructura energética, que sea segura, accesible, limpia y barata, fomentando la generación de energía con recursos renovables.

- Balance en la Generación de Energía 
El gobierno incentiva el desarrollo y ejecución de centrales hidroeléctricas a las empresas privadas y públicas, balanceando la generación según la demanda nacional.

- Infraestructura

El Ministerio de Energía y Minas concede autorizaciones para la ejecución de investigación y creación de nuevas propuestas para el desarrollo de nuevas plantas de producción de energía renovable.

- Análisis Político y Social

El país viene presentando conflictos socio ambiental en las regiones donde existe presencia de proyectos mineros y eléctricos que utilizan los recursos naturales.

\subsubsection{Análisis Económico.}

Para le evaluación del entorno macroeconómico hemos utilizado los indicadores del producto Bruto Interno, tipo de cambio, riesgo país y tasa de inflación, datos que nos permiten medir la estabilidad del país. En la Figura 6 se evidencia las variaciones del PBI proyectado, donde se muestra un crecimiento al año 2008, pero al año 2009 el crecimiento fue $1.05 \%$ más bajo que lo observado en los años 2004 al 2008 , ocasionado por la crisis mundial.

Según INEI al 2016 el Perú viene teniendo un crecimiento constante, debido al impulso de las empresas mineras y de telecomunicación, para el caso de las mineras e Hidrocarburos solo creció $16,29 \%$ en el año 2016, en cuanto a las empresas de telecomunicaciones y servicios de información solo fue de $8,09 \%$.

INEI (2016) indicó que "el desempeño de la economía peruana fue opacado por la disminución de la inversión, tanto pública como privada, que provocaron que el sector construcción se mantuviera en recesión (-3,15\%)"; también se indicó que mientras que la manufactura bajó 1,63\%, aunque mostró un repunte hacia el final del año; mientras que la pesca cayó 10,09\%".

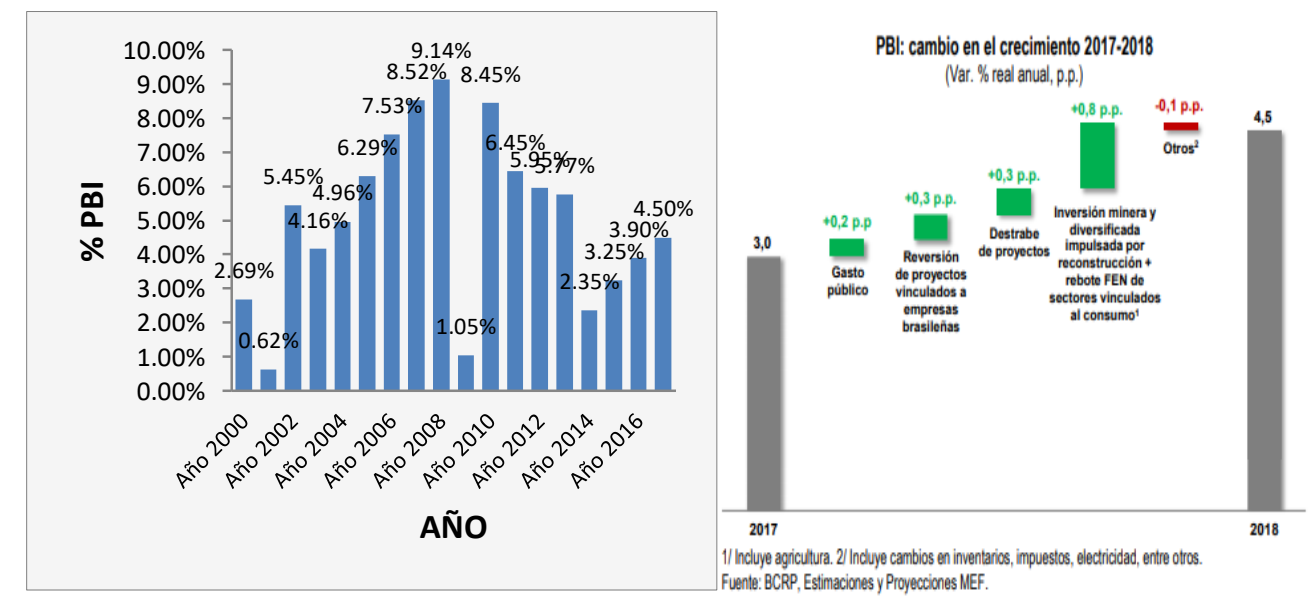

Figura 6. Variación del PBI 2000-2017. Adaptado del INEI - Gestión. 
Respecto a la proyección realizada por el BCRP (2018) a partir del año que está en curso y hasta 2019 la economía peruana crecería 4.2\%, mientras que en 2020 la expansión del PBI sería de $4.1 \%$. No obstante, el pronóstico para este año es menor al estimado oficial de $4 \%$ del MEF plasmado en el Marco Macroeconómico Multianual Revisado (MMMR) 2017-2019, igual proyección tiene el Banco Central de Reserva (BCR). En el Perú, la inversión privada representa $80 \%$ del total de la inversión, mientras que la pública solo $20 \%$. Está claro que no se puede crecer sobre la base de la inversión pública, por lo que solo queda pensar que el MMM plantea enlazar los aumentos en la inversión pública con la privada (Parodi, 2018).

En cuanto a la inflación del País, el BCRP tiene como objetivo tener una inflación entre $1 \%$ al $3 \%$, para tener un escenario positivo para el ingreso de inversión privada y lograr una estabilidad laboral (BCRP, 2017).

En la Figura 7 observamos que en el 2015 la inflación cerró en 4,40\%, con lo cual se situó por encima del rango meta del Banco Central de Reserva (entre 1\% y 3\%). El resultado del año 2015 se ubica en un nivel superior al comportamiento que se registró en los tres años anteriores, presentando en el 2014 una tasa de 3,22\% y en los años 2013 y 2012 una variación de 2,86\% y 2,65\%, respectivamente (BCRP, 2017).

Villar (2017) sostiene que "en diciembre del 2016, la inflación aumentó en 0,33\% en Lima Metropolitana y acumuló un total de 3,23\% en el año, cifra con la que se situó por encima del rango meta del Banco Central de la Reserva". Sin embargo, se redujo significativamente en relación con el resultado del 2015, cuando se situó en 4,40\%. Según el INEI, se observa una tendencia decreciente desde el año 2015 en las cifras obtenidas. Terminar el año 2016 con 3,23\% respecto a lo que se registró en el 2015 es una cifra significativamente menor, muy parecida al resultado del 2014, que alcanzó $3,22 \%$. Asimismo, durante las épocas de crisis la contracción de la economía conllevó una caída en la producción de energía. De acuerdo con el Banco Mundial, la infraestructura de energía es empleada en los procesos de producción de la gran mayoría de sectores (minería, pesca, banca, comercio, manufactura, entre otros); por lo tanto, el crecimiento económico de un país está estrechamente ligado a la capacidad y estabilidad de las fuentes de energía.

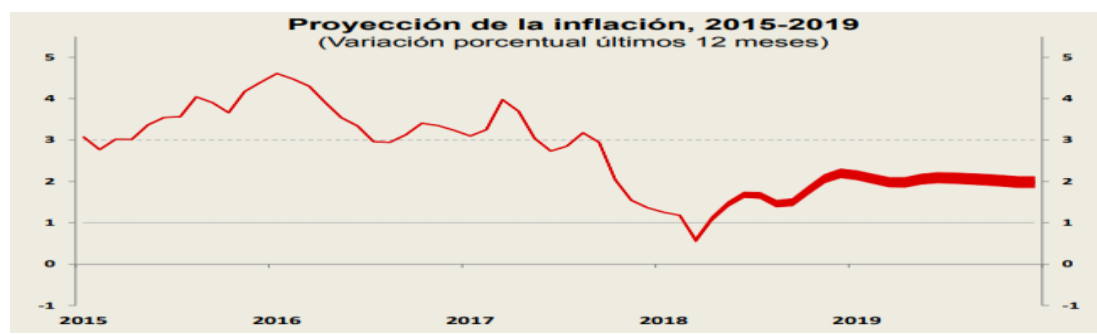

Figura 7. Evolución y proyección de la Inflación en el Perú año 2015 - 2019. INEI 
Se espera que la inflación interanual se ubique transitoriamente por debajo de 2,0 por ciento durante la primera mitad de 2018, como resultado de la reversión de los choques de oferta asociados a fenómenos climatológicos ocurridos a comienzos de 2017 (Fenómeno El Niño Costero) y por una brecha de producto negativa (BCRP, 2018).

Para muchos países como el Perú, el riesgo país es una variable fundamental ya que es un indicador de la situación económica del país y de las expectativas de las calificadoras de riesgo con respecto a la evolución de la economía en el futuro, en particular la posibilidad de que un país pueda incumplir con sus obligaciones de pago a los acreedores internacionales.

La Figura 8 muestra la evolución del riesgo País de Perú desde el año 1998 hasta el 2017 (hasta marzo del mismo año) en base a puntos básicos, de acuerdo a ello se observa que en los últimos años el país ha conservado cifras bajas a pesar de un ligero incremento en los años 2008 y 2009 debido a la crisis financiera internacional. Estos bajos niveles han permitido proyectar una imagen económica estable hacia la Inversión privada tanto nacional como Internacional (BCP, s.f.).

El Banco Central de Reserva del Perú (BCRP) define al sector electricidad como aquel que incluye la producción de energía suministrada por las centrales eléctricas. En el gráfico 8 se aprecia la relación directa entre el PBI y este sector. Por ejemplo, entre los años 2004 y 2011 (exceptuando el 2009), la economía peruana entró en expansión, siendo la producción de energía un motor importante para el crecimiento del país.

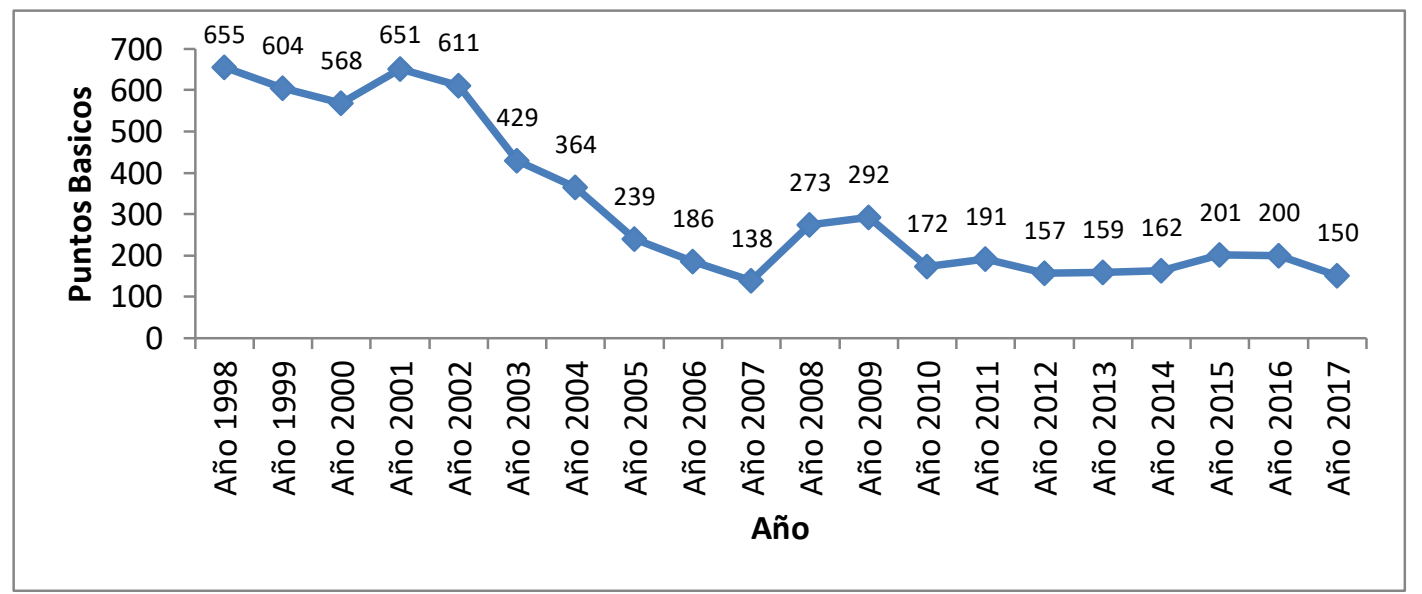

Figura 8. Evolución de riesgo País de Perú 1998 - 2017. Banco Central de Reserva

De acuerdo al BCR, el tipo de cambio es una relación cambiaria que existe entre 2 monedas de distintos países. Este dato establece el valor de la moneda nacional, en este caso el nuevo sol, respecto al valor de la moneda internacional, en este caso el dólar. 
Según la figura 9, se aprecia la valoración de la moneda nacional hasta el último año. Un incremento moderado en la valoración de la moneda nacional refleja una estabilidad en la economía del País generada por el superávit fiscal, ofreciendo un buen panorama al inversionista privado.

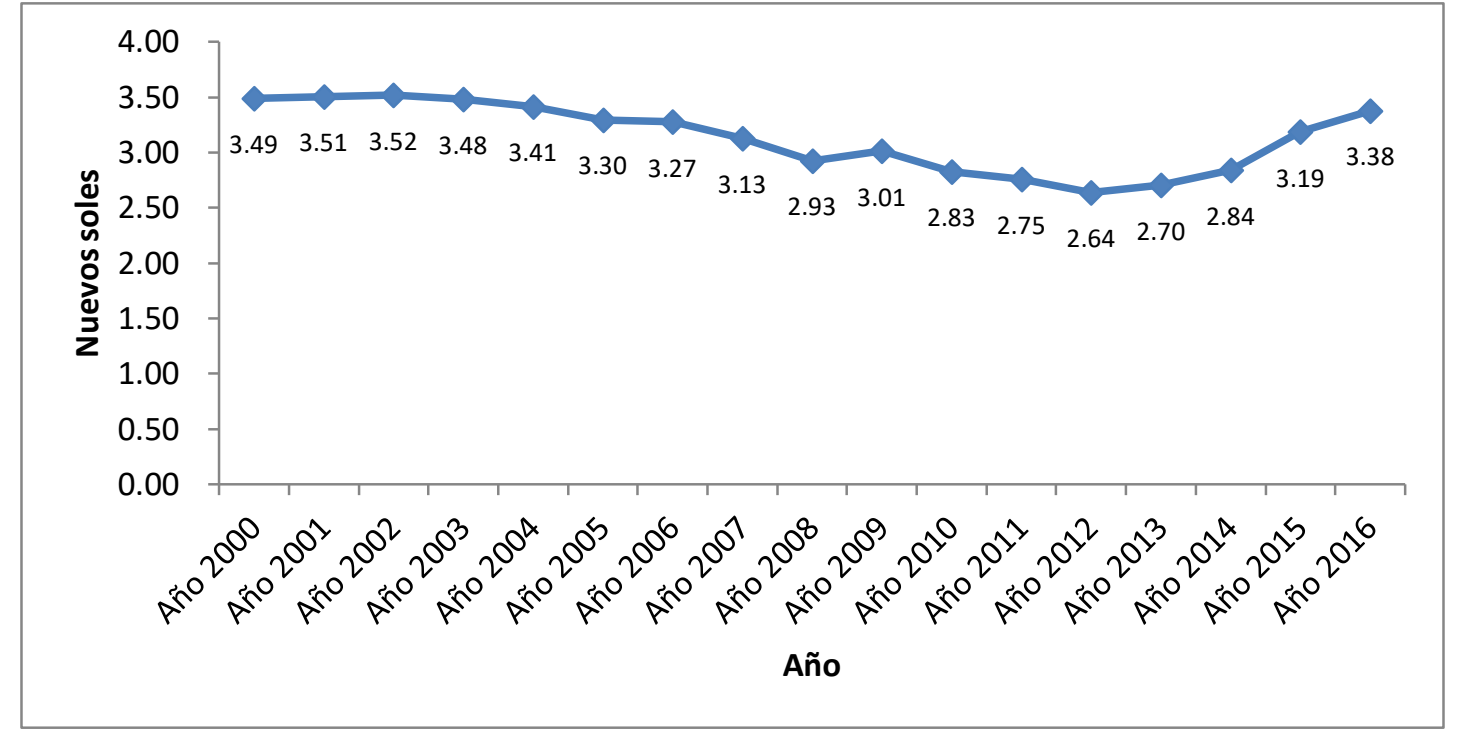

Figura 9. Tipo de cambio promedio anual 2000-2016Fuente: BCRP

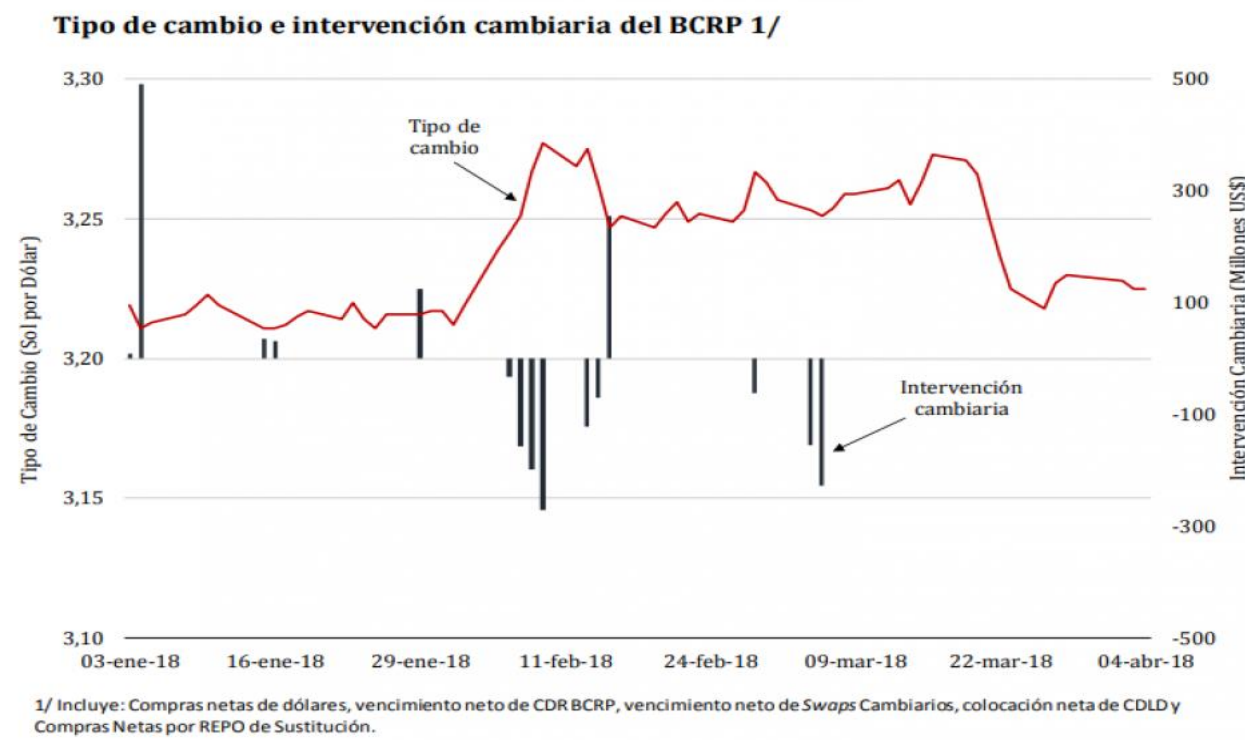

Figura 10. Tipo de cambio promedio anual 2000-2016Fuente: BCRP

De acuerdo con el Instituto Peruano de Economía (2017) indicó que el factor importante que existe en el Perú es trabajar en la reducción de la Pobreza. La pobreza no es solo problema relacionado con la carencia de ingresos, sino que también involucra la falta de acceso adecuado a servicios de salud, agua y saneamiento; a educación; y a una buena nutrición. El crecimiento económico registrado en nuestro 
país ha facilitado la labor del gobierno en la difícil tarea de reducirla. Sin embargo, dadas las diferencias preexistentes entre distintos grupos de la población, este crecimiento ha llevado a unos grupos a reducir sus niveles de pobreza más rápido que otros. En ese sentido, en el Perú, la pobreza es un problema predominantemente rural. Según las cifras del Instituto Nacional de Estadística e Informática (INEI), el 81\% de los individuos calificados como pobres extremos vive en zonas rurales.

No obstante, se ha registrado importantes mejoras en muchos de los indicadores sociales, entre las que destaca la reducción del nivel de pobreza extrema de $16 \%$ en 2004 a 7\% en 2011, el más bajo en toda su historia. Diferenciando por ámbito geográfico y región natural, se observa que las zonas que han presentado una mayor reducción son, justamente, las zonas rurales, encabezadas por la sierra rural (21 puntos porcentuales); seguida por la selva rural (16 puntos porcentuales) y, finalmente, la costa rural (7 puntos porcentuales).

En cuanto a las proyecciones, q través de su duodécimo resumen informativo semanal, el Banco Central de Reserva (BCR) mostró las proyecciones de tipo de cambio para el cierre del presente año, el 2019 y el 2020 de los diferentes agentes económicos del mercado peruano. Así, el dato que resaltó fue que se redujo el rango de las expectativas de tipo de cambio para este 2018 a un precio de entre $S / 3,23$ y S/3,28 por dólar.

Por el lado de los analistas económicos, la proyección del tipo de cambio para este año, a la fecha, es de $S / 3,25$. Para el 2019, esperan que el precio del dólar se encuentre entre $S / 3,30$ y con picos de $S / 3,35$. Mientras que para el 2020 , proyectan que el precio de la moneda estadounidense se encuentre rondando los $S / 3,35$. A su vez, el sondeo realizado entre empresas del sistema financiero refleja que el estimado del tipo de cambio al cierre del año sea S/3,23, que para el 2019 se encuentre en $\mathrm{S} / 3,25$, aproximadamente, y para un año antes del Bicentenario oscile entre los $S / 3,25$ y $S / 3,28$.

Por su parte, las empresas no financieras encuestadas redujeron su proyección para este año a $S / 3,28$. Sin embargo, para el siguiente año estiman que el tipo de cambio alcance los $S / 3,35$ con una baja hasta los $S / 3,30$, mientras que para el 2020 esperan que se sitúe en $S / 3,36$ con picos de $S / 3,40$. En resumen, las fuentes consultadas por el BCR esperan que el tipo de cambio tenga un crecimiento anual hasta llegar al 2020 a un valor que se encuentre entre los $S / 3,25$ y $S / 3,36$. 


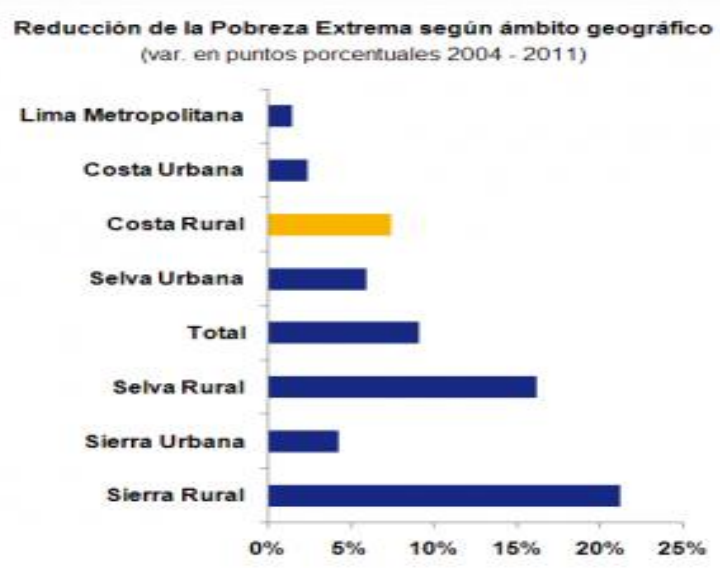

Figura 11. Reducción de la Pobreza Extrema según ámbito geográfico

En cuanto a pobreza no extrema, se logró reducir la pobreza de 37\% en el 2004 a 19\% en 2011. La variación más importante se encuentra en la costa urbana (24.2 puntos porcentuales) -sustentado fundamentalmente por la reducción de la pobreza en Lima metropolitana (25 puntos porcentuales)-, seguido por la costa rural y la selva rural (ambas de 22 puntos porcentuales)

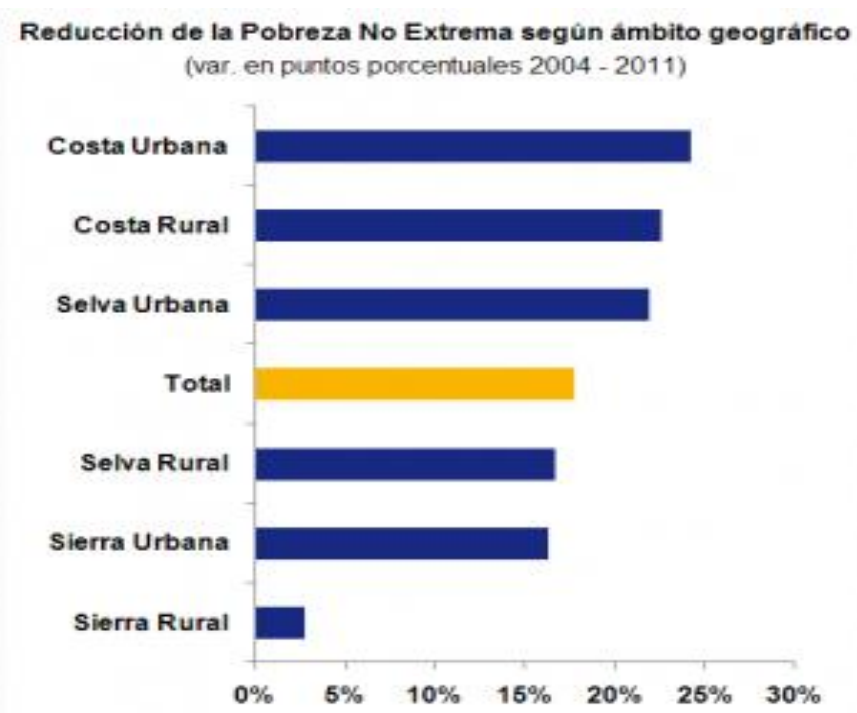

Figura 12. Reducción de la Pobreza No Extrema según ámbito geográfico

Es importante notar que el Estado cuenta con una oportunidad invaluable para contribuir a la reducción de la pobreza en zonas rurales con el recientemente creado Fondo Nacional para la Inclusión Económica (FONIE), a cargo del Ministerio de Inclusión Social, el cual podrá financiar proyectos de infraestructura y gastos de mantenimientos en los sectores de telecomunicaciones, caminos y carreteras, agua y saneamiento y energía en zonas rurales. EI FONIE cuenta con 600 millones de soles en 2013 para reducir la brecha de infraestructura en dichas zonas.

Asimismo, de lograr la colaboración del sector privado, la suma cofinanciada podría ser considerablemente mayor. Así, se contribuiría a la mejora de su situación de la 
población de zonas rurales mediante el acceso a servicios básicos. Instituto Peruano de Economía (2017).

\subsubsection{Análisis Legal.}

Marco Regulatorio

El sector eléctrico en el país es soportado con las siguientes leyes, que tiene el objetivo de regular dicho mercado.

La Ley de Concesiones Eléctricas establece como principio que más de una actividad, entre generación, transmisión y distribución, no pueden ser desarrolladas por una misma empresa, salvo lo previsto en la propia ley y en la Ley de Antimonopolio y Antioligopolio del Sector Eléctrico, Ley 26876.

La Ley $N^{\circ} 28832$ tiene como objetivo asegurar en forma suficiente una generación eficiente que reduzca el riesgo de la volatilidad de precios y el racionamiento, propiciando un establecimiento de precios de mercado basado en la competencia; planificar y asegurar un mecanismo que garantice la expansión de la red de transmisión, entre otros.

Con la finalidad de incentivar las inversiones en generación eficiente y la contratación con empresas distribuidoras, el estado promueve licitaciones de contratos de suministro de electricidad de largo plazo con precios firmes. Al respecto, las empresas distribuidoras deben iniciar los procesos de licitación por lo menos con tres años de anticipación a fin de evitar que la demanda de sus usuarios regulados quede sin cobertura. En cuanto al marco regulatorio para la transmisión, introducido por la Ley $\mathrm{N}^{\circ}$ 28832, se establece que la expansión de la transmisión debe ser planificada mediante un plan de transmisión de carácter vinculante, elaborado por el Coes y aprobado por el Mimen, previa opinión favorable del Osigermin. (Memoria Anual de Enel Generación Perú SAA, 2017, pp. 32 -35)

\subsubsection{Análisis de la Cultura, social y demográficas}

La tasa de crecimiento poblacional es un factor que tiene una influencia directa sobre la demanda de energía eléctrica. El censo del año 2017 indicó que el Perú cuenta con 31 '237, 385 habitantes, el país posee una tasa de crecimiento del orden del $1.0 \%$ lo que demuestra una tendencia decreciente del ritmo de crecimiento poblacional en los últimos 56 años. (INEl, 2017). A pesar de ello la demanda de energía se va a incrementar en los próximos años, las empresas de sistemas deben de planificar sus proyectos para satisfacer la demanda. 
A pesar de los logros económicos alcanzados existe aún el reto compartir equitativamente los avances haciendo que el desarrollo sea más incluyente. El impacto del fuerte crecimiento ha dado como resultado una importante disminución de las tasas de pobreza, al término del año 2018 , el $20.5 \%$ de la población del país que equivale en cifras absolutas a 6'593,000 personas que se encontraba en situación de pobreza, es decir tenían un nivel de gasto inferior al costo de la canasta básica de consumo compuesto por alimentos y no alimentos, según el informe Evolución de la Pobreza Monetaria 2007-2018 por el INEI.

Con respecto al nivel de la educación en los últimos años, se han logrado avances en materia educativa, en gran parte gracias a la reforma emprendida por el Ministerio de Educación (Minedu) y a un mayor gasto en este sector, que pasó de un $2.6 \%$ del PBI en 2000 a un 3.5\% en 2016, refiere ComexPerú.

Así, según el Inei, en 2016, el acceso a la educación, medido a través de la tasa neta de matrícula, aumentó en los niveles inicial y primaria, hasta alcanzar un $80.7 \%$ y un $91.4 \%$, respectivamente. No obstante, para el nivel secundario cayó, del $84.1 \%$ en 2015 al 83.6\% en 2016.

En cuanto al empleo, según estadísticas del MEM, el empleo directo del sector eléctrico acumuló un crecimiento de 66\% entre 2001 y 2015. Si bien el nivel de empleo en electricidad es inferior al 1\% con respecto a la población económica activamente ocupada, el sector demanda personal altamente calificado y especializado del exterior e interior del país. Los profesionales extranjeros transfieren conocimientos y capacitan al personal de nuestro país.

Figura 13. Evolución número de trabajadores en el rubro de generación

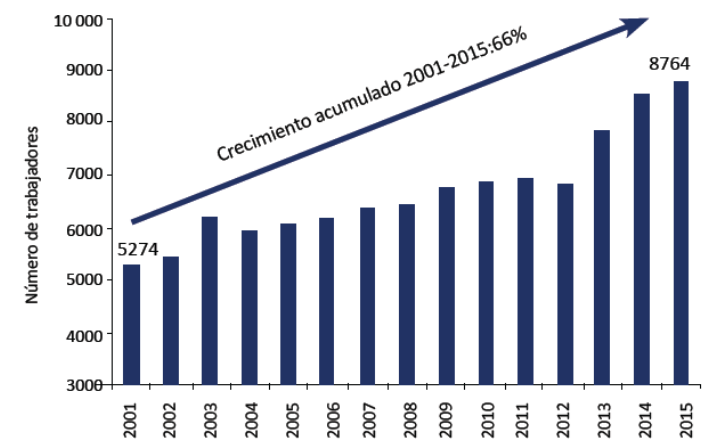

Fuente: Ministerio de Energía y Minas 


\subsubsection{Análisis Tecnológico.}

Big Data, Computación en la nube, Social Media, Movilidad, Internet de las cosas.

Estas son las cinco megas tendencias tecnológicas en todo el mundo que determinan el comportamiento de los usuarios y las empresas (Guzman, 2015).

El Perú, sus usuarios y sus mercados, no están exentos de esta tecnología y el nivel de implementación de las tendencias a sus procesos ha ido a la par con el ritmo regional. Para las empresas, lo más importante es cómo se aplican estas tendencias y qué tan rápido se pueden usar para beneficio del negocio.

Las tendencias son muy interesantes y son un ejercicio tecnológico muy simpático pero el valor es qué genera esto al negocio, por qué le interesaría (a un cliente) aprender, utilizar, desarrollar algo sobre esa tendencia. En la tecnología siempre se evalúan variables como el alcance con sus clientes, manejo de costos, flexibilidad, entre otras.

En Perú, la mega tendencia más acelerada es la computación en la nube. Luego, aparece la movilidad como el segundo en la concentración de interés empresarial. En menor medida, están considerados big data y social media.

Aunque el sector financiero y retail siempre están a la vanguardia en el uso y aplicación de instrumentos tecnológicos. A nivel local destacan las áreas propias de una compañía como operaciones, logística, entre otros.

A nivel mundial, Microsoft está invirtiendo US \$,000 millones en la continuación de la construcción de infraestructura en la nube y US\$9,000 millones para investigación y desarrollo. (Gestión, el diario de Economía y negocios del Perú. "Hablar de tendencias tecnológicas es un ejercicio simpático pero su valor está en qué genera al negocio". En el Perú se genera energía con tecnologías tradicionales como hidroeléctricas, termoeléctricas, solares y eólicas.

a. Tipos de Centrales Generadoras en el Perú

En el sistema interconectado, se presenta diversas tecnologías existentes: Centrales hidráulicas, centrales térmicas, solar, viento, turbo a gas, turbo a vapor, diesel, y el ciclo combinado.

b. Evolución Tecnológica

La utilización de la tecnología permite mayor eficiencia y reducción de costos en sus procesos operativos. El avance de la tecnología permite que las empresas que compiten en el mercado puedan realizar un benchmarking del sector para ser más eficientes y competitivos.

c. Principales funciones

Manejo del recurso hídrico (agua). 
Generación.

Transformación y transmisión.

Programación de la operación.

Operación en tiempo real.

Evaluación de la operación.

\subsubsection{Análisis Ambiental.}

Los factores que afectan al sector de electricidad son los cambios climáticos que se presentan en el año principalmente en la sierra del Perú.

La empresa Enel Generación Perú SAA no realiza actividad extractiva; por lo tanto, no presenta conflicto con poblaciones como en el caso de compañías de generación de energía eléctrica, petroleras y mineras. Adicionalmente, tampoco mantiene conflicto con agricultores o ganaderos, debido a que el recurso para la generación es el gas natural y no el agua.

Cambios Climáticos - Fenómeno del Niño

El fenómeno del niño afectará de manera negativa el sector agrícola, fuente principal de la Sierra Peruana, trayendo consigo complicaciones en la economía de los pobladores que dependen de este sector.

a. Impactos ambientales según tecnología

Termoeléctricas -Gas

Emisiones de gas.

Contaminación de la atmosfera.

Hidroeléctricas

Sedimentación.

Calidad del agua.

Perdida de lugares habítales para la población.

Perdida de especies.

Contaminación sonora.

b. Cambio de climas

Los cambios de las temperaturas ocasionan que las represas de almacenamiento e agua se vean afectadas debido agresivos que sufre el agua por evaporación y disminuir del nivel de agua. 


\subsection{Impacto en el entorno (proveedores y clientes)}

Tabla 6

Análisis Político

\begin{tabular}{lll}
\hline & Impacto & Impacto \\
& Clientes & Proveedores \\
\hline Cambio de la Matriz energética & Alto & Alto \\
$\begin{array}{l}\text { Plan de Gobierno presidente } \\
\text { electo }\end{array}$ & Alto & Alto \\
\hline
\end{tabular}

Fuente: Elaboración propia

Tabla 7

Análisis Económico

\begin{tabular}{|c|c|c|}
\hline & Impacto & Impacto \\
\hline & Clientes & Proveedores \\
\hline Volatilidad del tipo de cambio & Alto & Alto \\
\hline PBI en crecimiento. & Alto & Alto \\
\hline $\begin{array}{l}\text { Disminución inversión pública y } \\
\text { privada }\end{array}$ & Alto & Alto \\
\hline
\end{tabular}

Fuente:: Elaboración propia

Tabla 8

Análisis Legal

$\begin{array}{ll}\text { Impacto } & \text { Impacto } \\ \text { Clientes } & \text { Proveedores }\end{array}$

Las empresas son reguladas- No presentan barreras de entrada.

Alto

Alto

El Acuerdo Nacional y la CPP respaldan a empresas como ENEL Generación Perú

Alto

Alto

SAA

Fuente:: Elaboración propia

Tabla 9

Análisis Cultural

\begin{tabular}{lll}
\hline & Impacto & Impacto \\
& Clientes & Proveedores \\
\hline Conflictos sociales & Bajo & Alto
\end{tabular}

Fuente: Elaboración propia 
Tabla 10

Análisis Tecnológico

\begin{tabular}{lll}
\hline & Impacto & Impacto \\
& Clientes & Proveedores \\
\hline $\begin{array}{l}\text { Equipos especializados permiten brindar servicios } \\
\text { más eficientes }\end{array}$ & Alto & Alto \\
$\begin{array}{l}\text { Uso de equipos de oficina y Tecnología de punta. } \\
\begin{array}{l}\text { El personal operativo cuenta con equipamiento de } \\
\text { protección personal. }\end{array}\end{array}$ & Alto & Alto \\
\hline
\end{tabular}

Fuente:: Elaboración propia

La existencia de una entidad nacional de control y regulación del sector es necesaria.

Sin embargo, los controles previos o posteriores que pueda ejercer la administración no son suficientes. El mercado tiene un rol fundamental para el desarrollo de la actividad. El mercado es un elemento adicional para depurar las empresas buenas de las malas y las responsables de las irresponsables. Es fundamental una nueva regulación que involucre necesariamente a los clientes, generando incentivos adecuados a través de los cuales sea más seguro y eficiente contratar a una empresa formal que una informal.

\subsection{Efecto en la empresa}

Tabla 11

Análisis Político

Impacto en Comentario
empresa

\begin{tabular}{|c|c|c|}
\hline Cambio de la Matriz energética & Alto & $\begin{array}{l}\text { Fomentar un sistema que permita cumplir con la } \\
\text { demanda de energía. Permite el desarrollo de } \\
\text { proyectos renovables. }\end{array}$ \\
\hline $\begin{array}{l}\text { Plan de Gobierno presidente } \\
\text { electo }\end{array}$ & Alto & $\begin{array}{l}\text { Nuevas perspectivas y proyectos para proponer } \\
\text { nuevas inversiones en el sector. }\end{array}$ \\
\hline
\end{tabular}

Fuente: Elaboración propia 
Tabla 12

Análisis Económico

\begin{tabular}{lll}
\hline & Impacto en la empresa & Comentario \\
\hline & & Pone en riesgo que las \\
& & empresas que son clientes de \\
Disminución inversión pública y & \multirow{2}{*}{$\begin{array}{l}\text { Alto } \\
\text { privada }\end{array}$} & Enel Generación Perú SAA \\
& cierren sus operaciones. La \\
& empresa cuenta con una cartera \\
& amplia de clientes.
\end{tabular}

\begin{tabular}{lll} 
La volatilidad del dólar & Alto & $\begin{array}{l}\text { Afecta a la empresa debido a } \\
\text { que los comoddities son el } \\
\text { moneda extranjera } \$ \text { que } \\
\text { contrae la demanda }\end{array}$ \\
PBI en crecimiento & Alto & $\begin{array}{l}\text { Permitiría darle sostenimiento a } \\
\text { empresas que podrían contratar } \\
\text { los servicios de la empresa Enel } \\
\text { Generación Perú SAA. }\end{array}$ \\
\hline
\end{tabular}

Fuente: Elaboración propia

Tabla 13

Análisis Legal

\begin{tabular}{lll}
\hline & Impacto en la empresa & Comentarios \\
\hline $\begin{array}{l}\text { Las empresa son reguladas- No } \\
\text { se presentan barreras de }\end{array}$ & Alto & $\begin{array}{l}\text { Incremento de nuevos } \\
\text { competidores }\end{array}$ \\
$\begin{array}{l}\text { entrada. } \\
\text { El Acuerdo Nacional y la CPP }\end{array}$ & & Mayor prestigio para la \\
respaldan a empresas como & Medio & compañía con los entes \\
Enel Generación Perú SAA & & reguladores y clientes \\
\hline
\end{tabular}

Fuente:: Elaboración propia

Tabla 14

Análisis Cultural

\begin{tabular}{lll}
\hline & Impacto en la empresa & Comentarios \\
\hline & & Paralizan la actividad de las \\
& empresas que son clientes de \\
Conflictos sociales & Elto & comel Generación Perú SAA \\
& que se ubican en las minas. \\
& Ocasionan perdidas económicas \\
\hline
\end{tabular}

Fuente: Elaboración propia 


\subsection{Oportunidades y amenazas}

Las oportunidades son factores externos que la empresa puede aprovechar para obtener una competitividad en el mercado utilizando sus recursos propios, al contrario de ello las amenazas afectan directamente los ingresos y participación en el mercado. Oportunidades para la empresa Enel Generación Perú SAA encontradas en las variables externas:

Crecimiento de la economía peruana, impulsado por los decretos legislativos en materia económica para la reactivación de la economía peruana.

Fortalecimiento del desarrollo del sector energía, de acuerdo al Plan Energético Nacional 2014 - 2025, publicado por la Dirección General de Eficiencia Energética del Ministerio de Energía y Minas (MEM).

Integración Energética: Actualmente existen diferentes proyectos de integración energética con Ecuador, Brasil, Chile, Colombia y Bolivia. El país tiene el potencial de convertirse en HUB Energético y poder exportar energía de manera sostenible, luego de abastecer la demanda interna

Compromiso en aumentar la competitividad del Sector Minero - Energético mediante la Resolución Ministerial

Compromiso del gobierno en cerrar la brecha en la cobertura eléctrica en los próximos 10 años.

Sector eléctrico cuenta con un sistema interconectado

Nuevas tecnologías para automatización de las instalaciones

Migración de la población.

Como dato principal para el soporte a las oportunidades que se presentan en el sector, el experto sostiene que el Perú es el segundo país de la región Latinoamericana y el Caribe con el mayor potencial hídrico, el primero es Brasil (90,000 MW Instalados). El principal recurso energético renovable del Perú es el hidroeléctrico, como base de la Generación. El Potencial Hidroeléctrico del Perú es 69,445 MW, de los cuales 4,841 MW están Instalados, (6.97\% del potencial total).

Amenazas para la empresa Enel Generación Perú SAA encontradas en las variables externas:

El precio del petróleo y gas natural han mantenido un comportamiento muy volátil en los últimos años.

Actualmente el tipo de cambio PEN/USD se ha mantenido estable, sin embargo, los factores político - económicos del país pueden generar volatilidad.

Perú es un país expuesto a desastres naturales como sismos, tsunamis, e inundaciones los cuales pueden afectar considerablemente la infraestructura de EGP. 
Nuevos competidores con grandes inversiones

Cambio en el uso de recursos renovables para la generación de energía.

Conflictos Sociales.

En este acápite se toma en cuenta lo dicho por el entrevistado, donde la promoción de la energía térmica de origen combustibles líquidos como el diésel, puesto que encarece el suministro eléctrico, como también los costos productivos, y además contribuye negativamente al cambio climático por el efecto del calentamiento global debido a la emisión de gases de efecto invernadero como lo es el CO2 en su mayor porcentaje producto de los procesos industriales, del transporte vehicular, y otros gases originados por descomposición de material orgánico depositado en ubicaciones de colmatación de aguas tipo presas, embalses que quedan al descubierto cuando son desembalsadas.: metano: $\mathrm{CH} 4$. El combustible tipo gas licuado o natural también afecta en menor grado al petróleo, sin embargo, es motivo de la generación de CO2.

\subsection{Matriz de Evaluación de los Factores Externos EFE}

En la Matriz de evaluación de factor externo (EFE) se detalla los factores externos que influyen en la empresa. 


\section{Tabla 15}

Matriz EFE de Enel Generación Perú SAA

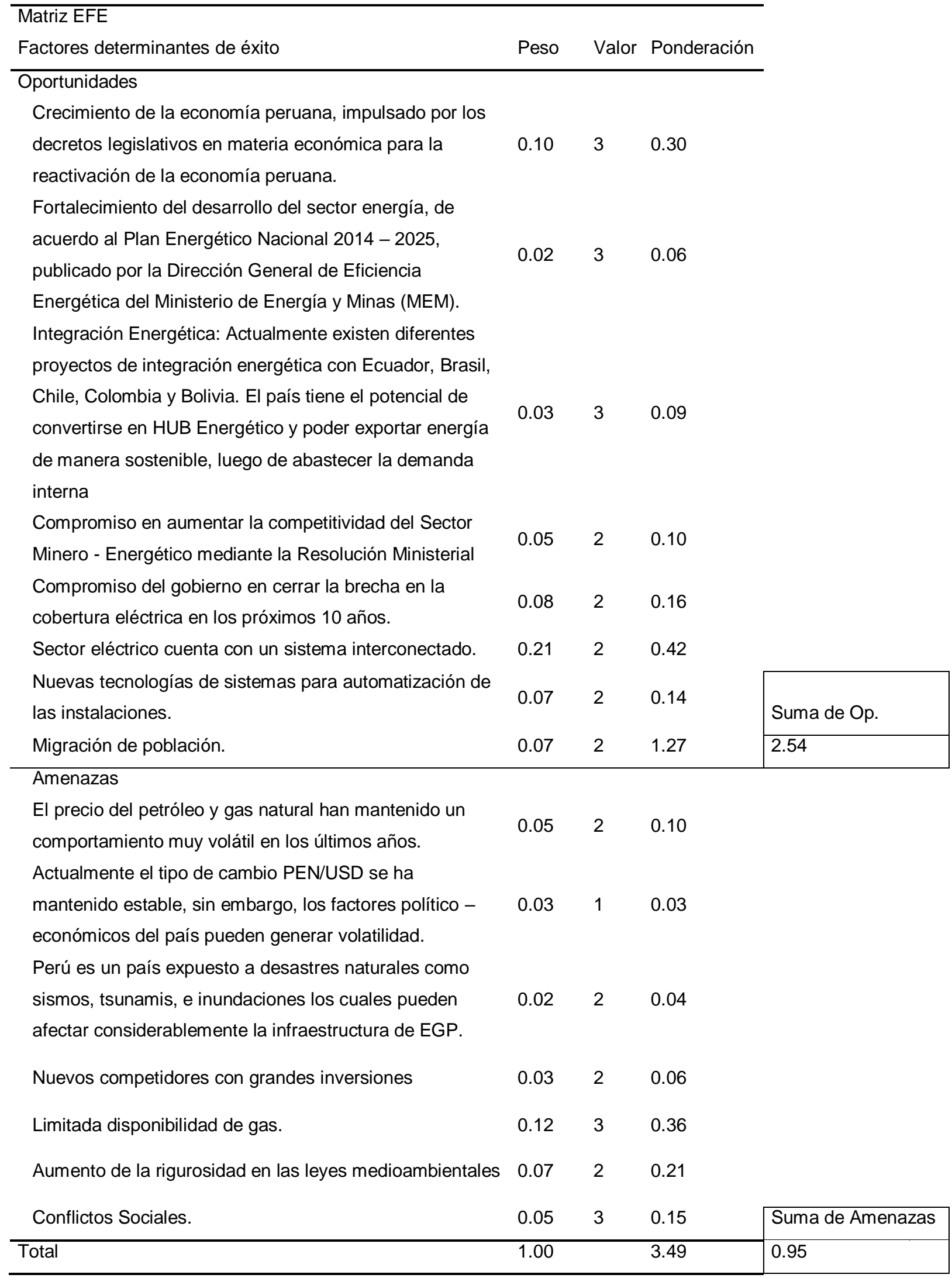

Fuente: Adaptado de Fred, R. David (1997) Conceptos de administración estratégica. 
Según Fred, R. David (1997) para elaborar la matriz EFE considera lo siguiente:

Se detallas las oportunidades y amenazas donde se pondera un peso de 0.0 como un factor menos importante hasta un factor de 1.0 siendo el más importante, dando una suma total de 1.0 entre dichos factores.

Para la ponderación se utiliza el puntaje entre 1 y 4, el cual 1 representa una mayor amenaza y 4 una mayor oportunidad, luego se multiplica los pesos por el valor de cada factor para obtener el ponderado de cada uno de los factores. Finalmente se suma los puntajes ponderados para obtener el ponderado total de la empresa.

\section{Conclusión}

El Estado Peruano promociona la inversión de plantas de energía renovables mediante incentivos a los inversionistas, como la prioridad en el despacho, el acceso a las redes de transmisión y distribución, y tarifas estables a largo plazo determinadas mediante subastas competitivas a esto le sumamos que el contar con una diversificación de la matriz energética, vía introducción de tecnologías renovables, aumenta la confiabilidad del sistema eléctrico y reduce la dependencia de combustibles fósiles. Asimismo, permite cumplir con los compromisos del país con respecto a la reducción de emisiones de GEI y favorece un mayor acceso a la electricidad en las zonas más vulnerables.

Los combustibles fósiles constituyen recursos no renovables y que están expuestos al agotamiento. El gas natural, dado sus ventajas ecológicas y económicas, constituye el principal insumo para el sector de generación térmica de electricidad; pero viene amenazado debido a una inadecuada infraestructura de transporte y la congestión en el suministro, siendo escaso para la demanda.

\section{Capítulo V. Análisis de la Industria}

Con el desarrollo del análisis de la industria del sector de energía se identificaron los principales actores y cuál es su poder de negociación en la cadena, lo cual servirá de marco para establecer las estrategias que maximicen las relaciones con los participantes del sector.

\subsection{Descripción del Mercado (demanda) e Industria (oferta)}

Se estima que la capacidad instalada de producción energética llegará a 14,208 MW el 2022, mientras que la demanda interna solo será de $9.393 \mathrm{MW}$, manteniéndose una producción superior a la requerida del mercado.

Esta situación se mantendrá a lo largo de los próximos cinco años, cuando se llegue a tener 14.208 MW de capacidad instalada mientras que la demanda máxima será de 
8.933 MW, 30\% más de los registrado en la actualidad. Mendoza Riofrío M. (26 de setiembre de 2017). Demanda interna de energía crecerá un 30\% en los próximos cinco años. El Comercio.

Los ingresos por venta de gas natural son indirectos al ser propietarios de los contratos asociados a la planta procesadora vendida a Graña y Montero Petrolera (GMP) en el 2016.

De manera mucho más específica, los expertos entrevistados indicaron que el sector de generación de energía eléctrica en el Perú, es un sector productivo activo con una trascendencia histórica con énfasis en la tecnología hidráulica, una realidad actual muy dinámica desde la participación en el mercado eléctrico de las energías de tecnología hidráulica, térmica (carbón en retiro, diésel, y en mayor aplicación el gas), y una proyección expectante no solo en el ámbito de las energías convencionales, sino también en la incursión en las nuevas tecnologías renovables no convencionales (entrevista, Lamas, 2018).

Proyectándose a cinco años, nivel nacional y global la tendencia del mercado eléctrico es orientarse hacia la generación de energía renovable sea esta de tecnología solar fotovoltaica, la macro y mini eólica, las Minihidros que es lo que más predomina, también las tecnologías solares de concentración media y alta temperatura, la biomasa, y a mediano plazo la energía geotérmica (entrevista, Lamas, 2018).

En cuanto a las Tendencias globales de inversión en energías limpias:

La inversión energética limpia o renovable global comparada con el precio al contado (spot) del mercado de negociación del crudo de petróleo en el período del 2004 al 2015 muestra que la inversión energética limpia ha crecido, mientras que el costo del crudo de petróleo ha caído verticalmente. El declive del precio de los combustibles fósiles no ha afectado la competitividad de las RER (recursos energéticos renovables). La competitividad de las RER es una tendencia global, reflejada en menores costos y mayor eficiencia con relación a los países donde se han dado inversiones en RER, como lo son en la región: Brasil, Chile, Emiratos Árabes Unidos, Egipto, Estados Unidos, India, México, Morocco, Perú y Sud África, por orden alfabético y considerando a las tecnologías de energías renovables de vanguardia como son la tecnología Eólica, la Solar Fotovoltaica, y la Minihidráulica (entrevista, Lamas, 2018).

\subsection{Descripción las cinco fuerzas competitivas de la industria}

Se analiza el grado de influencia que las cinco fuerzas de Porter, influyen directamente en la rentabilidad de una empresa a largo plazo. 


\subsubsection{Fuerza Competitiva de Porter: Poder de los Sustitutos.}

La Energía eléctrica no tiene producto sustituto, y se obtiene de diferentes recursos, como:

Dentro la gama de renovables, se obtiene de fuerza del viento, hidráulica, radiación solar, olas marinas.

Dentro la gama de No renovables, se obtiene de combustibles fósiles, gas, los minerales, biomasa (leña, bagazo), etc.

El experto entrevistado indicó que se deben reducir indicadores de generación de energía eléctrica en el Perú, si esta afirmación es correcta, luego se induce que existe sobreoferta de energía generada, lo cual debe ser analizado bajo el contexto energético actual del mercado eléctrico peruano. La reducción de energía gestionándola desde un enfoque eficiente, sostenible y de calidad implica priorizar la producción de las plantas que presentan mayor eficiencia operativa, luego las que son mayormente amigables con el medio ambiente, y cuyos costos de generación son cada vez menores frente a los insumos que se requieren para desarrollar el proceso productivo.

Desde este punto de vista se debe ir rescindiendo la producción de energía que proviene de procesos térmicos por afectar el ecosistema, por otro lado, las tecnologías de energías no convencionales se encuentran actualmente a un nivel muy competitivo respecto a las energías convencionales, las cuales de acuerdo a la tendencia del mercado global deben tender a disminuir los costos de inversión, al punto que no sea necesaria la ejecución de subastas de energías renovables para su integración en la matriz energética. Por otro lado, es importante el tema regulatorio sobre todo en la energía de tecnología eólica, la cual tiene buen potencial en el país, pero requiere de apoyo normativo para su desarrollo.

\subsubsection{Fuerza competitiva de Porter: Potenciales.}

Según Porter "la amenaza de entrada marca un límite al potencial de beneficios de una industria. Cuando la amenaza es real, los miembros deben reducir los precios o incrementar la inversión para detener a los nuevos competidores" (Porter, 2009). La oportunidad de desarrollo del sector eléctrico se encuentra en función de lo que determine el Ministerio de Energía y Minas a través de la definición de una Matriz Energética.

El Ministerio de Energía y Minas ha informado que en el Perú el crecimiento de la demanda de electricidad hasta el año 2020 será cubierto con centrales hidroeléctricas, unidades de generación a gas natural ubicadas en la zona Central y zona Sur, así como con energías renovables. Posteriormente, la generación de electricidad también 
será hecha con centrales hidroeléctricas, fuentes renovables y con centrales de gas natural ubicadas tanto en la zona Central, como en la zona Sur y en la zona Norte. La producción acumulada de las empresas generadoras ascendió a 12,490.66 GWh. (+1.7\% respecto al primer trimestre de 2017). Por fuente de generación, el recurso hídrico representó $68.6 \%$ de los recursos energéticos utilizados en la producción de energía, dado que la temporada de avenida tiene lugar entre los meses de noviembre y mayo. En este contexto, la demanda por fuentes de generación termoeléctrica (gas natural, carbón, residual y diésel) fue menor, situándose en $27.6 \%$ a la fecha de corte. Asimismo, destaca la mayor participación de energía generada por fuentes renovables, las cuales mostraron un incremento interanual de $2.2 \%$ a $3.8 \%$.

Figura 14. Muestra la producción acumulada por tipo de recurso a diciembre 2018.

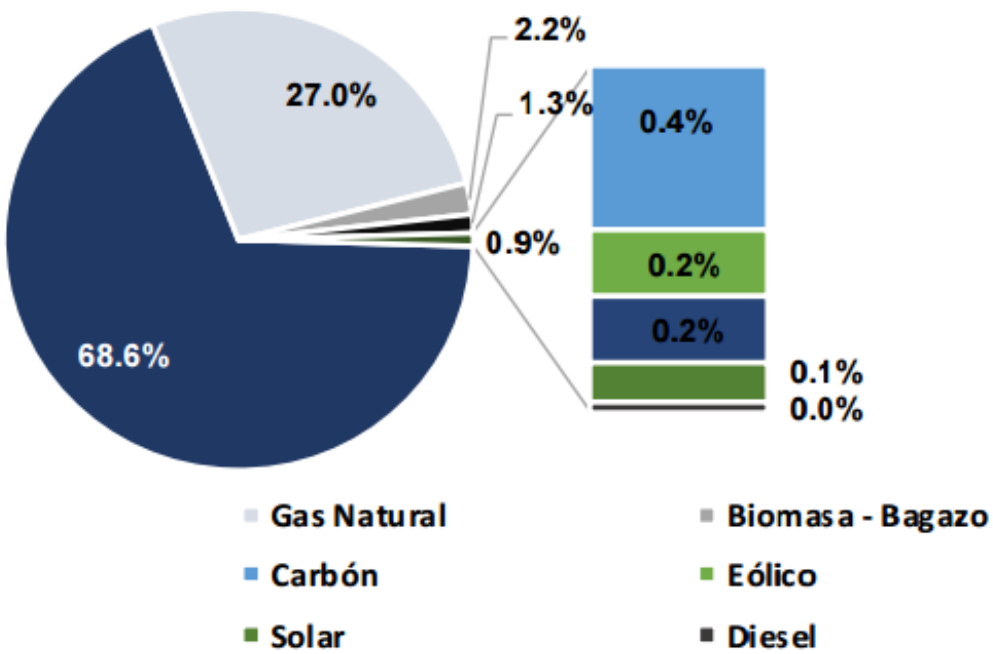

Figura 15. Muestra la producción acumulada por tipo de recurso a diciembre 2018. Fuente: COES / Elaboración: Equilibrium

Según datos del Organismo Supervisor de la Inversión de Energía y Minería el Al 2017, el sector eléctrico alcanzó US\$ 2593 millones

en inversiones, de los cuales $91.2 \%$ correspondió a inversiones de empresas privadas, $4.1 \%$ a inversiones de empresas públicas y $4.7 \%$ a inversiones en electrificación rural.

\section{Barreras de Salida:}

El decidir dar por cerrado una instalación, trae como consecuencia un alto costo de salida, ya sea por la infraestructura y equipos instalados, los cuales por sus características tiene un valor alto en el mercado. 


\section{Barreras de ingreso:}

La inversión de un proyecto para la construcción de una planta generadora es alta, teniendo en cuenta la capacidad instalada y el plazo mínimo que es de uno a dos años para su puesta en servicio.

\section{Tabla 16}

\section{Barrera de Entrada}

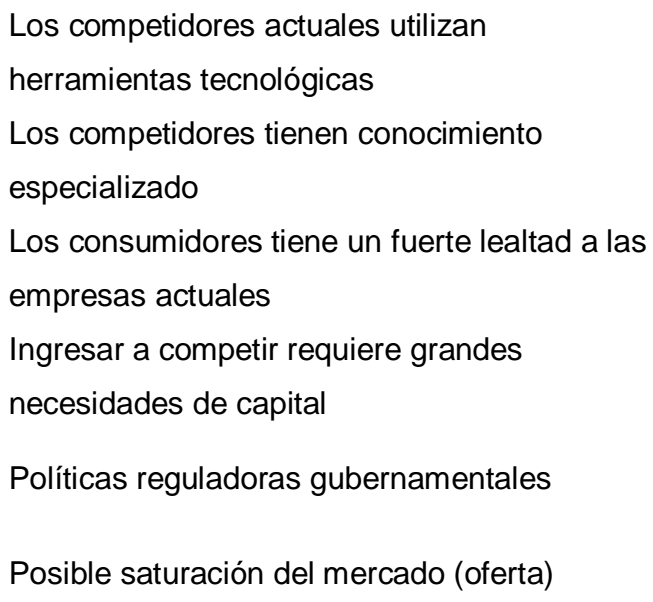

\section{Barrera de Salida}

Baja activos (plantas generadoras)

Cambio de sistema de generación por tecnología

Capacitación a personal técnico especializado

Cumplimiento legal para permisos ante organismos reguladores

Modificación contractual con clientes

Gastos en servicio en dejar fuera de servicio plantas generadoras

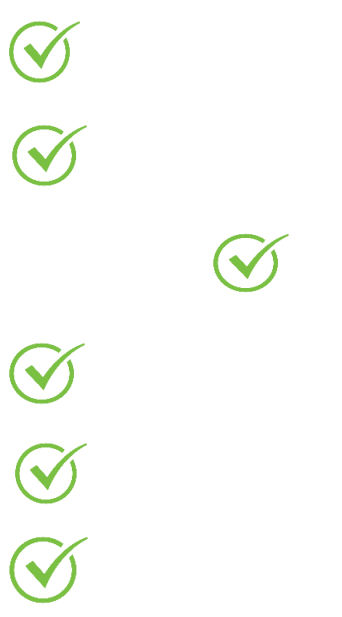

V




\subsubsection{Fuerza competitiva de Porter: Clientes.}

Los clientes al tener mayor oferta en el mercado, ejercen una presión a la reducción de precios.

En el país el estado se constituye como el actor más poderoso en el mercado de la energía eléctrica.

Los precios se encuentran regulados por el Organismo Supervisor de la Inversión en Energía y Minas (OSINERGMIN).

Para los clientes libres el poder de negociación es alto debido a que tienes varias opciones de empresas generadoras que comercializan energía barata.

\section{Tabla 18}

Comparativa de clientes

$\begin{array}{ll}\begin{array}{l}\text { Niveles de consumo con potencia } \\ \text { contratada igual y/o superior a }\end{array} & \begin{array}{l}\text { Niveles de consumo con potencia } \\ \text { contratada menores a 0.2 MW. } \\ 0.2 \mathrm{MW} \text {. (Rango Optativo: Entre }\end{array} \\ \begin{array}{l}\text { (No hay rango optativo) } \\ \text { Los Usuarios Libres no se }\end{array} & \text { Los Usuarios Regulados se } \\ \text { encuentran sujetos a regulación } & \text { encuentran sujetos a regulación } \\ \text { de precios. } & \text { de precios. } \\ \text { Los precios que paga un Usuario } & \text { Los precios que paga un Usuario } \\ \text { Libre dependen de lo establecido } & \text { Regulado son establecidos por } \\ \text { en el contrato de suministro de } & \text { OSINERGMIN a través del } \\ \text { cada Usuario Libre con su } & \text { procedimiento a Tarifas en barra. } \\ \text { Suministrador. } & \text { Los Usuarios Regulados no } \\ \text { Los Usuarios Libres pueden } & \text { pueden participar del Mercado de } \\ \text { participar del Mercado de Corto } & \text { Corto Plazo. } \\ \text { Plazo. } & \end{array}$

Fuente: Elaboración propia.

Ante un precio spot bajo, las generadoras tienen incentivos para suscribir mayores contratos dado que cuentan con la alternativa de efectuar mayores retiros a un costo que, en ocasiones, puede ser inferior a su costo de producción. Producto de lo anterior, las distribuidoras ven reducida su base de clientes sin la posibilidad de renegociar las características principales de los contratos "take or pay" a largo plazo suscritos con las generadoras. 
El Ministerio de Energía y Minas está evaluando la posibilidad de modificar el consumo mínimo que una empresa debería tener para poder acceder a este mercado y negociar directamente con las generadoras, lo cual impactaría directamente en las pequeñas y medianas empresas

El mercado de generación peruano es competitivo, existen 49 compañías. Los clientes regulados, las bases de licitaciones son públicas y el mecanismo de adjudicación es por medio de subasta, por lo tanto, las distribuidoras no presentan poder de negociación. En cambio, los clientes libres si ejercen un mayor poder de negociación al existir mayor oferta.

Otro factor a tener en cuenta por el cual los clientes tienen un escaso poder de negociación es que la energía es un bien de primera necesidad, lo cual hace que no puedan negociar con las grandes eléctricas.

\subsubsection{Fuerza Competitiva de Porter: Proveedores.}

Los proveedores del sector eléctrico por lo general no tienen un poder de negociación alto ya que las eléctricas son grandes consumidores y conviene tenerlos como clientes, De todas formas, hay una gran diferencia entre los proveedores, ya que los proveedores de tecnología hidráulicas y térmicas tienen un poder de negociación muy reducido debido a las escasas cantidades que se consumen, mientras que los proveedores de la energía solar y eólica tienen un elevado poder de negociación debido a la escasez de estos productos

\subsubsection{Fuerza Competitiva de Porter: Competencia en el mismo sector.}

La existencia de varios competidores influye en la baja de los precios, incremento de la calidad y valor agregado en los servicios, incremento en el presupuesto para publicidad e imagen y desarrollo de proyectos de sostenibilidad, generando una Alta rivalidad en la industria (Porter, 2009).

En el caso de clientes no regulados hay bastante competencia para los contratos de suministro a largo plazo. En el caso de clientes regulados, la cantidad de postores en las subastas para los contratos con distribuidoras, ponen en evidencia la alta rivalidad de los competidores.

Se puede observar que promover la competencia en el sector eléctrico no es fácil ya que para conseguir una liberalización del sector no sirve con crear un mercado organizado y eliminar las trabas legales que dificultan la entrada de nuevos agentes. Las empresas que operan actualmente en el mercado se encuentran en una posición privilegiada, además tienen una capacidad elevada para influir sobre los precios ya 
que sólo participan unos pocos agentes y éstos van a intentar coordinar sus estrategias para conseguir mayores precios. Además de esto, los nuevos productores tienen varios obstáculos debido a que las centrales instaladas actualmente van a seguir construyendo nuevas plantas y van a ocupar los huecos que podrían ocupar sus competidores.

\subsection{Matriz de atractividad de cada una de las cinco fuerzas}

La estructura del sector y los impulsores subyacentes que determinan la rentabilidad en ella, se analizan a través de las cinco fuerzas de Porter, encontrándose lo siguiente:

Amenaza de nuevos entrantes: existiría una amenaza alta de nuevos entrantes considerando que no existen barreras de entrada significativas al sector, ni se toman represalias contra ellos.

Poder de negociación de los proveedores: los proveedores de insumos y tecnología (construcción, operación, mantenimiento) presentarían un alto poder de negociación en el sector de generación eléctrica.

Poder de los compradores: los compradores, clientes libres y regulados, presentan un poder alto para capturar más valor en las transacciones con las empresas de generación eléctrica, dado que los productos en el sector no tienen diferenciación ni se incurren en costos adicionales al cambiar de proveedor.

Amenaza de productos o servicios sustitutos: si bien no se tienen sustitutos importantes para la generación eléctrica, entre las fuentes de generación, un sustituto que va cobrando relevancia son los recursos energéticos renovables (RER). Si se llegara a mejorar la eficiencia en la generación RER podría significar una amenaza alta en el sector, considerando el apoyo del Estado a la diversificación de la matriz energética.

Rivalidad entre los competidores existentes: los competidores existentes presentan una alta rivalidad considerando su participación en el mercado y la diversificación de sus fuentes de producción. 


\section{Tabla 19}

Poder de nuevos competidores

\begin{tabular}{|c|c|c|c|}
\hline \multicolumn{2}{|c|}{ Ame naza de entrada nuevos competidores } & \multirow{2}{*}{ Amenaza } & \multirow{2}{*}{$\begin{array}{l}\text { Comentarios } \\
\text { Rápido agotamiento de las economías de escala debido a que el costo medio } \\
\text { mínimo de producción se alcanza rapidamente. Las economías de escala son } \\
\text { pequeñas respecto a la demanda del mercado. }\end{array}$} \\
\hline \multirow{7}{*}{ Barre ras de entrada } & $\begin{array}{l}\text { Economías de escala por el lado } \\
\text { de la oferta }\end{array}$ & & \\
\hline & $\begin{array}{l}\text { Beneficios de escala por el lado } \\
\text { de la demanda }\end{array}$ & Alta & $\begin{array}{l}\text { La demanda se satisface en función de la eficiencia de los participantes en el } \\
\text { mercado. No hay predisposición por un proveedor en especial. }\end{array}$ \\
\hline & $\begin{array}{l}\text { Costos para los clientes por } \\
\text { cambiar de proveedor }\end{array}$ & Alta & $\begin{array}{l}\text { El cambio de proveedor no genera costos adicionales para los clientes } \\
\text { interconectados al SEIN. En Sistemas Aislados se podrían generar costos } \\
\text { adicionales. }\end{array}$ \\
\hline & Requisitos de capital & Baja & $\begin{array}{l}\text { Los montos de inversión para la construcción de centrales son altos y no tienen un } \\
\text { uso alternativo al momento de su disposición. }\end{array}$ \\
\hline & $\begin{array}{l}\text { Ventajas de los actores } \\
\text { establecidos independientemente } \\
\text { del tamaño }\end{array}$ & Me dia & $\begin{array}{l}\text { Si bien la tecnología y los insumos necesarios para la generación (agua y gas) se } \\
\text { encuentran al alcance de todos los competidores, en el futuro podrían existir } \\
\text { algunas restricciones principalmente relacionadas con los insumos (gas: contratos } \\
\text { de abastecimiento). }\end{array}$ \\
\hline & $\begin{array}{l}\text { Acceso desigual a canales de } \\
\text { distribución }\end{array}$ & Alta & $\begin{array}{l}\text { Los generadores tienen libre acceso a las redes de transmisión y distribución, } \\
\text { realizando el pago del peaje correspondiente. }\end{array}$ \\
\hline & Politicas gubernamentales & Alta & $\begin{array}{l}\text { Se ha fomentado en los últimos años el desarrollo de centrales térmicas por el } \\
\text { acceso a gas barato, limitando la generación hidroeléctrica. Asimismo se está } \\
\text { fomentando el acceso a generación RER. }\end{array}$ \\
\hline \multirow{4}{*}{ Represalias } & $\begin{array}{l}\text { Respuesta enérgica a entrantes } \\
\text { anteriores }\end{array}$ & Alta & No se han generado represalias contra muevos competidores en el pasado \\
\hline & $\begin{array}{l}\text { Competidores actuales tienen } \\
\text { recursos para defenderse }\end{array}$ & Alta & Si cuentan con recursos pero no se aplican \\
\hline & $\begin{array}{l}\text { Reducción de precio por parte de } \\
\text { competidores actuales }\end{array}$ & Alta & Los precios reflejan los costos marginales de producción \\
\hline & $\begin{array}{l}\text { Crecimiento lento del sector, } \\
\text { nuevos deben quitar espacio a } \\
\text { actuales }\end{array}$ & Alta & $\begin{array}{l}\text { Si bien existe una sobreoferta, la demanda presenta un crecimiento y se espera } \\
\text { que siga creciendo en los próximos años por el desarrollo de proyectos a nivel } \\
\text { nacional }\end{array}$ \\
\hline
\end{tabular}




\section{Tabla 20}

Poder de los proveedores

\section{Poder de negociación de los proveedores}

Mayor concentración del sector al cual provee

Alto

Ingresos que no dependen fuertemente del sector

Medio

Participantes deben asumir costos por cambiar de proveedores

Bajo

Proveedor con productos diferenciados

Sustitutos a lo que se provee

Amenaza que proveedor entre a participar en el sector

Poder
Bajo

Medio

Alto

Comentarios

Insumos: el gas proviene principalmente de camisea. Es explotado por un consorcio liderado por Pluspetrol y distribuido por TGP.

Tecnología: la construcción de las centrales, la adquisición de maquinarias y a operación y mantenimiento se realizan a través de contratos con empresas

de gran envergadura y experiencia en el sector.

Insumos: el principal destino del gas de camisea es a las empresas de generación y distribución de energía.

Tecnología: las empresas encargadas de la construcción no son

especializadas en dichas infraestructuras, están más diversificadas.

Insumos: la operación del sistema de transporte por ductos de gas de Camisea está a cargo de TGP por lo que es el principal proveedor.

Tecnología: los participantes deberán incurrir en gastos para realizar la contratación de un nuevo proveedor.

No existe diferenciación de insumos, tecnología

A futuro se espera una mayor participación de la generación RER

Insumos : Pluspetrol no tiene participación en el sector de generación, sin embargo en otros países (Argentina) si está presente.

Tecnología: Muchos proveedores son también Sponsor de las empresas que participan en el sector. 
Tabla 21

Poder de los competidores

\section{Poder de los competidores}

Poder Comentarios

Pocos compradores o compran en gran volumen

Existen muchos clientes regulados que presentan un consumo bajo de

Bajo energía y pocos clientes libres con un mayor consumo de energía. En el mercado la energía se destina principalmente a clientes regulados.

Costos bajos para el comprador por cambiar hacia el substituto Alto preferencia.

Bajos costos por cambiar de proveedor

Alto Al estar interconectado principalmente a través del SEIN no tienen costos por cambiar de proveedor.

Compradores amenazan con entrar a participar en el

Fuente: Elaboración propia 
Tabla 22

Amenaza de los sustitutos

\begin{tabular}{lll}
\hline Amenaza de los sustitutos & Amenaza & Comentarios \\
\hline $\begin{array}{l}\text { Atractivo trade-off de precio y desempeño respecto a } \\
\text { producto del sector }\end{array}$ & Media & $\begin{array}{l}\text { La generación RER aún no presenta la eficiencia necesaria para competir } \\
\text { con la generación hidráulica y térmica, sin embargo el estado apoya este } \\
\text { tipo de generación con la finalidad de diversificar la matriz energética }\end{array}$ \\
$\begin{array}{lll}\text { Costos bajos para el comprador por cambiar hacia el } \\
\text { substituto }\end{array}$ & Alta & $\begin{array}{l}\text { El cambio de la generación hidráulica o térmica por generación RER no } \\
\text { implicaría costos adicionales para comprador }\end{array}$
\end{tabular}

Fuente: Elaboración propia

Tabla 23

Rivalidad entre competidores

\begin{tabular}{|c|c|c|}
\hline Rivalidad entre competidores existentes & Rivalidad & Comentarios \\
\hline Competidores, con igual tamaño y relevancia & Alta & $\begin{array}{l}\text { Los principales participantes están diversificados con centrales hidráulicas y } \\
\text { termicas que les permiten tener una presencia significativa en el mercado }\end{array}$ \\
\hline Crecimiento lento del sector & Media & $\begin{array}{l}\text { Si bien existe una sobreoferta, la demanda presenta un crecimiento y se espera que siga creciendo } \\
\text { en los próximos años por el desarrollo de proyectos a nivel } \\
\text { nacional }\end{array}$ \\
\hline Barreras de salida altas & Alta & $\begin{array}{l}\text { Existen barreras de salida altas relacionadas con los activos especializados } \\
\text { (centrales) que se requieren para la generación }\end{array}$ \\
\hline Rivales comprometidos con el negocio & Baja & $\begin{array}{l}\text { Más allá de las metas en el desempeño económico de la empresa, no se } \\
\text { identifican metas adicionales que comprometan a los rivales con el negocio. }\end{array}$ \\
\hline Enfoques competitivos distintos & Baja & $\begin{array}{l}\text { La competencia en el sector está basada fundamentalmente en la eficiencia de } \\
\text { las operaciones }\end{array}$ \\
\hline
\end{tabular}

Fuente: Elaboración propia 
Como resultado de la evaluación, encontramos una competencia fuerte en el sector de generación eléctrica que se refleja en una alta amenaza de entrada nuevos competidores, un alto poder de negociación de los proveedores y compradores, así como por la rivalidad entre competidores existentes, y una potencial amenaza por productos sustitutos relevantes (generación RER).

\subsection{Análisis del Grado de atractividad de la industria}

La infraestructura energética es esencial para el adecuado desarrollo de los mercados energéticos, en muchos casos, sectores donde la competencia se encuentra limitada al tener características de monopolio natural. Asimismo, el impacto económico de la misma depende, en gran medida, de la eficiencia de su establecimiento, operación y mantenimiento y de la calidad en su provisión. En los próximos años, uno de los principales desafíos del Perú será la implementación de infraestructura que permita continuar con el desarrollo del país, en donde se abran las puertas a proyectos de envergadura regional. Asimismo, es necesario una revisión sistemática e integral del funcionamiento del marco regulatorio eléctrico, a fin de adecuarlo al nuevo entorno, complejo y dinámico, que viene experimentando el país.

A partir de las necesidades surgidas en el sector eléctrico y la importancia que este tiene para el desarrollo, tanto de la industria como de la población, se han dictado medidas que promuevan la inversión, afianzando la seguridad energética.

Tabla 24

Compromiso de Inversión privada 2017-2019 por sectores (Millones de US\$)

\begin{tabular}{|c|c|}
\hline Minería & 8911 \\
\hline Hidrocarburos $\pi$ & 4821 \\
\hline Electricidad 受 & 3985 \\
\hline Industria & 2240 \\
\hline Infraestructura 䮲直 & 5028 \\
\hline Otros Sectores & 8142 \\
\hline Total & 33127 \\
\hline
\end{tabular}

Fuente: Informe de la Industria de la electricidad en el Perú: 25 años de apostes al crecimiento del país, Organismo Supervisor de la Inversión en Energía y Minería. 
El Estado desarrolla estrategias que faciliten la inversión privada, definiendo políticas de seguridad energética a largo plazo. Es por ello que el Ministerio de Energía y Minas (MEM) ha desarrollado el Plan Energético Nacional para el periodo 2014-2025, con el objetivo de contar con abastecimiento competitivo, lograr la seguridad y el acceso al suministro energético y desarrollar recursos energéticos con mínimo impacto ambiental y menos emisiones de carbono

\subsection{Matriz de Perfil Competitivo MPC}

En dicha Matriz se pondera las debilidades y fuerzas de cada competidor para lograr el éxito. 
Tabla 25

Matriz de Perfil Competitivo (MPC)

\begin{tabular}{|c|c|c|c|c|c|c|c|c|c|c|c|}
\hline \multirow{3}{*}{ Factores } & \multicolumn{11}{|c|}{ EMPRESAS } \\
\hline & \multirow[b]{2}{*}{ Peso } & \multicolumn{2}{|l|}{ ENEL } & \multicolumn{2}{|c|}{$\begin{array}{l}\text { ENGIE ENERGÍA } \\
\text { PERÚ }\end{array}$} & \multicolumn{2}{|c|}{ KALLPA } & \multicolumn{2}{|c|}{ ELECTROPERÚ } & \multicolumn{2}{|c|}{ EGENOR } \\
\hline & & Valor & Ponderación & Valor & Ponderación & Valor & Ponderación & Valor & Ponderación & Valor & Ponderación \\
\hline Poder Financiero & 0.20 & 3 & 0.60 & 1 & 0.20 & 3 & 0.60 & 3 & 0.60 & 3 & 0.60 \\
\hline Procesos productivos & 0.15 & 3 & 0.45 & 3 & 0.45 & 3 & 0.45 & 3 & 0.45 & 2 & 0.30 \\
\hline $\begin{array}{l}\text { Capacidad y entrenamiento del } \\
\text { personal }\end{array}$ & 0.13 & 3 & 0.39 & 4 & 0.52 & 3 & 0.39 & 3 & 0.39 & 3 & 0.39 \\
\hline Mix fuentes de generación de energía & 0.12 & 3 & 0.36 & 2 & 0.24 & 4 & 0.48 & 2 & 0.24 & 2 & 0.24 \\
\hline Captación de nuevos clientes & 0.15 & 4 & 0.60 & 2 & 0.30 & 2 & 0.30 & 2 & 0.30 & 2 & 0.30 \\
\hline Sistema de control y comunicaciones & 0.09 & 4 & 0.36 & 3 & 0.27 & 3 & 0.27 & 4 & 0.36 & 4 & 0.36 \\
\hline $\begin{array}{l}\text { Política de seguridad para gestión de } \\
\text { contratistas }\end{array}$ & 0.09 & 4 & 0.36 & 2 & 0.18 & 2 & 0.18 & 3 & 0.27 & 2 & 0.18 \\
\hline $\begin{array}{l}\text { Ubicación geográfica de las plantas de } \\
\text { generación de energía }\end{array}$ & 0.07 & 4 & 0.28 & 2 & 0.14 & 3 & 0.21 & 3 & 0.21 & 3 & 0.21 \\
\hline Total & 1.00 & & 3.40 & & 2.30 & & 2.88 & & 2.82 & & 2.58 \\
\hline
\end{tabular}

Fuente: Matriz de Perfil Competitivo (MPC). Tomado de “El Proceso Estratégico: Un Enfoque de Gerencia (6a ed.)," por F. A. D’Alessio, 2015. Lima, Perú:

Pearson. 
Según las entrevistas realizadas a expertos ajenos a la empresa (Anexo 2), fortalecen los factores considerados en la Matriz MPC, donde de acuerdo a sus repuestas se ha colocado la ponderación de acuerdos a las empresas del sector y considerando la información según lo señalado por la viceministra de electricidad del Ministerio de Energía y Minas (MEM) Patricia Elliot (Julio 2019), el 63\% de la energía generada en el Perú proviene de fuentes renovables: centrales hidroeléctricas $(92 \%)$ y plantas eólicas y solares $(8 \%)$, del otro lado el $37 \%$ está constituida por gas natural. Dada su diversidad y ecosistemas únicos, el Perú es rico en climas y recursos renovables (energía eólica, solar, geotérmica, biomasa e hidroeléctrica), los cuales brindan la capacidad para que existan fuentes alternativas al gas natural y a las grandes hidroeléctricas para generar energía eléctrica, ratifica que la diversificación de generación es un factor importante en el sector.

El sistema de generación de electricidad se desarrolla en un contexto competitivo, en donde está permitida la libre competencia debido a la reducción de barreras de entrada y/o agotamiento temprano de economías de escala; es por ello, que la gestión empresarial repercute en la rentabilidad y la eficiencia orientada a incrementar el valor económico en cada una de las empresas del sistema, respetando la normativa y el marco regulatorio.

En cuanto a la inversión en energía renovable, según el Informe Global del Estado de las Renovables 2019 publicado en les mes de junio, hubo un aumento del $6 \%$ en diversos países de Sudamérica. Para el caso de Perú el incremento de inversión de debió a las adjudicaciones de 71 proyectos por un total de 1,34GW en tecnologías en parques solares y centrales hidráulicas, lo que sustenta el factor de poder financiero.

Actualmente, existe una competencia entre las empresas de generación, por conseguir más clientes en la modalidad de contratos bilaterales, lo cual promueve que los precios libres sean cada vez más competitivos.

Según la reunión realizada con Eugenio Calderón, Head of Renewable Energies Perú, los objetivos de las generadoras deben ser:

- Conseguir un margen comercial; definido por el precio spot y precio del suministro de competencia. Al negociarse menores bloque de demanda los precios serán mayores, aumentando el beneficio. 
- Obtener acuerdos más flexibles; durante la negociación el generador puede explicar y justificar los distintos elementos de su oferta y pudiera lograr obtener acuerdos para compartir el riesgo, estableciendo una relación de mayor colaboración entre las empresas, lo que resulta útil en la administración de contrato durante el periodo de duración.

- Nivel de competencia; a través de servicios adicionales la empresa puede ser más competitiva agregando servicios adicionales dentro de la oferta.

Del análisis de competitividad, se concluye que Perú tiene condiciones propicias para un adecuado desarrollo y crecimiento sostenido del Sector Eléctrico, con un adecuado modelo regulatorio que promueve la competencia a nivel del subsector de generación convirtiéndose en un mercado atractivo para inversionistas extranjeros. De acuerdo a la evaluación realizada en la Matriz MPC, Enel Generación Perú S.A.A obtiene la mayor puntuación debido a que tiene una fortaleza significativa en cada uno de los factores evaluados en comparación con sus competidores. 


\section{Capítulo VI. Análisis interno}

El análisis interno entrega un enfoque que se sostiene en los elementos característicos de los recursos y medios que utiliza la empresa Enel Generación Perú SAA para afrontar el entorno competitivo del giro de negocio. En este análisis descriptivo se identifica las debilidades y fortalezas con el fin de conocer la competitividad del sector.

A continuación, se describe el aporte de los gestores y expertos de la empresa Enel Generación Perú SAA.

\subsection{Descripción de las actividades de la cadena de valor de la empresa}

Representa las actividades, acciones y funciones que al vincularse crean valor. Porter mantiene que "el negocio de una empresa se describe como una cadena de valor, donde los ingresos totales menos los costos totales de las actividades que se llevan a cabo para desarrollar y comercializar un producto o servicio generan valor" (1987, p. 142).

La Figura 16, detalla los componentes de la cadena de valor que son actividades primarias y de apoyo.

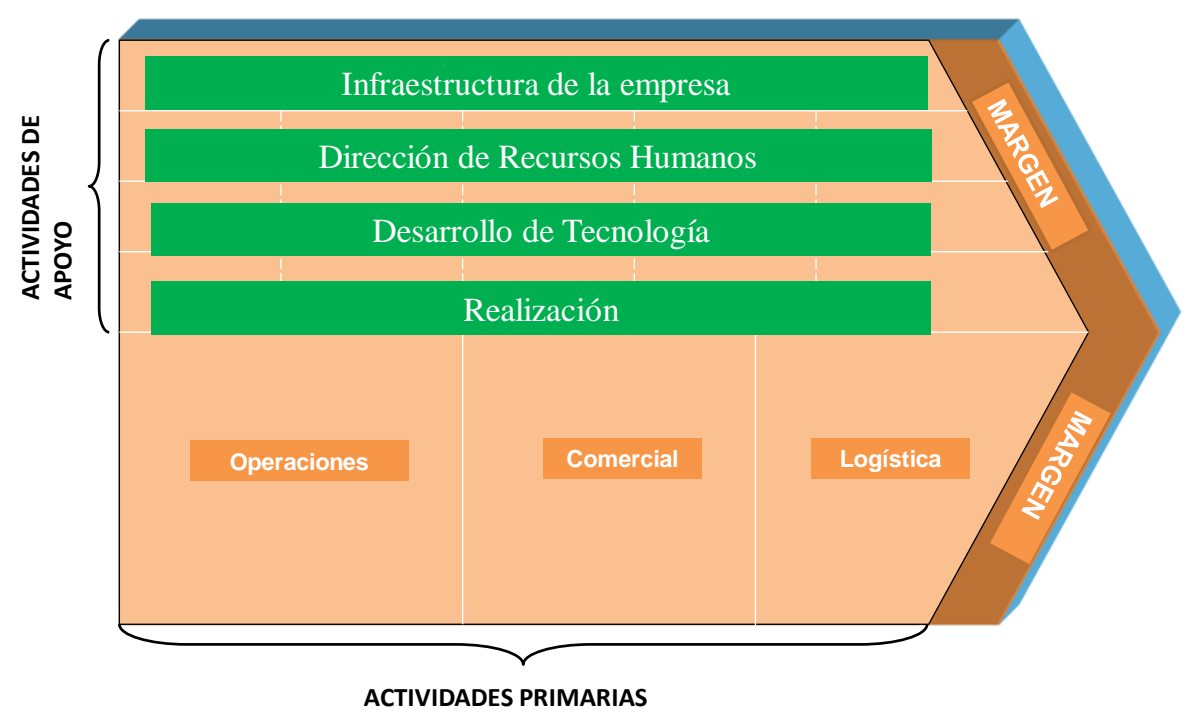

Figura 16. La cadena de Valor en Servicios.

Tomado de "On competition. USA: Harvard Business School Publishing Corporation. (11a ed.)," por Porter, M. (2009). 
Con la información obtenida en el proceso de investigación, existen tres puntos clave que los usuarios de Enel Generación Perú SAA toman en cuenta:

a) Producto Regulado, el abastecimiento debe cumplir con lo exigido por los organizamos reguladores.

b) Seguridad en el servicio, debe ser constante, sin interrupciones en la entrega de energía.

c) Precio, el precio ofertado debe ser competitivo teniendo en cuenta el mercado que es competitivo.

d) Valor Agregado: servicios adicionales que acompañan la propuesta económica.

\section{Actividades primarias:}

a. Generación

Centrales Hidráulicas. Instalaciones que aprovechan las masas de agua en movimiento que discurren por los ríos para transformarlas en energía eléctrica, utilizando turbinas alternadores.

Ventajas de la Generación Hidráulica:

No necesitan combustibles y son limpias

Muchas veces los embalses tienen otras utilidades importantes: regadío, como protección contra las inundaciones o para suministrar agua a las poblaciones próximas.

Tienen costes de explotación y mantenimiento bajos.

Las turbinas hidráulicas son de fácil control y tienen costos de mantenimiento reducidos.

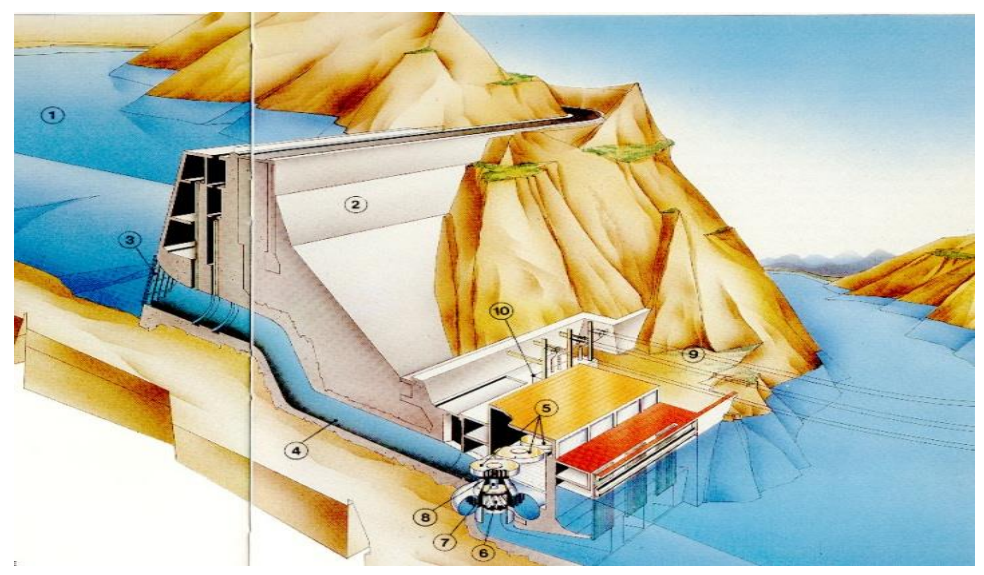

Figura 17. Esquema de una Central Hidroeléctrica.

Tomado de "On competition. USA: Harvard Business School Publishing Corporation. (11a ed.)," por M. Porter. México: Ediciones Deusto. 
Centrales Térmicas. Instalación que genera energía utilizando la energía liberada en forma de calor, normalmente mediante la combustión de combustibles fósiles como petróleo, gas natural o carbón. Este calor es empleado por un ciclo termodinámico convencional para hacer rotar un alternador y producir energía eléctrica.

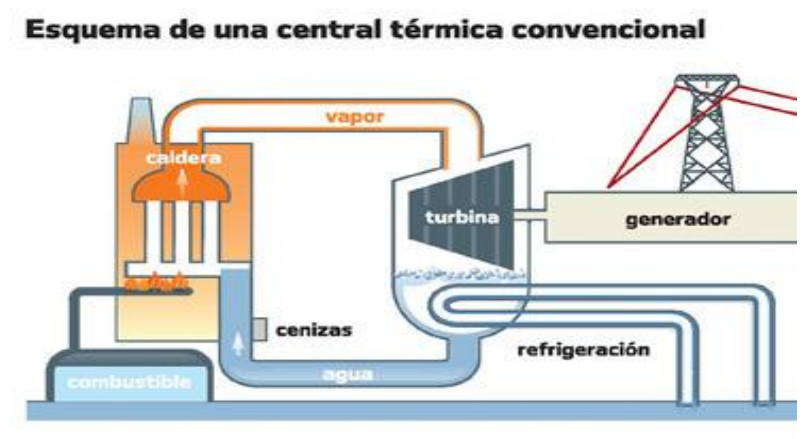

Figura 18. Esquema de una Central I ermıca a Gias.

Tomado de "On competition. USA: Harvard Business School Publishing Corporation. (11a ed.)," por M. Porter. México: Ediciones Deusto.

Central Solar Fotovoltaica. La energía solar se aprovecha transformándola directamente en electricidad mediante el efecto fotovoltaico. En la instalación la obtención de energía eléctrica se produce a través de paneles fotovoltaico que captan la energía luminosa del sol para transformarla en energía eléctrica

Centrales Eólicas. La energía eólica es obtenida del viento, este es un efecto derivado del calentamiento desigual de la superficie de la tierra por el sol. La energía eólica es un recurso abundante, renovable, limpio y ayuda a disminuir los gases de efecto invernadero al reemplazar termoeléctricas a base de combustibles fósiles, lo que se convierte en un tipo de energía verde.

b. Transmisión

A través de las sub estaciones de transformación y líneas aéreas de transmisión en alta tensión se traslada la energía de las centrales.

El valor agregado es el de trasladar y disponer el producto en los lugares donde se le requiere, es decir en los clientes finales. En el caso de

c. Programación de la operación

Según los recursos de energía disponible (agua y gas) se planifica la producción de cada grupo de generación.

El valor agregado consiste en contar con los recursos en el tiempo y plazo que se requiere. 


\section{Actividades de apoyo}

\section{a. Comercial}

Responsable de establecer estrategias para la captación de nuevos clientes libres y regulados.

Efectuar benchmarking para medir la participación y rentabilidad de la empresa.

\section{Tabla 26}

Relación de Clientes Libres y Regulados de Enel Generación Perú SAA

\begin{tabular}{ll}
\hline Clientes Libres & Clientes Regulados \\
\hline Jockey Plaza Shopping Center SA & Enel Distribución Peru \\
Compañía Minera Ares SAC & Electro Puno SAA \\
Compañía Minera Casapalca SA & Electrosur SA \\
Corporación Lindley SA & Hidrandina SA \\
Creditex SAA & Luz del Sur SAA \\
Empresa Siderúrgica del Perú SAA & Sur Oeste - SEAL \\
Hudbay Perú SAC & Electro Sur Este SAA \\
La Arena SA & \\
Mall Aventura SA & \\
Minera Chinalco Perú SA & \\
Minera Las Bambas SAC & \\
Minera Shouxin SAC & \\
Moly-Cop Adesur SA & \\
Productos Tissue del Peru SA & \\
Saga Falabella SA & \\
Tejidos San Jacinto SA & \\
Tiendas por Departamento Ripley SA & \\
Votorantin Metais-Cajamarquilla &
\end{tabular}

Fuente: Elaboración propia

b. Telecomunicaciones e informática

Su objetivo es asegurar la adecuada dirección de tratamiento de información, entre las distintas áreas con el fin de lograr una certera decisión para la ejecución de las estrategias. 


\section{c. Procurement}

Establece estrategias de compras de bienes y servicios que son importante para el proceso de generación de energía.

d. Legal

Velar por los intereses de la compañía en temas legales, de normatividad y administración.

e. HSEQ

Minimizar los riesgos a la salud, accidentes de trabajo y cualquier evento que afecte a las personas, por eso se realizar actividades de identificación, evaluación y control de los riesgos que pueden desencadenar una fatalidad, así también se implementan programas de seguridad y salud laboral.

f. Finanzas

Planificar y controlar las variaciones presupuestales y el gasto interno para el cumplimiento de sus objetivos estratégicos.

g. RR.HH.

Gestión de talento que se sostiene en una adecuada medición del rendimiento y del potencial de los colaboradores, identificando fortalezas, capacidades y aspiraciones, con el fin de diseñar planes de desarrollo que permitan acelerar el crecimiento profesional y ganar experiencias de aprendizaje para afrontar nuevos retos y desafíos.

h. Sostenibilidad

Como parte del Grupo Enel Generación Perú SAA, en la Cumbre para el Desarrollo Sostenible en las Naciones Unidas, existe un compromiso a contribuir con cuatro de los 17 Objetivos de Desarrollo Sostenible (ODS), que apuntan a acabar con la pobreza, promover la prosperidad y el bienestar y crecimiento inclusivo de todas las personas alrededor de sus operaciones.

Estos objetivos son: Educación de calidad ( $\left.\mathrm{N}^{\circ} 4\right)$, Energía asequible y no contaminante $\left(\mathrm{N}^{\circ}\right.$ 7), trabajo decente y crecimiento económico ( $\left.N^{\circ} 8\right)$ y Acción por el clima ( $\left.N^{\circ} 13\right)$.

i. Atención al Cliente

Enel Generación Perú SAA, se tiene un sistema de atención de consultas, quejas y pedidos que se encuentran a disposición de los clientes las 24 horas del día, ateniendo de manera eficiente a los clientes. Los diversos tipos de requerimientos son solucionados en tiempo real. 
Se muestra un índice de satisfacción para Enel Generación Perú SAA de 85\% al 2017, en el año 2003 se implementó un programa de atención al cliente, el cual tuvo una alta aceptación debido al estudio realizado, el propósito actual es incrementar la satisfacción de los usuarios. Enel Generación Perú SAA incentiva el tener una presencia digital, creando puntos de contacto en internet y espacios de conversación con los Stakeholders.

\subsection{Indicadores de cada una de las actividades de la cadena de valor}

Se detalle los indicadores por cada actividad.

Actividades Primarias

Generación:

\begin{tabular}{|l|}
\hline NÚMERO - Hora (kwh) \\
\hline COSTO DE GENERAR \\
\hline
\end{tabular}

Este indicador se utiliza para medir la productividad de la compañía, de acuerdo a sus procesos de producción y medir así la eficiencia.

Transmisión

\begin{tabular}{|l|}
\hline Número Voltaje Entregado \\
\hline Número Voltaje Atendido \\
por usuario
\end{tabular}

Este indicador mide interrupciones ocasionadas al momento de la transmisión.

Planificación de la Producción:

\begin{tabular}{|l|}
\hline Producción Planificada \\
\hline \% Oferta del Mercado \\
\hline
\end{tabular}

Esto mide tu plan de generación anual y que no existan desviaciones dentro del mismo.

\section{Actividades de Apoyo}

Comercial

\begin{tabular}{|l|}
\hline \% PROYECCIÓN DE \\
VENTA \\
\hline \% DE NUEVOS \\
CONTRATOS \\
\hline
\end{tabular}


Este indicador mide la cantidad a generar, teniendo los nuevos clientes libres y regulados que se tiene planificado atender y proyección de nuevos contratos.

Telecomunicación e Informática:

\begin{tabular}{l} 
\% INVERSIÓN EN SIST. \\
INFORMACIÓN \\
\hline$\%$ DE EFICIENCIA EN \\
PROCESOS \\
\hline
\end{tabular}

Este indicador permite medir si la inversión realizada a mejorar el nivel de error por procesos manuales.

\section{Procurement:}

\begin{tabular}{|l|}
\hline \% COMPRA RPTOS. POR \\
CADA ALMACÉN \\
\hline \% ROTACIÓN DE \\
INVENTARIOS \\
\hline
\end{tabular}

Este indicador permite identificar la rotación de las existencias y el incremento en el costo de almacenamiento.

\section{Legal}

\begin{tabular}{|l|}
\hline$\%$ PROCESOS Y LITIGIOS \\
\hline$\%$ CASOS RESUELTOS \\
\hline
\end{tabular}

Nos permite medir la resolución de casos con la compañía y exposición reputacional. HSEQ

\begin{tabular}{|l|}
\hline \% IMPACTOS NEGATIVOS \\
INTERNO Y EXTERNO \\
\hline \% INTERRUPCIONES EN \\
TRANSMISIÓN Y \\
OPERACIÓN \\
\hline
\end{tabular}

Ese indicador permite medir el porcentaje de incidentes presentados en la organización. 
Finanzas

\begin{tabular}{|l|}
\hline UTILIDAD NETA \\
\hline PATRIMONIO NETO \\
\hline
\end{tabular}

Este indicador mide el rendimiento económico de la compañía.

\section{Recursos Humanos:}

\begin{tabular}{|l|}
\hline$\%$ Horas Hombre de \\
Entrenamiento
\end{tabular}

Mide el cumplimiento del personal ante las capacitaciones programas y el nivel de preparación de los colaboradores.

\section{Sostenibilidad}

\begin{tabular}{|l|}
\hline$\%$ PROGRAMAS SOCIALES \\
\hline$\%$ MEJORA CALIDAD DE \\
VIDA EN COMUNIDADES
\end{tabular}

Nos permite medir el nivel de aceptación de las comunidades con las cuales se trabajan programas sociales.

\section{Atención al Cliente}

\begin{tabular}{|l|}
\hline Cantidad de Usuarios \\
\hline$\%$ Solicitudes de Incidencias \\
\hline
\end{tabular}

Este indica mide la satisfacción del cliente por los servicios brindados.

\subsection{Benchmarking y comparación con los líderes de la industria de cada una de las} actividades de la cadena de valor

Según Thompson y Strickland "el benchmarking del desempeño de actividades de una compañía con el de sus rivales y de las mejores prácticas de otras compañías proporciona una evidencia sólida de su competitividad de costos" (2011, p.128). Thompson y Strickland afirman también que "el mejor instrumento para que un administrador determine si la compañía está desempeñando con eficiencia sus funciones y actividades, si sus costos se 
ajustan a los de sus competidores y cuáles son las actividades y procesos que se deben mejorar" (2011, p.131).

Para Hellriegel el benchmarking es un "proceso sistemático y continuo para medir y comparar los bienes, servicios y prácticas de una organización con los líderes de su industria, con el propósito de obtener información que le ayudará a registrar un mejor desempeño" (2011, p. 307).

De forma progresiva, existen compañías posicionadas que se orientan al mismo público objetivo y la misma cadena de valor.

En relación con la logística interna de Enel Generación Perú SAA, viene desarrollando estrategias de licitación utilizando las buenas prácticas en lo que respecta a procesos de negociación en otras empresas de la corporación a nivel global.

Dirección/Recursos Humanos: la empresa debe mejorar sus programas de motivación, capacitación y fomentar la inclusión de nuevos talentos en la compañía.

\section{Presencia de Líderes en el Sector:}

Tomando como indicador, la capacidad instalada, la diversidad de tipo de generación y número clientes libres y regulados, se identifica cuatro competidores importantes en el mercado de generación.

Competidores Directos:

ENGIE ENERGíA.

ENERSUR.

KALLPA.

ELECTROPERÚ.

EGENOR.

Respecto a la producción de energía por generadora integrante del COES durante el primer trimestre de 2018, se observa que las empresas de mayor participación fueron: Enel

Generación Perú S.A. (15.0\%), Kallpa Generación (15.0\%) y Engie (10.5\%)

En ese mismo periodo la producción de energía del Sein fue de 50,816 GWh, correspondiendo a Enel Generación Perú S.A., incluida nuestra subsidiaria Chinango, una participación de $15.02 \%$, que representa 7,631 GWh. 
Por ello, se establecieron indicadores a los cuáles se les asignó un peso relativo por su influencia en la operación de cada actividad, cuya suma total es igual a 1. La matriz de comparación de Enel Generación Perú con sus competidores se muestra en la Tabla 25. A cada indicador y por competidor se le ha asignado una clasificación, valor relativo a su capacidad entre 1 y 15 , donde 1 es muy baja capacidad y 15 alta capacidad. Finalmente, con estos valores y los pesos relativos se obtiene una puntuación ponderada que se totalizan para cada empresa de generación analizada. Este total representa su perfil medio. Cabe resaltar que los valores obtenidos responden en base al juicio experto de las entrevistas que se realizaron a los especialistas en el sector. Anexo 2. 
Tabla 27

Comparación entre otras empresas del sector

\begin{tabular}{|c|c|c|c|c|c|c|c|c|c|c|c|c|c|c|}
\hline & & & \multicolumn{2}{|c|}{$\begin{array}{c}\text { ENEL } \\
\text { GENERACIÓN }\end{array}$} & \multicolumn{2}{|c|}{$\begin{array}{c}\text { ENGIE } \\
\text { ENERGÍA }\end{array}$} & \multicolumn{2}{|c|}{ KALLPA } & \multicolumn{2}{|c|}{ ENERSUR } & \multicolumn{2}{|c|}{ ELECTROPERÚ } & \multicolumn{2}{|c|}{ EGENOR } \\
\hline Factor & Criterio & Peso & Calif. & Pond. & Calif. & Pond. & Calif. & Pond. & Calif. & Pond. & Calif. & Pond. & Calif. & Pond. \\
\hline $\begin{array}{l}\text { Generación } \\
\text { propia }\end{array}$ & $\begin{array}{l}\text { Nivel de } \\
\text { generación } \\
\text { propia } \\
\text { Inversiones en } \\
\text { generación } \\
\text { propia }\end{array}$ & 0.2 & 14 & 2.8 & 8 & 1.6 & 13 & 2.6 & 6 & 1.2 & 6 & 1.2 & 5 & 1 \\
\hline $\begin{array}{l}\text { Reducción de } \\
\text { costos } \\
\text { operativos }\end{array}$ & $\begin{array}{l}\text { Procesos, } \\
\text { eficiencias } \\
\text { administrativas, } \\
\text { actividades } \\
\text { subcontratadas, } \\
\text { costo promedio } \\
\text { de energía }\end{array}$ & 0.1 & 13 & 1.3 & 10 & 1 & 11 & 1.1 & 9 & 0.9 & 9 & 0.9 & 6 & 0.6 \\
\hline $\begin{array}{l}\text { Explotación y } \\
\text { optimizacion de } \\
\text { activos }\end{array}$ & $\begin{array}{l}\text { Capacidad } \\
\text { instalada con la } \\
\text { que cuenta la } \\
\text { infraestructura y } \\
\text { la realmente } \\
\text { utilizada }\end{array}$ & 0.3 & 14 & 4.2 & 12 & 3.6 & 13 & 3.9 & 6 & 1.8 & 6 & 1.8 & 5 & 1.5 \\
\hline $\begin{array}{l}\text { Inteligencia de } \\
\text { Negocios }\end{array}$ & $\begin{array}{l}\text { Contratos, } \\
\text { clientes libre, } \\
\text { servicio al cliente }\end{array}$ & 0.3 & 14 & 4.2 & 12 & 3.6 & 12 & 3.6 & 4 & 1.2 & 5 & 1.5 & 4 & 1.2 \\
\hline $\begin{array}{l}\text { Cultura } \\
\text { organizacional }\end{array}$ & $\begin{array}{l}\text { Personal en } \\
\text { nómina, } \\
\text { proyectos a nivel } \\
\text { de RRHH, nivel } \\
\text { de } \\
\text { profesionalismo, } \\
\text { ambiente laboral } \\
\text { y forma de } \\
\text { comunicación } \\
\text { (participativa o } \\
\text { burocrática) }\end{array}$ & 0.1 & 8 & 0.8 & 8 & 0.8 & 8 & 0.8 & 5 & 0.5 & 5 & 0.5 & 5 & 0.5 \\
\hline & & 1 & & 13.3 & & 10.6 & & 12 & & 5.6 & & 5.9 & & 4.8 \\
\hline
\end{tabular}

Fuente: Elaboración propias. 
Analizando los resultados se observa que Enel Generación Perú tiene un total de 13.3 mostrándose como líder entre sus competidores, esto debido a que la empresa cuenta con diversas fuentes de generación de energía como renovables y térmicas, lo que permite captar mayores clientes y otorgar una seguridad en el servicio brindado a diferencia de sus competidores.

PRODUCCIÓN DE ENERGÍA EN EL SEIN - 2018

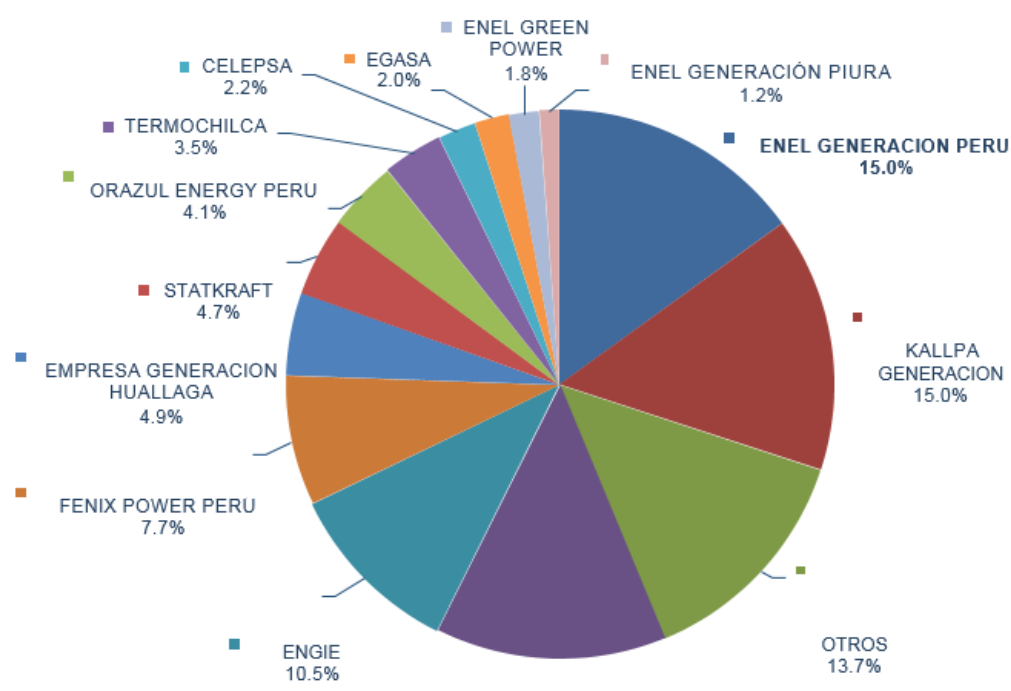

Figura 19:Participación de Mercado Sector Eléctrico 2018

Fuente: COES / Elaboración: Equilibrium

Las estrategias que aplican las empresas del sector de electricidad y generación son:

Contratos con recursos humanos especializados y experiencia.

Desarrollo de programas del sector energía.

Trabajo en equipos con organismos reguladores del sector, clientes y proveedores.

Impulso en la creación de plantas renovables.

\section{Nivel de Fuerza}

Alto: el sector de generación este en un ciclo de vida de crecimiento por lo tanto el incremento de competidores es cada vez mayor, considerando un elemento importante la presencia en el mercado y el grado de inversión que es una ventaja para las compañías actuales.

\section{Sustentación y Variables de Análisis}

a. Barreras de Salida:

Nivel de fuerza Alto 
- Conocimiento de la industria donde se encuentra desarrollando.

- Relación y compromiso de tipo estratégico de acuerdo al servicio de calidad y a la tecnología instalada.

- Especialización en el manejo de su tecnología.

- Formulación de relaciones estratégicas con Stakeholders del sector.

- Tratamiento de los costos altos de acuerdo al tiempo en la formación de recurso humano.

- Baja y/o retiro de activos adquiridos de la planta, el ingreso por la venta es mínima debido a la confiabilidad del bien y de la necesidad local.

b. Compromisos y Alianzas Estratégicas con Proveedores

Nivel es Medio Alto, para el caso de aquellos proveedores que brindan servicios que están relacionado al proceso de generación de energía, como mantenimiento y operación de centrales, obras civiles.

c. Valor Agregado de los Servicios

Alto: relacionado al cumplimiento en suministrar energía con cantidad y calidad, que ante cualquier interrupción por falla la empresa pueda seguir brindando el mismo servicio.

Tabla 28

Rivalidad entre Competidores

\begin{tabular}{ll}
\hline Variables de Análisis & Nivel \\
\hline Barreras de Salida & Alto \\
Compromisos y Alianzas Estratégicas con Proveedores & Medio alto \\
Valor agregado de los Servicio & Alto \\
\hline
\end{tabular}

Fuente: Elaboración propias. Adaptado de Porter, M. (2009).

\subsection{Determinar las competencias de la empresa}

Competencias de Enel Generación Perú SAA

Personas: Se aseguran las oportunidades de desarrollo en base al mérito y a la aportación profesional.

Trabajo En Equipo: Fomentar la participación de todos para un objetivo común, compartiendo la información y los conocimientos.

Conducta Ética: Actuar con profesionalismo, integridad moral, lealtad y respeto a las personas.

Orientación Al Cliente: Centrar los esfuerzos en la satisfacción del cliente, aportando soluciones competitivas y de calidad. 
Innovación: Promover la mejora continua y la innovación para alcanzar la máxima calidad desde criterios de rentabilidad.

Orientación a Resultados: Dirigir las actuaciones hacia la consecución de los objetivos del proyecto empresarial y de la rentabilidad para sus accionistas, tratando de superar sus expectativas.

Comunidad y Medio Ambiente: Compromiso social y cultural con la comunidad. Adaptando sus estrategias empresariales, a la preservación del medio ambiente. Estas competencias permiten que la empresa sea reconocida en el mercado peruano como una organización sólida a nivel gestión y de buen gobierno corporativo, siendo sostenible en el tiempo y participe del desarrollo del sector energético en el Perú.

\subsection{Identificación y determinación de las ventajas competitivas de la empresa}

En la Tabla 27 se aprecia que la ventaja competitiva de Enel Generación Perú SAA, se fundamenta en las buenas relaciones con sus clientes corporativos; sin embargo, puede ser de riesgo debido a que no depende de manera directa de este tipo de organizaciones empresariales, algunos factores externos pueden afectar dicha ventaja.

Se debe tomar en cuenta para fortalecer la ventaja competitiva, la ampliación de servicios, tal como lo ha indicado el experto entrevistado, se debe fomentar e incentivar por parte del Gobierno la continuidad y sostenibilidad de las Subastas de Energías Renovables. También se debe gestionar la eficiencia energética en todos los procesos e instalaciones de producción y generación de energía eléctrica, aplicando la metodología que dicta el ISO 50001, para mejorar el ahorro de los consumos energéticos (entrevista, Lamas, 2018).

El fortalecimiento de la ventaja competitiva se sostiene en la actividad de la industria y el análisis de sus competidores.

Tabla 29

Ventajas competitivas

\begin{tabular}{ll}
\hline Ventajas competitivas & \\
\hline 1. Conducción de relaciones & Buenas relaciones con los clientes. \\
$\begin{array}{l}\text { 2. Distribución del servicio } \\
\text { 3. Servicio operativo (innovación y }\end{array}$ & Personal capacitado, debidamente especializado para \\
capacidad de desempeño & cada función que se le encomienda. \\
industrial) &
\end{tabular}

Fuente: Tomado de "Ventajas competitivas. Administración Estratégica”, por Fred R. David, 14th Edition, Prentice Hall, México, 2012. 
Tabla 30

Análisis VRIO

\section{Evaluación de los Recursos y capacidades}

\section{Recurso}

Humano y técnico

Financiero

Tecnología

Investigación y desarrollo

Sostenibilidad

Seguridad

Servicio al cliente

Comunicación

\section{Valioso}

Si

$\mathrm{Si}$

Si

Si

Si

Si

$\mathrm{Si}$

Si

Si

$\mathrm{Si}$

\section{Costoso de}

Imitar

No

No

Si

$\mathrm{Si}$

$\mathrm{Si}$

No

Si

$\mathrm{Si}$
Explotado por la

Organización

Muy explotado

Muy explotado

Muy explotado

Muy explotado

Muy explotado

Muy explotado

Muy explotado

Muy explotado
Análisis Competitivo

\section{Implicancias}

Competitivas

Paridad Competitiva

Paridad Competitiva

Paridad Competitiva

Ventaja Competitiva Sostenible

Paridad Competitiva

Paridad Competitiva

Ventaja Competitiva Sostenible

Ventaja Competitiva Sostenible

$\begin{array}{cc}\text { Resultado } & \text { Posición } \\ \text { Económico } & \text { Competitivas }\end{array}$

Competitivas

Fortaleza

Fortaleza

$\begin{array}{ll}\text { Normal } & \text { Fortaleza } \\ \text { Normal } & \text { Fortaleza }\end{array}$

Fortaleza y

Arriba de lo Normal competencia distintiva sostenible

Fortaleza

Normal

Fortaleza

Fortaleza y

Arriba de lo Normal competencia distintiva

sostenible

Fortaleza y

Arriba de lo Normal competencia distintiva

Fuente: Elaboración propia. Adaptada de Jay Barney (1991). 
Luego del análisis se puede concluir que Enel Generación Perú SAA, posee ventajas competitivas sostenibles en tres capacidades principales:

Calidad y seguridad de los procesos. Evidencia que se tienen y presentan adecuadas estrategias de servicio al cliente.

Desarrollo de la productividad de los empleados. Se capacita de manera muy frecuente al personal, y se busca que esta atención tenga una propuesta integral en el servicio.

Sistemas de información. Se busca que el personal preste servicio de manera innovadora, aplicado técnicas y sistemas de información.

\subsection{Matriz de Evaluación de los Factores Internos EFI}

Según David es "un paso que constituye un resumen en la conducción de una auditoría interna de la dirección estratégica" (2013, p. 31).

La sumatoria de la calificación asignada debe ser 1.0. Los factores deben tener una calificación (del 1 al 4) para calificar la eficacia, Enel Generación Perú SAA reconoce la calificación excelente con "4" y deficiente "1".

La asignación de la calificación entre 1 y 4 a cada uno de los factores a efecto de indicar si el factor representa una debilidad mayor (calificación =1), una debilidad menor (calificación $=2$ ), una fuerza menor (calificación =3) o una fuerza mayor (calificación $=4$ ). Así, las calificaciones se refieren a la compañía, mientras que los pesos del paso 2 se refieren a la industria.

La ponderación más alta es 4.0 que caracteriza a las empresas fuertes internamente, el ponderado promedio es 2.5 que significa que la empresa aún le falta mejorar algunos aspectos internos, y el ponderado más bajo es 1.0 que caracteriza a una empresa débil en lo interno. 
Tabla 31

Matriz de Evaluación de Factores Internos (EFI)

\begin{tabular}{|c|c|c|c|c|}
\hline Matriz EFI & PESO & $\begin{array}{l}\text { CALI } \\
\text { F. }\end{array}$ & $\begin{array}{l}\text { PESO } \\
\text { POND. }\end{array}$ & \\
\hline \multicolumn{5}{|l|}{ Fortalezas } \\
\hline Propiedad de ENEL (Italia). & 0.08 & 4 & 0.32 & \\
\hline Tiempo en el negocio hidráulico & 0.12 & 3 & 0.36 & \\
\hline $\begin{array}{l}\text { Infraestructura para la generación hydro y } \\
\text { térmico }\end{array}$ & 0.10 & 4 & 0.40 & \\
\hline Ubicación estratégica de las centrales & 0.04 & 4 & 0.16 & \\
\hline $\begin{array}{l}\text { Liderazgo en generación de energía } \\
\text { eléctrica en el Perú }\end{array}$ & 0.05 & 3 & 0.15 & \\
\hline Contratos a largo plazo con clientes Libre. & 0.11 & 3 & 0.33 & \\
\hline Networking con instituciones reguladoras. & 0.07 & 3 & 0.21 & \\
\hline Excelente imagen reputacional en el país & 0.08 & 3 & 0.24 & \\
\hline Eficiencia en la producción. & 0.05 & 3 & 0.15 & $\begin{array}{l}\text { Suma } \\
2.32\end{array}$ \\
\hline \multicolumn{5}{|l|}{ Debilidades } \\
\hline $\begin{array}{l}\text { Bajo estudio para desarrollo de nuevas } \\
\text { oportunidades de negocio (plantas } \\
\text { renovables) }\end{array}$ & 0.07 & 3 & 0.21 & \\
\hline $\begin{array}{l}\text { Cuellos de botellas para ejecución de } \\
\text { proyectos (dependencia) }\end{array}$ & 0.06 & 2 & 0.12 & \\
\hline $\begin{array}{l}\text { Bajo desarrollo de proyectos sociales } \\
\text { sostenibles }\end{array}$ & 0.03 & 2 & 0.06 & \\
\hline Baja repotenciación de plantas antiguas & 0.05 & 2 & 0.10 & \\
\hline $\begin{array}{l}\text { Falta de comunicación entre áreas de staff y } \\
\text { negocio }\end{array}$ & 0.03 & 2 & 0.06 & \\
\hline Baja nivel de Control de contratistas. & 0.03 & 2 & 0.06 & \\
\hline $\begin{array}{l}\text { Dependencias de personas en puestos } \\
\text { claves, por falta de transferencia de } \\
\text { información }\end{array}$ & 0.03 & 2 & 0.06 & Suma \\
\hline TOTAL & 1.00 & & 2.99 & 0.67 \\
\hline
\end{tabular}

Nota. 4= Fortaleza mayor, 3= Fortaleza menor, 2= Debilidad menor, 1= Debilidad mayor.

Nota. Tomado de "El Proceso Estratégico: Un Enfoque de Gerencia (6a ed.)," por F. A. D'Alessio, 2015. Lima., Perú: Pearson.

Los criterios de jerarquización de la selección de fortalezas y debilidades se han seleccionado tomando en cuenta la experiencia que se tiene desde el punto de vista de la observación. Por otro lado, las respuestas dadas por los entrevistados tienen un adecuado sustento para el planteamiento de la matriz. 
Enel Generación Perú SAA, de acuerdo con el análisis de la Matriz EFI, tiene una posición interna fuerte, además las fuerzas internas son favorables a la organización. Por lo tanto, se puede apreciar en la resultante de la matriz EFI, que la organización empresarial se encuentra en una posición intermedia para la ejecución de sus estrategias internas.

En el ámbito interno, Enel Generación Perú SAA posee sus principales fortalezas, el Know How marcado en el tiempo del negocio hidráulico (0.12) y un posicionamiento financiero debido a los contratos celebrados con clientes libres (0.11), el cual es resultado por su trayectoria en el mercado, por otro lado, la debilidad de la organización es la carencia de estudios para desarrollo de nuevas oportunidades de negocio (plantas renovables) y estudios de investigación (0.7). 


\section{Capítulo VII. Formulación de los objetivos y diseño de las estrategias}

\subsection{Alcance y Programación de Objetivos Estratégicos}

"Representan los resultados que la organización empresarial que se espera alcanzar luego de implementar las estrategias escogidas, que la conducen hacia el cumplimiento de la visión establecida articulando y ejecutando la misión. Son necesarios en todos los niveles de estrategias para la organización: corporativo, divisional y funcional; están asociados a áreas de resultados clave y constituyen medidas del desempeño gerencial". (D' Alessio, 2015).

\subsubsection{Objetivos estratégicos.}

Los objetivos estratégicos permiten expresar de una manera específica la visión para el futuro cercano. (D’Alessio F. , 2015).

Los objetivos estratégicos proveen una dirección para delinear el curso de acción de una empresa para el largo plazo (para los próximos tres o cinco años) y establecen metas específicas de desempeño. Por tal motivo, para plantear los objetivos se requiere un análisis interno para identificar la posición competitiva de la organización y evaluar el entorno mediante el análisis externo de identificación del grado de atractividad de un negocio.

Los objetivos estratégicos, permiten hacer más explícitos los fines que la empresa espera alcanzar, no solamente en términos de desempeño financiero sino también en su fortalecimiento para el largo plazo e incrementar su posición competitiva. Así, están más vinculados con la situación competitiva global de la empresa e involucran medidas de desempeño para la dirección (D’Alessio F. , 2015).

Los objetivos estratégicos son expresados en términos de crecimiento, rentabilidad y supervivencia:

Crecimiento: para fijar una meta de crecimiento en el negocio en un periodo determinado. Rentabilidad: a fin de establecer un retorno sobre el capital empleado y que sea razonablemente adecuado.

Supervivencia: para establecer la intención de la empresa de continuar operando en el futuro.

A continuación, se explica en el titulo 7.1.2., el planeamiento de los objetivos estratégicos. Objetivo estratégico 1. Incrementar ingreso por venta de energía en un $4 \%$ en promedio para el periodo 2018- 2023

Objetivo estratégico 2. Incrementar la producción de generación en un 3\%, optimizando la capacidad instalada de las plantas (eficiencia operativa) para los años en proyección. 
Objetivo estratégico 3. Incrementar el EBITDA promedio para los años en proyección en un $13 \%$ ejecutando una reducción progresiva de los costos operativos.

Objetivo estratégico 4. Desarrollar una cultura de aplicación de metodologías agiles.

Soportado por el área de $\mathrm{RRHH}$ con el fin de estar a la vanguardia con la ola de transformación digital.

\subsubsection{Análisis de los objetivos estratégicos.}

Objetivo N 1: Enel Generación Perú SAA lograría percibir mayores ingresos y poder reorientar el recurso en actividades de investigación y desarrollo en nuevos proyectos de mejora para los procesos actuales de operación y comercialización.

Objetivo №2: En un mercado donde existen plantas con más de 35 años de funcionamiento, se requiere el cambio o la actualización de los sistemas en dichas plantas para potenciar su generación de energía, percibiendo mayores ingresos y cumpliendo con lo exigido por los entes reguladores del sector.

Objetivo $N^{\circ} 3$ : A partir de la optimización de procesos productivos críticos, se estima reducir en un $5 \%$ los gastos operativos, generando con ello, que el indicador del EBITDA (Utilidad Operativa + Depreciación + Amortización) incremente en un 13\% en promedio para los años en proyección, considerar que este indicador muestra la capacidad que tiene la empresa para ser auto sostenible.

Objetivo $N^{\circ} 4$ : Debido a los entornos cambiantes que se vive actualmente, la empresa busca ser eficiente y proactivo desarrollando una cultura de transformación digital, que sea soportado por la aplicación de metodologías ágiles (Agile/Solving problem creative).

\subsection{Diseño y Formulación de Estrategias}

Para el diseño y formulación de estrategias, usaremos el análisis del modelo océano azul y las matrices de estrategias.

Estrategia 1: Incrementar cartera de nuevos clientes en el Perú.

Con plantas automatizadas en su mayoría y con un recurso hídrico favorable por las constantes lluvias en las zonas altas donde se originan las lagunas, esto le permite e Enel Generación Perú SAA, cumplir con las exigencias de demanda de energía que el usuario requiere para sus instalaciones.

Estrategia 2: Tecnología para el desarrollo de la generación de energía, implementando recursos renovables

Con las políticas de cambio de matriz energética implantada por el Ministerio de Energía y Minas, se fomenta la implementación de nuevos proyectos de plantas renovables, con costos menores para la implementación y mantenimiento de dichas plantas.

Estrategia 3: Construcción de nuevas plantas hidroeléctricos 
Con el horizonte de un mercado energético donde las centrales térmicas para el caso de Perú se irán cerrando para ser reemplazadas por centrales renovables, es oportuno el incentivar a la construcción de centrales hidráulicas.

Estrategia 4: Afianzar la perpetuidad del servicio con los clientes libres y regulados La posición actual que Enel Generación Perú SAA tiene en el sector energético, le permite poder afianzar acuerdos comerciales con empresas que exigen mayor volumen de energía.

Estrategia 5: Calidad del servicio, tomando en cuenta la experiencia de las empresas que son parte de las empresas de la corporación a nivel global.

Con la experiencia de generar energía con diferentes tecnologías a nivel mundial, esto le permite poder transferir buenas prácticas en sus diferentes procesos, reduciendo y/o mitigando fallas en el camino y asegurando la confiabilidad de su servicio.

Estrategia 6: Potenciar la comunicación con diversos grupos comuneros donde opera la compañía a través de los programas de RSE.

La cercanía de la infraestructura civil con las comunidades campesinas es un riesgo para Enel Generación Perú SAA, ya sea por la influencia alta que tienen los Stakeholders, se debe establecer programas a largo plazo que permitan un crecimiento de dichas comunidades.

Estrategia 7: Establecer procedimientos locales eficaces para la gestión de sus proveedores.

La importancia de llevar un control de las actividades que realiza cada contratista en las instalaciones, permitirá un mejor desempeño y adecuada ejecución cumpliendo los estándares de calidad exigidos por la empresa.

Estrategia 8: Productividad y eficiencia de los procesos implementando un área de desarrollo de negocio.

Implementar un área de negocio que tenga la responsabilidad de investigar y desarrollar nuevos proyectos de energía renovable, de igual manera identificar nuevos sistemas que permitan obtener eficiencias en la gestión de la generación.

Estrategia 9: Generar un compromiso de sus colaboradores hacia a empresa.

Enel Generación Perú debe fomentar el crecimiento y desarrollo de sus colaboradores, incentivando a realizar y liderar proyectos digitales con el fin de optimizar y mejorar procesos y ser más eficientes en su día a día. 


\subsubsection{Modelo océano azul.}

Según Chan y Mauborgne sostienen "la importancia de la innovación para encontrar nuevos mercados (océano azul)" (2013, p. 48), evitando la competencia destructiva que existe en los mercados más explotados (océanos rojos).

Océano azul precisa como una estrategia en los mercados no explotados para generación de la demanda con vista a una oportunidad de crecimiento rentable.

La empresa tiene características que se clasifican de acuerdo a los procesos de la tabla 30. En dicha tabla hemos comparado a la empresa Enel Generación Perú con el sector energía, estas características han sido analizadas en el punto 6.3: Benchmarking y comparación con los líderes de la industria de cada una de las actividades de la cadena de valor.

A cada indicador y por competidor se le ha asignado una clasificación, valor relativo a su capacidad entre 1 y 5 , donde 1 es muy baja capacidad y 5 alta capacidad.

Tabla 32

Características de las empresas de Generación

\begin{tabular}{|c|c|c|c|c|c|c|}
\hline \multicolumn{2}{|c|}{ Factores } & $\begin{array}{c}\text { ENEL } \\
\text { GENERACIÓN }\end{array}$ & $\begin{array}{c}\text { ENGIE } \\
\text { ENERGÍA }\end{array}$ & KALLPA & ELECTROPERÚ & EGENOR \\
\hline $\begin{array}{l}\text { Generación } \\
\text { propia }\end{array}$ & $\begin{array}{l}\text { Mix fuentes de } \\
\text { generación de } \\
\text { energía }\end{array}$ & 3 & 2 & 5 & 2 & 2 \\
\hline $\begin{array}{l}\text { Reducción de } \\
\text { costos }\end{array}$ & $\begin{array}{l}\text { Procesos } \\
\text { productivos }\end{array}$ & 4 & 5 & 5 & 5 & 3 \\
\hline operativos & $\begin{array}{l}\text { Poder Financiero } \\
\text { Ubicación }\end{array}$ & 5 & 2 & 5 & 5 & 4 \\
\hline \multirow[t]{2}{*}{$\begin{array}{l}\text { Explotación y } \\
\text { optimizacion de } \\
\text { activos }\end{array}$} & $\begin{array}{l}\text { geográfica de las } \\
\text { plantas de } \\
\text { generación de } \\
\text { energía }\end{array}$ & 2 & 1 & 2 & 2 & 2 \\
\hline & $\begin{array}{l}\text { Captación de } \\
\text { nuevos clientes }\end{array}$ & 4 & 3 & 3 & 3 & 3 \\
\hline Inteligencia de & Política de & & & & & \\
\hline Negocios & $\begin{array}{l}\text { seguridad para } \\
\text { gestión de } \\
\text { contratistas }\end{array}$ & 3 & 2 & 2 & 2 & 1 \\
\hline \multirow{3}{*}{$\begin{array}{l}\text { Cultura } \\
\text { organizacional }\end{array}$} & $\begin{array}{l}\text { Capacidad y } \\
\text { entrenamiento del } \\
\text { personal }\end{array}$ & 3 & 5 & 3 & 3 & 3 \\
\hline & $\begin{array}{l}\text { Sistema de control } \\
\text { y comunicaciones } \\
\text { Procesos }\end{array}$ & 4 & 2 & 2 & 3 & 3 \\
\hline & burocráticos & 5 & 5 & 5 & 5 & 5 \\
\hline
\end{tabular}

Fuente: Elaboración propia.

\subsubsection{Lienzo de la estrategia actual de la empresa.}

Mediante un juicio experto se elaboró un lienzo con los atributos de Enel Generación

Perú SAA, donde los aspectos valorados por los clientes se describen en el eje " $x$ " y la calificación de valor por la empresa se describe en el eje "y".

Dichas variables de la curva de valor, identifican a la compañía dentro del mercado. 
Enel Generación Perú SAA cuenta con los siguientes factores:

Para el caso del mercado eléctrico, se define factores que son relevantes:

Potencia Nominal; capacidad instalada del generador. No es aprovechable en su totalidad.

Potencia Efectiva; capacidad de generación que tiene una central y que puede garantizar con una continuidad aceptable.

Potencia Instalada; es la sumatoria de las capacidades reales de generación de cada central eléctrica.

Transmisión Eléctrica; permite transportar electricidad desde los centros de generación hacia las zonas de consumo final.

Regulación Social; se enfoca en la protección del ambiente, salud y la seguridad industrial, inclusive en el ámbito laboral.

Protección de los consumidores; sistema de supervisión de la calidad y seguridad en el sector eléctrico, mejorar atributos a fin de prevenir accidentes o contingencias.

Tarifas de Electricidad; precio fijado dentro del mercado aplicable a los usuarios regulados, aquellos con una demanda anual hasta $220 \mathrm{~kW}$; y los medianos que sus consumos anuales se encuentran entre 200 y $2500 \mathrm{Kw}$.

Precios firmes; contratos a mediano y largo plazo, donde se establecen precios firmes, que incluyen precios de energía y potencia. (Osinergmin, 2016)

En la Figura 20 se muestra el lienzo actual de Enel Generación Perú comparado con las empresas competidoras. 


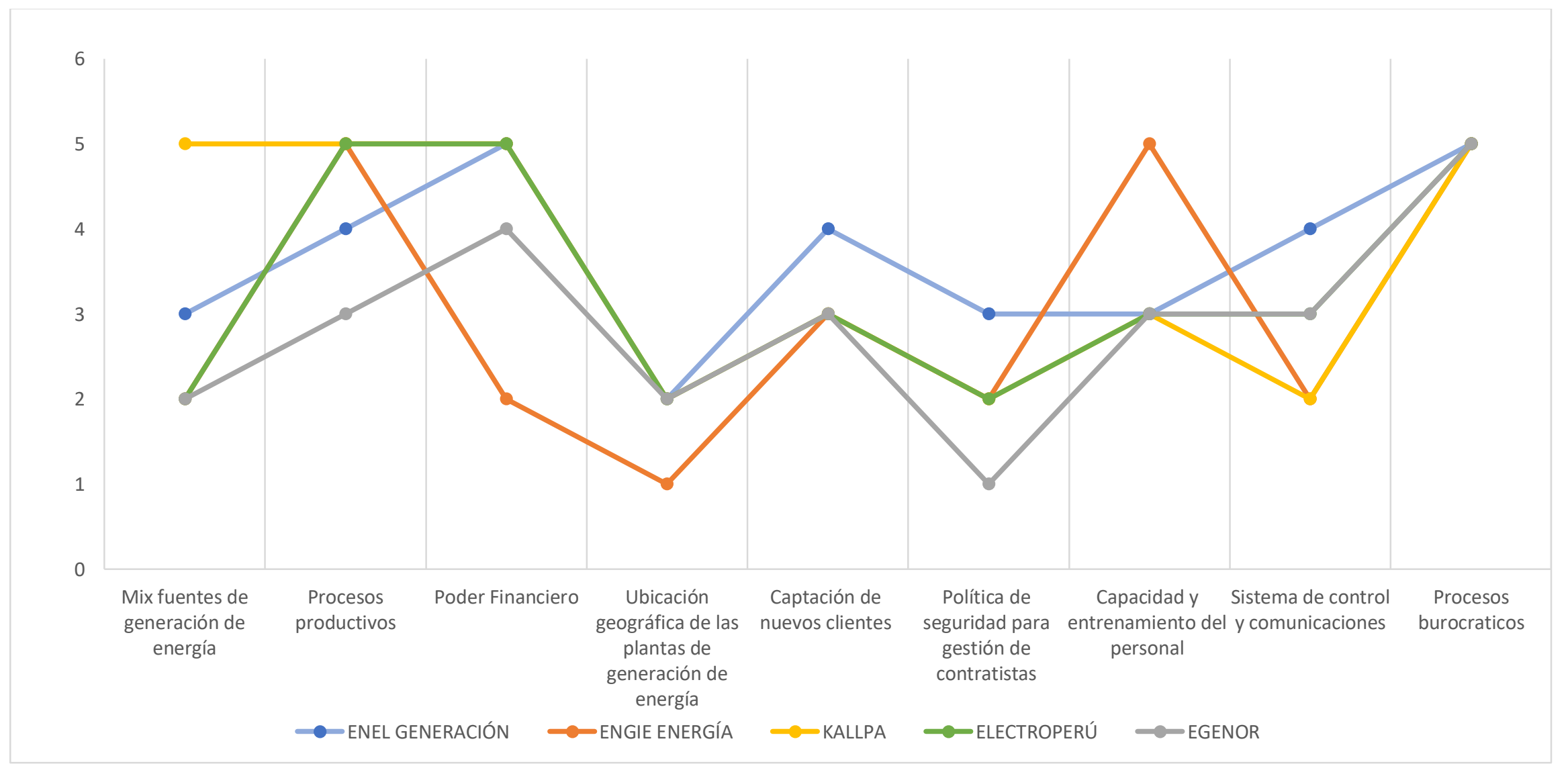

Figura 20. Lienzo de la empresa y sus competidores.

Tomado de "El Proceso Estratégico: Un Enfoque de Gerencia (6a ed.)," por F. A. D’Alessio, 2015. Lima., Perú: Pearson. 


\subsubsection{Matriz (eliminar, reducir, incrementar, crear).}

Tabla 33

Matriz de acciones

\begin{tabular}{ll}
\hline Desechar & Incrementar \\
Procesos burocráticos & Mix fuentes de generación de energía \\
& Procesos productivos \\
& Ubicación geográfica de las plantas de generación de energía \\
& Captación de nuevos clientes \\
Reducir & Crear \\
& Capacidad y entrenamiento del personal. \\
& Servicio Post Venta \\
& Cultura en transformación digital
\end{tabular}

Nota. Adaptado de "Administración estratégica," por F. R. David, 2003, p. 110. Copyright 2003 por Pearson Educación de México. 


\subsubsection{Lienzo de la nueva estrategia considerada.}

El esquema o matriz de las cuatro acciones que se han ponderado establece características que se deberán aplicarse.

Tabla 34

Matriz de las características

\begin{tabular}{lcc}
\multicolumn{1}{c}{ TIPO } & LA EMPRESA & $\begin{array}{c}\text { Nueva Estrategia OCÉANO } \\
\text { AZUL }\end{array}$ \\
\hline CREAR & 3 & 6 \\
Capacidad y entrenamiento del personal & 1 & 3 \\
Servicio Post Venta & 1 & 4 \\
Cultura en transformación digital & & \\
ELIMINAR & 5 & 1 \\
Procesos burocráticos & & \\
INCREMENTAR & 3 & 6 \\
Mix fuentes de generación de energía & 4 & 5 \\
Procesos productivos & 2 & 5 \\
Ubicación geográfica de las plantas de & & \\
generación de energía & & 6 \\
Captación de nuevos clientes & 4 &
\end{tabular}

Nota. Elaboración propia. Adaptado de "Administración estratégica," por F. R. David, 2003, p. 110. Copyright 2003 por Pearson Educación de México.

Analizando las propuestas obtenemos el nuevo lienzo donde se añaden tres criterios nuevos. 


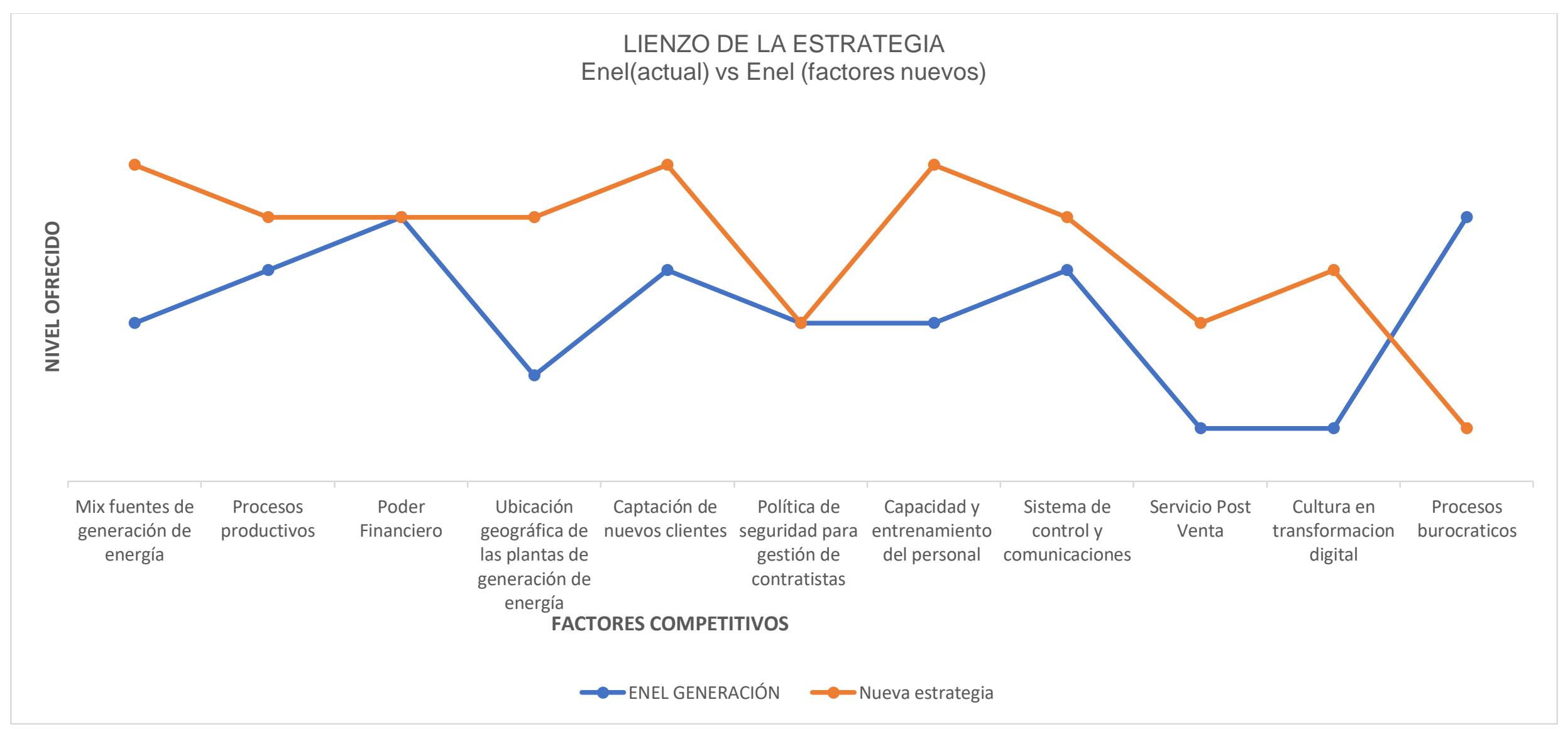

Figura 21. Lienzo de la nueva estrategia considerada.

Tomado de "El Proceso Estratégico: Un Enfoque de Gerencia (6a ed.)," por F. A. D’Alessio, 2015. Lima., Perú: Pearson. 
Es importante que Enel Generación Perú SAA incremente su participación en el mercado, redefiniendo estrategias y cambios organizativos que permitan un incremento en el desempeño en sus operaciones propias del negocio y de soporte.

Se propone reorientar el esfuerzo humano, como es el caso de número de operadores y mantenedores distribuidos para cada tecnología, de igual forma evaluar el número de personas asignadas a cada área de Staff.

Por el lado del core business, desarrollar o adoptar nuevas tecnologías para los sistemas y sub sistemas que son usados en el proceso de generación de energía.

\subsubsection{Matrices de formulación de estrategias.}

Luego de desarrollar la Matriz de Evaluación de los Factores Externos EFE, la Matriz de Perfil Competitivo MPC y la Matriz de Evaluación de los Factores Internos EFI, se procede a la aprobación de la información que demuestre la factibilidad de las estrategias.

\subsubsection{Matriz FODA.}

Según David "las empresas deben responder a los factores de manera tanto ofensiva como defensiva, por medio de la formulación de estrategias que aprovechen las oportunidades externas o que reduzcan el impacto de las amenazas potenciales" (2018, p. 82).

Esta herramienta permite identificar las estrategias correctas y para ello se efectúa un análisis con los datos obtenidos en los capítulos anteriores.

En análisis FODA es importante para evaluar las fortalezas y debilidades de la compañía en comparación con la competencia y el entorno. 


\section{FORTALEZAS-F}

1.- Propiedad de ENEL (Italia).

2.- Tiempo en el negocio hidráulico.

3.- Infraestructura para la generación hydro y térmico

4.- Ubicación estratégica de las centrales

5.- Liderazgo en la Generación de Energía

6.- Contratos a largo plazo con clientes libres.

7.- Networking con instituciones reguladoras.

8.- Excelente imagen reputacional en el país.

9.- Eficiencia en la producción

\section{DEBILIDADES-D}

Bajo estudio para desarrollo de nuevas

1.- oportunidades de negocio (plantas renovables).

Cuellos de botellas para ejecución de

2.- proyectos (dependencia)

3.- Bajo desarrollo de proyectos sociales sostenibles

4.- Baja repotenciación de plantas antiguas

5.- Falta de comunicación entre áreas de staff y negocio.

6.- Bajo nivel de Control de contratistas.

7.- Dependencias de personas en puestos claves,

por falta de transferencia de información.

\section{ESTRATEGIAS - DO}

Crecimiento de la economía peruana

impulsado por los decretos legislativos en materia económica para la reactivación de la economía peruana.

Fortalecimiento del desarrollo del secto energía, de acuerdo al Plan Energético Nacional 2014 - 2025, publicado por la Dirección General de Eficiencia Energética del Ministerio de Energía y Minas (MEM).
Incremento de la cartera de clientes a nivel nacional.

Participación en licitaciones realizados por el

Ministerio de Energía y Minas (F1, F2, F5, O3, O4)

Desarrollo y ejecución de proyectos Solar, eólicos y

2. mini hidros. Productividad y eficiencia de los procesos

creado área de desarrollo de negocio. (F3, F6, O7 -

O8)
Creación área de desarrollo de negocios, para

1.- la investigación y ejecución de proyectos renovables. (D1 D7, O3, O4)

Fortalecer el nivel de compromiso y

2.- satisfacción de los clientes internos. Mejorar e compromiso organizativo y la satisfacción laboral (D5 - O6) 
Integración Energética: Actualmente

existen diferentes proyectos de integración

energética con Ecuador, Brasil, Chile

3.- Colombia y Bolivia. El país tiene el

potencial de convertirse en HUB

3. Aumentar capacidad instalada de generación

Energético y poder exportar energía de

manera sostenible, luego de abastecer la

demanda interna

Compromiso en aumentar la

competitividad del Sector Minero -

Energético mediante la Resolución

Ministerial

Compromiso del gobierno en cerrar la

5.- $\quad$ brecha en la cobertura eléctrica en los próximos 10 años.

Sector eléctrico cuenta con un sistema interconectado

7. Nuevas tecnologías de sistemas para automatización de las instalaciones.

8.- Migración de zona rural a urbana hidráulica. $(\mathrm{O} 1, \mathrm{f} 4)$

Expansión de servicios de ENEL Generación Perú SAA en nuevas zonas (F3, F4, F6, O6, O7)

5.- Benchmarking sobre buenas practicas con otras empresas del Grupo (F1, F2, O2)
Establecer un plan de mejora continua para la 3.- confiabilidad de la transmisión de energía (Plan Operativo) (D4 -O8)

Analizar procesos de contratación para mejor 4.- lead time del proceso de celebración de contratos (D2- O6)

Establecer procesos de mejora continua a

5.- $\quad$ través de la implementación de herramientas tecnologicas. (D5, O7)

AMENAZAS-A

ESTRATEGIAS - FA

ESTRATEGIAS - DA

El precio de petróleo y gas natural han

1.- mantenido un comportamiento muy volátil en los últimos años.

Actualmente el tipo de cambio PEN/USD

- se ha mantenido estable, sin embargo, los

factores político - económicos del país pueden generar volatilidad.

Perú es un país expuesto a desastres naturales como sismos, tsunamis, e

3.- inundaciones los cuales pueden afectar considerablemente la infraestructura de EGP.

1.- Estructurar fuentes de inversión (F1, F6, A1, A2, A3)

Aumentar niveles de generación solar, eólica e hidráulica (F2, F4, F6, A2, A3)

Elevar los lazos en pobladores aledaños a F8, A7)
Implementación de mecanismos para negociar contratos (D3, D6, A4, A5)

Diseñar nuevos proyectos socio - ambientales (D1 - D3 - A1)

Construcción de nuevas plantas con fuentes de energía alternas (D1, D7, A2, A3) 
4.-

Nuevos competidores con grandes inversiones

5.- $\quad$ Limitada disponibilidad de gas

Aumento de la rigurosidad en las leyes

medioambientales

7.- $\quad$ Conflictos Sociales

$\left(^{*}\right) \mathrm{A}=$ Alto impacto; $\mathrm{M}=$ Mediano impacto; $\mathrm{B}=$ Bajo Impacto

Nota. Elaboración propia. Adaptado de “Administración estratégica,” por F. R. David, 2003, p. 110. Copyright 2003 por Pearson Educación de México.
Calidad del servicio, tomando en cuenta la

4.- experiencia de las empresas que son del grupo Enel

Generación Perú SAA
Elaborar políticas internas de contratación de servicios (D6, A1, A2) 


\subsubsection{Matriz PEYEA.}

La matriz tiene cuatro cuadrantes donde se especifica la estrategia sugerida.

La tabla 34 muestra los factores analizados, la calificación otorgada en comparación con la importancia de cada factor. De esta puntuación resultan cuatro puntos que permitirá construir el polígono e identificar el vector que mostrará la estratégica más adecuada para Enel Generación Perú SAA.

Los factores considerados para la posición estratégica para la empresa son la posición interna y externa que se muestra a continuación. 
Tabla 36

Factores que constituyen las Variables de los Ejes de la Matriz PEYEA de Enel Generación Perú SAA

\begin{tabular}{|c|c|c|c|}
\hline \multirow{20}{*}{ Posición estratégica interna } & \multicolumn{2}{|c|}{ Factores determinantes de fortaleza financiera (FF) } & Valor \\
\hline & 1 & Retorno en la inversión & 6 \\
\hline & 2 & Apalancamiento & 5 \\
\hline & 3 & Liquidez & 3 \\
\hline & 4 & Capital requerido versus capital disponible & 4 \\
\hline & 5 & Flujo de caja & 4 \\
\hline & 6 & Facilidad de salida al mercado & 2 \\
\hline & 7 & Riesgo involucrado en el negocio & 4 \\
\hline & 8 & Rotación de inventarios & 0 \\
\hline & 9 & Economías de escala y de experiencia & 6 \\
\hline & \multicolumn{2}{|c|}{ Factores determinantes de ventaja competitiva (VC) } & Valor \\
\hline & 1 & Participación en el mercado & -2 \\
\hline & 2 & Calidad del servicio & -3 \\
\hline & 3 & Diversidad del servicio en Enel Generación Perú SAA & -5 \\
\hline & 4 & Ciclo de vida de Enel Generación Perú SAA & -4 \\
\hline & 5 & Lealtad del cliente & -2 \\
\hline & 6 & Utilización de la capacidad de los competidores & -2 \\
\hline & 7 & Conocimiento tecnológico & -1 \\
\hline & 8 & Integración vertical & 0 \\
\hline & 9 & Velocidad de introducción de los nuevos productos & -2 \\
\hline \multirow{9}{*}{ Posición estratégica externa } & \multicolumn{2}{|c|}{ Factores determinantes de la estabilidad del entorno (EE) } & Valor \\
\hline & 1 & Cambios tecnológicos & -1 \\
\hline & 2 & Tasa de inflación & -3 \\
\hline & 3 & Variabilidad de la demanda & -2 \\
\hline & 4 & Rango de precios de servicios competitivos & -2 \\
\hline & 5 & Barreras de entrada al mercado & -2 \\
\hline & 6 & Rivalidad / Presión competitiva & -3 \\
\hline & 7 & Elasticidad de precios de la demanda & -3 \\
\hline & 8 & Presión de productos sustitutos & -2 \\
\hline
\end{tabular}




\begin{tabular}{llll} 
& Factores determinantes de la fortaleza de la industria $(\mathrm{FI})$ & Valor \\
& 1 & Potencial de crecimiento & 5 \\
& 2 & Potencial de utilidades & 4 \\
& 3 & Estabilidad financiera & 1 \\
& 4 & Conocimiento tecnológico & 5 \\
& 5 & Utilización de recursos & 4 \\
& 6 & Intensidad de capital & 4 \\
& 7 & Facilidad de entrada al mercado & 4 \\
\hline Factor & 8 & Productividad/Utilización de la capacidad & 3 \\
FF & 9 & Poder de negociación de los competidores & Eector Direccional \\
VC & Valor & Promedio & 1.45 \\
EE & 34 & 3.78 & 1.53 \\
FI & -21 & -2.33 & Eje Y \\
\hline Nota. Elaboración propia. Adaptado de "Administración estratégica," por F. R. David, 2003, p. 110. Copyright 2003 por Pearson Educación de México
\end{tabular}

En cuanto a factores determinantes que se han considerado en la parte de fortalezas financieras, se toma en cuenta la liquidez neta, este factor es importante y trascendental debido al porcentaje no menor del $20 \%$ que estable como un parámetro. 


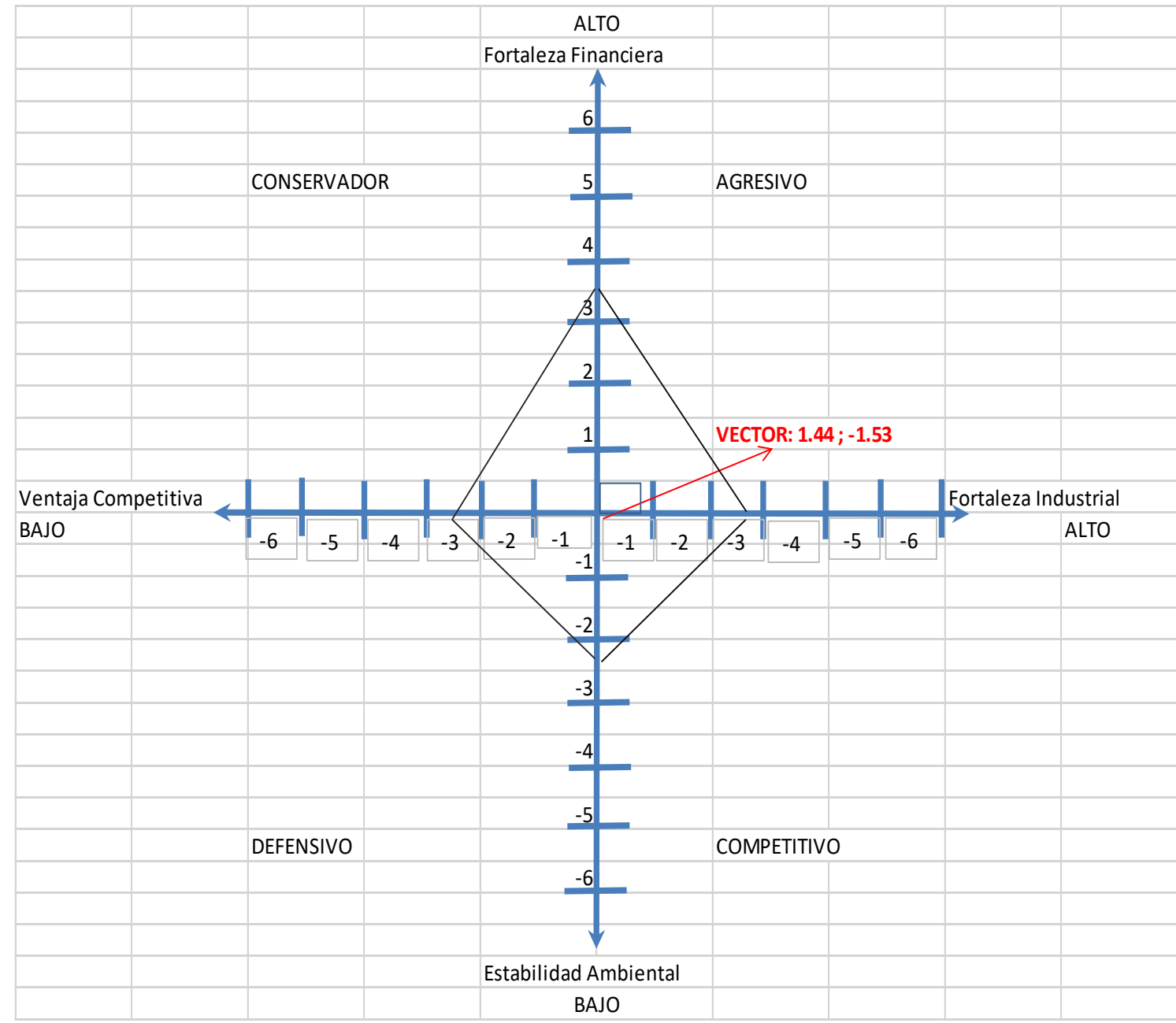

Figura 22. Matriz PEYEA de Enel Generación Perú SAA.

Elaboración propia. Adaptado de "Administración estratégica" por F. R. David, 2003, p. 110.

Copyright 2003 por Pearson Educación de México.

A continuación, se muestra las Estrategias, resultado de la matriz PEYEA:

\section{Diversificación}

1. Nuevos mercados en provincias, buscar nuevos nichos de mercado.

2. Inversión en reemplazo de sistemas y equipos en las plantas, estrategia orientada al cumplimiento que exige el organismo regulatorio del gobierno.

\section{Segmentación de mercados}

1. Potenciar y Desarrollar vínculos con organismos del estado y compañías que están relacionada al sector de energía. Esta estrategia está basada en la ventaja competitiva de Enel Generación Perú SAA.

2. Ampliar la participación en el mercado a nivel del Estado. Estrategia basada frente a los principales competidores. 


\section{Enfoque en diferenciación}

1. Contratación de personal capacitado.

2. Mejorar los procesos productivos de la mano con la tecnología. Es una estrategia que está basada en la capacidad operativa ante la competencia.

\subsubsection{Matriz Interna -Externa.}

Evaluando las fortalezas y debilidades de Enel Generación Perú SAA, se obtuvo un puntaje de 2,99 para la matriz EFI, lo cual se considera un valor promedio dentro de la matriz IE; asimismo, luego de evaluar las oportunidades y amenazas externas, se obtuvo un puntaje de 3,78 para la matriz EFE, lo cual indica un valor alto dentro de la matriz IE, de acuerdo a la figura 23.

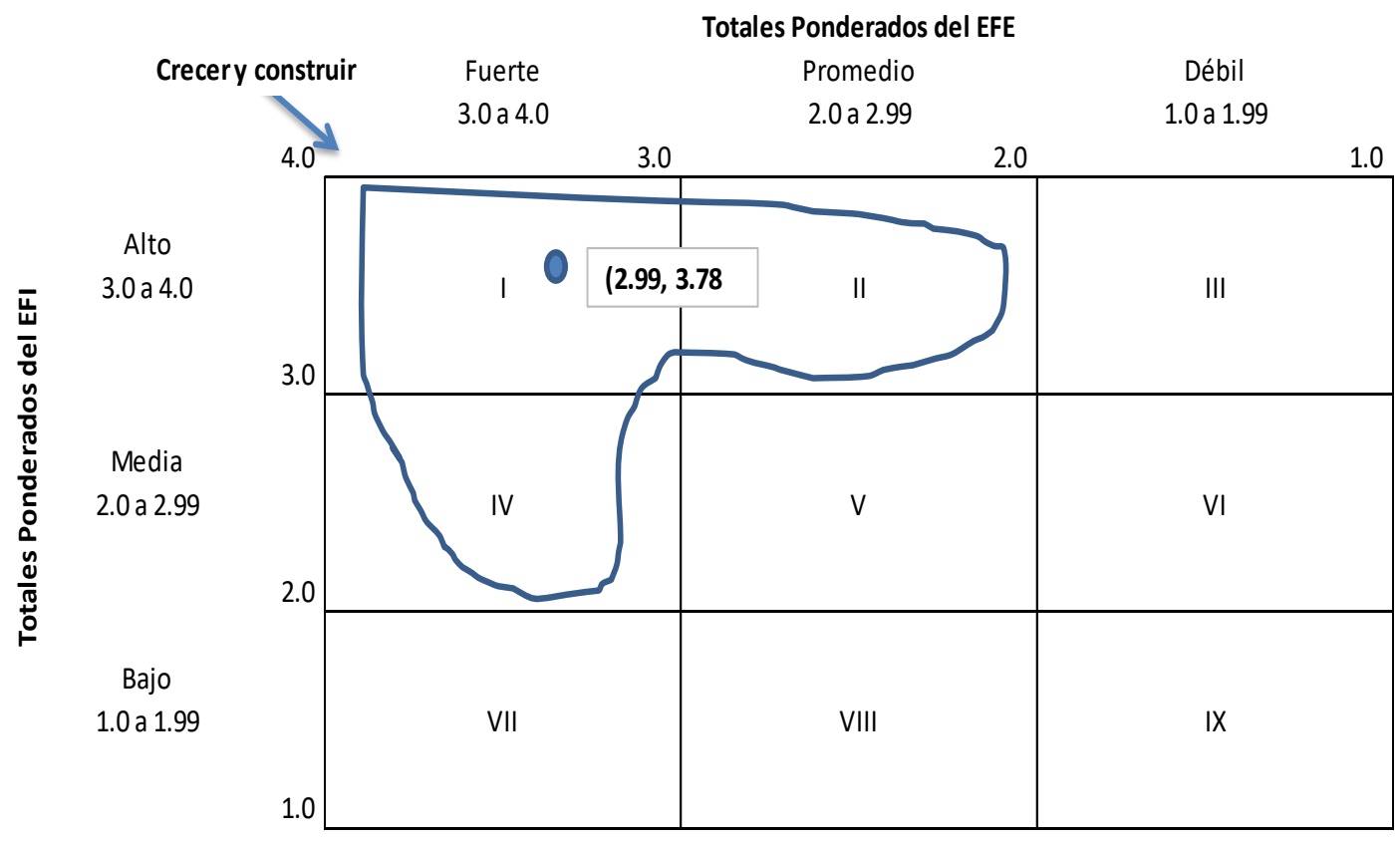

Figura 23. Matriz Interna -Externa de Enel Generación Perú SAA.

Elaboración propia. Adaptado de "Administración estratégica," por F. R. David, 2003, p. 110. Copyright 2003 por Pearson Educación de México.

La empresa se ubica en los cuadrantes II, II y IV de la matriz IE, importante para establecer estrategias de crecimiento, como es el caso de captar nuevo clientes libres y regulados, potenciar sus instalaciones para obtener mayor cantidad de energía y optar por proyectos de construcción de centrales con energía renovables.

Las Estrategias crecer y construir son las siguientes:

a) Penetración de mercados

Captación de clientes libres y regulados.

b) Mejora de mercados 
Ampliar el alcance del servicio de Enel Generación Perú S.A.A. en nuevos nichos de mercado.

c) Desarrollo de la capacidad

Potenciar sus instalaciones para obtener mayor cantidad de energía.

d) Desarrollo de personal

Fidelizar a colaboradores internos, incrementando el grado de satisfacción.

\subsubsection{Matriz Boston Consulting Group.}

En este análisis se ha considerado la participación en el mercado y el crecimiento en las ventas del sector de transmisión eléctrico. En la figura 24 se observa que el sector de transmisión es representado como un solo negocio dado que ofrece un único servicio. El sector de transmisión eléctrico, según la matriz BCG, es un signo de "vaca", pues es una industria consolidada y posee una tasa de crecimiento media. En este caso, el sector tiene las siguientes características y estrategias:

1. Tiene alta participación relativa del mercado, pero compite en una industria de mediano crecimiento (esto cambiaría si se llegaran a concretar los contratos para abastecer demandas fuera del país).

2. Genera exceso de liquidez para sus necesidades.

3. Este exceso es recolectado para todos los propósitos (nuevas inversiones).

4. Debe ser administrados para mantener una posición sólida durante el mayor tiempo posible.

5. Es conveniente aplicar estrategias de desarrollo de nuevos mercados.

6. Si el sector se debilita (el rendimiento llega a niveles iguales o similares a los que ofrece el sistema bancario), la estrategia sería la liquidación.

7. Debe mantener una estructura organizativa óptima.

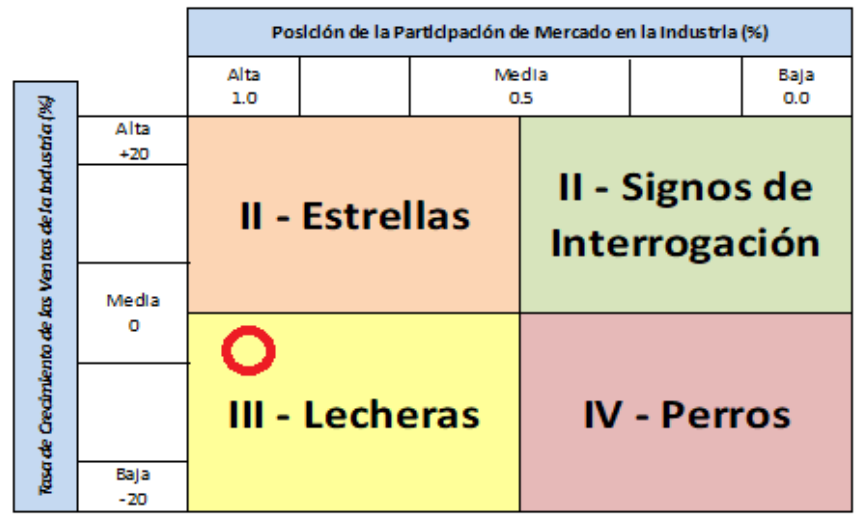

Figura 24. Matriz BCG.

Elaboración propia. Adaptado de "Administración estratégica," por F. R. David, 2003, p. 110. Copyright 2003 por Pearson Educación de México. 


\subsubsection{Matriz Gran Estrategia.}

Enel Generación Perú SAA se ubica dentro del cuadrante I, siendo la empresa débil competitivamente ante un mercado de crecimiento medio.

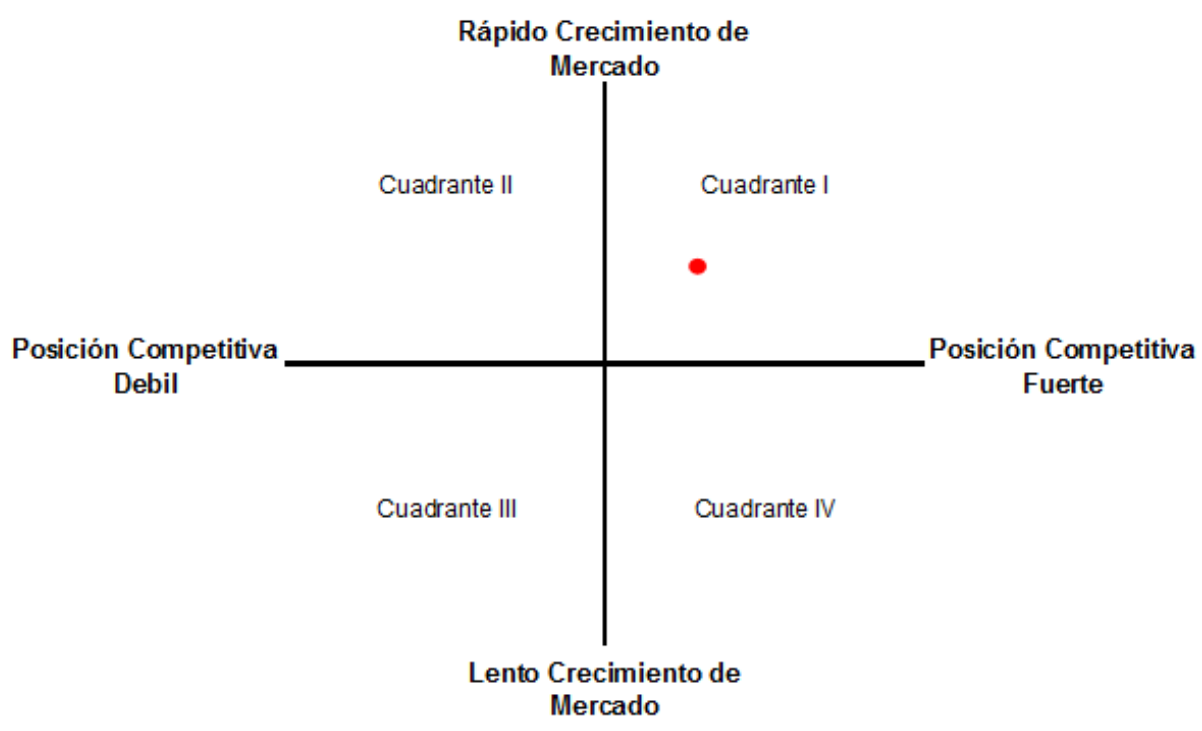

Figura 25. Matriz de la Gran Estrategia.

Elaboración propia. Adaptado de "Administración estratégica," por F. R. David, 2003, p. 110. Copyright 2003 por Pearson Educación de México.

La matriz de la Gran Estrategia se basa en dos dimensiones de evaluación: la posición competitiva y el crecimiento de mercado. Enel Generación Perú SAA se ubica en el cuadrante I, lo que nos muestra que la empresa es asertiva en las actividades realizadas para un mercado en desarrollo que demanda cada vez garantías en el suministro de energía a un costo favorable para el cliente.

\subsection{Resumen de las Estrategias Formuladas}

Estas herramientas cuya formulación está acorde a las pautas de David (2008) son de gran ayuda para la toma de decisiones respecto a las estrategias que planteamos para Enel Generación Perú SAA. Los resultados de estas matrices están relacionados entre sí. Así, las matrices EFE y EFI permitirán diseñar la matriz FODA, donde se realiza una primera selección de estrategias. Las matrices IE, PEYEA y de la Gran Estrategia son de comprobación (que en teoría es, lo que se debe realizar). Finalmente, se hace un resumen de las estrategias, destacando las más repetidas por cada matriz elaborada. Se resume las estrategias que sobresalen y que se deben poner en práctica por la empresa como: incremento de la cartera de nuevos clientes y el desarrollo de nuevas tecnologías para la generación de energía, implementando recursos renovables. 


\section{Capítulo VIII. Selección de la Estrategia}

En el presente capítulo, se plantea la selección de la estrategia, la cual consiste en escoger aquella que permita a la empresa Enel Generación Perú SAA, una ventaja sobre su competencia. La elección de la estrategia se sustenta bajo un análisis del estudio de las variables cuali y cuanti que permiten poder determinar la alternativa de mayor conveniencia para la empresa Enel Generación Perú SAA, de acuerdo a sus capacidades y las oportunidades.

\subsection{Método Factores Estratégicos Claves}

Este método permite encontrar los factores estratégicos más importantes dentro de los identificados anteriormente, a los cuales se les considera claves y se obtuvieron de las matrices desarrolladas en la etapa de identificación de la estrategia.

Como primer paso, están los criterios de selección como factores clave, para los cuales se empleará la información que destaca como valorada para Enel Generación Perú SAA en el transcurso de la investigación realizada. Posteriormente, se establecerá la matriz de selección.

\subsubsection{Criterios de selección.}

Del resultado del análisis obtenido en las matrices FODA, PEYEA, BCG, IE, y GE, se han seleccionado ocho estrategias retenidas, dejando algunas estrategias como contingencia y son los siguientes:

Estrategia 1: Incrementar la cartera de nuevos clientes libres en el Perú.

Estrategia 2: Tecnología para el desarrollo de la generación de energía, implementando recursos renovables

Estrategia 3: Construcción de nuevas plantas hidroeléctricos

Estrategia 4: Afianzar la perpetuidad del servicio con los clientes libres y regulados

Estrategia 5: Calidad del servicio, tomando en cuenta la experiencia de las empresas que son parte de las empresas de la corporación a nivel global.

Estrategia 6: Potenciar la comunicación con diversos grupos comuneros donde opera la compañía a través de los programas de RSE.

Estrategia 7: Establecer procedimientos locales eficaces para la gestión de sus proveedores.

Estrategia 8: Productividad y eficiencia de los procesos implementando un área de desarrollo de negocio.

Estrategia 9: Generar un compromiso de sus colaboradores hacia a empresa. 


\subsubsection{Matriz de selección.}

En la Tabla 37, se presenta la matriz consolidada de estrategias, para iniciar la selección.

Tabla 37

Matriz de Selección de la estrategia

\begin{tabular}{|c|c|c|c|c|c|c|c|c|c|c|}
\hline Ítem & \multicolumn{3}{|c|}{ Estrategias generales } & \multirow{2}{*}{$\begin{array}{l}\text { FODA } \\
\mathrm{X}\end{array}$} & \multirow{2}{*}{$\begin{array}{l}\text { PEYEA } \\
X\end{array}$} & \multirow{2}{*}{$\begin{array}{c}\mathrm{BCG} \\
\mathrm{X}\end{array}$} & \multirow{2}{*}{$\mathrm{IE}$} & \multirow{2}{*}{$\begin{array}{l}\text { GE } \\
X\end{array}$} & \multirow{2}{*}{$\begin{array}{l}\text { OCÉANO } \\
\text { AZUL } \\
x\end{array}$} & \multirow{2}{*}{$\begin{array}{c}\text { Total } \\
6\end{array}$} \\
\hline 1 & Generación propia & $\begin{array}{l}\text { Mix fuentes de } \\
\text { generación de } \\
\text { energía }\end{array}$ & $\begin{array}{l}\text { Tecnología para el desarrollo de la } \\
\text { generación de energía, implementando } \\
\text { recursos renovables }\end{array}$ & & & & & & & \\
\hline 2 & Reducción de & $\begin{array}{l}\text { Procesos } \\
\text { productivos }\end{array}$ & $\begin{array}{l}\text { Productividad y eficiencia de los procesos } \\
\text { implementando un área de desarrollo de }\end{array}$ & $\mathrm{x}$ & $\mathrm{x}$ & & $x$ & $x$ & $\mathrm{x}$ & 5 \\
\hline & costos operativos & Poder Financiero & negocio. & & & & & & & \\
\hline 3 & $\begin{array}{l}\text { Explotación y } \\
\text { optimizacion de } \\
\text { activos }\end{array}$ & $\begin{array}{l}\text { Ubicación geográfica } \\
\text { de las plantas de } \\
\text { generación de } \\
\text { energía }\end{array}$ & $\begin{array}{l}\text { Construcción de nuevas plantas } \\
\text { hidroeléctricos }\end{array}$ & $x$ & $x$ & & & $\mathrm{X}$ & $x$ & 4 \\
\hline 4 & & Captación de nuevos & $\begin{array}{l}\text { Afianzar la perpetuidad del servicio con } \\
\text { los clientes libres y regulados }\end{array}$ & $\mathrm{X}$ & & $x$ & $x$ & & $x$ & 4 \\
\hline 5 & $\begin{array}{l}\text { Inteligencia de } \\
\text { Negocios }\end{array}$ & clientes & $\begin{array}{l}\text { Incremento cartera de nuevos clientes en } \\
\text { el Perú. }\end{array}$ & $\mathrm{x}$ & $\mathrm{x}$ & $\mathrm{x}$ & $x$ & $\mathrm{x}$ & $x$ & 6 \\
\hline 6 & & $\begin{array}{l}\text { Política de seguridad } \\
\text { para gestión de } \\
\text { contratistas }\end{array}$ & $\begin{array}{l}\text { Afianzar la calidad de los servicios con } \\
\text { contratistas especialistas en el sector }\end{array}$ & $\mathrm{X}$ & & & & & $\mathrm{X}$ & 2 \\
\hline 7 & & $\begin{array}{l}\text { Capacidad y } \\
\text { entrenamiento del } \\
\text { personal }\end{array}$ & $\begin{array}{l}\text { Generar un compromiso de sus } \\
\text { colaboradores hacia a empresa }\end{array}$ & & $\mathrm{x}$ & $\mathrm{x}$ & $x$ & $\mathrm{x}$ & & 4 \\
\hline 8 & Cultura & $\begin{array}{l}\text { Sistema de control y } \\
\text { comunicaciones }\end{array}$ & $\begin{array}{l}\text { Potenciar la comunicación con diversos } \\
\text { grupos comuneros donde opera la } \\
\text { compañía a través de los programas de } \\
\text { RSE. }\end{array}$ & & & & $x$ & & $\mathrm{x}$ & 2 \\
\hline 9 & organizacional & $\begin{array}{l}\text { Procesos } \\
\text { burocraticos }\end{array}$ & $\begin{array}{l}\text { Establecer procedimientos locales } \\
\text { eficaces para la gestión de sus } \\
\text { proveedores. }\end{array}$ & $x$ & & & & & $x$ & 2 \\
\hline 10 & & Servicio post venta & $\begin{array}{l}\text { Calidad del servicio, tomando en cuenta } \\
\text { la experiencia de las empresas que son } \\
\text { parte de las empresas de la corporación } \\
\text { a nivel global. }\end{array}$ & $x$ & & & & & $\mathrm{x}$ & 2 \\
\hline
\end{tabular}


Estrategias a implementar:

a) Captación nuevos clientes. Incremento la cartera de nuevos clientes en el Perú.

b) Procesos productivos. Productividad y eficiencia de los procesos implementando un área de desarrollo de negocio

c) Mix de Generación de Energía. Tecnología para el desarrollo de la generación de energía, implementando recursos renovables.

\subsection{Método de Escenarios}

Según Godet, el escenario es "un conjunto formado por la descripción de una situación futura y de la trayectoria de eventos que permiten pasar de una situación origen a una situación futura" (2011, p. 89).

Los escenarios tienen por finalidad estimar los distintos resultados que se obtendrán en base a la información plasmada en las matrices EFE y EFI, entendiendo que los factores vinculados a cada una de ellas tendrán una especial importancia sobre el desempeño de Enel Generación Perú SAA frente a la estrategia por la cual finalmente se decida.

\subsubsection{Descripción de escenarios considerados.}

Escenario 01, D'Alessio señaló que los "retos sociales y ambientales actuales asociados al consumo de energía para la generación de energía requerirán inversiones suplementarias" (2014, pág.73).

Se toma como referencia para eventos futuros el programa elaborado por CEPLAN "Plan Bicentenario para el 2021"

Tabla 38

Objetivos estratégicos al 2021 CEPLAN

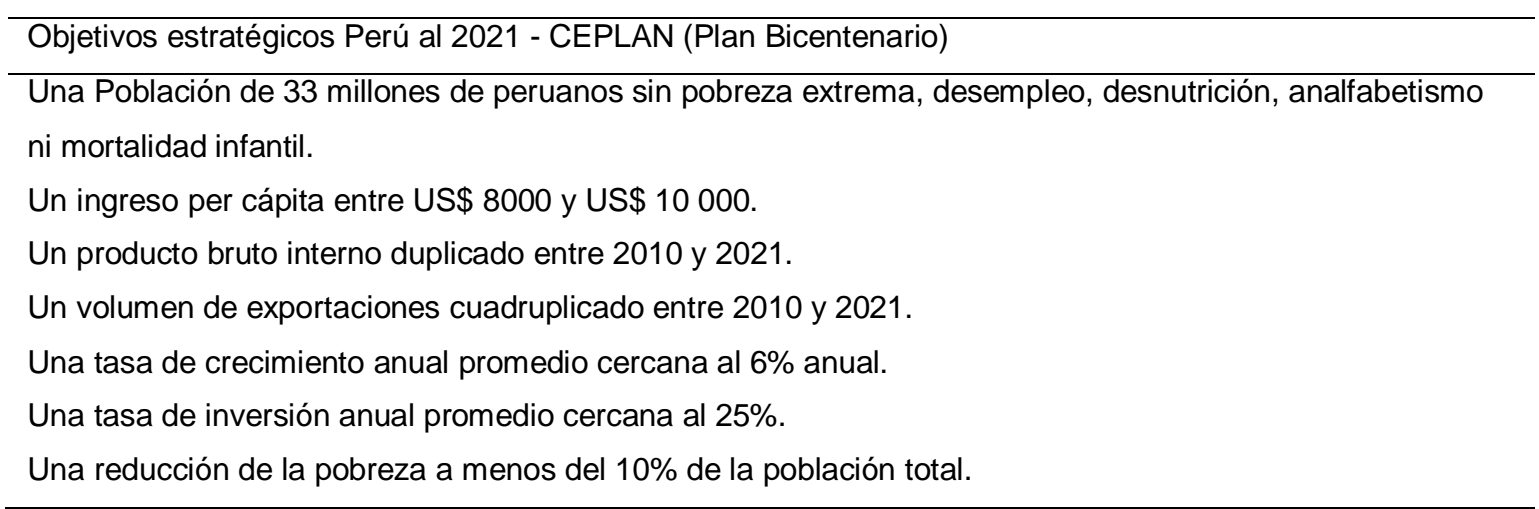
Nota. Adaptado de CEPLAN. Plan estratégico de desarrollo nacional al 2021. Disponible en: ceplan.gob.pe 
Se estructuran tres escenarios, tomando en consideración tendencias del entorno.

\section{a. Escenario 1 - Al año 2021 (Optimista)}

En el ámbito económico el Perú, será uno de los países que tome el liderazgo en el tema de las exportaciones por producción minera y precios favorables de los commodities, aportando valor agregado a América Latina, de igual forma, por pertenecer a diversos grupos económicos en el mundo, con una estrategia de libre mercado que permite ser atractivo para nuevas inversiones públicas y privadas.

En el ámbito social, el Perú será un país con un alto nivel de calidad de vida mayor al de otros países de la región, debido a la continuidad de los proyectos sociales que son ejecutados por los diferentes gobiernos de turno.

Perú, es fuente de desarrollo de proyectos tecnológicos y de transformación de procesos de producción, creando nuevos programas que impulsen la creación de nuevos puestos de trabajo.

En relación a las políticas energéticas, el gobierno estructura una matriz energética diversa, poniendo énfasis en las fuentes renovables.

Se prevé necesidades energéticas, considerando recursos existentes en el Perú y requerimientos de importación, el comportamiento del mercado energético, las tendencias de la actividad económica, población y la tecnología, así como de la infraestructura necesaria de producción, transporte y distribución.

\section{b. Escenario 2 - Al año 2021 (Conservador)}

Debido a la serie de sucesos controversiales que se vienen dando en el Perú. Los partidos con presencia en el congreso han tenido un bajo nivel de aceptación en los últimos procesos electorales y los movimientos independientes regionales se han posicionado en los electores.

La producción eléctrica en el Perú se mantiene, gracias al moderado crecimiento de la demanda y disponibilidad de diversos recursos naturales.

El suministro eléctrico es seguro, confiable y accesible para todos los sectores económicos y en lo que respecta a lo socio ambiental existe un crecimiento económico hacia el desarrollo sostenible.

\section{c. Escenario 3 - Al año 2021 (Pesimista)}

El Perú continúa con un sistema político de bajo nivel de aceptación por la población, debido a los diferentes escándalos dentro de las instituciones legales, originando conflictos sociales. 
Tabla 39

Escenarios 2017-2021

\begin{tabular}{|c|c|c|c|}
\hline Demografía & Pesimista & Conservador & Optimista \\
\hline Tasa de crecimiento poblacional & $\begin{array}{l}\text { Tendencia a } \\
\text { baja }<1 \%\end{array}$ & Estable +/- 1.1\% & $\begin{array}{l}\text { Tendencia Alza } \\
>1.1 \%\end{array}$ \\
\hline Crecimiento de la población urbana & $\begin{array}{l}\text { Crece más que } \\
\text { rural }\end{array}$ & $\begin{array}{l}\text { Crece menos que } \\
\text { rural }\end{array}$ & Estancado \\
\hline Distribución de la pirámide poblacional & Más adultos & Más jóvenes & Estancado \\
\hline Estructura poblacional según NSE & Mayoría A-B & Mayoría C & Mayoría D-E \\
\hline Economía & Pesimista & Normal & Optimista \\
\hline Crecimiento del PBI & Bajo $<3 \%$ & Estable 3\%-5\% & Alto $5-9 \%$ \\
\hline Tendencia del tipo de cambio & $\begin{array}{l}\text { A la baja }<3 \\
\text { Estable }\end{array}$ & Estable 2.8 - 3.1 & Alza $>3$ \\
\hline Política de importaciones & Estable & Proteccionismo & Más TLC \\
\hline Ingreso per cápita & Disminuye & Estable & Crece \\
\hline Tecnología & Pesimista & Normal & Optimista \\
\hline $\begin{array}{l}\text { Desarrollo tecnológico para medianas } \\
\text { empresas (Innovación en B2B - EDI - BI) }\end{array}$ & $\begin{array}{l}\text { Estándar se } \\
\text { mantiene }\end{array}$ & Poco agresivo & Muy agresivo \\
\hline $\begin{array}{l}\text { Redes sociales (desarrollo con } \\
\text { orientación al negocio y posicionamiento } \\
\text { de marcas) }\end{array}$ & Estable & Proteccionismo & Más TLC \\
\hline Tecnología para la parte operativa & $\begin{array}{l}\text { Estándar se } \\
\text { mantiene }\end{array}$ & Normal & Optimista \\
\hline $\begin{array}{l}\text { Desarrollo en los canales/puntos de venta } \\
\text { (acceso y medios de pago) }\end{array}$ & Estándar & Sofisticado & Muy sofisticado \\
\hline Sociedad y político & Pesimista & Normal & Optimista \\
\hline Estabilidad política & Sin cambios & Viraje moderado & Viraje radical \\
\hline Mercado laboral & Estable & Crece empleo & Decrece el empleo \\
\hline Conflictos sociales & Estable & Disminuyen & Se acentúan \\
\hline Estabilidad jurídica & $\begin{array}{l}\text { Se mantiene tal } \\
\text { cual }\end{array}$ & Se fortalece & Se debilita \\
\hline
\end{tabular}

Fuente: Elaboración propia

Con los criterios mencionados anteriormente, se selecciona dos escenarios a juicio experto, que se detallan en la siguiente tabla.

Tabla 40

Escenarios Probables

\begin{tabular}{lll}
\hline Demografía & I (más probable) & II (menos probable) \\
\hline Tasa de crecimiento poblacional & Estable $+/-1.1 \%$ & $\begin{array}{l}\text { Tendencia a la baja } \\
>1.1 \%\end{array}$ \\
$\begin{array}{ll}\text { Crecimiento de la población urbana } \\
\text { Distribución de la pirámide poblacional }\end{array}$ & $\begin{array}{l}\text { Crece menos que } \\
\text { rural } \\
\text { Más adultos }\end{array}$ & $\begin{array}{l}\text { Estancado } \\
\text { Estructura poblacional según NSE }\end{array}$ \\
$\begin{array}{l}\text { Economía } \\
\text { Crecimiento del PBI }\end{array}$ & Mayoría C & Mayoría A -B \\
\hline
\end{tabular}




\begin{tabular}{|c|c|c|}
\hline Tendencia del tipo de cambio & Estable $2.8-3.1$ & Alza $>3$ \\
\hline Política de importaciones & Estable & Más TLC \\
\hline Ingreso per cápita & Crece & Estable \\
\hline Tecnología & Normal & Optimista \\
\hline $\begin{array}{l}\text { Crecimiento tecnológico para medianas } \\
\text { empresas (Innovación en B2B - EDI - BI) }\end{array}$ & Muy agresivo & Poco agresivo \\
\hline $\begin{array}{l}\text { Redes sociales (desarrollo con orientación al } \\
\text { negocio y posicionamiento de marcas) }\end{array}$ & Proteccionismo & Más TLC \\
\hline Tecnología para la parte operativa & & \\
\hline $\begin{array}{l}\text { Desarrollo en los canales/puntos de venta } \\
\text { (acceso y medios de pago) }\end{array}$ & $\begin{array}{l}\text { Sofisticado } \\
\text { Cambios drásticos }\end{array}$ & $\begin{array}{l}\text { Muy sofisticado } \\
\text { Cambios menores }\end{array}$ \\
\hline Sociedad y político & Normal & Optimista \\
\hline Estabilidad política & Viraje moderado & Sin cambios \\
\hline Mercado laboral & Crece empleo & Decrece el empleo \\
\hline Conflictos sociales & Se acentúan & Estable \\
\hline Estabilidad jurídica & Se mantiene igual & Se debilita \\
\hline
\end{tabular}

Fuente: Elaboración propia

Los escenarios se explican a continuación:

\section{Escenario I (más probable):}

Crecimiento sostenible del sector urbano. EI PBI Global muestra un crecimiento sostenido de 3.5 a 5\%. En el aspecto financiero, la volatilidad del tipo de cambio se encontraba en alza. Aplicación de Tecnología de Información generando cambios al país.

\section{Escenario II (menos probable):}

No existen cambios en el nivel de crecimiento del PBI, el tipo de cambio no es volátil, incremento de las exportaciones y estabilidad política.

\subsubsection{Comparación de estrategias con escenarios.}

Las estrategias que se plantean y se comparan en los escenarios son las de diferenciación de la calidad de producto a brindar y el desarrollo de nuevas fuentes de generación. 
Tabla 41

Selección de Estrategia

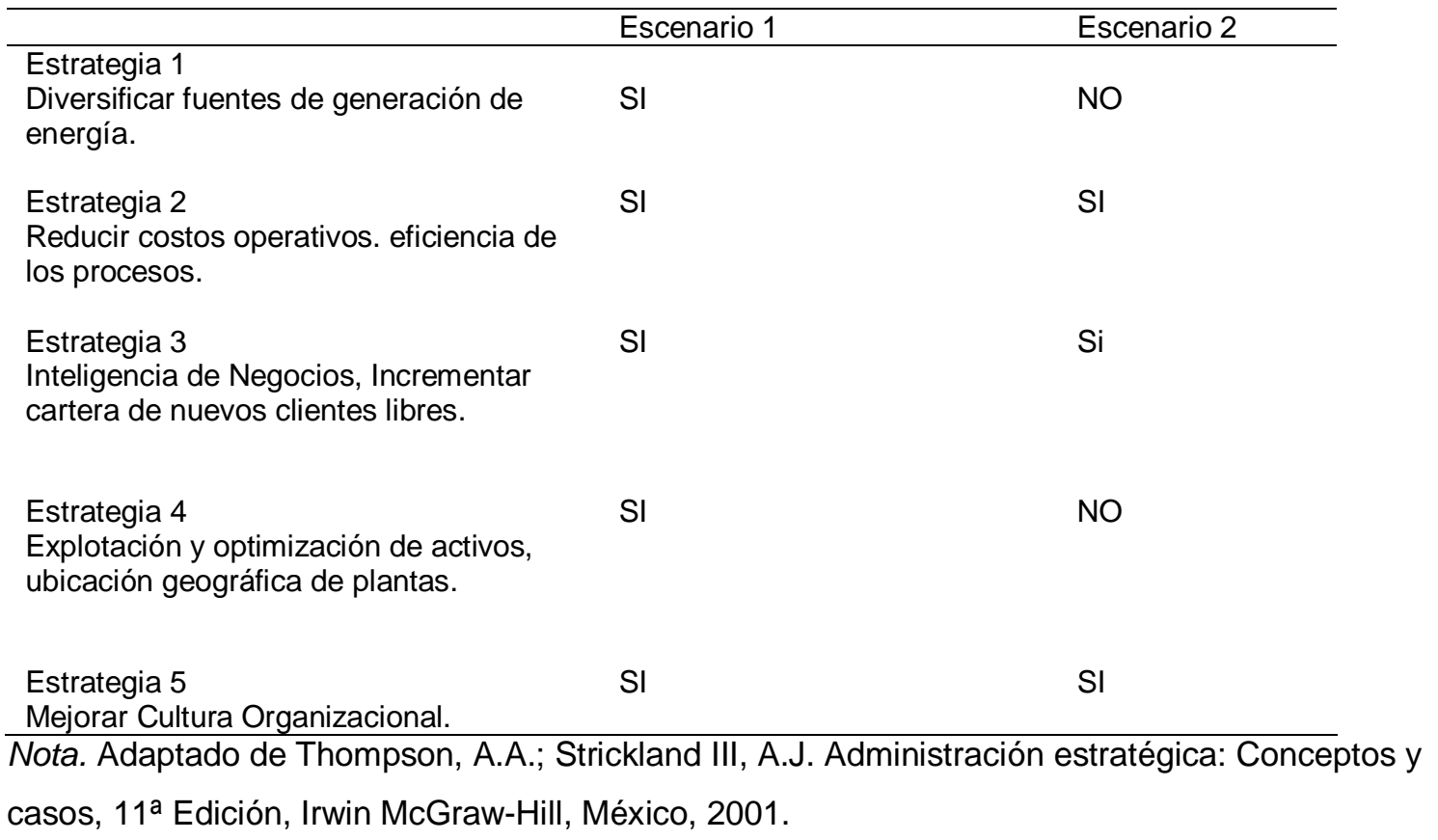

Las estrategias seleccionadas se validan con los escenarios y objetivos estratégicos, fortaleciendo el sustento de ellos.

Tabla 42

Matriz de Estrategias vs. Objetivos a Largo Plazo

\begin{tabular}{|c|c|c|c|c|c|c|}
\hline Ítem & Estrategia Seleccionada & $\begin{array}{l}\text { Diversificar } \\
\text { fuentes de } \\
\text { generación } \\
\text { de energía }\end{array}$ & $\begin{array}{l}\text { Reducir } \\
\text { costos } \\
\text { operativos. } \\
\text { eficiencia } \\
\text { de los } \\
\text { procesos }\end{array}$ & $\begin{array}{l}\text { Inteligencia } \\
\text { de } \\
\text { Negocios, } \\
\text { Incrementar } \\
\text { cartera de } \\
\text { nuevos } \\
\text { clientes } \\
\text { libres }\end{array}$ & $\begin{array}{l}\text { Explotación } \\
\text { y } \\
\text { optimización } \\
\text { de activos, } \\
\text { ubicación } \\
\text { geografica } \\
\text { de plantas }\end{array}$ & $\begin{array}{l}\text { Mejorar } \\
\text { Cultura } \\
\text { Organizacional }\end{array}$ \\
\hline EST1 & $\begin{array}{l}\text { Incrementar la cartera de } \\
\text { nuevos clientes en el } \\
\text { Perú. }\end{array}$ & Sí & Sí & Sí & Sí & Sí \\
\hline EST2 & $\begin{array}{l}\text { Tecnología para el } \\
\text { desarrollo de la } \\
\text { generación de energía, } \\
\text { implementando recursos } \\
\text { renovables }\end{array}$ & Sí & & Sí & Sí & Sí \\
\hline EST3 & $\begin{array}{l}\text { Construcción de nuevas } \\
\text { plantas hidroeléctricos }\end{array}$ & Sí & Sí & Sí & Sí & \\
\hline EST4 & $\begin{array}{l}\text { Afianzar la perpetuidad } \\
\text { del servicio con los } \\
\text { clientes libres y regulados }\end{array}$ & Sí & Sí & Sí & & \\
\hline
\end{tabular}


Calidad del servicio,

tomando en cuenta la

experiencia de las

EST5 empresas que son parte

de las empresas de la

corporación a nivel

global.

Potenciar la

comunicación con

diversos grupos

comuneros donde opera

la compañía a través de

los programas de RSE.

Establecer

EST7 procedimientos locales

Sí

Sí

Sí

Sí

de sus proveedores.

Productividad y eficiencia

EST8 de los procesos

implementando un área

de desarrollo de negocio.

Sí

Sí

Sí

Sí

Generar un compromiso

EST9 de sus colaboradores hacia a empresa.

Nota: Elaboración propia. Adaptado de Thompson, A.A.; Strickland III, A.J. Administración estratégica: Conceptos y casos, 11르 Edición, Irwin McGraw-Hill, México, 2001. 


\subsection{Matriz de Planeación Estratégica Cuantitativa MPEC}

Según D'Alessio sostiene que la matriz MPEC es "una herramienta que evalúa las estrategias posibles, con base en la identificación previa de factores críticos de éxito, externos e internos" (2015, p. 251). Esta técnica señala que alternativas estratégicas, de todas las presentadas para el sector de generación eléctrica, son las mejores. 


\begin{tabular}{|c|c|c|c|c|c|c|c|c|c|c|c|}
\hline \multirow[b]{2}{*}{ FACTORES CLAVE DE ÉXITO } & \multirow[b]{2}{*}{ PESO } & \multicolumn{2}{|c|}{$\begin{array}{l}\text { Diversificar } \\
\text { fuentes de } \\
\text { generación de } \\
\text { energía }\end{array}$} & \multicolumn{2}{|c|}{$\begin{array}{l}\text { Reducir costos } \\
\text { operativos. } \\
\text { eficiencia de los } \\
\text { procesos }\end{array}$} & \multicolumn{2}{|c|}{$\begin{array}{l}\text { Inteligencia de } \\
\text { Negocios, } \\
\text { Incrementar } \\
\text { cartera de nuevos } \\
\text { clientes libres }\end{array}$} & \multicolumn{2}{|c|}{$\begin{array}{c}\text { Explotación y } \\
\text { optimización de } \\
\text { activos, ubicación } \\
\text { geografica de plantas }\end{array}$} & \multicolumn{2}{|c|}{$\begin{array}{l}\text { Mejorar Cultura } \\
\text { Organizacional }\end{array}$} \\
\hline & & PA & PTA & $\mathrm{PA}$ & PTA & PA & PTA & PA & PTA & $\mathrm{PA}$ & PTA \\
\hline \multicolumn{12}{|l|}{ OPORTUNIDADES } \\
\hline $\begin{array}{l}\text { Crecimiento de la economía peruana, impulsado por } \\
\text { los decretos legislativos en materia económica para } \\
\text { la reactivación de la economía peruana. }\end{array}$ & 0.1 & 1 & 0.1 & 2 & 0.2 & 2 & 0.2 & 1 & 0.1 & 1 & 0.1 \\
\hline $\begin{array}{l}\text { Fortalecimiento del desarrollo del sector energía de } \\
\text { acuerdo al plan energético nacional 2014-2025 }\end{array}$ & 0.02 & 1 & 0.1 & 2 & 0.2 & 2 & 0.2 & 1 & 0.1 & 1 & 0.1 \\
\hline $\begin{array}{l}\text { Integración Energética: Actualmente existen } \\
\text { diferentes proyectos de integración energética con } \\
\text { Ecuador, Brasil, Chile, Colombia y Bolivia. El país } \\
\text { tiene el potencial de convertirse en HUB Energético y } \\
\text { poder exportar energía de manera sostenible, luego } \\
\text { de abastecer la demanda interna }\end{array}$ & 0.03 & 2 & 0.2 & 3 & 0.3 & 2 & 0.2 & 3 & 0.3 & 1 & 0.1 \\
\hline $\begin{array}{l}\text { Compromiso en aumentar la competitividad del } \\
\text { Sector Minero - Energético mediante la Resolución } \\
\text { Ministerial }\end{array}$ & 0.05 & 1 & 0.1 & 3 & 0.3 & 1 & 0.1 & 2 & 0.2 & 2 & 0.2 \\
\hline $\begin{array}{l}\text { Compromiso del gobierno en cerrar la brecha en la } \\
\text { cobertura eléctrica en los próximos } 10 \text { años. }\end{array}$ & 0.08 & 1 & 0.1 & 1 & 0.1 & 1 & 0.1 & 2 & 0.2 & 1 & 0.1 \\
\hline $\begin{array}{l}\text { Sector eléctrico cuenta con un sistema } \\
\text { interconectado. }\end{array}$ & 0.21 & 2 & 0.2 & 2 & 0.2 & 3 & 0.3 & 3 & 0.3 & 2 & 0.2 \\
\hline $\begin{array}{l}\text { Nuevas tecnologías de sistemas para automatización } \\
\text { de las instalaciones. }\end{array}$ & 0.07 & 1 & 0.1 & 2 & 0.2 & 2 & 0.2 & 2 & 0.2 & 2 & 0.2 \\
\hline Migración de población. & 0.07 & 1 & 0.1 & 3 & 0.3 & 3 & 0.3 & 2 & 0.2 & 3 & 0.3 \\
\hline \multicolumn{12}{|l|}{ AMENAZAS } \\
\hline $\begin{array}{l}\text { El precio de petróleo y gas natural han mantenido un } \\
\text { comportamiento muy volátil en los últimos años. }\end{array}$ & 0.05 & 3 & 0.3 & 3 & 0.3 & 3 & 0.3 & 4 & 0.4 & 2 & 0.2 \\
\hline
\end{tabular}


Actualmente el tipo de cambio PEN/USD se ha

mantenido estable, sin embargo, los factores político

- económicos del país pueden generar volatilidad.

Perú es un país expuesto a desastres naturales

como sismos, tsunamis, e inundaciones los cuales

pueden afectar considerablemente la infraestructura

de EGP.

Nuevos competidores con grandes inversiones

Limitada disponibilidad de gas o recursos

Aumento de la rigurosidad en la leyes

medioambientales

Conflictos Sociales.

SUMA O y A

\section{FORTALEZAS}

Propiedad de ENEL (Italia).

Tiempo en el negocio hidráulico

Infraestructura para la generación hydro y térmico

Ubicación estratégica de las centrales

Liderazgo en generacion de energia

Contratos de largo plazo con clientes libres.

Networking con instituciones reguladoras.

Excelente imagen reputacional en el país

Eficiencia en la producción.

\section{DEBILIDADES}

Bajo estudio para desarrollo de nuevas

oportunidades de negocio (plantas renovables)
0.03

2

$0.2 \quad 3$

$0.3 \quad 3$

0.3

3

0.3

2

0.2

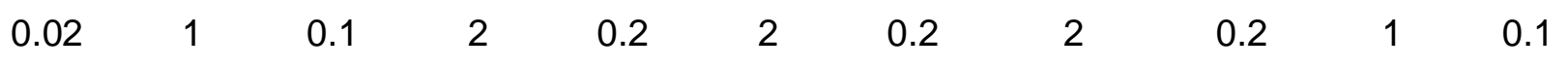

$\begin{array}{lllllllllll}0.03 & 1 & 0.1 & 2 & 0.2 & 2 & 0.2 & 1 & 0.1 & 3 & 0.3\end{array}$

$\begin{array}{lllllllllll}0.12 & 1 & 0.1 & 2 & 0.2 & 2 & 0.2 & 1 & 0.1 & 3 & 0.3\end{array}$

$\begin{array}{lllllllllll}0.07 & 2 & 0.2 & 3 & 0.3 & 4 & 0.4 & 2 & 0.2 & 3 & 0.3\end{array}$

0.05

0.2

0.1

\begin{tabular}{ccccc}
0.3 & 2 & 0.2 & 2 & 0.2 \\
\hline 3.50 & & 3.1 & & 2.9
\end{tabular}

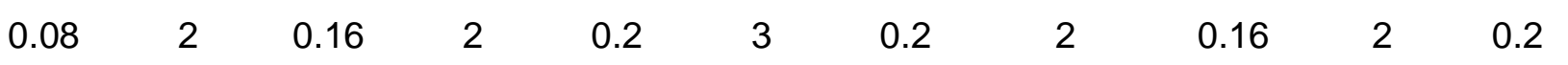

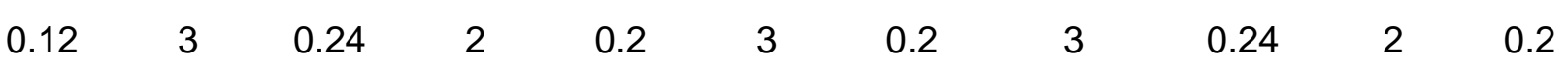

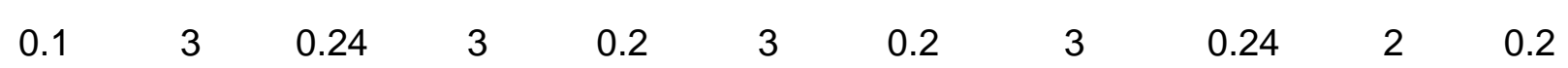

\begin{tabular}{|c|c|c|c|c|c|c|c|c|c|}
\hline 0.04 & 1 & 0.08 & 2 & 0.2 & 2 & 0.2 & 1 & 0.08 & 0.2 \\
\hline
\end{tabular}

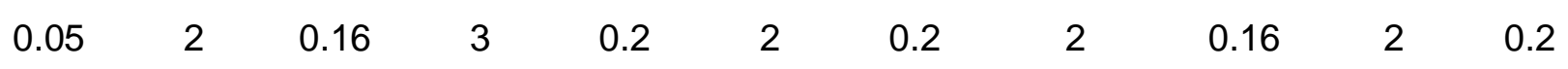

$\begin{array}{lllllllllll}0.11 & 2 & 0.16 & 2 & 0.2 & 2 & 0.2 & 2 & 0.16 & 3 & 0.2\end{array}$

\begin{tabular}{|c|c|c|c|c|c|c|c|c|}
\hline 0.07 & 1 & 0.08 & 1 & 0.1 & 2 & 0.2 & 1 & 0.08 \\
\hline
\end{tabular}

$\begin{array}{lllllllllll}0.08 & 1 & 0.08 & 2 & 0.2 & 2 & 0.2 & 1 & 0.08 & 2 & 0.2\end{array}$

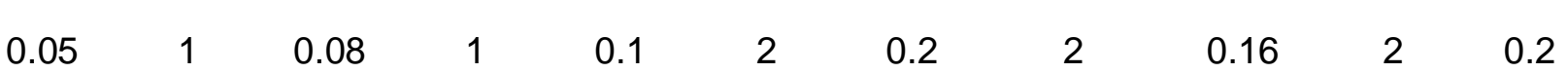

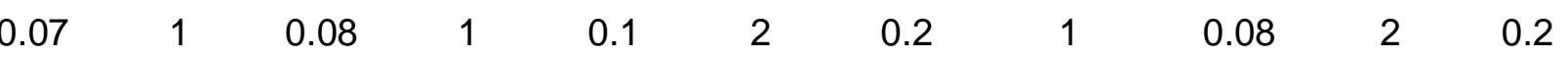




\begin{tabular}{|c|c|c|c|c|c|c|c|c|c|c|c|}
\hline $\begin{array}{l}\text { Cuellos de botellas para ejecución de proyectos } \\
\text { (dependencia) }\end{array}$ & 0.06 & 2 & 0.16 & 2 & 0.2 & 2 & 0.2 & 1 & 0.08 & 2 & 0.2 \\
\hline Bajo desarrollo de proyectos sociales sostenibles & 0.03 & 2 & 0.16 & 3 & 0.2 & 3 & 0.2 & 1 & 0.08 & 1 & 0.1 \\
\hline Baja repotenciación de plantas antiguas & 0.05 & 3 & 0.24 & 3 & 0.2 & 2 & 0.2 & 2 & 0.16 & 2 & 0.2 \\
\hline $\begin{array}{l}\text { Falta de comunicación entre áreas de staff y } \\
\text { negocio. }\end{array}$ & 0.03 & 1 & 0.08 & 1 & 0.1 & 1 & 0.1 & 1 & 0.08 & 2 & .2 \\
\hline Baja nivel de Control de contratistas. & 0.03 & 2 & 0.16 & 1 & 0.1 & 2 & 0.2 & 2 & 0.16 & 2 & 0.2 \\
\hline $\begin{array}{l}\text { Dependencia de personas en puestos clave, por falta } \\
\text { de transferencia de información }\end{array}$ & 0.03 & 1 & 0.08 & 2 & 0.2 & 2 & 0.2 & 1 & 0.08 & 1 & 0.1 \\
\hline Suma F y D & 1 & & 2.24 & & 2.5 & & 2.8 & & 2.08 & & 2.6 \\
\hline $\begin{array}{l}\text { SUMA DEL PUNTAJE DEL GRADO DE } \\
\text { ATRACCION }\end{array}$ & 2 & & 4.44 & & 5.88 & & 6.30 & & 5.18 & & 5.5 \\
\hline
\end{tabular}

$P A=$ Puntuación del grado de atractivo; $P T A=$ Puntuación total del grado de atractivo.

Escala del grado del atractivo: 1 = no atractivo; 2 = poco atractivo; 3 = razonablemente atractiva; 4 = muy atractiva.

Nota: Elaboración propia. Adaptado de Thompson, A.A.; Strickland III, A.J. Administración estratégica: Conceptos y casos, 11ª Edición, Irwin McGraw-Hill, México, 2001 


\subsection{Estrategia Elegida}

Estrategia 2: Reducir costos operativos. eficiencia de los procesos.

Estrategia 3: Inteligencia de Negocios, Incrementar cartera de nuevos clientes libres.

Las estrategias seleccionadas admitirán desarrollar y fortalecer una ventaja cuyo

potencial ya ha sido manifestado por el largo período de operaciones de Enel Generación Perú SAA con su presencia en el mercado peruano.

Sin embargo, la estrategia 2 de tecnología para el desarrollo de la generación de energía, implementando recursos renovables calidad, que se encuentra posicionada en el tercer lugar, no menos importante, pero con un sector que apuesta por el desarrollo de plantas que requieren recursos renovables y con una sobre oferta de energía en el mercado, no sería factible la implementación a corto plazo por lo cual dicha estrategia se rechaza.

\subsection{Descripción de Estrategia Contingente}

El desarrollar e implementación de nuevos proyectos de centrales renovables, reducen el tiempo y costo de instalación, del igual reduce la dependencia que tiene la compañía en generar energía mediante sus plantas instaladas usando recursos hídricos y de gas, esto representa factores que hacen vulnerable a Enel Generación Perú SAA. 


\section{Capítulo IX. Implantación de la Estrategia}

\subsection{Mapa de la Estrategia}

De acuerdo a D'Alessio (2013) "se puede ejercer una visión integral, holística de la organización; además, facilita la evaluación del desempeño por medición y comparación, lo que sirve para una implementación exitosa, porque se puede ver hacia dónde se está yendo y corregir si es necesario"

Para la elaboración del BSC se han contemplado los 4 objetivos estratégicos establecidos, vinculados a los ingresos, calidad, posicionamiento y eficiencia de procesos.

Para lograr fortalecer los objetivos estratégicos se ofrecerá un servicio con altos estándares de calidad, con información a tiempo real sobre el comportamiento de la entrega de energía y mejorando canales de comunicación hacia sus clientes como producto del servicio brindado.

El valor agregado que ofrécete Enel Generación Perú SAA, es brindar un servicio ininterrumpido.

Las características del servicio brindado son: alto costo de almacenamiento de energía lo que implica producir de acuerdo a la demanda, por otro lado una consecuencia que afecta directamente a los clientes es que no estén informados de los precios en el mercado spot, los cuales afectan directamente a ellos y que se ve reflejado por las variantes en la oferta y demanda.

Otra consecuencia es que los clientes mantienen un contrato por una cantidad de energía, la cual es brindada sin importar los cambios en los precios.

A continuación, se muestra el Mapa Estratégico BSC. 


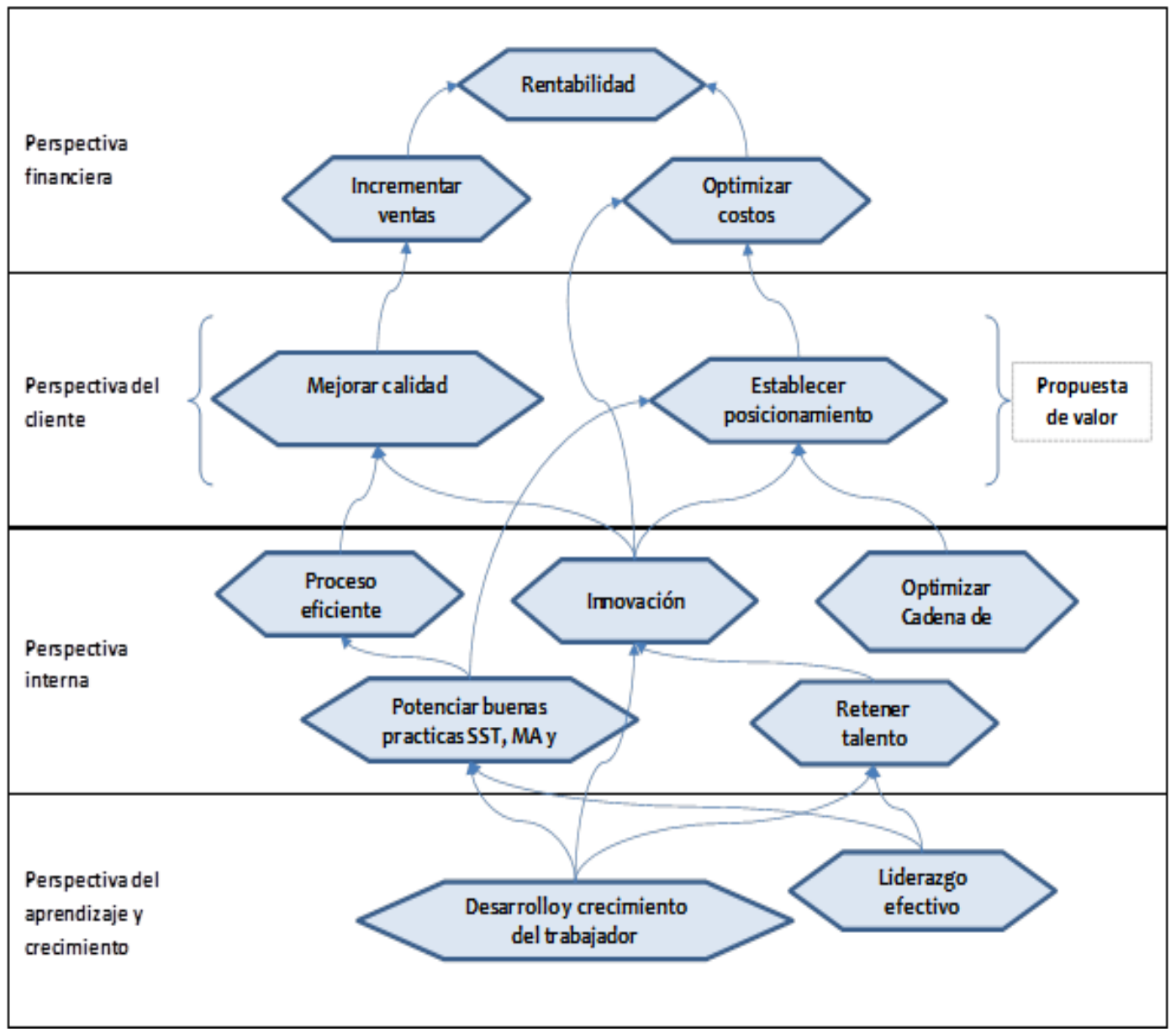

Figura 26. Mapa estratégico de Enel Generación Perú SAA.

Adaptado de "Planeamiento estratégico razonado", por F. A. D’Alessio, 2014.

\subsection{Objetivos Específicos Según Mapa de la Estrategia}

Según el Mapa Estratégico se establecen los objetivos específicos, alineado con la misión y visión.

Tabla 44

Objetivos específicos de acuerdo con el mapa de la estrategia

\begin{tabular}{ll}
\hline Perspectiva & Objetivos específicos \\
\hline Financiera & Reducir y mejorar costos operativos \\
& Incrementar las ventas \\
\hline \multirow{2}{*}{ Clientes } & Mejorar la calidad de los procesos operativos y de gestión. \\
& Lograr posicionamiento a través de la gestión comercial. \\
\hline & Invertir en máquinas eficientes en las centrales \\
& Invertir en la construcción de centrales hidroeléctricas \\
& Mejorar los procesos internos. \\
& Crear área de desarrollo e investigación \\
Interna-Procesos & Optimizar los recursos \\
& Crear eficiencia en procesos de generación. \\
\hline
\end{tabular}


Fomentar involucramiento de colaboradores

Aprendizaje y Crecimiento

Reestructurar la cultura de la empresa

Nota: Elaboración propia

\subsection{Indicadores para cada uno de los objetivos específicos}

El plan estratégico debe detallar los puntos de seguimiento para garantizar el cumplimiento de las metas establecidas.

Según Muñoz (2015) "Los indicadores deben usar los requisitos de relevancia, pertinencia, integración, independencia, oportunidad, homogeneidad, sencillez, confiabilidad, participativa, y que tengan un costo razonable, para una adecuada toma de decisiones; debe estar en constante actividad y ser factible de cambios de acuerdo con los nuevos procedimientos, protocolos, directivas, instructivos y normativas vigentes donde se tenga el compromiso de la Alta Dirección y la participación activa de los trabajadores que involucren personal asistencial, de apoyo y personal administrativo". 
Tabla 45

Indicadores para cada objetivo específico.

\begin{tabular}{|c|c|c|c|}
\hline \multirow{2}{*}{$\begin{array}{l}\text { Perspectiva } \\
\text { Financiera }\end{array}$} & Objetivos específicos & \multirow{2}{*}{$\begin{array}{c}\text { Indicador } \\
{[(C \vee \text { año } 0 \text { - CV año 1) / (CV año 0)]x }} \\
100 \%\end{array}$} & Unidades \\
\hline & Reducción y mejoramiento de los costos operativos & & $\%$ \\
\hline & Incrementar las ventas & Crecimiento de venta de energía eléctrica & $\%$ \\
\hline \multirow[t]{3}{*}{ Usuarios } & Mejorar la calidad de los procesos operativos y de gestión. & Procesos sin tiempos muertos & $\%$ \\
\hline & Incrementar participación a través de herramientas comerciales & Accidentabilidad & Unid. \\
\hline & & Numero de observaciones & $\%$ \\
\hline \multirow[t]{7}{*}{$\begin{array}{l}\text { Procesos - in } \\
\text { house }\end{array}$} & Invertir en máquinas eficientes & Implementación de nuevos sistemas & $\mathrm{SI} / \mathrm{NO}$ \\
\hline & Disminuir inversión en equipos de apoyo a la operación & [(Capex año 0 - año 1) / (año 0)] x 100\% & $\%$ \\
\hline & Mejorar los procesos operativos & [(Recup año 1 - año 0) / (año 0)] x 100\% & $\%$ \\
\hline & Crear área de desarrollo e investigación & Implementación del departamento & $\mathrm{SI} / \mathrm{NO}$ \\
\hline & Asegurar la optimización de recursos & Disponibilidad real/Disponibilidad objetivo & $\%$ \\
\hline & Eficiencia en los procesos internos. & Producción de energía x 100\% & $\%$ \\
\hline & Mejorar estándares de gestión de la producción de energía. & Disponibilidad de los grupos & $\mathrm{SI} / \mathrm{NO}$ \\
\hline \multirow[t]{2}{*}{$\begin{array}{l}\text { Aprendizaje y } \\
\text { Crecimiento }\end{array}$} & Fomentar el involucramiento de los colaboradores & [(S año 0 - S año 1) / S año 0)] x 100\% & $\%$ \\
\hline & Restructuración de la cultura de la empresa & Uso real / Uso disponible & $\%$ \\
\hline
\end{tabular}

Nota: Elaboración propia 


\subsection{Metas Para Cada Uno de los Objetivos Específicos}

Se han propuesto metas para los objetivos específicos, según las estrategias para Enel Generación Perú SAA, tomando como base el año base 2018, para lo cual se detalla los siguientes enfoques por cada perspectiva:

Perspectiva Financiera. El enfoque financiero en el sector de generación está determinado por el cumplimiento de los indicadores de gestión financiera que permitan a las empresas mantener su rentabilidad y capacidad para crear valor económico continuo en sus proyectos de transmisión. A su vez, el Estado debe asegurar que los indicadores económicos del país generen confianza a los inversionistas respecto al sector, para, de este modo, garantizar sus inversiones y promover los nuevos proyectos de generación eléctrica necesarios para el país en los próximos años. En suma, los indicadores financieros más relevantes en el sector son aquellos que están relacionados con la gestión de rentabilidad del costo marginal US\$ MWh.

Perspectiva Usuarios. Los indicadores del cliente establecen ratios para medir y controlar los cambios en la demanda de energía que afectan al sector, la satisfacción de los usuarios y los nuevos proyectos para alcanzar mayor demanda de energía. En este enfoque, la integración al Sistema Eléctrico Interconectado Nacional (SEIN) es muy relevante para alcanzar la competitividad en el sector en el nivel regional. Por ello, es importante la inversión en nuevas plantas de generación para el mercado interno y para exportar electricidad a otros países, debido a la mayor capacidad del sector para transportar energía a grandes distancias y con menor pérdida de electricidad (merma). Asimismo, es importante ampliar el portafolio de fuentes alternativas de energía -como la eólica y geotérmica, que permitan instalar nuevas redes de transmisión para atender a nuevos clientes.

Perspectiva procesos internos. Estos indicadores muestran la gestión del sector en su operatividad, así como el nivel de eficiencia y competitividad en sus procesos. En esta perspectiva es importante la agilidad en los procesos, así como, la integración de modernos sistemas de generación, lo cual generará mayor potencia instalada y reducirá las mermas en generación.

Perspectiva de aprendizaje y crecimiento. La evaluación de estos indicadores muestra la capacidad de cambio a través del liderazgo y aprendizaje para alcanzar la visión. Debido al riesgo latente en el negocio, es importante evaluar y monitorear los accidentes ocasionados por errores humanos en las actividades de mantenimiento de la infraestructura instalada y no instalada del sistema, es muy importante para la identificación de responsables y la definición de las tareas del día a día. Asimismo, es 
muy importante contar con personal altamente capacitado para la nueva tecnología en el sector. 
Tabla 46

Metas Para Cada Uno de los Objetivos Específicos

\begin{tabular}{|c|c|c|c|c|}
\hline Perspectiva & Objetivos específicos & Indicador & Unidades & Actual \\
\hline \multirow[t]{3}{*}{ Financiera } & $\begin{array}{c}\text { Reducción y mejoramiento de los costos } \\
\text { operativos }\end{array}$ & $\begin{array}{c}\text { [(CV año } 0 \text { - CV año 1) / (CV año } \\
0)] \times 100 \%\end{array}$ & $\%$ & $3.6 \%$ \\
\hline & Incrementar las ventas & Cantidad de MW mensual & $\%$ & 2,669 \\
\hline & $\begin{array}{l}\text { Mejorar la calidad de los procesos operativos } \\
\text { y de gestión. }\end{array}$ & $\begin{array}{l}\text { Cumplimiento de programa de } \\
\text { proyectos de inversión }\end{array}$ & $\%$ & $0.91 \%$ \\
\hline \multirow[t]{3}{*}{ Usuarios } & & $\begin{array}{l}\text { Estrategias comerciales } \\
\text { optimizadas }\end{array}$ & $\begin{array}{l}\text { Margen de ventas } \\
\%\end{array}$ & 8.86 \\
\hline & $\begin{array}{c}\text { Incrementar participación a través de } \\
\text { herramientas comerciales. }\end{array}$ & Implementar programas de RSE & $\%$ & 90 \\
\hline & & $\begin{array}{l}\text { Mejorar los niveles de gestión de } \\
\text { la producción }\end{array}$ & $\%$ & 96 \\
\hline \multirow{8}{*}{$\begin{array}{l}\text { Perspectiva } \\
\text { Procesos - In house }\end{array}$} & Objetivos específicos & Indicador & Unidades & Actual \\
\hline & Invertir en equipos eficientes de planta & Instalación de equipos & $\mathrm{SI} / \mathrm{NO}$ & SI \\
\hline & $\begin{array}{c}\text { Disminuir inversión en equipos de apoyo a la } \\
\text { operación }\end{array}$ & $\begin{array}{l}\text { [(Capex año } 0 \text { - Capex año 1) / } \\
(\text { capex año 0)] x 100\% }\end{array}$ & $\%$ & $6.5 \%$ \\
\hline & Mejorar los procesos de producción & $\begin{array}{c}\text { [(Recup año } 1 \text { - Recup año 0) / } \\
(\operatorname{Rec} \text { año 0)] x 100\% }\end{array}$ & $\%$ & 91 \\
\hline & $\begin{array}{l}\text { Implementar departamento de } \\
\text { innovación/investigación }\end{array}$ & Instalación de departamento & $\mathrm{SI} / \mathrm{NO}$ & SI \\
\hline & Asegurar la optimización de recursos & $\begin{array}{l}\text { Disponibilidad real/Disponibilidad } \\
\text { objetivo }\end{array}$ & $\%$ & 95 \\
\hline & Eficiencia en los procesos internos & $\begin{array}{c}{[(\text { Producción MW -) / MW año 0)] x }} \\
100 \%\end{array}$ & $\%$ & 45 \\
\hline & $\begin{array}{l}\text { Mejorar estándares de gestión de la } \\
\text { producción de energía }\end{array}$ & Realización de auditorias & $\mathrm{SI} / \mathrm{NO}$ & $\mathrm{SI}$ \\
\hline
\end{tabular}




\begin{tabular}{lcc}
\hline $\begin{array}{l}\text { Aprendizaje y } \\
\text { Crecimiento }\end{array}$ & $\begin{array}{c}\text { Fomentar el involucramiento de los } \\
\text { colaboradores satisfacción del personal }\end{array}$ & {$\left[\begin{array}{c}(\mathrm{S} \text { año } 0-\mathrm{S} \text { año 1) / S año 0)] } \mathrm{x} \\
100 \%\end{array}\right.$} \\
Restructuración de la cultura de la empresa & Uso real / Uso disponible \\
\hline
\end{tabular}

Nota: Elaboración propia

\subsection{Iniciativas (Acciones a Llevar a Cabo Para Cada Uno de los Objetivos Específicos) Estrategias, Programas, Políticas, Reglas,}

\section{Procedimiento}

En la tabla 47 se ilustra iniciativas propuestas para ejecución de los objetivos específicos.

Tabla 47

Iniciativas para cada uno de los objetivos-Perspectiva financiera y clientes

\begin{tabular}{lll}
\hline Perspectiva & Objetivos específicos & Iniciativas \\
\hline Financiera & Reducción y mejoramiento de los costos operativos & Implantación de costos ABC \\
\cline { 2 - 3 } & Mejorar la calidad de los procesos operativos y de gestión. & Creación de área de desarrollo de negocio \\
\cline { 2 - 3 } & $\begin{array}{l}\text { Incrementar participación a través de herramientas } \\
\text { Usuarios }\end{array}$ & Benchentificación de nuevos usuarios \\
\hline
\end{tabular}


Desarrollar canal de comunicación para sensibilización seguridad y ambiental

\begin{tabular}{|c|c|c|}
\hline Perspectiva & Objetivos específicos & Iniciativas \\
\hline \multirow{7}{*}{$\begin{array}{l}\text { Procesos - In } \\
\text { house }\end{array}$} & Invertir en equipos eficientes de planta & Automatización de plantas. \\
\hline & Disminuir inversión en equipos de apoyo a la operación & $\begin{array}{l}\text { Desarrollar indicadores de } \\
\text { rentabilidad por equipo }\end{array}$ \\
\hline & Mejorar los procesos de producción & Aplicar estándares de calidad. \\
\hline & Implementar departamento de innovación/investigación & $\begin{array}{l}\text { Crear área de Desarrollo de } \\
\text { negocios. }\end{array}$ \\
\hline & Asegurar la optimización de recursos & $\begin{array}{l}\text { Correcta planificación de } \\
\text { mantenimientos. }\end{array}$ \\
\hline & Eficiencia en los procesos internos & $\begin{array}{l}\text { Desarrollo y/o actualización de } \\
\text { procedimientos. }\end{array}$ \\
\hline & Mejorar estándares de gestión de la producción de energía & $\begin{array}{l}\text { Análisis de los sistemas principales } \\
\text { de planta. }\end{array}$ \\
\hline \multirow{2}{*}{$\begin{array}{l}\text { Aprendizaje y } \\
\text { Crecimiento }\end{array}$} & Fomentar el involucramiento de los colaboradores satisfacción del personal & $\begin{array}{l}\text { Emplear sistemas de motivación e } \\
\text { incentivos }\end{array}$ \\
\hline & Reestructuración de la cultura de la empresa & $\begin{array}{l}\text { Servicio externo para } \\
\text { implementación sistema de gestión } \\
\text { ERP }\end{array}$ \\
\hline
\end{tabular}

\section{Nota: Elaboración propia}




\subsection{Responsable de Cada Una de las Iniciativas}

En la Tabla 48 se puede apreciar los responsables asignados para cada una de las iniciativas propuestas, y de esta manera poder desarrollar las estrategias.

Tabla 48

Responsables

\begin{tabular}{ll}
\hline Iniciativas & Responsables \\
\hline Implantación de costos ABC & Gerencia comercial y subgerencia de mercado \\
Identificación de nuevos usuarios & $\begin{array}{l}\text { Gerencia comercial y subgerencia de mercado } \\
\text { Crear área de desarrollo de negocios } \\
\text { Benchmarking con empresas del grupo Enel. }\end{array}$ \\
Desarrollar canal de comunicación para sensibilización seguridad y ambiental & Gerencia comercial y subgerencia de mercado \\
Automatización de plantas. & Gerencia Operación \\
Desarrollar indicadores de rentabilidad por equipo & Gerencia comercial y gerencia de explotación \\
Aplicar estándares de calidad & Gerencia comercial y gerencia de explotación \\
Correcta planificación de mantenimientos. & Gerencia Operación \\
Desarrollo y/o actualización de procedimientos. & Gerencia Operación \\
Análisis de los sistemas principales de planta & Gerencia Operación \\
Emplear sistemas de motivación e incentivos & Gerencia General y Recursos Humanos \\
Servicio externo para implementación sistema de gestión ERP & Gerencia General e ICT \\
\hline
\end{tabular}

Nota: Elaboración propia 


\subsection{Presupuesto de Cada Una de las Iniciativas}

En la Tabla 49 se detalla el presupuesto de cada una de las iniciativas para los 5 años.

Tabla 49

Presupuesto de las iniciativas

\begin{tabular}{ll}
\hline \multicolumn{1}{c}{ INICIATIVAS } & \multicolumn{1}{c}{ DETALLE } \\
\hline Implementación de costos ABC & $\begin{array}{l}\text { Curso de Costeo por actividades a personal clave de la } \\
\text { empresa y consultoria para situación actual. }\end{array}$ \\
Identificación de nuevos clientes libres y su & $\begin{array}{l}\text { Seguimiento y control de la jefatura de costos (auditoria) } \\
\text { Estudio de viabilidad para aplicación e instalación de }\end{array}$
\end{tabular}

ubicación geografica

Instalar un departamento de

Innovación/Investigación. maquinarias.

Año

Año

Año

Año

Año

2019

2020

2021

2022

2023

Ejecución de infraestructura para personal y equipamiento

Evaluación de escenarios de Riesgo

(Benchmarking con empresas del Grupo Enel)

Implementación de módulos de entrenamiento práctico equipados para simular las condiciones de alto riesgo. Capacitación en habilidades de prevención en riesgos críticos para empresa y contratistas.

Desarrollo de canales de comunicación para sensibilizacion de Seguridad y Ambiental

Implementación del programa de actividades de concientización dentro de la empresa

Contratacion de asesoria para la evaluacion e informe de

la situacion operativa e implementacion de cambios de los equipos principales de las plantas (reguladores de tensión y velocidad, tubinas, generadores, obras civiles)

Establecer un programa de reducción de costos por área y

Programa de Incentivos

un plan de bonos por cumplimiento de objetivos.

Contratar consultora externa, para que realice el

Contratar asesoría para implementar un sistema levantamiento de informacion, informe e implementacion de los cambios

de gestión de mantenimiento- Reingeniería del proceso de mantenimiento. 
Crear puesto dentro del area se deguridad y medio ambiente un Perfil de calidad de los sistemas de seguridad para todas las plantas

\section{El puesto debe hacer una analisis de como se encuentran} los sistemas y subsistemas de las diferentes plantas en cuanto al funcionamiento con el apoyo de la contratacion de una empresa especializada en sguridad de energia

Implementar programas de meritocracia y plan de desarrollo individual para el personal

Generar plan de desarrollo individual y meritocracia para puestos claves

Aprovechamiento del recurso hidro en plantas ya instaladas

Contratar empresa consultora, implementación y lincencias

\section{TOTAL}

Nota: Elaboración propia

Construccion de plantas minihidro

Contratar asesoría externa para el desarrollo del ERP (SAP) 


\subsection{Cronograma de Cada Una de las Iniciativas}

En la Tabla 50, se ilustra programación de cada iniciativa para Enel Generación Perú SAA.

Tabla 50

Cronograma de cada una de las iniciativas

\begin{tabular}{|c|c|c|c|c|c|c|}
\hline Iniciativas & Responsable & Año 2019 & Año 2020 & Año 2021 & Año 2022 & Año 2023 \\
\hline Implantación de costos $\mathrm{ABC}$ & $\begin{array}{l}\text { Gerencia comercial y subgerencia } \\
\text { de mercado }\end{array}$ & & & & & \\
\hline $\begin{array}{l}\text { Identificación de clientes libres en los } \\
\text { sectores de mayor crecimiento económico }\end{array}$ & $\begin{array}{l}\text { Gerencia comercial y subgerencia } \\
\text { de mercado }\end{array}$ & & & & & \\
\hline $\begin{array}{l}\text { Instalar un departamento de } \\
\text { Innovación/Investigación }\end{array}$ & Gerencia de operaciones & & & & & \\
\hline $\begin{array}{l}\text { Implementación de módulos de } \\
\text { entrenamiento práctico equipados para } \\
\text { simular las condiciones de alto riesgo. }\end{array}$ & Gerencia comercial y subgerencia & & & & & \\
\hline $\begin{array}{l}\text { Capacitación en habilidades de } \\
\text { prevención en riesgos críticos para } \\
\text { empresa y contratistas. }\end{array}$ & de mercado & & & & & \\
\hline $\begin{array}{l}\text { Implementación del programa de } \\
\text { actividades de concientización ambiental }\end{array}$ & $\begin{array}{l}\text { Gerencia comercial y subgerencia } \\
\text { de mercado. }\end{array}$ & & & & & \\
\hline $\begin{array}{l}\text { Establecer un comité de gestión para } \\
\text { elaboración del Informe de principios de } \\
\text { BGC }\end{array}$ & $\begin{array}{l}\text { Gerencia comercial y subgerencia } \\
\text { de mercado. }\end{array}$ & & & & & \\
\hline $\begin{array}{l}\text { Renovación de maquinarias. } \\
\text { Asesoría para potenciar las competencias. }\end{array}$ & $\begin{array}{l}\text { Gerencia comercial y gerencia de } \\
\text { explotación }\end{array}$ & & & & & \\
\hline $\begin{array}{l}\text { Establecer un programa de reducción de } \\
\text { costos por área y un plan de bonos por } \\
\text { cumplimiento de objetivos. }\end{array}$ & $\begin{array}{l}\text { Gerencia comercial y gerencia de } \\
\text { explotación. }\end{array}$ & & & & & \\
\hline Aplicar estándares de calidad. & $\begin{array}{l}\text { Gerencia comercial y gerencia de } \\
\text { explotación. }\end{array}$ & & & & & \\
\hline
\end{tabular}


Instalar un departamento de

Innovación/Investigación

Contratar asesoría para implementar un

sistema de gestión de mantenimiento-

Reingeniería del proceso de

mantenimiento.

Contratar asesoría externa para mejorar

parámetros técnicos en planta

Establecer un Ing. Seguridad por áreas

críticas.

Contratar auditoria externa al sistema

integrado de gestión.

Instalar un centro de capacitación en

competencias técnicas y personales

Implementar programas de meritocracia y

plan de desarrollo individual

Contratar asesoría externa ORACLE para

el desarrollo del ERP.

Profis - Proyecto de Generación

hidroeléctrico

Nota: Elaboración propia
Gerencia de operaciones

Gerencia comercial y gerencia de

explotación.

Gerencia comercial y gerencia de explotación

Gerencia comercial y gerencia de explotación

Gerencia General.

Jefatura de Sistemas

Gerencia comercial y gerencia de explotación.
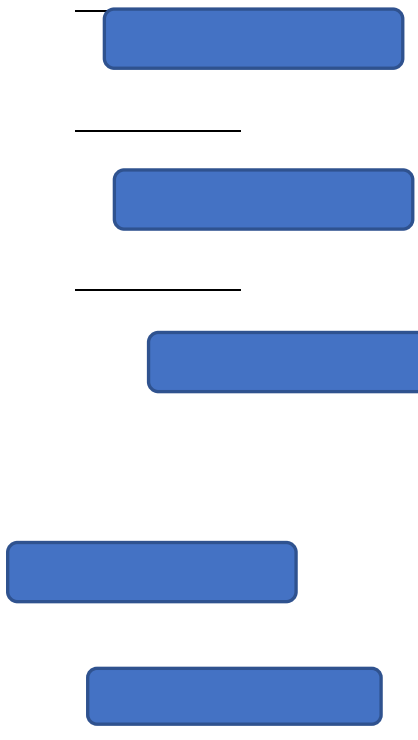

$+2$ 


\section{Capítulo X. Evaluación}

\subsection{Evaluación Cualitativa}

En el presente capitulo se revisa las estrategias, teniendo como input los factores internos y externos.

Según Diez de Castro \& Redondo López (1996) "El proceso de evaluación de estrategias, debe iniciar un cuestionamiento gerencial sobre expectativas y supuestos, generar una revisión de objetivos y valores, y por último estimular la creatividad en la generación de alternativas y criterios de evaluación". En tal sentido, para la realización de las proyecciones se han tomado en cuenta criterios cuantitativos que son válidos para formular proyecciones; en efecto, es importante tomar cifras que sean confiables y válidas para poder tener escenarios apropiados y que posteriormente concuerden o se aproximen con lo esperando en la implementación del plan estratégico.

\subsubsection{Criterios de Evaluación.}

De acuerdo a Rumelt (1980) "cualquier criterio se puede usar siempre y cuando tenga lógica y coherencia, lo que se desea es ver si las estrategias que se están implementando van por buen camino o no. Rumelt planteó que, en la revisión de las estrategias, en primer lugar, se debe evaluar la consistencia y consonancia, luego la factibilidad y se ha de cerrar con la evaluación de la ventaja". Lo dicho se da desde el escenario de tipo cualitativo, donde se analizan las características sustanciales para poder plantear estrategias que sean el complemento de la estrategia general.

"La consistencia evalúa que la estrategia no presente objetivos ni políticas inconsistentes y que no haya objetivos ni políticas en conflicto. Muchas veces los especialistas, resuelven sus problemas específicos pero su solución puede afectar otras áreas de la organización" (Rumelt, 1980). En el análisis económico - financiero se han tomado en cuenta indicadores bases como el PBI y otros indicadores macroeconómicos extraídos del análisis macroeconómico del BCRP.

\subsubsection{Comparación de la Estrategia con los Criterios.}

A continuación, se muestra el análisis realizado para Enel Generación Perú SAA, donde se ha tomado en cuenta la macro estrategia o gran estrategia (Ver Tabla 49). 
Tabla 51

Análisis de Rumelt de estrategias

\begin{tabular}{|c|c|c|c|c|c|}
\hline Iniciativas & Consistencia & Consonancia & Ventaja & Factibilidad & ¿Se acepta? \\
\hline Implantación de costos $A B C$ & SI & $\mathrm{SI}$ & SI & SI & SI \\
\hline Identificación de nuevos usuarios & SI & SI & SI & SI & SI \\
\hline Crear área de desarrollo de negocios & SI & $\mathrm{SI}$ & SI & SI & SI \\
\hline Benchmarking con empresas del grupo Enel. & SI & $\mathrm{SI}$ & SI & SI & SI \\
\hline $\begin{array}{l}\text { Desarrollar canal de comunicación para } \\
\text { sensibilización seguridad y ambiental }\end{array}$ & SI & $\mathrm{SI}$ & SI & SI & SI \\
\hline Automatización de plantas. & SI & $\mathrm{SI}$ & $\mathrm{SI}$ & $\mathrm{SI}$ & SI \\
\hline Desarrollar indicadores de rentabilidad por equipo & SI & $\mathrm{SI}$ & SI & SI & SI \\
\hline Aplicar estándares de calidad & SI & $\mathrm{SI}$ & SI & SI & SI \\
\hline Correcta planificación de mantenimientos & SI & SI & SI & SI & SI \\
\hline Desarrollo y/o actualización de procedimientos. & SI & $\mathrm{SI}$ & SI & SI & SI \\
\hline Análisis de los sistemas principales de planta & SI & $\mathrm{SI}$ & SI & SI & SI \\
\hline Emplear sistemas de motivación e incentivos & SI & $\mathrm{SI}$ & SI & SI & SI \\
\hline $\begin{array}{l}\text { Servicio externo para implementación sistema de } \\
\text { gestión ERP. }\end{array}$ & SI & SI & SI & SI & SI \\
\hline
\end{tabular}

Nota: Elaboración propia

\subsection{Evaluación Financiera de la Estrategia}

Se requieren contar con cifras que sean confiables y que también le den un soporte de tipo económico financiero con proyecciones que no tengan amplia dispersión a lo sucedido.

\subsubsection{Proyección de Estados Financieros. (Situación Actual y con la Nueva}

\section{Estrategia)}

El 2014 presentó una disminución de 5\% en las ventas respecto al año anterior, pero la utilidad neta del 2014 se mostró superior al año 2013 pese a tener dicha reducción en las ventas (Facturación 2013 - S/. 1,347,273 / Facturación 2014 - S/. 1,284,263), esto, debido al incremento de los trabajos de manutención en las centrales. Por lo tanto, se hizo necesario trabajar con datos que han sido tomados de la serie histórica de los años que no han sido evaluados de manera estratégica. En la Tabla 50, se presentan las aproximaciones de los indicadores que se han tomado en cuenta en un escenario moderado, el análisis se ha realizado con una proyección sin estrategia y con estrategia. 
La simulación sin estrategia se considera con indicadores más bajos en comparación a lo esperado en la implementación del plan y en un futuro escenario con la implementación se tengan mayores utilidades. Para cumplir las expectativas de formularlo con estrategia se han tomado en cuenta los criterios porcentuales que se aprecian en la Tabla. Cabe resaltar que en el incremento de ingresos y reducción del costo de ventas se contempla la implementación de la Construcción de una Hidroeléctrica con Energía Renovable la cual mejoraría los resultados económicos y financieros de Enel Generación Perú SAA, en los próximos años.

Los datos son sustentados en base a información histórica y tendencias presentadas, donde:

1. Crecimiento en $3 \%$ anual de la producción de energía en los próximos 5 años, por mayor. (El comercio, economía)

2. Crecimiento de $1 \%$ anual del precio por Mwh del 2019 a 2025, se muestra que hay tendencia al alza como en los últimos 8 años, en base a estos datos el plan estratégico busca aprovechar estas alzas con mayor producción. (RPP, mercados)

3. Reducción de costos operativos en $5 \%$ anual por los próximos 5 años debido a las eficiencias que se plantean y la inversión en maquinaria moderna que permite aprovechar las tendencias que se muestran los últimos años.

Tabla 52

Principales variables y supuestos

Variables de crecimiento del sector-

Empresa

\begin{tabular}{|c|c|c|c|c|c|}
\hline 1 & $\begin{array}{r}\text { Año } \\
2019 \\
\end{array}$ & $\begin{array}{r}\text { Año } \\
2020 \\
\end{array}$ & $\begin{array}{r}\text { Año } \\
2021 \\
\end{array}$ & $\begin{array}{r}\text { Año } \\
2022 \\
\end{array}$ & $\begin{array}{r}\text { Año } \\
2023 \\
\end{array}$ \\
\hline \multirow{3}{*}{$\begin{array}{l}\text { Producción Energía Mwh } \\
\text { Precio promedio por } \\
\text { (PEN/MwH) }\end{array}$} & $11,334.4$ & $11,674.4$ & $12,024.7$ & $12,385.4$ & $12,757.0$ \\
\hline & 4 & 7 & 0 & 4 & 1 \\
\hline & 132.03 & 133.35 & 134.69 & 136.03 & 137.39 \\
\hline $\begin{array}{l}\text { Producción Energía Mwh } \\
\text { Precio promedio por }\end{array}$ & $3 \%$ & $3.0 \%$ & $3.0 \%$ & $3.0 \%$ & $3.0 \%$ \\
\hline$(\mathrm{PEN} / \mathrm{MwH})$ & $1 \%$ & $1.0 \%$ & $1.0 \%$ & $1.0 \%$ & $1.0 \%$ \\
\hline
\end{tabular}

Indicadores proyectados/ con Estrategia

Perspectiva Financiera

Incremento Generación de Energía

\begin{tabular}{rrrrr}
2019 & 2020 & 2021 & 2022 & 2023 \\
\hline $3 \%$ & $3.0 \%$ & $3.0 \%$ & $3.0 \%$ & $3.0 \%$ \\
$1.0 \%$ & $1.0 \%$ & $1.0 \%$ & $1.0 \%$ & $1.0 \%$
\end{tabular}

Inc. Ingresos 
Costo de ventas (Se reduce)

Red. Gast. Ope

Perspectiva Financiera

Inc. Ingresos

Red. Gast. Ope
$-5.0 \% \quad-5.0 \% \quad-5.0 \% \quad-5.0 \% \quad-5.0 \%$

$-1.0 \% \quad-1.0 \% \quad-1.0 \% \quad-1.0 \% \quad-1.0 \%$

Indicadores proyectados/ sin Estrategia

Nota: Elaboración propia

\begin{tabular}{lllll}
2019 & 2020 & 2021 & 2022 & 2023 \\
\hline $3.3 \%$ & $4.3 \%$ & $2.0 \%$ & $2.0 \%$ & $2.0 \%$ \\
$4.6 \%$ & $4.7 \%$ & $4.9 \%$ & $5.0 \%$ & $5.2 \%$
\end{tabular}

10.2.2. Estado de Resultados. (Situación Actual y Nueva Estrategia)

Según datos de cada de diferentes años se elabora el Estado de Ganancias y Pérdidas de Enel Generación Perú SAA, en nuevos soles, donde se muestran los resultados históricos de los ejercicios del 2015 al 2016 (sin considerar la estrategia) y los años 2019 al 2023 se muestra el estado de resultados (considerando la implementación de la estrategia), pudiendo ver una mejora en la rentabilidad.

Situación nueva estrategia: Las proyecciones se realizan en base a la iniciativas planteadas, debido que dicha estrategia permite enfocar los recursos para la búsqueda o identificación de nuevas oportunidades de negocio en lo que respecta a nuevas instalaciones que, si bien es cierto, se debe realizar una inversión, pero a largo plazo permitirá obtener beneficios debido a la identificación de nuevas tecnologías que mejoren los sistemas de producción de cada planta convencional e incrementar los ingresos al contar con nuevas fuentes de energía (minihidro) que usan el mismo recurso hídrico de las plantas convencionales.

A continuación, se muestra los Estados de Resultados Proyectados, donde se ha utilizado para los años a evaluar el porcentaje de crecimiento promedio del sector energético como tasa referencial siendo este $2.7 \%$. (Ver Tabla 51). 
Tabla 53

Estado de Resultados: Situación Actual S/.

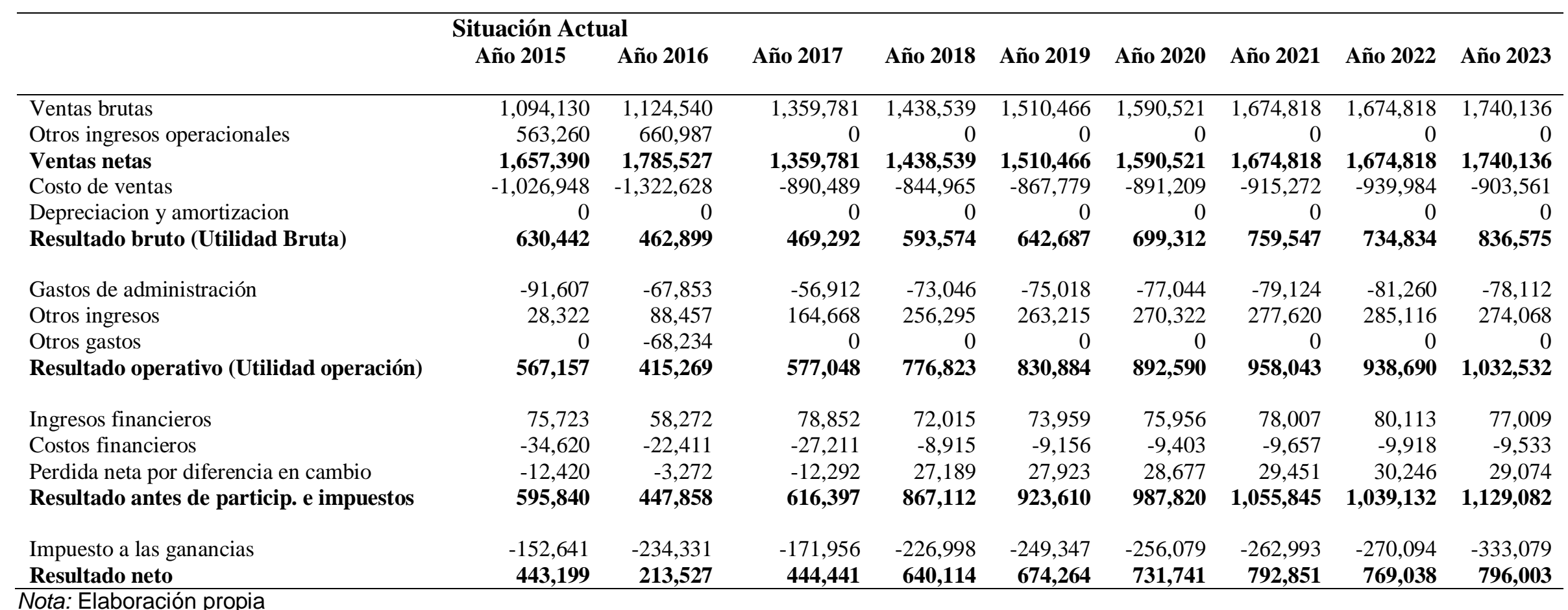


Tabla 54

Estado de Resultados: Situación Nueva Estrategia, S/. (000)

\begin{tabular}{|c|c|c|c|c|c|c|c|c|c|}
\hline & $\begin{array}{l}\text { Año } \\
2015\end{array}$ & $\begin{array}{l}\text { Año } \\
2016\end{array}$ & $\begin{array}{l}\text { Año } \\
2017\end{array}$ & $\begin{array}{l}\text { Año } \\
2018\end{array}$ & $\begin{array}{l}\text { Año } \\
2019\end{array}$ & $\begin{array}{l}\text { Año } \\
2020\end{array}$ & $\begin{array}{l}\text { Año } \\
2021\end{array}$ & $\begin{array}{l}\text { Año } \\
2022\end{array}$ & $\begin{array}{l}\text { Año } \\
2023\end{array}$ \\
\hline Ventas brutas & $1,094,130$ & $1,124,540$ & $1,359,781$ & $1,438,539$ & $1,496,512$ & $1,556,822$ & $1,619,561$ & $1,684,830$ & $1,752,728$ \\
\hline $\begin{array}{l}\text { Ganancia neta por liquidacion de contratos } \\
\text { derivados }\end{array}$ & 563,260 & 660,987 & - & 0 & , & $2,0=0,0-1$ & 0 & , & , \\
\hline Ventas netas & $\begin{array}{r}1,657,390 \\
-\end{array}$ & $\begin{array}{r}1,785,527 \\
-\end{array}$ & $1,359,781$ & $1,438,539$ & $1,496,512$ & $\mathbf{1 , 5 5 6 , 8 2 2}$ & $1,619,561$ & $1,684,830$ & $1,752,728$ \\
\hline Costo de ventas & $1,026,948$ & $1,322,628$ & $-890,489$ & $-844,965$ & $-802,717$ & $-762,581$ & $-724,452$ & $-688,229$ & $-653,818$ \\
\hline Depreciacion y amortizacion & 0 & 0 & 0 & 0 & 0 & 0 & 0 & 0 & 0 \\
\hline Resultado bruto (Utilidad Bruta) & 630,442 & 462,899 & 469,292 & $\mathbf{5 9 3 , 5 7 4}$ & 693,795 & 794,241 & 895,110 & 996,601 & $1,098,911$ \\
\hline Gastos de administración & $-91,607$ & $-67,853$ & $-56,912$ & $-73,046$ & $-72,316$ & $-71,592$ & $-70,876$ & $-70,168$ & $-69,466$ \\
\hline Otros ingresos & 28,322 & 88,457 & 164,668 & 256,295 & 169,807 & 196,923 & 207,675 & 191,468 & 198,689 \\
\hline Otros gastos & 0 & $-68,234$ & 0 & 0 & 0 & 0 & 0 & 0 & 0 \\
\hline Resultado operativo (Utilidad operación) & 567,157 & 415,269 & 577,048 & $\mathbf{7 7 6 , 8 2 3}$ & 791,286 & 919,571 & $1,031,908$ & $1,117,901$ & $1,228,133$ \\
\hline Ingresos financieros & 75,723 & 58,272 & 78,852 & 72,015 & 69,713 & 73,527 & 71,752 & 71,664 & 72,314 \\
\hline Costos financieros & $-34,620$ & $-22,411$ & $-27,211$ & $-8,915$ & $-19,512$ & $-18,546$ & $-15,658$ & $-17,905$ & $-17,370$ \\
\hline Pérdida neta por diferencia en cambio & $-12,420$ & $-3,272$ & $-12,292$ & 27,189 & 0 & 0 & 0 & 0 & 0 \\
\hline Resultado antes de particip. e impuestos & 595,840 & 447,858 & 616,397 & 867,112 & 841,487 & $\mathbf{9 7 4 , 5 5 2}$ & $1,088,002$ & $1,171,659$ & $1,283,078$ \\
\hline Impuesto a las ganancias & $-152,641$ & $-234,331$ & $-171,956$ & $-226,998$ & $-235,616$ & $-272,875$ & $-304,641$ & $-328,065$ & $-359,262$ \\
\hline Resultado neto & 443,199 & 213,527 & 444,441 & 640,114 & 605,871 & 701,677 & 783,361 & 843,595 & $\mathbf{9 2 3 , 8 1 6}$ \\
\hline
\end{tabular}

Nota: Elaboración propia 


\subsubsection{Balance General. (Situación Actual y con la Nueva Estrategia)}

Los resultados que se en la Tabla 53 se han elaborado con los presupuestos que contamos de Enel Generación Perú SAA, de las cuentas del estado financiero.

El balance indica cual será el patrimonio líquido del Enel Generación Perú SAA. De acuerdo a la proyección. En la gestión del 2017 del escenario normal (sin estrategia), se muestra el saldo de caja en Miles S/. 537,060, y para el período 2023 mejora este dato en Miles de S/. 1,310,554. Sin embargo, con la aplicación de la estrategia el saldo de caja mejor en el año 2023 en Miles S/. 1,819,666.

Con respecto al patrimonio contable, este capital se mantiene en S/. 2,498,101 no requiriendo un aumento del mismo en la gestión de estudio. El escenario que muestra el balance es positivo lo cual es un indicador que la estrategia es coherente. 
Tabla 55

Balance General: Situación Actual, S/.

\begin{tabular}{|c|c|c|c|c|c|c|c|c|c|}
\hline & \multicolumn{9}{|c|}{ Situación Actual } \\
\hline & 2015 & 2016 & 2017 & 2018 & 2019 & 2020 & 2021 & 2022 & 2023 \\
\hline \multicolumn{10}{|l|}{$\underline{\text { ACTIVO }}$} \\
\hline \multicolumn{10}{|l|}{ ACTIVO CORRIENTE } \\
\hline Efectivo y equivalentes de efectivo & 79,052 & 534,068 & 272,394 & 537,060 & 679,216 & 682,639 & 925,970 & 834,450 & $1,310,554$ \\
\hline Cuentas por cobrar comerciales y diversas, neto & 317,596 & 168,873 & 198,058 & 191,490 & 417,515 & 455,436 & 647,813 & 837,053 & $1,401,393$ \\
\hline Cuentas por cobrar relacionadas & 32,153 & 80,937 & 500,535 & 319,958 & 143,097 & 173,031 & 209,227 & 252,995 & 231,111 \\
\hline Existencias & 74,954 & 70,513 & 72,102 & 75,984 & 124,667 & 150,746 & 182,280 & 220,411 & 201,346 \\
\hline Gastos pagados por anticipado & 24,828 & 24,731 & 1,646 & 2,498 & 43,724 & 52,871 & 63,931 & 77,305 & 70,618 \\
\hline TOTAL ACTIVO CORRIENTE & 528,583 & 879,122 & $1,044,735$ & $1,126,990$ & $1,408,219$ & $1,514,723$ & $2,029,222$ & $2,222,214$ & $3,215,021$ \\
\hline \multicolumn{10}{|l|}{ ACTIVO NO CORRIENTE } \\
\hline Cuentas por cobrar a entidades relacionadas & 6,140 & 0 & 0 & 0 & 0 & 429,718 & 488,994 & 674,325 & 674,326 \\
\hline Inversiones & 360,511 & 360,511 & 360,511 & 187,718 & 637,383 & 770,717 & 814,018 & $1,126,894$ & 970,456 \\
\hline Propiedades, plantas y equipos, neto & $3,061,717$ & $2,848,355$ & $2,760,372$ & $2,827,442$ & $2,755,551$ & $2,685,488$ & $2,617,206$ & $2,550,660$ & $2,485,807$ \\
\hline Activos, intangible, neto & 52,307 & 53,237 & 54,856 & 69,409 & 94,123 & 113,812 & 137,621 & 166,409 & 28,789 \\
\hline Otros activos no financieros & 0 & 0 & 0 & 5,356 & 20,706 & 38,340 & 59,070 & 90,908 & 90,908 \\
\hline TOTAL ACTIVO NO CORRIENTE & $3,480,675$ & $3,262,103$ & $3,175,739$ & $3,089,925$ & $3,507,763$ & $4,038,075$ & $4,116,908$ & $4,609,196$ & $4,250,285$ \\
\hline TOTAL ACTIVO & $4,009,258$ & $4,141,225$ & $4,220,474$ & $4,216,915$ & $4,915,982$ & $\mathbf{5 , 5 5 2 , 7 9 7}$ & $6,146,130$ & $6,831,410$ & $7,465,306$ \\
\hline \multicolumn{10}{|l|}{ PASIVO Y PATRIMONIO } \\
\hline \multicolumn{10}{|l|}{ PASIVO CORRIENTE } \\
\hline Otros Pasivos Financieros & 243,657 & 152,250 & 36,420 & 55,770 & 122,024 & 130,457 & 86,168 & 98,605 & 109,313 \\
\hline Cuentas por pagar comerciales & 173,126 & 188,775 & 192,999 & 199,608 & 188,627 & 192,502 & 193,434 & 193,543 & 192,027 \\
\hline Otras cuentas por pagar & 92,806 & 124,815 & 98,025 & 59,680 & 93,832 & 94,088 & 86,406 & 83,501 & 89,457 \\
\hline Cuentas por pagar a entidades relacionadas & 30,131 & 27,136 & 28,284 & 76,896 & 40,612 & 43,232 & 47,256 & 51,999 & 45,775 \\
\hline
\end{tabular}




\begin{tabular}{|c|c|c|c|c|c|c|c|c|c|}
\hline Ingresos Diferidos & 6,531 & 4,179 & 3,289 & 3,289 & 4,322 & 3,770 & 3,667 & 3,762 & 3,880 \\
\hline Otras Provisiones & 18,294 & 154,919 & 176,018 & 150,577 & 160,505 & 162,367 & 157,816 & 160,229 & 160,137 \\
\hline Pasivos por impuesto a las ganancias & 671 & 4,176 & 5,698 & 27,331 & 7,383 & 8,928 & 10,795 & 13,053 & 10,040 \\
\hline TOTAL PASIVO CORRIENTE & 565,216 & 656,250 & 540,733 & 573,151 & 617,304 & 635,343 & 585,543 & 604,692 & 610,629 \\
\hline \multicolumn{10}{|l|}{ PASIVO NO CORRIENTE } \\
\hline Pasivos financieros & 256,569 & 178,238 & 141,399 & 92,580 & 167,197 & 144,853 & 136,507 & 135,284 & 145,960 \\
\hline Anticipos recibidos & 89,736 & 86,447 & 83,158 & 79,869 & 84,803 & 83,569 & 82,850 & 82,773 & 83,498 \\
\hline Provisión por beneficios a los empleados & 3,653 & 4,315 & 4,928 & 5,332 & 7,629 & 9,225 & 9,225 & 13,488 & 10,646 \\
\hline Provisiones & 15,809 & 16,450 & 17,465 & 57,270 & 29,084 & 35,168 & 35,168 & 51,420 & 40,585 \\
\hline Pasivo por imopuesto a las ganancias diferidos & 540,375 & 592,709 & 560,940 & 557,029 & 563,765 & 570,582 & 577,481 & 584,464 & 591,531 \\
\hline TOTAL PASIVO NO CORRIENTE & 906,142 & 878,159 & 807,890 & 792,080 & 852,476 & 843,396 & 841,230 & 867,428 & 872,221 \\
\hline TOTAL PASIVO & $1,471,358$ & $1,534,409$ & $1,348,623$ & $1,365,231$ & $1,469,780$ & $1,478,739$ & $1,426,773$ & $1,472,121$ & $1,482,849$ \\
\hline \multicolumn{10}{|l|}{ PATRIMONIO NETO } \\
\hline Capital emitido & $2,302,144$ & $2,545,960$ & $2,545,960$ & $2,498,101$ & $2,498,101$ & $2,498,101$ & $2,498,101$ & $2,498,101$ & $2,498,101$ \\
\hline Capital adicional & 3,713 & 3,713 & 3,713 & 3,713 & 3,713 & 3,713 & 3,713 & 3,713 & 3,713 \\
\hline Otras reservas de capital & & 31 & 21,384 & 65,828 & 49,833 & 45,682 & 53,781 & 49,765 & 49,743 \\
\hline Resultados acumulados & 272,736 & 95,445 & 333,951 & 318,452 & 958,566 & $1,589,674$ & $2,227,550$ & $2,872,172$ & $3,492,981$ \\
\hline Otras reservas de patrimonio & $-40,693$ & $-38,333$ & $-33,157$ & $-34,410$ & $-64,011$ & $-63,111$ & $-63,788$ & $-64,462$ & $-62,081$ \\
\hline TOTAL PATRIMONIO & $2,537,900$ & $2,606,816$ & $\mathbf{2 , 8 7 1 , 8 5 1}$ & $2,851,684$ & $3,446,202$ & $4,074,058$ & $4,719,357$ & $5,359,289$ & $5,982,457$ \\
\hline TOTAL PASIVO Y PATRIMONIO NETO & $4,009,258$ & $4,141,225$ & $4,220,474$ & $4,216,915$ & $4,915,982$ & $\mathbf{5 , 5 5 2 , 7 9 7}$ & $6,146,130$ & $6,831,410$ & $7,465,306$ \\
\hline
\end{tabular}

Nota: Elaboración propia 
Tabla 56

Balance General: Situación con la Nueva Estrategia, S/.

\begin{tabular}{|c|c|c|c|c|c|c|c|c|c|}
\hline \multirow[b]{3}{*}{ ACTIVO } & \multicolumn{9}{|c|}{ Situación con la Nueva Estrategia } \\
\hline & \multirow[t]{2}{*}{2015} & \multirow[t]{2}{*}{2016} & \multirow[t]{2}{*}{2017} & \multirow[t]{2}{*}{2018} & \multirow[t]{2}{*}{2019} & \multirow[t]{2}{*}{2020} & \multirow[t]{2}{*}{2021} & \multirow[t]{2}{*}{2022} & \multirow[t]{2}{*}{2023} \\
\hline & & & & & & & & & \\
\hline \multicolumn{10}{|l|}{ ACTIVO CORRIENTE } \\
\hline Efectivo y equivalentes de efectivo & 79,052 & 534,068 & 272,394 & 537,060 & 539,499 & $1,068,766$ & $1,678,160$ & $1,688,546$ & $1,819,666$ \\
\hline Cuentas por cobrar comerciales y diversas, neto & 317,596 & 168,873 & 198,058 & 191,490 & 305,958 & 372,205 & 462,821 & 567,710 & 771,814 \\
\hline Cuentas por cobrar relacionadas & 32,153 & 80,937 & 500,535 & 319,958 & 143,097 & 173,031 & 209,227 & 252,995 & 369,913 \\
\hline Existencias & 74,954 & 70,513 & 72,102 & 75,984 & 76,418 & 76,854 & 77,293 & 77,734 & 78,178 \\
\hline Gastos pagados por anticipado & 24,828 & 24,731 & 1,646 & 2,498 & 43,724 & 52,871 & 63,931 & 77,305 & 113,030 \\
\hline TOTAL ACTIVO CORRIENTE & 528,583 & 879,122 & $1,044,735$ & $1,126,990$ & $1,108,696$ & $1,743,727$ & $2,491,431$ & $2,664,289$ & $3,152,601$ \\
\hline \multicolumn{10}{|l|}{ ACTIVO NO CORRIENTE } \\
\hline Cuentas por cobrar a entidades relacionadas & 6,140 & 0 & 0 & 0 & 533,404 & 779,023 & $1,067,532$ & $1,558,445$ & $1,863,685$ \\
\hline Inversiones & 360,511 & 360,511 & 360,511 & 187,718 & 637,383 & 770,717 & 931,942 & $1,126,894$ & $1,647,673$ \\
\hline Propiedades, plantas y equipos, neto & $3,061,717$ & $2,848,355$ & $2,760,372$ & $2,827,442$ & $2,755,551$ & $2,685,488$ & $2,617,206$ & $2,876,915$ & $2,803,766$ \\
\hline Activos, intangible, neto & 52,307 & 53,237 & 54,856 & 69,409 & 94,123 & 113,812 & 137,621 & 166,409 & 243,313 \\
\hline Otros activos no financieros & 0 & 0 & 0 & 5,356 & 0 & 0 & 0 & 0 & \\
\hline TOTAL ACTIVO NO CORRIENTE & $3,480,675$ & $3,262,103$ & $3,175,739$ & $3,089,925$ & $4,020,461$ & $4,349,040$ & $4,754,300$ & $5,728,663$ & $6,558,438$ \\
\hline TOTAL ACTIVO & $4,009,258$ & $4,141,225$ & $4,220,474$ & $4,216,915$ & $5,129,157$ & $6,092,766$ & $7,245,731$ & $8,392,952$ & 9,711,039 \\
\hline \multicolumn{10}{|l|}{ PASIVO Y PATRIMONIO } \\
\hline \multicolumn{10}{|l|}{ PASIVO CORRIENTE } \\
\hline Otros Pasivos Financieros & 243,657 & 152,250 & 36,420 & 55,770 & 269,178 & 325,487 & 393,575 & 475,907 & 575,461 \\
\hline Cuentas por pagar comerciales & 173,126 & 188,775 & 192,999 & 199,608 & 333,754 & 403,572 & 487,994 & 590,077 & 713,515 \\
\hline Otras cuentas por pagar & 92,806 & 124,815 & 98,025 & 59,680 & 47,976 & 58,013 & 70,148 & 84,822 & 102,566 \\
\hline Cuentas por pagar a entidades relacionadas & 30,131 & 27,136 & 28,284 & 76,896 & 273,897 & 331,193 & 400,475 & 484,249 & 585,549 \\
\hline Ingresos Diferidos & 6,531 & 4,179 & 3,289 & 3,289 & 220,673 & 266,835 & 322,654 & 390,150 & 471,764 \\
\hline
\end{tabular}




\begin{tabular}{|c|c|c|c|c|c|c|c|c|c|}
\hline Otras Provisiones & 18,294 & 154,919 & 176,018 & 150,577 & 7,383 & 8,928 & 10,795 & 13,053 & 15,784 \\
\hline Pasivos por impuesto a las ganancias & 671 & 4,176 & 5,698 & 27,331 & 7,383 & 8,928 & 10,795 & 13,053 & 7,411 \\
\hline TOTAL PASIVO CORRIENTE & 565,216 & 656,250 & 540,733 & 573,151 & $1,160,244$ & $1,402,954$ & $1,696,437$ & $2,051,312$ & $2,464,639$ \\
\hline \multicolumn{10}{|l|}{ PASIVO NO CORRIENTE } \\
\hline Pasivos financieros & 256,569 & 178,238 & 141,399 & 92,580 & 66,125 & 47,230 & 33,734 & 24,095 & 17,210 \\
\hline Anticipos recibidos & 89,736 & 86,447 & 83,158 & 79,869 & 76,827 & 73,902 & 71,087 & 68,380 & 65,776 \\
\hline Provisión por beneficios a los empleados & 3,653 & 4,315 & 4,928 & 5,332 & 6,078 & 6,929 & 7,900 & 9,006 & 10,266 \\
\hline Provisiones & 15,809 & 16,450 & 17,465 & 57,270 & 29,084 & 35,168 & 49,990 & 66,243 & 62,176 \\
\hline Pasivo por impuesto a las ganancias diferidos & 540,375 & 592,709 & 560,940 & 557,029 & 563,765 & 570,582 & 577,481 & 584,464 & 591,531 \\
\hline TOTAL PASIVO NO CORRIENTE & 906,142 & 878,159 & 807,890 & 792,080 & 741,879 & 733,810 & 740,192 & 752,187 & 746,959 \\
\hline TOTAL PASIVO & $1,471,358$ & $1,534,409$ & $1,348,623$ & $1,365,231$ & $1,902,124$ & $2,136,765$ & $2,436,629$ & $2,803,499$ & $3,219,009$ \\
\hline \multicolumn{10}{|l|}{ CAPITAL Y PATRIMONIO } \\
\hline Capital emitido & $2,302,144$ & $2,545,960$ & $2,545,960$ & $2,498,101$ & $2,498,101$ & $2,498,101$ & $2,498,101$ & $2,498,101$ & $2,498,101$ \\
\hline Capital adicional & 3,713 & 3,713 & 3,713 & 3,713 & 63,111 & 63,788 & 64,462 & 62,081 & 63,360 \\
\hline Otras reservas de capital & 0 & 31 & 21,384 & 65,828 & 88,693 & 156,732 & 233,966 & 179,127 & 164,629 \\
\hline Resultados acumulados & 272,736 & 95,445 & 333,951 & 318,452 & 605,871 & $1,307,548$ & $2,090,910$ & $2,934,504$ & $3,858,320$ \\
\hline \multirow[t]{2}{*}{ Otras reservas de patrimonio } & $-40,693$ & $-38,333$ & $-33,157$ & $-34,410$ & $-28,742$ & $-70,168$ & $-78,336$ & $-84,359$ & $-92,382$ \\
\hline & 0 & 0 & & & & & & & \\
\hline PATRIMONIO NETO & $2,537,900$ & $2,606,816$ & $\mathbf{2 , 8 7 1 , 8 5 1}$ & $2,851,684$ & $\mathbf{3 , 2 2 7 , 0 3 3}$ & $3,956,002$ & $4,809,102$ & $5,589,454$ & $6,492,029$ \\
\hline TOTAL PASIVO Y PATRIMONIO & $4,009,258$ & $4,141,225$ & $4,220,474$ & $4,216,915$ & $5,129,157$ & $6,092,766$ & $7,245,731$ & $8,392,952$ & $\mathbf{9 , 7 1 1 , 0 3 9}$ \\
\hline
\end{tabular}




\subsubsection{Flujo de Efectivo. (Situación Actual y con la Nueva Estrategia)}

En la Tabla 55, muestra un estado financiero coherente, en la gestión 2015, con un saldo de caja de Miles S/. 511,61, lo que nos indica que los resultados son positivos, pese a la inversión en centrales de energía renovable que permiten el desarrollo de una mejor gestión y que nos da como resultado mejorar la liquidez de Enel Generación Perú SAA. Por lo que con la ejecución de las estrategias se obtiene un saldo de caja en Miles de S/. $515,357$.

Por otro lado, en el Estado de Flujo de Efectivo Proyectado se aprecia para finalizar la gestión del 2023 un incremento considerable de Miles de S/. 1,012,075. En efecto, de los flujos incrementales de una situación sin estrategia con otra que sí la tiene, nos da en términos nominales una utilidad acumulada de $S / 1,402,359$, para un nivel de inversión en la estrategia de $S / 410,929$. En términos de costo beneficio se obtiene un considerable incremento de las utilidades para los accionistas.

Con respecto a los egresos que se muestran con la implementación de la estrategia se puede observar que existe un balance de costos que permitirá obtener los saldos de caja presentados. 
Tabla 57

Flujo de efectivo: Situación Actual, S/.

\begin{tabular}{|c|c|c|c|c|c|c|}
\hline & 2018 & 2019 & 2020 & 2021 & 2022 & 2023 \\
\hline Ingresos & $1,438,539$ & $1,467,310$ & $1,496,656$ & $1,526,589$ & $1,526,589$ & $1,571,593$ \\
\hline \multicolumn{7}{|l|}{ Gastos } \\
\hline Gastos de Administración & 73,046 & 75,018 & 77,044 & 79,124 & 81,260 & 78,112 \\
\hline Costos de Ventas & 844,965 & 867,779 & 891,209 & 915,272 & 939,984 & 903,561 \\
\hline Cargas Financieras & 8,915 & 9,156 & 9,403 & 9,657 & 9,918 & 9,533 \\
\hline FLUJO DE CAJA ECONÓMICO & 511,613 & 515,357 & 519,000 & 522,537 & 495,427 & 580,387 \\
\hline Saldo Final de Caja & 511,613 & 515,357 & 519,000 & 522,537 & 495,427 & 580,387 \\
\hline \multirow[t]{2}{*}{ FLUJO DE CAJA ACUMULADO } & $1,773,632$ & $2,288,989$ & $2,807,989$ & $3,330,526$ & $3,825,953$ & $4,406,340$ \\
\hline & 2017 & 2018 & 2019 & 2020 & 2021 & 2021 \\
\hline SALDO DE CAJA PARA EFECTOS DEL VANE S/. & 511,613 & 515,357 & 519,000 & 522,537 & 495,427 & 580,387 \\
\hline
\end{tabular}

Nota: Elaboración propia 
Tabla 58

Flujo de efectivo: Situación con la Nueva Estrategia, S/. - Flujo de Caja Diferencial

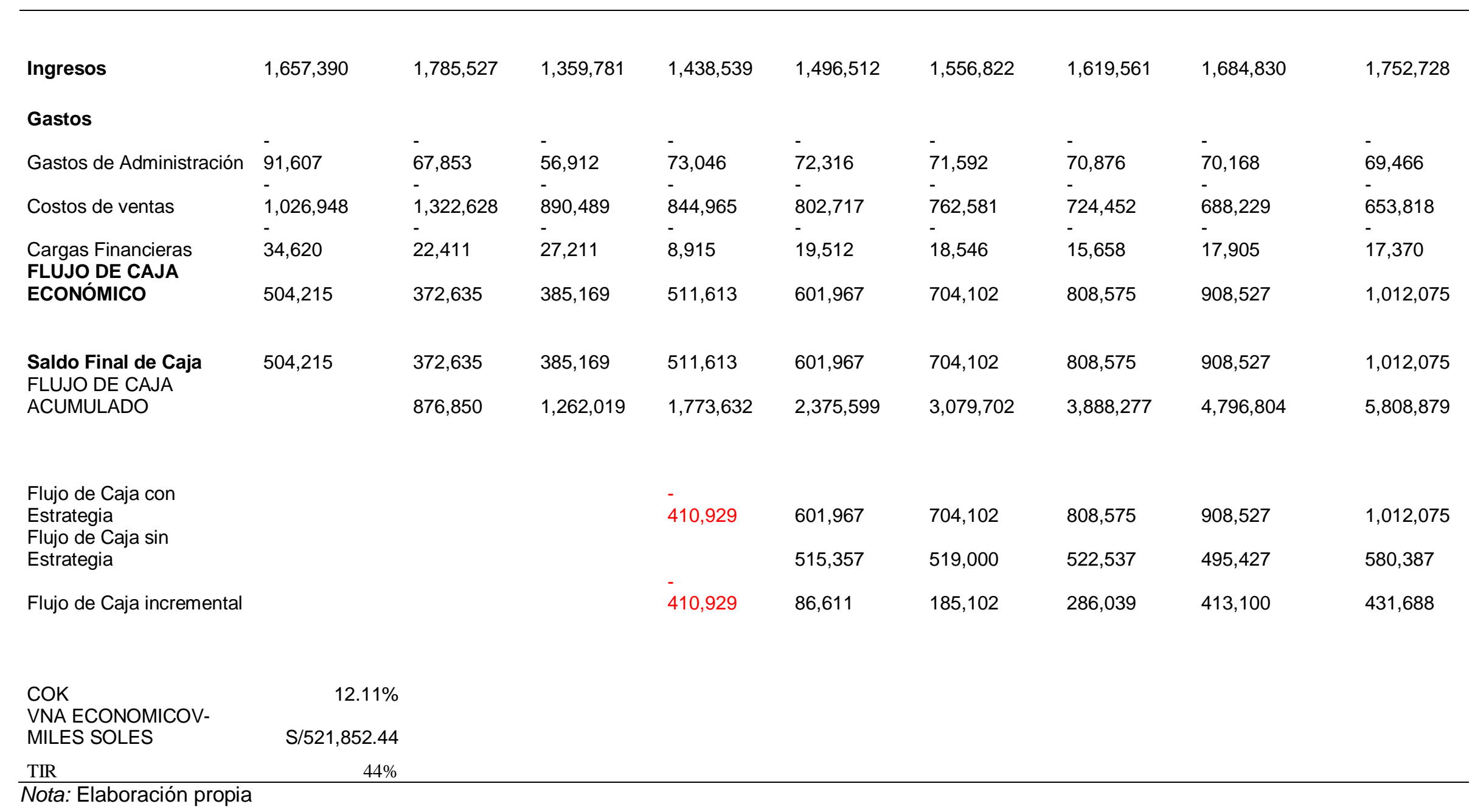




\subsubsection{Evaluación Financiera. (VAN, TIR y Ratios Financieros)}

Con el fin de obtener el resultado del valor actual neto o VAN y la tasa interna de retorno o TIR, se ha calculado un costo de capital promedio ponderada (WACC), partiendo de determinados supuesto que son explicados en detalle en el punto 10.3 Cálculo de tasa de descuento, los cálculos dieron como resultado una tasa de descuento de $12.11 \%$ La TIR calculada en la proyección con estrategia ha sido 44\%, lo cual indica que en el escenario esperado hay un resultado positivo en rentabilidad financiera, dando un VAN S/. 521,852 (miles de soles) a un nivel de inversión de S/410,929 (miles de soles) y obteniendo una utilidad nominal para los siguientes 5 años de implementada la estrategia de la estrategia de $\mathrm{S} / 1,402,539$ (miles de soles) Las principales ratios financieros con la estrategia implementada se detallan en la tabla 57. Ratios financieras proyectados.

Ratios de liquidez: La empresa muestra ratios de liquidez robustos, con capacidad de asumir todas sus obligaciones de corto plazo, a una razón promedio de 2.91 durante los 5 años del plan estratégico, ello quiere decir que por cada sol de deuda que asume la empresa cuenta con 2.90 soles para pagarlo.

Razón de efectivo: Es una prueba acida a la liquidez, lo que permite determinar la capacidad que tiene la empresa para asumir sus obligaciones de corto plazo solo con la caja, si bien la ratio promedio es menor a 1 ( 0.79 en los 5 años), la correcta gestión de las cuentas por cobrar y pagar es fundamental para que la liquidez no se vea impactada.

Capital de Trabajo: Según las proyecciones el año 2019 mostraría un capital de trabajo negativo, -S/ 51,594 (miles de soles), lo que obligue a la empresa a asumir deuda, sin embargo, el monto no es representativo para para los niveles de efectivo que maneja la compañía, muestra de ello después de implementada la estrategia los siguientes años el capital de trabajo vuelve a positivo con promedio de S/ 609,176 (miles de soles)

Endeudamiento sobre el patrimonio: Solo representa el $51 \%$ del patrimonio de la compañía, por lo que esta tiene capacidad de pagar sus deudas con capital propio (accionista), en tal sentido el nivel de deuda es manejable con la estrategia implementada.

Endeudamiento sobre la Inversión El mismo análisis anterior aplicado sobre los activos totales, muestran que la deuda de la compañía solo representa $33 \%$ en promedio, esto demuestra capacidad financiera para sostener futuras inversiones ya sea asumiendo deuda con terceros o propia.

Margen de Utilidad: el margen de utilidad neto de la compañía representará $47 \%$ en promedio en los siguientes años, siendo sumamente positivo respecto a otras industrias productivas, cuyos márgenes netos oscilan entre $10 \%$ y $20 \%$ en promedio. 
Tabla 59

Ratios financieros proyectados, Análisis Dupont y Liquidez

\begin{tabular}{lccccc}
\hline Ratios de liquidez a corto plazo & $\mathbf{2 0 1 9}$ & $\mathbf{2 0 2 0}$ & $\mathbf{2 0 2 1}$ & $\mathbf{2 0 2 2}$ & $\mathbf{2 0 2 3}$ \\
Ratio de Liquidez & 2.70 & 2.85 & 2.97 & 2.99 & 3.02 \\
Razón de Efectivo & 0.46 & 0.76 & 0.99 & 0.82 & 0.74 \\
Capital de Trabajo & $-51,549$ & 340,772 & 794,994 & 612,977 & 687,962 \\
& & & & & \\
Razones de Apalancamiento Financiero & $\mathbf{2 0 1 9}$ & $\mathbf{2 0 2 0}$ & $\mathbf{2 0 2 1}$ & $\mathbf{2 0 2 2}$ & $\mathbf{2 0 2 3}$ \\
Endeudamiento sobre Patrimonio & $58.94 \%$ & $54.01 \%$ & $50.67 \%$ & $50.16 \%$ & $49.47 \%$ \\
Endeudamiento sobre la inversión & $37.08 \%$ & $35.07 \%$ & $33.63 \%$ & $33.40 \%$ & $33.07 \%$ \\
& & & & & \\
Medidas de Rentabilidad & $\mathbf{2 0 1 9}$ & $\mathbf{2 0 2 0}$ & $\mathbf{2 0 2 1}$ & $\mathbf{2 0 2 2}$ & $\mathbf{2 0 2 3}$ \\
Margen de utilidad & $40.5 \%$ & $45.1 \%$ & $48.4 \%$ & $50.1 \%$ & $52.7 \%$ \\
ROA & $11.81 \%$ & $11.52 \%$ & $10.81 \%$ & $10.05 \%$ & $9.51 \%$ \\
ROE & $18.77 \%$ & $17.74 \%$ & $16.29 \%$ & $15.09 \%$ & $14.23 \%$ \\
\hline
\end{tabular}

Nota: Elaboración propia

Para el 2019, el margen de la utilidad neta es favorable, el ROE en el 2017 fue de $7.84 \%$ y mejora a $11.55 \%$ para el 2018 ; y, para el año 2021 sería de $16.29 \%$.

\subsection{Cálculo de la Tasa de Descuento}

\subsubsection{Costo de Oportunidad. (Ke)}

El costo de capital se relaciona con la rentabilidad del accionista y se calculará empleando el modelo CAPM. Este modelo permite calcular el costo de capital exigido para un determinado instrumento financiero en función a la tasa libre de riesgo, una prima por riesgo de mercado y un Beta que mide la volatilidad del retorno del instrumento respecto al mercado. Adicionalmente, el costo de capital debe considerar una prima por riesgo país como compensación por el riesgo asumido en un país emergente como Perú. La fórmula es: $K_{e}$ USD $=R_{f}+B$ * $\left(R_{m}-R_{f}\right)+R P$.

Tasa Libre de riesgo $\left(\mathrm{R}_{\mathrm{f}}\right)$.

Se emplea como referencia los bonos del tesoro americano a 10 años (T-Bond) considerando la vida útil de las centrales de generación eléctrica que posee la empresa y el plazo de sus contratos, el $\mathrm{R}_{\mathrm{f}}$ a diciembre del 2018 corresponde a $2.28 \%$, la cual refleja las condiciones actuales del mercado.

Prima por riesgo de mercado $\left(R_{m}-R_{f}\right)$.

Se emplea como referencia el exceso de retorno del índice S\&P500 sobre la tasa libre de riesgo. Este índice se ha seleccionado por ser uno de los más representativo del mercado. Se toma el promedio del periodo $2009-2018$ que corresponde $13.49 \%$ con la finalidad de considerar acontecimientos positivos y negativos que hayan impactado sobre el índice. 
Beta apalancado $\left(B_{a}\right)$.

Se emplea el valor 0.63 calculado en función del beta desapalancado que corresponde al promedio de (i) Beta obtenido de la regresión realizada entre el exceso del rendimiento del precio de la acción de la empresa sobre los rendimientos de la BVL del mismo periodo, el valor obtenido es 0.53 , (ii) Beta publicado por Damodaran para las empresas en la industria "Green \& Renewable Energy" con un valor de 0.70.

Fórmula: $\mathrm{B}_{\mathrm{a}}=\mathrm{B}_{\mathrm{d}}{ }^{*}\left(1+(\mathrm{D} / \mathrm{C})^{*}(1-\mathrm{T})\right.$

Cálculo del $B_{a}$

\begin{tabular}{ll}
\multicolumn{2}{c}{ Beta Desapalancado } \\
\hline i. Damodaran & 0.70 \\
ii. Regresión & 0.53 \\
\hline Promedio & 0.62
\end{tabular}

\begin{tabular}{lr}
\multicolumn{2}{c}{ ENEL GENERACIÓN PERÚ } \\
\hline Beta desapalancado & 0.62 \\
Deuda (D. miles S/.) & 145.200 \\
Capital (C. miles de S/.) & $5,620.727$ \\
Tasa de Impuestos (T) & $29.5 \%$ \\
\hline Beta Apalancado $\left(\mathrm{B}_{\mathrm{a}}\right)$ & 0.63
\end{tabular}

Nota: Elaboración propia

Riesgo país (RP).

Se emplea como referencia el spread EMBIG Perú que mide el riesgo país con un valor de 1.39\%, según el banco de inversión JP Morgan.(Gestión, Economía riesgo país) Considerando lo mencionado anteriormente, el costo de capital, nominal en dólares exigido por el accionista sería $10.72 \%$. Teniendo en cuenta que contamos con información de los EEFF en soles, se debe ajustar el Ke a la misma moneda por los que se empleará la relación de la inflación a largo plazo de EEUU y la inflación de largo plazo de Perú de un promedio 10 años.

Siendo la inflación para EEUU 1.77\% y para Perú 3.23\%.

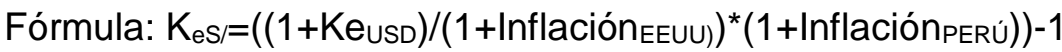

Tabla 60

Cálculo del Ke

\begin{tabular}{lc}
\hline \multicolumn{2}{c}{ Costo de Capital } \\
\hline Rm Rendimiento de mercado & $13.49 \%$ \\
Rf Tasa libre de riesgo & $2.28 \%$ \\
Rm-Rf: prima de Mercado & $11.22 \%$ \\
Beta & 0.63 \\
Rf $+B^{*}($ Rm-Rf $)$ & $9.33 \%$ \\
RIESGO PAIS Embig Perú & $1.39 \%$
\end{tabular}




\begin{tabular}{lc} 
Ke: Costo de Capital USD & $10.72 \%$ \\
EEUU inflación & $1.77 \%$ \\
Perú Inflación & $3.23 \%$ \\
\hline Ke: Costo de Capital S/. & $12.31 \%$ \\
\hline
\end{tabular}

Nota: Elaboración propia

\subsubsection{Costo de Oportunidad de la Deuda. $(\mathrm{Kd})$}

El costo de la deuda se relaciona con el costo del financiamiento contraído por la empresa. El costo de la deuda nominal en soles es $6.47 \%$ y se obtiene con el promedio ponderado de las tasas de mercado de los bonos de la empresa.

Tabla 61

Cálculo del Kd

\begin{tabular}{|c|c|c|c|c|c|}
\hline \multirow{2}{*}{ Empresa } & \multicolumn{4}{|c|}{ Miles de S/. } & \multirow[b]{2}{*}{ Vencimiento } \\
\hline & Tipo & Moneda & Dic-2018 & Tasa & \\
\hline \multicolumn{6}{|c|}{ Tercer programa de bonos } \\
\hline 1ra Emisión, Serie A & Bono & $S /$. & 25,480 & $6.313 \%$ & Jun-22 \\
\hline 3ra Emisión, Serie A & Bono & S/. & 26,090 & $6.281 \%$ & Jul-19 \\
\hline 8va Emisión, Serie A & Bono & $\$$ & 36,509 & $6.344 \%$ & Ene-28 \\
\hline 11ma Emisión, Serie A & Bono & $\$$ & 28,562 & $7.781 \%$ & Ene-19 \\
\hline \multicolumn{6}{|c|}{ Cuarto programa de bonos } \\
\hline 5ta Emisión, Serie A & Bono & $\$$ & 34,514 & $5.781 \%$ & Set-20 \\
\hline Total & & & 151,155 & $6.471 \%$ & \\
\hline
\end{tabular}

Fuente: Notas de los estados financieros

\subsubsection{WACC}

EI WACC se construye empleando el costo de capital (Ke), el costo de la deuda (Kd), la estructura de capital $(D / C)$ y la tasa de impuesto $(T)$. EI WACC calculado para Enel Generación Perú es de 12.11\% para las etapas de proyección.

Tasa de impuesto ( $\mathrm{T})$.

La tasa de impuestos empleada en el modelo se estableció de acuerdo a lo indicado por SUNAT con un valor de $29.5 \%$. (SUNAT)

Estructura de capital (Deuda/Capital).

Relaciona las fuentes de financiamiento de los activos de la empresa, para su cálculo se emplea la relación entre el valor de mercado de la deuda y el valor de mercado de capital de la empresa. Se toma el ratio D/C 2.58\% que corresponde al diciembre 2018, fecha de valorización, debido a que la empresa presenta una reducción constante de su deuda durante los últimos años. 
Tabla 62

Deuda / Capital

\begin{tabular}{lrrrrr}
\hline \multicolumn{1}{c}{ Miles de S/. } & \multicolumn{1}{c}{ Dic-14 } & \multicolumn{1}{c}{ Dic-15 } & \multicolumn{1}{c}{ Dic-16 } & \multicolumn{1}{c}{ Dic-17 } & Dic-18 \\
\hline Valor de mercado de deuda & $\mathbf{8 1 0 . 2 6 7}$ & $\mathbf{6 2 9 . 2 1 8}$ & $\mathbf{3 3 0 . 4 0 0}$ & $\mathbf{1 7 3 . 8 0 0}$ & $\mathbf{1 4 5 . 2 0 0}$ \\
Bonos & 248.576 & 253.481 & 182.319 & 177.819 & 148.35 \\
Préstamos y arrendamientos & 561.691 & 373.693 & 363.878 & 221.283 & 276.504 \\
Valor de mercado de capital & $\mathbf{7 , 5 4 1 . 5 8 2}$ & $\mathbf{7 , 0 6 3 . 3 9 5}$ & $\mathbf{7 , 5 2 2 . 1 5 3}$ & $\mathbf{7 , 5 2 2 . 1 5 3}$ & $\mathbf{5 , 6 2 0 . 7 2 7}$ \\
Número de acciones (miles) & 2293.669 & 2616.072 & 2893.136 & 2893.136 & 2838.751 \\
Precio de acción (S/) & 3.29 & 2.70 & 2.70 & 2.60 & 1.98 \\
\hline \multicolumn{1}{c}{ Ratio D/C } & $\mathbf{1 0 . 7 4 \%}$ & $\mathbf{8 . 9 1 \%}$ & $\mathbf{4 . 3 9 \%}$ & $\mathbf{2 . 3 1 \%}$ & $\mathbf{2 . 5 8 \%}$ \\
\hline
\end{tabular}

Nota: Elaboración propia

El cálculo del WACC se muestra en la tabla 61.

Fórmula:

$W A C C=D /(D+C){ }^{*} K d *(1-T)+C /(D+C) * K e$

Tabla 63

Cálculo del WACC

\begin{tabular}{lc}
\hline \multicolumn{2}{c}{ Costo de Capital } \\
\hline Rm Rendimiento de mercado & $13.49 \%$ \\
Rf Tasa libre de riesgo & $2.28 \%$ \\
Rm-Rf: prima de Mercado & $11.22 \%$ \\
Beta & 0.63 \\
Rf + B*(Rm-Rf) & $9.33 \%$ \\
RIESGO PAIS Embig Perú & $1.39 \%$ \\
\hline Ke: Costo de Capital USD & $10.72 \%$ \\
\hline EEUU inflación & $1.77 \%$ \\
Perú Inflación & $3.23 \%$ \\
\hline Ke: Costo de Capital S/. & $12.31 \%$ \\
\hline Kd: Costo de la Deuda S/. & $6.47 \%$ \\
\hline Nota: Elaboración propia
\end{tabular}

Tasa de impuestos

T: tasa de impuestos

$29.50 \%$

Estructura de capital

\begin{tabular}{lr}
\hline Deuda (D. miles S/.) & 145.200 \\
Capital (C. miles de S/.) & $5,620.727$ \\
D/D+C & $2.52 \%$ \\
C/D+C & $97.5 \%$ \\
\hline WACC en S/. & $12.11 \%$ \\
\hline
\end{tabular}

Nota: Elaboración propia 


\section{Conclusiones}

1. El Perú cuenta con diversidad de recursos energéticos, tales como renovables y no renovables, la principal fuente de generación eléctrica en el país ha sido hídrica, pero las condiciones geográficas nacionales se inclinan hacia la inversión en energía renovables, que el gobierno apoya con el fin que se desarrollen nuevas fuentes de generación aprovechando los recursos del país y llegando a más usuarios. Actualmente, la matriz energética está compuesta de hídrica $57 \%$, no renovable $40 \%$, renovable $3 \%$. 2. Enel Generación Perú SAA, se encuentra en un mercado que cuenta con una proyección favorable en lo que respecta a la demanda de energía con fuentes renovables. Al realizar el análisis de la Matriz Interna Externa, se ha determinado que la posición Enel Generación Perú SAA está en el cuadrante de las estrategias intensivas de penetración de mercado, desarrollo de mercado y desarrollo de producto.

3. Las estrategias seleccionadas están orientadas a garantizar a los clientes un producto con un alto nivel de calidad y que influye de manera favorable para el mercado peruano.

4. Enel Generación Perú SAA, cuenta con estrategias que le permite dinamizar los procesos operativos y buscar alternativas de tecnología para la generación de energía. 5. El planteamiento del Balance Scorecard a través de la medición del control de iniciativas en Enel Generación Perú SAA, lleva a la optimización del control financiero y no financiero, si se aplica adecuadamente.

6. Enel Generación Perú SAA, debe buscar perfeccionar los ratios financieros, como no financieros y tener un equilibrio que permita a la compañía obtener resultados favorables en menor plazo.

7. Según el análisis del entorno Enel Generación Perú SAA tiene muy buenas expectativas para desarrollarse en el mercado que se desempeña. Así, la implementación de las estrategias permitirá mejorar la performance de Enel Generación Perú SAA y cumplirá con los objetivos propuestos.

8. El Plan estratégico tiene la importancia de orientar a la empresa para el adecuado desarrollo de sus estrategias. 


\section{Recomendaciones}

1. Llevar a cabo el Plan Estratégico adoptando una visión clara para Enel Generación Perú SAA.

2. Aplicar el plan de acción sugerido y que sea evaluados de manera mensual, con la finalidad de realizar los ajustes correspondientes oportunamente, en caso de que no se llegara a cumplir con alguna de las actividades programadas.

3. Desarrollar nuevas estrategias de negocios tomando en cuenta las oportunidades que viene ofreciendo el sector de energía eléctrica propiamente dicho.

4. Para fomentar el intercambio de conocimientos y experiencias con otras subsidiarias, es necesario, hacer de conocimiento del plan de acción a la matriz.

5. Potenciar un Networking con los diferentes grupos que conforman el sector eléctrico.

7. El Plan Estratégico ha realizado su análisis para un periodo de 5 años; se recomienda revisar las estrategias que se han planteado y reformularlas desde ese tiempo.

8. Desarrollar las buenas prácticas en cada una de las actividades de la cadena de valor, teniendo en cuenta el grado de importancia de Enel Generación Perú S.A.A. para el sector energético. 


\section{Referencias}

Alcalde, D., Aquino, I., Duran, M., Núñez, D., \& Trelles, J. (2017). Valor Compartido en las Empresas de Generación de Energía Eléctrica en el Perú. Lima: Centrum PUCP.

Recuperado el 14 de Noviembre de 2017, de

http://tesis.pucp.edu.pe/repositorio/handle/123456789/8753

Apoyo \& Asociados. (31 de Diciembre de 2017). Enel Generación Perú S.A.A. (antes Edegel). Obtenido de http://www.aai.com.pe/wp-content/uploads/2017/05/EnelGeneraci\%C3\%B3n_1216.pdf

Balarezo Valdez, J., García, A., Catherine, V., \& Zambrano, G. (2014). Planeamiento estratégico del sector de generación de energía eléctrica del Perú. Lima: PUCP.

Banco Central de Reserva del Perú (BCRP). (31 de Marzo de 2018). Reporte de Inflación: Panorama actual y proyecciones macroeconómicas 2018-2019. Recuperado el 10 de Julio de 2018, de http://www.bcrp.gob.pe/docs/Publicaciones/ReporteInflacion/2018/marzo/reporte-de-inflacion-marzo-2018-presentacion.pdf

BCP. (s.f.). Indicador de Riesgo País. Obtenido de Banco Central de Reserva del Perú: http://www.bcrp.gob.pe/component/itpgooglesearch/search.html?gsquery=riesgo+pais BCRP. (2017). Reporte de Inflación. Obtenido de http://www.bcrp.gob.pe/docs/Publicaciones/Reporte-Inflacion/2017/marzo/reporte-deinflacion-marzo-2017.pdf

Bolsa de Valores de Lima (BVL). (31 de Diciembre de 2007). Valuación de activo fijo de Edegel. Obtenido de http://www.bvl.com.pe/empresas/alertas/EDEGEL\%20Complemento\%20Anexo\%20F.pdf Celis, A., Gutiérrez, A., Silva Matos, J., \& Torres, L. (2012). Plan Estratégico del Sistema de Generación Térmica de Electricidad en el Perú. Lima: PUCP.

D’Alessio, F. (2015). El proceso estratégico: un enfoque de gerencia. Lima: Pearson. Diez de Castro, J., \& Redondo López, C. (1996). Administración de empresas. Madrid: Pirámide. Dirección General de Minería, M. d. (Mayo de 2015). Obtenido de http://www.minem.gob.pe/minem/archivos/file/Mineria/ESTADISTICA/PRODUCCI ON/2015/mayo/mayo.pdf Edegel. (23 de Setiembre de 2013). Miprimerblog de Edegel. Recuperado el 31 de Enero de 2018, de http://ignacioproelectrotecnia.blogspot.pe/2013/09/edegel.html 
Enel. (8 de Marzo de 2018). Visión de la empresa. Recuperado el 15 de Marzo de 2018, de https://www.enel.pe/es/quienes-somos/a201612-vision.html

El comercio, economía. https://elcomercio.pe/economia/peru/mem-produccionelectricidad-aumento-1-8-2017-noticia-495120 https://www.americaeconomia.com/negocios-industrias/produccion-de-energia-electricaen-peru-aumento-en-6-en-febrero-2019

Enel Generación Perú SAA. (26 de Noviembre de 2017). Negocio Enel Perú SAA. Obtenido de https://www.enel.pe/es/quienes-somos/a201612-conocenos.html

Enel Generación Perú SAA. (Memoria Anual Enel Generación Perú SAA, 2017, pp 12-13) Finanzas, M. d. (31 de Diciemnbre de 2010). Obtenido de https://www.mef.gob.pe/es/porinstrumento/ley/6055-ley-n-27506/file

Fred, R. David (1997) Conceptos de administración estratégica.

Gestion. (10 de Noviembre de 2016). CCL: PBI peruano crecerá 3.8\% el 2016 y $4.2 \%$ el 2017. Recuperado el 15 de Junio de 2017, de http://gestion.pe/economia/ccl-pbi-peruanocrecera-38-2016-y-42-2017-2174394

Gestión, (Economía riesgo país) https://gestion.pe/economia/riesgo-pais-peru-subecuatro-puntos-basicos-cierra-1-39-puntos-porcentuales-254208)

Gobierno Unidad Nacional . (28 de Agosto de 2011). Plan Estratégico Empresa Nacional de Energía Eléctrica 2011 - 2014. Recuperado el 12 de Noviembre de 2017, de http://www.enee.hn/Portal_transparencia/planes/Plan_EstrategicoENEE_2011_2014.pdf?t rust $=898211987 \&$ format $=0$

Godet (2011). La prospectiva Estratégica. Recuperado de https://administracion.uexternado.edu.co/matdi/clap/la\%20prospectiva\%20estrategica.pdf

Guzman, G. (5 de Enero de 2015). Hablar de tendencias tecnológicas es un ejercicio simpático pero su valor está en qué genera al negocio. Recuperado de http://gestion.pe/tecnologia/microsoft-peru-hablar-megatendencias-ejercicio-tecnologicosimpatico-valor-esta-que-genera-al-negocio-2118687 
Información del Grupo Enel. (24 de Noviembres de 2017). Portal del Grupo Enel. Obtenido de https://www.enel.pe/es/quienes-somos/a201611-grupo-enel.html

INEI. (2016). Estadísticas: Población y Vivienda. Obtenido de Instituto Nacional de Estadística : https://www.inei.gob.pe/estadisticas/indice-tematico/poblacion-y-vivienda/ Instituto Peruano de Economía (2017). http://www.ipe.org.pe/portal/erradicando-lapobreza-extrema/ Jay Barney (1991). file://C:/Users/chanc/Downloads/1754Texto\%20del\%20art\%C3\%ADculo-6021-1-10-20130116.pdf

Kim \& Mauborgne, (2005).La Estrategia del oceano azul. Bogotá: Grupo editorial norma Matthew, G., Quintanilla Pacheco, M., \& Sulca Gómez, L. (31 de Diciembre de 2017). Valorización de ENEL Generación Piura SA.

Muñoz (2015). https://repositorio.ins.gob.pe/bitstream/handle/INS/329/BOLETIN2015mar-abr-47-54.pdf?sequence=1\&isAllowed=y

Organismo Supervisor de la Inversión en Energía y Minería 2017 https://www.osinergmin.gob.pe/seccion/centro_documental/mineria/Documentos/Publicaci ones/Osinergmin-Industria-Mineria-Peru-20anios.pdf

Organismo Supervisor de la Inversión en Energía y Minería 2015. Recuperado de: ONU, Enerdata y MEM. Elaboración: GPAE-Osinergmin / www.osinergmin.gob.pe

Organismo Supervisor de la Inversión en Energía y Minería 2016 http://www.osinergmin.gob.pe/seccion/centro_documental/Institucional/Estudios_Economi cos/Libros/Osinergmin-Industria-Electricidad-Peru-25anios.pdf

Porter, M. (1991). Estrategia Competitiva. EEUU: Compañía Editorial Continental. Porter, M. (2009). Ser Competitivo. EEUU: Deusto

Parodi, C. (31 de Enero de 2018). Proyecciones del MEF 2018-2021. Recuperado el 12 de Julio de 2018, de Diario Gestión: https://gestion.pe/blog/economiaparatodos/2017/09/proyecciones-del-mef-2018-2021.html RPP, mercados. https://rpp.pe/economia/mercados/tarifas-electricas-suben-para-clientesresidenciales-e-industriales-noticia-1108462 
https://diariocorreo.pe/economia/energia-electrica-tarifas-subieron-50-en-los-ultimos-8anos-853675/

Robbins, S., \& Judge, T. (2012). Comportamiento organizacional. México: Pearson. Decimotercera edición.

Rumelt (1980). Good strategy, bad strategy: The diference and why it matters. NY: Crown Bussiness

Salas, D. (2013). Diagnóstico, análisis y propuesta de mejora al proceso de gestión de interrupciones imprevistas en el suministro eléctrico de baja tensión: Empresa Distribuidora de electricidad en Lima. Lima: PUCP Tesis.

Thompson, A., \& Strickland, A. (2011). Administración estratégica: conceptos y casos. México: Mc Graw-Hill.

Sunat. http://orientacion.sunat.gob.pe/index.php/empresas-menu/impuesto-a-la-rentaempresas/regimen-general-del-impuesto-a-la-renta-empresas/calculo-anual-del-impuestoa-la-renta-empresas/2900-03-tasas-para-la-determinacion-del-impuesto-a-la-renta-annual 


\section{Anexos}

Anexo 1

Riesgos externos: Los riesgos externos son aquellos que se originan fuera de la compañía, es decir, que la empresa no tiene control sobre ellos y que podrían impactar negativamente en la operación de Enel.

\begin{tabular}{|c|c|c|}
\hline Fuente & Tipo de Riesgo & Riesgo \\
\hline \multirow{7}{*}{ Externo } & $\begin{array}{c}\text { Riesgo } \\
\text { Macroeconómico }\end{array}$ & $\begin{array}{l}\text { Relacionado a la volatilidad de las principales variables macroeconómica } \\
\text { tales como el producto bruto interno, inflacion que podrian afectar el } \\
\text { desempeño de ENEL. El deterioro en la economia implicaria la reducción } \\
\text { del consumo de energia sobre todo en el sector industrial y comercial } \\
\text { impactando negativamente en los resultados }\end{array}$ \\
\hline & Riesgo Regulatorio & $\begin{array}{l}\text { Relacionado a la posibilidad de cambios en la regulación del sector que } \\
\text { conlleve a una mayor intervención del gobierno en la determinación de los } \\
\text { precios de energia u las leyes aplicables a la empresa tales como la Ley } \\
\text { de Conseciones Eléctricas. }\end{array}$ \\
\hline & Riesgo Legal & $\begin{array}{l}\text { Relacionado a la declaración de la caducidad de las concesiones } \\
\text { eléctricas de forma unilateral por parte del Estado. }\end{array}$ \\
\hline & & $\begin{array}{l}\text { Relacionado a la modificación de las políticas de gobierno ya } \\
\text { implementadas asi como cambios en los planes de desarrollo del sector } \\
\text { que puedan afectar la situación de la empresa. }\end{array}$ \\
\hline & Riesgo Pais & $\begin{array}{l}\text { Relacionado al cambio del rating crediticio peruano que podria generar } \\
\text { mayores costos de endeudamiento y menor atracción de inversionistas. } \\
\text { Relacionado al riesgo de expropiación o nacionalización de las centrales } \\
\text { hidráulicas y termoeléctricas }\end{array}$ \\
\hline & Riesgo Social & $\begin{array}{l}\text { Relacionado al conflicto social que pueden generar como consecuencia } \\
\text { vandalismo contra la propiedad privada y retrasar las operaciones de la } \\
\text { empresa }\end{array}$ \\
\hline & Riesgo Ambiental & $\begin{array}{l}\text { Relacionado a que las operaciones de la empresa afecten el } \\
\text { medioambiente de las comunidades aledañas } \\
\text { Relacionado a posibles desastres naturales en zonas de influencia que } \\
\text { paralicen las operaciones de la empresa }\end{array}$ \\
\hline
\end{tabular}

Fuente: Elaboración propia, 2018 
Riesgos internos: los riesgos internos son aquellos relacionados a los procesos más críticos de la operación de Enel y que están dentro del control de la empresa.

\begin{tabular}{|c|c|c|}
\hline Fuente & Tipo de riesgo & Riesgo \\
\hline \multirow{7}{*}{ Interno } & & $\begin{array}{l}\text { Relacionado con el riesgo de no contar con el caudal de agua } \\
\text { suficiente debido a fenómenos climatológicos para la } \\
\text { generación de energía en las centrales hidroeléctricas. }\end{array}$ \\
\hline & Riesgo de suministro & $\begin{array}{l}\text { Relacionado con el riesgo de no contar con el abastecimiento } \\
\text { de gas por parte de la empresa Transportadora de Gas del } \\
\text { Perú (TGP) a través del gaseoducto de Camisea para la } \\
\text { generación de energía eléctrica en las centrales } \\
\text { termoeléctricas. }\end{array}$ \\
\hline & & $\begin{array}{l}\text { Relacionado a la congestión de la línea de transmisión que } \\
\text { impida la entrega de energía a los clientes de forma oportuna. }\end{array}$ \\
\hline & Riesgo de operaciones & $\begin{array}{l}\text { Relacionado a la obsolescencia de las centrales hidroeléctricas } \\
\text { y termoeléctricas de la empresa, la mayor eficiencia de nuevas } \\
\text { tecnologías como por ejemplo el ciclo combinado así como por } \\
\text { la aparición de fuentes de energía alternativas como las } \\
\text { relacionadas con recursos energéticos renovables (RER). }\end{array}$ \\
\hline & \multirow[b]{2}{*}{ Riesgo de demanda } & $\begin{array}{l}\text { Relacionado con la posibilidad de que clientes libres puedan } \\
\text { contratar servicios de la competencia. }\end{array}$ \\
\hline & & $\begin{array}{l}\text { Relacionado con la posibilidad de ingreso de nuevos } \\
\text { competidores generando sobreoferta en el mercado teniendo } \\
\text { como consecuencia la reducción de precios. }\end{array}$ \\
\hline & Riesgo financiero & $\begin{array}{l}\text { Riesgo de crédito: relacionado al incumplimiento de los pagos } \\
\text { de las cuentas por cobrar relacionadas con la venta de energía } \\
\text { a clientes finales. } \\
\text { Riesgo tasa de interés: relacionado a la volatilidad de las tasas } \\
\text { de mercado que pueden afectar negativamente el valor de las } \\
\text { obligaciones financieras de la empresa. } \\
\text { Riesgo tipo de cambio: relacionado a la volatilidad del tipo de } \\
\text { cambio que puede generar un descalce en sus activos y } \\
\text { pasivos en moneda extranjera. } \\
\text { Riesgo de liquidez relacionado al descalce en el vencimiento } \\
\text { de los activos y pasivos de la empresa que le impidan } \\
\text { desarrollar sus actividades con normalidad. }\end{array}$ \\
\hline
\end{tabular}

Fuente: Elaboración propia, 2018. 
Se realizó la matriz de probabilidad e impacto para definir cuáles son los riesgos con mayor probabilidad de ocurrencia y mayor impacto a la empresa, los cuales son:

Riesgos externos (E): ambiental y social, relacionado a afectar el medioambiente de las comunidades aledañas, desastres naturales que afecten las operaciones de la empresa, y conflictos sociales, como vandalismos.

Riesgos internos (I): suministro, operaciones y demanda, relacionado al control de los caudales de los ríos, abastecimientos de gas, obsolescencia de las centrales y al ingreso de nuevos competidores.

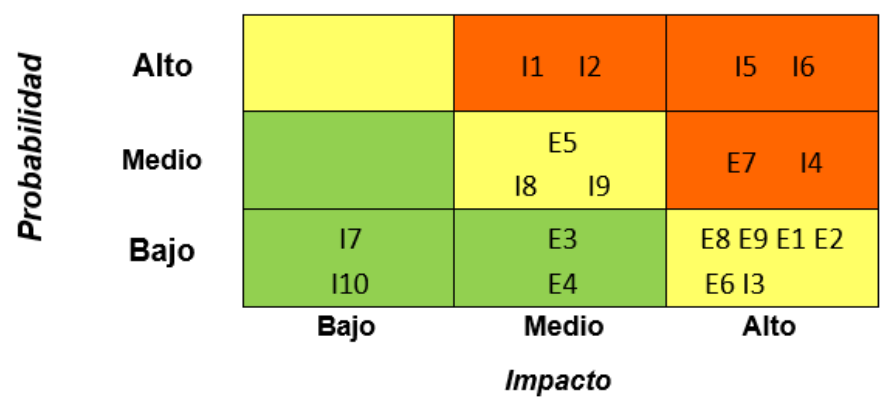

Fuente: Memoria y Notas a los Estados Financieros Consolidados Enel 


\section{Anexo 2}

\section{Entrevistas a Profundidad}

Expertos 1 del Sector de Generación de energía eléctrica en el Perú

Técnica empleada

Localización

Técnica

Objetivo del estudio:

Temas estudiados:

\section{Entrevista profundidad}

Lima Metropolitana

Entrevista a Profundidad

Obtener información acerca del sector de generación de energía eléctrica en el Perú. Identificar las amenazas y oportunidades del sector.

a) Entorno del sector de abastecimiento de energía eléctrica.

b) Buenas prácticas

c) Organización del sector

d) Factores internos y externos del sector

\section{FICHA TÉCNICA DEL ENTREVISTADO}

\begin{tabular}{ll}
\hline Nombre: & Pablo Raúl Lamas Noriega \\
Edad: & 58 años \\
Nacionalidad: & Peruano \\
Ocupación: & Empleado: Especialista Soporte Técnico Proyectos y Mejora de \\
& $\begin{array}{l}\text { Procesos Operación \& Mantenimiento Centrales Hidroeléctricas y } \\
\text { Renovables }\end{array}$ \\
Profesión: & Experto en generación de energía eléctrica en el Perú. \\
Distrito de & Lima \\
residencia: & \\
Breve reseña &
\end{tabular}

\section{Guía de Entrevista}

Día: Miércoles 28/02/2018 Hora: 11:30’ hrs.
Lugar: Entrevistado: Oficinas Administrativas Taller Moyopampa

Tema:

Duración: 


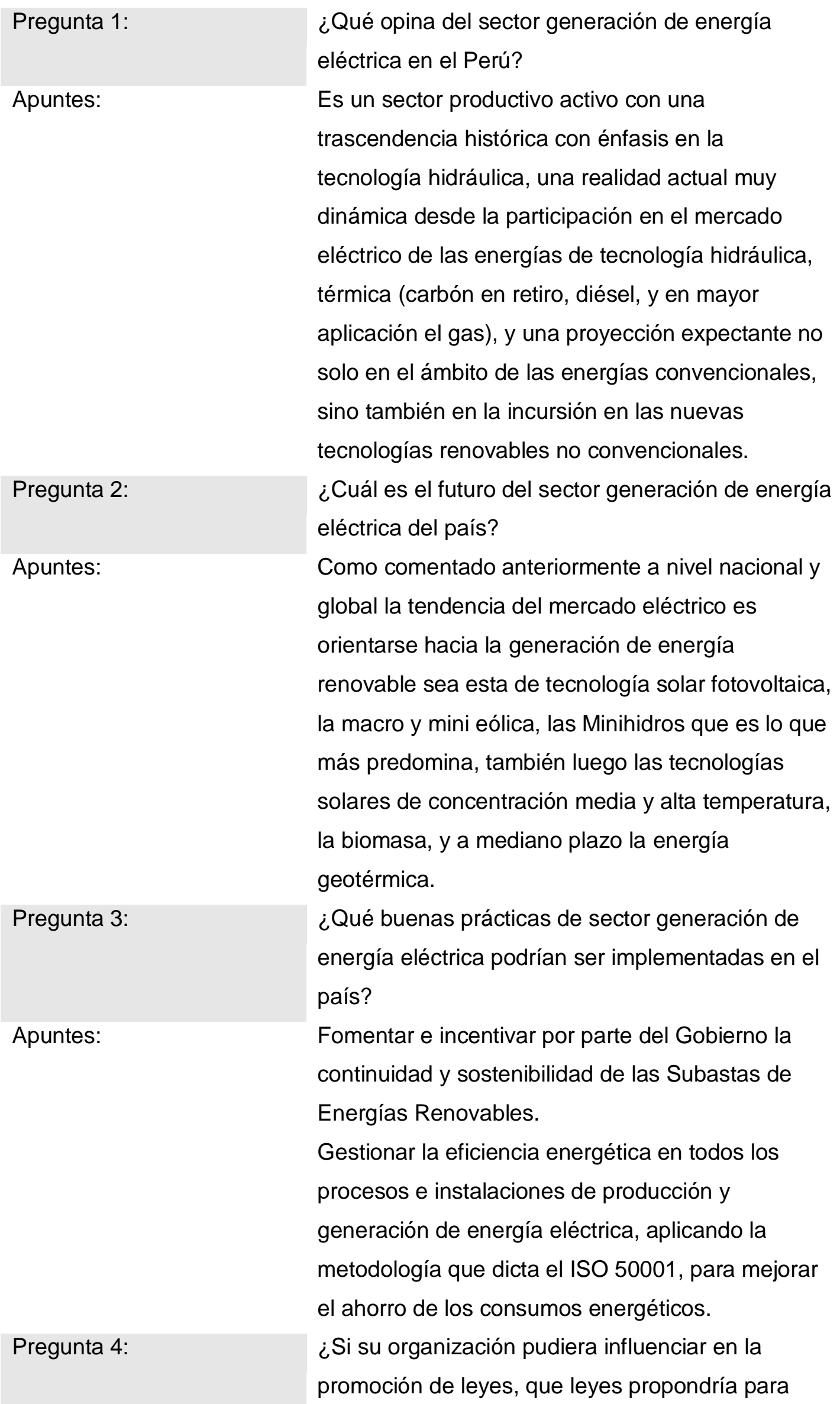


mejorar los indicadores de sector generación de energía eléctrica?

Apuntes:

La ley sobre la gestión de la energía que se encuentra directamente relacionada con la gestión de la eficiencia energética y el ISO 50001 en todos los procesos de producción.

Pregunta 5: ¿Cuáles son los factores en el sector generación de energía eléctrica que a su criterio afectan más al país?

Apuntes:

La promoción de la energía térmica de origen combustibles líquidos como el diésel, puesto que encarece el suministro eléctrico, como también los costos productivos, y además contribuye negativamente al cambio climático por el efecto del calentamiento global debido a la emisión de gases de efecto invernadero como lo es el $\mathrm{CO} 2$ en su mayor porcentaje producto de los procesos industriales, del transporte vehicular, y otros gases originados por descomposición de material orgánico depositado en ubicaciones de colmatación de aguas tipo presas, embalses que quedan al descubierto cuando son desembalsadas.: metano: $\mathrm{CH} 4$. El combustible tipo gas licuado o natural también afecta en menor grado al petróleo, sin embargo es motivo de la generación de $\mathrm{CO} 2$.

Pegunta 6:

¿En su experiencia cuales son los retos principales de una empresa de generación de energía eléctrica en el Perú?

Apuntes:

Los clientes tanto libres como regulados.

La competencia y las estrategias desarrolladas para adjudicarse contratos

El territorio como entorno principal del proceso de generación eléctrica en la ubicación de la planta de producción 
¿Hablamos de rotación, como ser exitoso en su manejo?

El procedimiento Just and Time permite mantener una producción adecuada, con mínimos recursos disponibles a tiempo real. También permite rotar las máquinas, las unidades generadoras propiciando ciclos de operación oportunos y holgados, frente a las faenas de mantenimiento a desarrollar en las unidades planificadas fuera de servicio, tratando de optimizar los factores de indisponibilidad de unidades o centrales en general.

Por el lado de los recursos humanos, la rotación permite ganar experiencia y redistribuir al factor personal para optimizar actividades en pro de la gestión de operaciones.

Pregunta 8: ¿En su opinión, quienes son los líderes en el sector generación de energía eléctrica en el Perú?

Son las empresas de generación de energía que se encuentran a la vanguardia tanto de procesos como de tecnología desde una referencia global, gestionan la energía con tecnología de vanguardia o de punta, como lo es el caso de desarrollar generación de energía con recursos energéticos renovables, incursionando para ello en campos generadores solares fotovoltaicos, campos generadores eólicos, etc.

Pregunta 9: ¿Cómo ve a ENEL GENERACIÓN PERÚ SAA en el mercado peruano?

Es la empresa que desarrolla este tipo de estrategia operativa gestionando nuevos proyectos de energía renovable, apuntando por la tecnología limpia, de rápida ejecución e implantación de proyectos, y retornos económicos en orden con los periodos previstos y la inversión realizada estratégicamente desde un respaldo global de Enel Italia. 
Pregunta 10:

Apuntes:

Pregunta 11:

Apuntes:

Pregunta 12:

Apuntes:

Pregunta 13:

Apuntes:
¿Qué medidas debería tomar el ente regulador para facilitar/mejorar el desempeño de la generación de energía eléctrica en el país?

Debe emitir regulaciones acordes con la inversión en energías renovables, para lograr la abierta y libre competencia frente a las tecnologías clásicas existentes. Con ello se podrá prescindir de los actuales programas de subastas de energía renovables, fomentando la inversión sin el uso de estas prácticas muy competitivas

¿Cómo se está dinamizando el mercado actual? La inversión en generación de tecnología hidroeléctrica se orienta a la operatividad, al desarrollo de proyectos, y al estudio de la tecnología mini hydro frente a la gran hidro. En cantidad son mayores en cantidad, las centrales mini hidráulicas o de energía renovable hidráulica con potencias instaladas menores a $20 \mathrm{MW}$, que con respecto a las centrales hidroeléctricas convencionales mayores a $20 \mathrm{MW}$.

¿Qué se espera para el sector en los próximos cinco años?

Aumentar la matriz energética hacia el crecimiento de las energías renovables, con la correspondiente disminución de la matriz energética orientada a las energías de origen térmico cuya fuentes de alimentación provienen de los combustibles fósiles en retiro y extinción.

¿Qué otros factores afectan a la organización y la administración de una empresa de generación de energía eléctrica?

El recurso del personal es muy neurálgico, la disponibilidad de mano de obra muy calificada es crítico para toda empresa líder y que plantea estratégicamente seguir en vanguardia frente a la competencia. 
Es por ello importante mantener políticas de recursos humanos adecuadas para la buena gestión del personal propio y de terceros que realizan servicios para el desarrollo de los procesos y el bienestar de la organización.

Las personas con cargos directivos deben ser seleccionados adecuadamente para liderar a los equipos de trabajo al unísono y en sintonía con los requerimientos de los procesos productivos, la metas de la empresa y el alcance de la visión organizativa. 


\section{Entrevistas a profundidad}

\section{Experto 2 en el Sector de Generación de energía eléctrica en el Perú}

Técnica empleada

Localización

Técnica

Objetivo del estudio:

Temas estudiados:

\section{Entrevista profundidad}

Lima Metropolitana

Entrevista a Profundidad

Obtener información acerca del sector de generación de energía eléctrica en el Perú. Identificar las amenazas y oportunidades del sector.

a) Entorno del sector de abastecimiento de energía eléctrica.

b) Buenas prácticas

c) Organización del sector

d) Factores internos y externos del sector

\section{FICHA TÉCNICA DEL ENTREVISTADO}

Nombre:

Cesar Arturo Díaz Ponce

Edad: 56 56

Nacionalidad:

Peruano

Ocupación:

Especialista en Tecnología Hidráulica, térmicas

Profesión: Ingeniero Electrónico

Distrito de Surco

residencia:

\section{Guía de Entrevista}

Día: 11.06 .2019 Hora: 13:00 pm

Lugar: Oficinas Centrales Entrevistado: Cesar Arturo Díaz Ponce

Hidráulicas

Duración: 30 min

Pregunta 1: ¿Qué opina del sector generación de energía eléctrica en el Perú?

Apuntes: En estos momentos en el Perú, en el sector de generación de energía como en otras sectores la inversión está paralizada por conflictos sociales o por estabilidad política 


\begin{tabular}{|c|c|}
\hline Pregunta 2: & $\begin{array}{l}\text { ¿Cuál es el futuro del sector generación de energía } \\
\text { eléctrica del país? }\end{array}$ \\
\hline Apuntes: & $\begin{array}{l}\text { El futuro es la energía renovable, fotovoltaica o } \\
\text { eólica, }\end{array}$ \\
\hline Pregunta 3: & $\begin{array}{l}\text { ¿Qué buenas prácticas de sector generación de } \\
\text { energía eléctrica podrían ser implementadas en el } \\
\text { país? }\end{array}$ \\
\hline Apuntes: & $\begin{array}{l}\text { Es importante la generación de energía de la } \\
\text { empresa privada, como las empresas mineras que } \\
\text { están empezando a implementar plantas } \\
\text { fotovoltaicas para consumo propio }\end{array}$ \\
\hline Pregunta 4: & $\begin{array}{l}\text { ¿Si su organización pudiera influenciar en la } \\
\text { promoción de leyes, que leyes propondría para } \\
\text { mejorar los indicadores de sector generación de } \\
\text { energía eléctrica? }\end{array}$ \\
\hline Apuntes: & $\begin{array}{l}\text { La promoción de leyes a favor de la inversión en } \\
\text { energías renovables }\end{array}$ \\
\hline Pregunta 5: & $\begin{array}{l}\text { ¿Cuáles son los factores en el sector generación } \\
\text { de energía eléctrica que a su criterio afectan más } \\
\text { al país? }\end{array}$ \\
\hline Apuntes: & $\begin{array}{l}\text { Un factor importante es que le precio del gas no } \\
\text { está sincerado, otro es que falta impulsar más la } \\
\text { generación de energía fotovoltaica y eólica }\end{array}$ \\
\hline Pregunta 6: & $\begin{array}{l}\text { ¿Qué es lo peor que le ha sucedido en una empresa } \\
\text { de generación de energía eléctrica en el Perú? }\end{array}$ \\
\hline Apuntes & $\begin{array}{l}\text { De lo que recuerdo es que sea administrada por el } \\
\text { Estado }\end{array}$ \\
\hline
\end{tabular}




\section{Entrevistas a profundidad}

\section{Experto 3 en el Sector de Generación de energía eléctrica en el Perú}

Técnica empleada

Localización

Técnica

Objetivo del estudio:

Temas estudiados:

\section{Entrevista profundidad}

Lima Metropolitana

Entrevista a Profundidad

Obtener información acerca del sector de generación de energía eléctrica en el Perú. Identificar las amenazas y oportunidades del sector.

a) Entorno del sector de abastecimiento de energía eléctrica.

b) Buenas prácticas

c) Organización del sector

d) Factores internos y externos del sector

\section{FICHA TÉCNICA DEL ENTREVISTADO}

Nombre:

Edad:

Nacionalidad:

Ocupación:

Profesión:

Distrito de residencia:

Lince

\section{Guía de Entrevista}

Día: 10.06.2018

Lugar: Oficina

Administrativa Maranga II

Duración: 25 min

\section{Pregunta 1:}

Apuntes:

\section{Manuel Jesús Pérez Melgar}

35

Peruano

Especialista en Eficiencia de la Producción Ingeniero Eléctrico

Lince
Hora:.09:00am

Entrevistado: Manuel Jesús Pérez Melgar

¿Qué opina del sector generación de energía eléctrica en el Perú?

Es uno de los principales sectores de operaciones y de desarrollo del país que sustenta el recurso energético para los requerimientos de los usuarios desde diferentes frentes consumidoras como lo 
domiciliario, lo industrial, de índole urbano y rural a lo largo de todo el territorio peruano.

Pregunta 2: ¿Cuál es el futuro del sector generación de energía eléctrica del país?

Apuntes:

Pregunta 3: El futuro de la generación eléctrica en el Perú tiende como en el ámbito global a desarrollar en mayor cuantía y en mayor calidad sostenible en sintonía con el ecosistema a las energías renovables no convencionales.

En este sentido la tradicional generación de energía desde las fuentes de origen térmico e hidráulico, ahora evolucionan a favor del medio ambiente con la incursión de energía de índole solar fotovoltaico y eólico de gran magnitud; los nuevos campos generadores de energía ahora, en los últimos tiempos, se implantan en el Perú por empresas nacionales de origen transnacional en base a subastas de energías renovables con el gobierno, o por medio de contratos de largo alcance con el sector privado.

¿Qué buenas prácticas de sector generación de energía eléctrica podrían ser implementadas en el país?

Apuntes:

A nivel internacional se han venido desarrollando matrices energéticas orientadas al desarrollo de las energías renovables sobre todo en lo que respecta a las tecnologías solar fotovoltaica y eólica de aerogeneradores de eje horizontal en tierra fuera del mar y dentro del mar, también con menor énfasis la generación de energía hidráulica desde la implementación de mini centrales hidroeléctricas en los cursos de agua de bajo salto y mediano caudal, y por ultimo a nivel de Estados Unidos y algunos países de Europa la energía geotérmica también ha migrado de una etapa de estudio a una 
de ejecución e implementación de proyectos concretos.

En el Perú la energía geotérmica se ha desarrollado a nivel de estudio de investigación de yacimientos posibles en el sur del país. La energía hidroeléctrica del tipo mini hidráulico se ha desarrollado siempre sin embargo con tecnología antigua, es decir con turbinas tipo Pelton, Francis, y Kaplan, sin embargo, últimamente se ha incursionado en algunas empresas con el uso de las nuevas tecnologías de origen mini hidráulico. Por último las prácticas internacionales de las centrales solares fotovoltaicas y las centrales eólicas se han iniciado a desarrollar e implementar a lo largo del litoral peruano donde las fuentes de radiación solar y de viento son mejores a nivel nacional.

Pregunta 4: ¿Si su organización pudiera influenciar en la promoción de leyes, que leyes propondría para mejorar los indicadores de sector generación de energía eléctrica?

Apuntes: Las centrales generadoras de energía venden dos variables principales dentro de su ámbito de producción, por un lado la energía generada diaria, mensual, o anual, y por otro lado la potencia firme que cada planta de producción puede alcanzar en base a sus recursos de generación y de volúmenes de embalses estacionales; sin embargo las nuevas centrales renovables de viento y de sol por energía fotovoltaica solo pueden en base a su tecnología entregar energía pero no potencia firme; en este sentido las políticas energéticas deberán impulsar la venta de potencia firme a las centrales renovables para poder hacerlas más rentables y atractivas al sector para futuras inversiones al respecto. 
Pregunta 5:

Apuntes:
¿Cuáles son los factores en el sector generación de energía eléctrica que a su criterio afectan más al país?

La política energética actual mantiene una matriz energética donde prevalece dos tipos de tecnologías clásicas y convencionales como lo son la energía hidráulica y la energía térmica con el predominio de centrales hidroeléctricas y centrales a gas o duales con la inclusión del diésel y de ciclo combinado respectivamente. Los porcentajes de participación de estas tecnologías en la matriz energética son muy grandes, alrededor del $95 \%$ considerando la suma de ambos casos, y dejando un pequeño porcentaje, en promedio del $5 \%$, mínimo para las centrales renovables, las cuales deberán remontar su participación actual para ampliar su margen favoreciendo al medio ambiente desde el ámbito sostenible, muy favorable en este sentido a la eficiencia energética y a la disminución de los efectos del cambio climático y gases de efecto invernadero.

Otro tema importante es el sustentado en la respuesta anterior a la pregunta $N^{\circ} 4$

Pregunta 6: ¿Qué es lo peor que le ha sucedido en una empresa de generación de energía eléctrica en el Perú? Apuntes es importante y a la ves critico no lograr desarrollar la generación declarada ante los contratos de producción con el gobierno, o con el sector privado, por diversos motivos técnicos, pero sobre todo por la disminución de sus recursos propios desde sus fuentes de origen como son en el caso de la energía hidroeléctrica la dotación de agua en suficiente flujo de caudal para poder cumplir sus márgenes previstos, 
o en el caso de las centrales térmicas la disminución del flujo de gas en su proceso de producción energética.

En el caso de los proyectos en estudio o en construcción es muy crítico no contar con la titularidad de los emplazamientos territoriales, puesto que los mismos pueden ser negociados o vendidos a otros postores o interesados. 
Entrevista a Profundidad

Personal de Operaciones

Técnica empleada

Localización

Técnica

Objetivo del estudio:

Temas estudiados:

\section{Entrevista profundidad}

Lima Metropolitana

Entrevista a Profundidad

Obtener información acerca del sector de generación de energía eléctrica en el Perú. Identificar las amenazas y oportunidades del sector.

a) Entorno del sector de abastecimiento de energía eléctrica.

b) Buenas prácticas

c) Organización del sector

d) Factores internos y externos del sector

FICHA TÉCNICA DEL ENTREVISTADO

Nombre:

Edad:

Nacionalidad:

Ocupación:

Profesión: Ingeniero

Distrito de residencia: Chosica

\section{Guía de Entrevista}

Día: 03.06.2019

Lugar: $\mathrm{CH}$ Huinco

Duración: 30 min

Pregunta 1:

Apuntes:

Pregunta 2:

\section{Ramón David, Monteviller Serraro}

59

Peruano

Operador de Centrales Hidráulicas

Ingeniero Eléctrico

Chosica - Lurigancho

Hora: 10:00 am

¿Cuáles son las principales operaciones de ENEL GENERACIÓN PERÚ SAA?

Maniobras de alta, media y baja tensión.

Arranque y parada de máquinas de generación

Control de avisos de fallas de mantenimiento.

control de instalaciones de equipos eléctricos ¿Podría describir los procesos operativos de ENEL GENERACIÓN PERÚ SAA? 
Apuntes:

Arranque de máquina - sincronizar y colocarlo en la red de energía, mediante el cierre del interruptor de alta tensión.

Pregunta 3:

¿Las empresas de generación de energía de la competencia cuentan con un plan de logística de manera adecuada?

Apuntes:

En efecto, hay que recordar que son empresas que tienen años en el sector por lo tanto cuenta con especialistas en el área logística que soportan la contratación de contratistas.

Pregunta 4: ¿Las empresas de generación de energía de la competencia cuentan con un plan de operaciones de manera adecuada?

Apuntes: Las principales empresas competidoras (Electro Perú, Mantaro, kallpa) si cuentan con un plan de operaciones,

Pregunta 5: $¿$ ¿De acuerdo con el objetivo que se ha planteado en esta entrevista, que sugerencias nos puede dar para implementar el Plan Estratégico para la empresa ENEL GENERACIÓN PERÚ SAA?

Apuntes:

Cambio de equipamiento antiguos (bobinados, reguladores, cables de alta tensión) que tienen más de 40 años.

Pregunta 6: ¿Estratégicamente que hace la empresa ENEL GENERACIÓN PERÚ SAA para mejorar y/o respaldar sus operaciones?

Apuntes:

Enel cuenta con otros sistemas alternativas (solar \& wind) que le permite respaldar si es que hubiese problemas en el suministro de energía.

Pregunta 7: ¿Cuáles son los procesos críticos que se presenta?

Apuntes: Cambio de tecnología permite reducir el KPI de indisponibilidad de las máquinas y cumplir con lo exigido por el regulador de energía (COES) 
Entrevista a Profundidad

Personal Administrativo

Técnica empleada

Localización

Técnica

Objetivo del estudio:

Temas estudiados:

\section{Entrevista profundidad}

Lima Metropolitana

Entrevista a Profundidad

Obtener información acerca del sector de generación de energía eléctrica en el Perú. Identificar las amenazas y oportunidades del sector.

a) Entorno del sector de abastecimiento de energía eléctrica.

b) Buenas prácticas

c) Organización del sector

d) Factores internos y externos del sector

FICHA TÉCNICA DEL ENTREVISTADO

\begin{tabular}{ll}
\hline Nombre: & Diana Melissa Muñoz Roca \\
Edad: & 25 años \\
Nacionalidad: & Peruana \\
Ocupación: & Analista de Planificación y Control \\
Profesión: & Administradora de Empresas \\
Distrito de residencia: & San Miguel
\end{tabular}

\section{Guía de Entrevista}

Día: 05.06.2019

Hora: 10:30 am

Lugar: Oficina Adm.

Entrevistado: Diana Melissa Muñoz Roca

Maranga II

Duración: 20 min

Pregunta 1:

Apuntes:

Pregunta 2:
¿Qué tipo de estrategias aplica la empresa? Enfoque de Liderazgo en costos, está enfocado en el mercado renovables buscando optimizar los servicios a través de la innovación y digitalización ¿Cómo luce la calidad de los servicios frente a los de la competencia? 
Apuntes:

Como empresa que se preocupa por la seguridad de la entrega de energía y la comunicación en tiempo real con los clientes.

Pregunta 3: ¿Cuáles son las estrategias que viene aplicado la empresa?

Apuntes:

Como mencione, como estrategia fundamental es la innovación y digitalización de sus procesos.

Pregunta 4: ¿Quiénes son los competidores de ENEL GENERACIÓN PERÚ SAA?

Apuntes:

Engie, Stakcraft, Termochilca y Kallpa

Pregunta 5: ¿Qué mercados se vienen atendiendo?

Apuntes: Mercados renovables, hidráulicas y térmicas, el mercado tradicional de generación de energía.

Pregunta 6: ¿Cómo monitorear los procesos?

Apuntes:

A travez de los KPls económicos y de producción

Pregunta 7: ¿Cómo se medirá la capacidad de los procesos de negociación?

Apuntes:

Por la optimización de costos, asegurando la calidad del servicio.

Pregunta 8: ¿Qué estrategias de negocios se aplica para la captación del cliente?

Apuntes:

Pruebas en situ, es decir el que sea parte de la experiencia Enel 
Entrevista a Profundidad

Personal de RRHH

Técnica empleada

Localización

Técnica

Objetivo del estudio:

Temas estudiados:

\section{Entrevista profundidad}

Lima Metropolitana

Entrevista a Profundidad

Obtener información acerca del sector de generación de energía eléctrica en el Perú. Identificar las amenazas y oportunidades del sector.
a) Entorno del sector de abastecimiento de energía eléctrica.
b) Buenas prácticas
c) Organización del sector
d) Factores internos y externos del sector

FICHA TÉCNICA DEL ENTREVISTADO

\begin{tabular}{ll}
\hline Nombre: & David Ulises Rodriguez Del Aguila \\
Edad: & 37 \\
Nacionalidad: & Peruano \\
Ocupación: & Business Partner \\
Profesión: & Ingeniero Industrial \\
Distrito de & La Molina \\
residencia: &
\end{tabular}

\section{Guía de Entrevista}

Día:

Lugar:

Tema:

Duración:

Pregunta 1:

Apuntes:
Hora:

Entrevistado:

¿Cuáles son los objetivos estratégicos de recursos humanos en la empresa de ENEL GENERACIÓN PERÚ SAA?

Desarrollo de los trabajadores en el ámbito profesional y personal implementando una medición de metas alcanzadas por el personal en el cumplimiento de los objetivos organizacionales. 
Pregunta 2:

Apuntes:

Pregunta 3:

Apuntes:

Pregunta 4:

Apuntes:
Fomentar la movilidad funcional y geográfica de las personas a través de concursos nacionales e internacionales (casa matriz), con el objetivo de lograr que las personas adquieran conocimientos y experiencia que aporten en su crecimiento profesional y al cumplimiento de las metas organizacionales.

Debido a que la compañía tiene más del $50 \%$ de personal que supera los 50 años de edad, se ha planteado implementar un programa de integración generacional con el fin de que los trabajadores nuevos puedan recibir el know how de aquellos expertos que tienen mas de 30 años de servicio.

¿Cómo se desarrollan el liderazgo en la compañía? Contamos con un programa de liderazgo LIDERA, que brindar herramientas de liderazgo y gestión a todos los líderes de la compañía, con el fin de brindar soporte para buscar alternativas de solución.

Contamos con un programa de comité de innovación que las diferentes áreas con sus líderes presentan, para su evaluación y posterior implementación de ser el caso. ¿Cuál será el estilo de liderazgo de los gerentes? El perfil de los managers es en su mayoría joven, se basa fundamentalmente en el manejo de la comunicación en la compañía, mediante el cual logran motivar e integrar, contribuyendo al desarrollo de sus colaboradores. Siendo una gerencia horizontal.

¿Cómo se maneja el clima laboral en la compañía?

Actualmente se ofrecen beneficios laborales que superan los exigidos por la ley.

Se maneja una comunicación activa con los trabajadores en cuando a necesidades profesionales y personales para lograr un equilibrio entre ambas variables.

Pregunta 5: ¿Cuál es la problemática laboral que maneja actualmente?

Apuntes: desarrollo profesional y no hay retención de los mismo, 
debido a que existen propuestas en el mercado con mayores beneficios económicos y de crecimiento profesional por el largo periodo que se mantienen en los mismo puestos. 
Entrevista a Profundidad

\section{Manager}

Técnica empleada

\section{Localización}

Técnica de reclutamiento

Objetivo del estudio:

Temas estudiados:

\section{Entrevista profundidad}

El tipo de técnica que se aplicó a la presente investigación son preguntas directas formuladas previamente antes de la entrevista.

Reunir información para conocer la percepción que se tiene acerca del sector de generación de energía eléctrica en el Perú.

Evaluar las oportunidades y amenazas que debe tomar en cuenta ENEL GENERACIÓN PERÚ SAA para continuar compitiendo en el mercado.

Conocer la misión, visión, valores.
a) Generación de energía eléctrica
b) Oportunidades del sector
C) Amenazas del sector
d) Estrategias que aplica la empresa

FICHA TÉCNICA DEL ENTREVISTADO

Nombre:

Edad:

Nacionalidad:

Ocupación:

Profesión:

Distrito de residencia:

\section{Guía de Entrevista}

Día: 10.06.2019 Hora: 19:00pm

Lugar: Oficina Central Entrevistado: Ernesto Villanueva Roca
Ernesto Villanueva Roca

66

\section{Peruano}

Head Tecnología Renovables

Ingeniero Eléctrico

Surco

ENEL

Duración: 20 min 


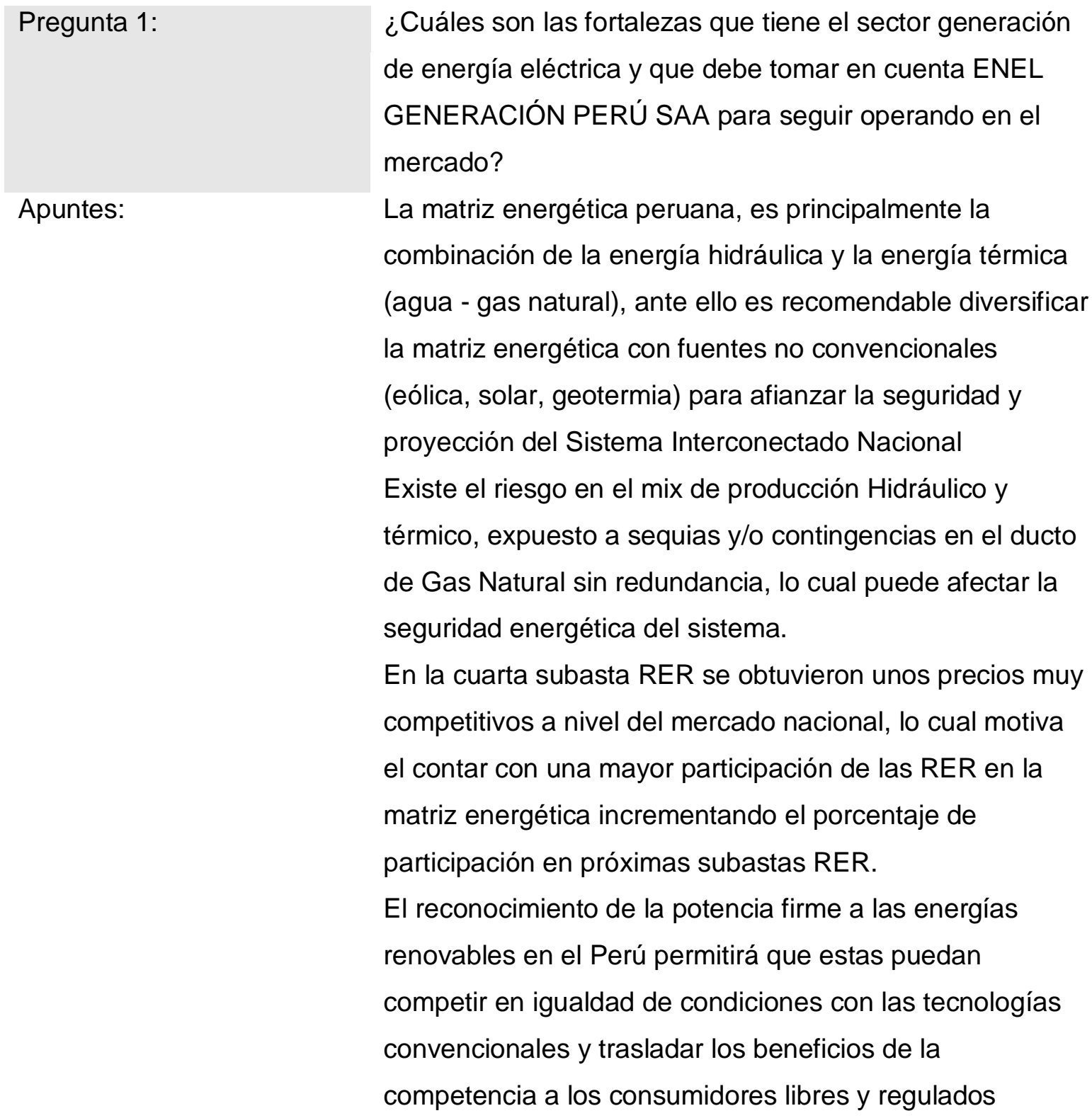

Algunas fortalezas:

$\checkmark \quad$ Leyes que fomentan la inversión privada

$\checkmark \quad$ Plan de futuras inversiones, que amplían el consumo de energía

$\checkmark \quad$ Crecimiento demográfico en todas las ciudades

$\checkmark \quad$ Apertura al desarrollo de energía renovables

Pregunta 2:

¿Cuáles son las oportunidades que brinda el sector a

ENEL GENERACIÓN PERÚ SAA para continuar operando en el mercado? 
Apuntes:

Pregunta 3:

Apuntes:

Pregunta 4:

Apuntes:
Migración de generación de la energía eléctrica para $100 \%$ renovable

Futura - apertura de generación eléctrica a todo el sistema automotor

Integración con nuestros países vecinos Latinoamericanos ¿Cuáles son las debilidades representativas que presenta el sector de energía eléctrica?

Ruido Político y Judicial

Lento proceso de reactivación publica

Ruido por Corrupción - Obredecht

Bajos Precios de Energía

¿Cuáles son las amenazas que presenta el sector de energía eléctrica en el país y que afectaría directamente a la empresa ENEL GENERACIÓN PERÚ SAA?

Existe una tendencia mundial para invertir en energía renovables no convencionales que está acompañada de una drástica reducción de precios en las tecnologías solar y eólica por su alta competitividad.

La alta competitividad de los precios de las RER es una oportunidad que el Perú ha aprovechado incrementando su participación en la matriz energética para lograr precios de la electricidad más competitivos en el largo plazo.

La matriz energética peruana es vulnerable por estar basada en gas natural e hidroelectricidad lo que obliga a impulsar una política de diversificación de la matriz con un incremento de la participación de las Energías Renovables no convencionales

Algunas Amenazas:

Pocos contratistas de talla mundial

Fabricantes con productos no confiables, con desarrollo cerrado, hecho a la medida del cliente 
La expansión tecnológica que desactualizada la inversión en poco tiempo y requiere una pronta reinversión de activos

Cambio Climático, afección de reservas de agua, incremento de radiación solar, viento y polución Expansión demográfica por migración externa, generando aumento de delincuencia y riesgo de robo a los activos Conflictos sociales con las comunidades aledañas al entorno de Enel

Enfermedades Virales

Perdida del Crecimiento Económico

Pregunta 5:

Apuntes:

Pregunta 6:

Apuntes:

Pregunta 7:

Apuntes:
¿Estratégicamente que hace la empresa ENEL

GENERACIÓN PERÚ SAA para mejorar y/o respaldar sus operaciones?

Crecimiento de Activos en nuevas tecnologías (Inversiones)

Mejora continua de sus procesos, que permitan optimizar recursos y gastos

Sostenimiento de los activos en curso ¿Cuál es la ventaja competitiva de ENEL GENERACIÓN PERÚ SAA?

Ser parte de una empresa externa, que permite el intercambio de conocimientos, experiencias y estrategias ¿Cuál son las herramientas de mercado que aplica ENEL GENERACIÓN PERÚ SAA?

Bolsa de Valores - Precio de las acciones del mercado (Desconozco)

Aplicación de Normativas ISO (Calidad, Seguridad, Medio Ambiente entre las principales)

SAP

Innovación

Herramientas Web - Office 365, Correo Web, Reportes en Línea

Herramientas Informáticas Portátiles 
Predictivas de Mantenimiento (Desarrollo)

Predicciones Climatológicas (Manejo de embalses)

Reporte de Conflictos con las Comunidades 
Entrevista a Profundidad

\section{Cliente (REP)}

Técnica empleada

Localización

Técnica de reclutamiento

Objetivo del estudio:

Temas estudiados:

\section{Entrevista profundidad}

El tipo de técnica que se aplicó a la presente investigación son preguntas directas formuladas previamente antes de la entrevista.

Reunir información para conocer la percepción que se tiene acerca del sector de generación de energía eléctrica en el Perú.

Evaluar las oportunidades y amenazas que debe tomar en cuenta ENEL GENERACIÓN PERÚ SAA para continuar compitiendo en el mercado.

Conocer la misión, visión, valores.
a) Generación de energía eléctrica
b) Oportunidades del sector
c) Amenazas del sector
d) Estrategias que aplica la empresa

FICHA TÉCNICA DEL ENTREVISTADO

Nombre:

Edad:

Nacionalidad:

Ocupación:

Profesión:

Distrito de

residencia:

\section{Guía de Entrevista}

Día: 11.06.2019

Lugar: San Isidro

Duración: 55 min
Luis Enrique Olivos Román

43

Peruano

Contralor

Licenciado en Administración y Finanzas

Surco
Hora: 10:00am

Entrevistado: Luis Olivos Román 


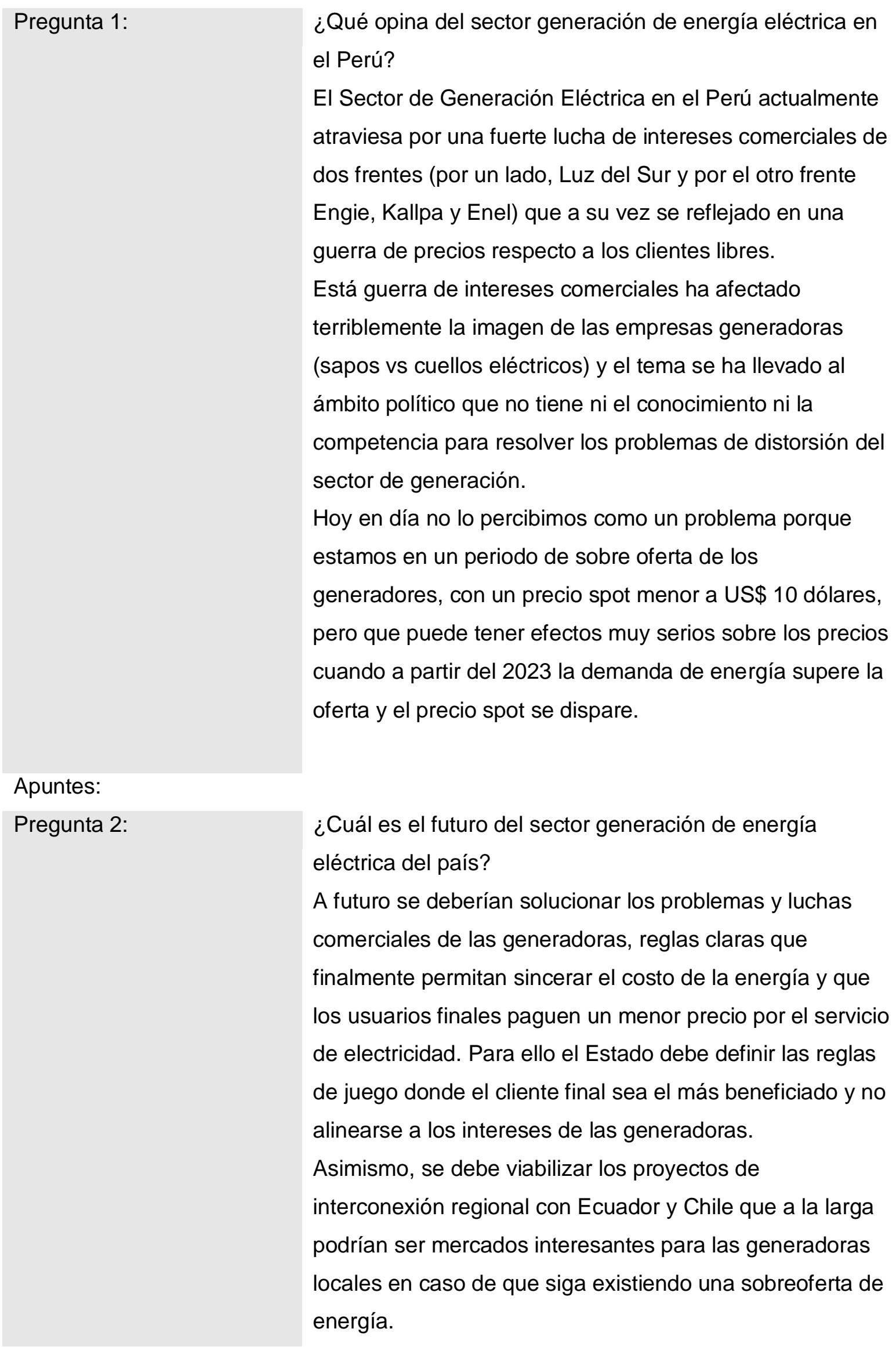


Otro tema a futuro es definir si nuestra matriz de generación debe apuntar a crecer en fuentes renovables. Actualmente no superan el $5 \%$ y los costos de las RER son asumidos por los usuarios finales.

Apuntes:

Pregunta 3: ¿Qué buenas prácticas de sector generación de energía eléctrica podrían ser implementadas en el país? Generación con recursos renovables (eólica, solar).

Apuntes:

Pregunta 4: ¿Si su organización pudiera influenciar en la promoción de leyes, que leyes propondría para mejorar los indicadores de sector generación de energía eléctrica?

Apuntes: Sincerar las reglas de juego para que el costo de energía sea el menor para los usuarios finales. Hoy en día gran parte del costo de la energía que pagan los usuarios finales corresponde a subsidios.

Definir a través de una política de estado como aseguramos la demanda futura de energía en el país (¿Hidroeléctricas? ¿Renovables? ¿Generación en base a gas?).

En el caso de las hidroeléctricas, pese al enorme potencial que tiene el país, hoy en día no resulta atractivo realizar ninguna inversión y además enfrentan una serie de complejidades en la ejecución de los proyectos (oposición ambiental, oposición social, la discusión sobre la propiedad del agua, etc.).

Pregunta 5: ¿Cuáles son los factores en el sector generación de energía eléctrica que a su criterio afectan más al país?

Apuntes: Los intereses comerciales de las generadoras, las reglas de juego existentes que les permiten obtener ventajas comerciales aun sin producir (retiran al spot del sistema). Esto sin duda puede beneficiar a los clientes libres. Pero el tema de fondo es que tales beneficios nunca llegan al usuario final que finalmente paga un precio mucho mayor al spot. 


\begin{tabular}{|c|c|}
\hline Pregunta 6: & $\begin{array}{l}\text { ¿Qué opina de la generación de energía eléctrica en el } \\
\text { Perú? ¿Y cómo la ve en relación con la región? }\end{array}$ \\
\hline Apuntes: & $\begin{array}{l}\text { Existen países de la región como Chile que están } \\
\text { impulsado el uso de energía renovables como fuentes de } \\
\text { generación de energía. Debemos apuntar a una mayor } \\
\text { generación con fuentes renovables. }\end{array}$ \\
\hline Pregunta 7: & $\begin{array}{l}\text { ¿Qué es lo peor que le ha sucedido en una empresa de } \\
\text { generación de energía eléctrica en el Perú? }\end{array}$ \\
\hline Apuntes: & No tengo referencia de ningún caso. \\
\hline Pregunta 8: & $\begin{array}{l}\text { ¿En su experiencia cuales son los retos principales de una } \\
\text { empresa de generación de energía eléctrica en el Perú? }\end{array}$ \\
\hline Apuntes: & $\begin{array}{l}\text { Las empresas de Generación deberían apuntar a la } \\
\text { implementación de nuevas tecnologías y buscar fuentes } \\
\text { de generación renovables (eólica, solar) buscando } \\
\text { mecanismos que permitan asegurar la potencia (por } \\
\text { ejemplo, baterías). } \\
\text { Asimismo, que las eficiencias que generan puedan hacer } \\
\text { que el costo de generación sea menor y se traslade a los } \\
\text { usuarios finales. }\end{array}$ \\
\hline Pregunta 9: & $\begin{array}{l}\text { ¿En su opinión, quienes son los líderes en el sector } \\
\text { generación de energía eléctrica en el Perú? }\end{array}$ \\
\hline Apuntes: & $\begin{array}{l}\text { Los líderes del sector de Generación en Perú son Engie, } \\
\text { Enel y Kallpa. }\end{array}$ \\
\hline Pregunta 10: & $\begin{array}{l}\text { ¿Qué medidas debería tomar el ente regulador para } \\
\text { facilitar/mejorar el desempeño de la generación de } \\
\text { energía eléctrica en el país? } \\
\text { El ente regulador debe buscar soluciones de largo plazo } \\
\text { que reactiven las inversiones en el sector, además de } \\
\text { incentivar las inversiones en las zonas norte y sur del } \\
\text { país, lo cual tendría un impacto significativo en los } \\
\text { proyectos de transmisión y distribución a desarrollarse en } \\
\text { dichas zonas y a su vez promoverían el acceso al servicio } \\
\text { eléctrico. }\end{array}$ \\
\hline
\end{tabular}

Apuntes:

Pregunta 11:

¿Cómo se está dinamizando el mercado actual? 
Existe una guerra comercial entre las generadoras que afecta tanto el precio de la energía, así como la reputación de las principales empresas generadoras.

Apuntes: No se aprecia ninguna dinamización, no hay inversiones significativas en proyectos de generación.

Pregunta 12: ¿Qué se espera para el sector en los próximos cinco años?

Apuntes:

Tanto la oferta como la demanda se concentran en la zona centro del país y, según las estimaciones del COES, este panorama no cambiaría en el corto plazo.

La descentralización es importante por lo que se debe incentivar el desarrollo de proyectos de gran envergadura en el norte y sur del país, implementar nuevas tecnologías, fomentar la generación con recursos renovables y principalmente brindar al usuario final un precio que sea razonable respecto al Spot,

Pregunta 13: ¿Qué otros factores afectan a la organización y la administración de una empresa de generación de energía eléctrica?

Apuntes:

Los niveles actuales del precio spot brindan incentivos para que las generadoras incrementen su base de clientes libres, acuden al Mercado de Electricidad para efectuar retiros a un costo inferior al de su generación. Esto genera una enorme guerra comercial, cabe mencionar que en los dos últimos años 1,100 empresas han migrado al mercado libre.

Otro factor a tener en cuenta es la época de lluvia que tiene mucha incidencia sobre la fuente de energía (agua o gas), lo cual tiene impacto sobre la capacidad de generación y despacho en cada una de ellas. 
Entrevistas a Profundidad

Experto $\mathrm{N}^{\circ} 1$ ajenos a la Empresa

Técnica empleada

Localización

Entrevista profundidad

Técnica

Lima Metropolitana

Objetivo del estudio:

Entrevista a Profundidad

Obtener información acerca del sector de generación de energía eléctrica en el Perú. Identificar las amenazas y oportunidades del sector.

Temas estudiados:

a) Entorno del sector de abastecimiento de energía eléctrica.

b) Buenas prácticas

c) Organización del sector

d) Factores internos y externos del sector

\section{FICHA TÉCNICA DEL ENTREVISTADO}

Nombre: Jorge Pastor

Edad: $\quad 38$ años

Nacionalidad: Peruano

Ocupación: Profesional en desarrollo de Proyectos de Energía

Profesión: Ingeniero Eléctrico

Distrito de Lima

residencia:

Breve reseña

\section{Guía de Entrevista}

Día: Miércoles 15/07/2018 Hora: 11:30’ hrs.

Lugar: Entrevistado: Miraflores

Tema:

Duración:

Pregunta 1: ¿Qué factores consideras importantes para ser competitivos en el mercado energético en el Perú?

Apuntes: Los principales factores para que una empresa generadora sea competitiva, es que sea respaldad por un poder económico sólido que permita 
afrontar los cambios regulatorios en el sector e invertir en nuevas tecnologías.

Es importante como estrategia comercial del sector, para atraer nuevos clientes libres, desarrollar dentro de sus servicios valores agregados que permitan obtener acuerdos más flexibles cerrando contratos a largo plazo.

Pregunta 2:

¿Es favorables para las generadoras contar con un Mix de Generación de Energía?

Apuntes:

Si es favorable, dada su diversidad y ecosistemas únicos, el Perú es rico en climas y recursos renovables (energía eólica, solar, geotérmica, biomasa e hidroeléctrica), los cuales brindan la capacidad para que existan fuentes alternativas al gas natural y a las grandes hidroeléctricas para generar energía eléctrica.

Pregunta 3: ¿Cuáles son los factores en el sector de energía eléctrica que a su criterio afecta más a las generadoras?

Apuntes: A mi criterio, el no llevar un adecuado control en los procesos de generación trae consigo deficiencias e interrupciones en la generación en las plantas.

El no contar con personal capacitado en las diferentes áreas que permita dar un soporte en cuanto a la generación de energía.

Pregunta 4: ¿Crees usted que es importante la ubicación geográfica de las centrales de generación?

Apuntes: Efectivamente es importante, porque depende de donde se encuentre instalado la planta para aprovechar una mayor de recursos; es decir si se proyecta consumir un cierto volumen de agua (en caso de hidroeléctricas), si en esa zona existe otras fuentes (lagunas) que permiten un mayor 
incremento de caudal, que como consecuencia permite producir mayor cantidad de MW.

Esto mismo sucede para otras fuentes de energía renovables, como es el caso de: Eólicas (Talara y Nazca) y solares (Piura y Moquegua).

Pregunta 5:

Apuntes:
¿Crees usted que el Perú cuenta con proveedor calificados para soporte a las empresas de generación de energía?

En el Perú son pocas las empresas calificadas peruanas que ofrecen servicio a generadoras, en su mayoría son extranjeras con profesionales que transfieren conocimientos y capacitan al personal de nuestro país; como, por ejemplo, en la instalación y operatividad de un turbogenerador (maquinaria y equipo importado), y las actividades de montaje electromagnético, supervisión, operación y mantenimiento estándar, a fin de cumplir con las normas de seguridad y calidad 
Entrevistas a Profundidad

Experto $\mathrm{N}^{\circ} 2$ ajenos a la Empresa

Técnica empleada

Localización

\section{Entrevista profundidad}

Técnica

Lima Metropolitana

Objetivo del estudio:

Entrevista a Profundidad

Obtener información acerca del sector de generación de energía eléctrica en el Perú. Identificar las amenazas y oportunidades del sector.

Temas estudiados:

a) Entorno del sector de abastecimiento de energía eléctrica.

b) Buenas prácticas

c) Organización del sector

d) Factores internos y externos del sector

\section{FICHA TÉCNICA DEL ENTREVISTADO}

Nombre:

Oscar Casariego

Edad:

48 años

Nacionalidad:

Peruano

Ocupación:

Project Control Manager

Profesión:

Ingeniero Mecánico

Distrito de Lima

residencia:

Breve reseña

\section{Guía de Entrevista}

Día: Miércoles 17/07/2018 Hora: 16:00' hrs.

Lugar: Entrevistado: San Borja

Tema:

Duración:

Pregunta 1: ¿Qué factores consideras importantes para ser competitivos en el mercado energético en el Perú?

Apuntes: Un factor muy importante es lo social, las compañías deben desarrollar programas sostenibles para no tener conflictos con las 
comunidades que paralicen su generación, debido

a que el País hoy por hoy se encuentra

enfrentando muchos conflictos de esta clase.

Por tal motivo es estratégico que las empresas

cuenten con plantas de generación de energía que permita tener una mayor capacidad de generación y diversificación en las fuentes de generación.

Pregunta 2:

¿Es favorables para las generadoras contar con un Mix de Generación de Energía?

Apuntes:

Efectivamente, como lo mencione en la pregunta anterior, es importante para la empresa y el mercado peruano contar con diversas fuentes de generación con el fin de abastecer al país sin interrupciones por problemas técnicos y sociales.

Pregunta 3: ¿Cuáles son los factores en el sector de energía eléctrica que a su criterio afecta más a las generadoras?

Apuntes:

A mi parecer, el problema principal en las empresas de generación no cumplan con la producción de energía planificada, debido a deficiencias en el control en su producción por falta de herramientas que le permitan tomar decisiones oportunas ante ciertas deficiencias, por ejemplo: medidores de potencia, un sistema integral de comunicación, controladores de nivel.

Pregunta 4: ¿Crees usted que es importante la ubicación geográfica de las centrales de generación?

Apuntes: En el estudio previo para la construcción de una planta, un factor importante es la ubicación geográfica, debido a que depende mucho de esta el éxito para la generación de energía y su continuidad a largo plazo.

Pregunta 5: ¿Crees usted que el Perú cuenta con proveedor calificados para soporte a las empresas de generación de energía? 
Apuntes:

Cada vez son más los inversionistas que desarrollan proyectos de construcción de nuevas plantas, para lo cual requieren de personal altamente calificado, por lo que actualmente existen proveedores del exterior que están abriendo sus oficinas en Perú, capacitando a personal local y ofreciendo nuevas soluciones tecnológicas. 


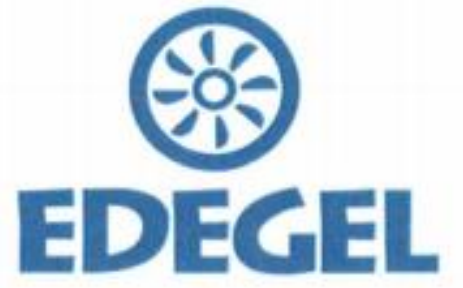

CONTRATO DE OBRA

$N^{\circ}$ G.I.42-2122.16

WATER TO WIRE - HER1 HUAMPANI 
Conste por el presente documento el Contrato de Obra (en adelante, el "Contrato"], que celebran, de una parte, ENEL GENERACIÓN PERÚ S.A.A., con Registro Único de Contribuyentes Ne 20330791412 con domicilio en Calle César López Rojas N*201, Urbanización Maranga, San Miguel, provinça y departamento de Lima representada por el señor William Telles Reyna, identificado con Documento Nacional de Identidad NN 10078370 , segùn poderes inscritos en la partida electrónica NP 11008822 del Registro de Personas Jurídicas de Lima (en adelante, "LA COMITENTE"): $y$, de la otra parte, el Consorcio sin contabilidad independiente conformado por KÖSSLER GmbH \& Co KG (en adelante, KÖSSLER), empresa extranjera debidamente constituida en Austria, representada por su CEO, señor Josef Lampl, con domicilio para estos efectos en Sanikt Georgener Hauptstrasse 122-124, 3151, Sankt Georgen am Steinfeld, y GCZ INGENIEROS S.A.C. (en adelante, GCZ), empresa debidamente constituida en Perú, con Registro Único de Contribuyente Ne 20135072797 , con domicilio para estos efectos en Carretera Panamericana Sur km 19.5, Villa El Salvador, Lima, debidamente representada por su Representante Legal, señor Pedro Enrique Gonzalez-Orbegoso Sanguineti, identificado con Documento Nacional de Identidad $\mathrm{N}^{*} 10609333$, según poder inscrito en la Partida Electrónica $\mathrm{N}^{*}$ 00582883; Conjuntamente, KOSSLER y GCZ se nombrarán en adelante, de manera conjunta, "EL CONTRATISTA", el domicilioldel Consorcio para estos efectos en Sankt Georgener Hauptstrasse 122-124, 3151, Sankt Georgen am Steinfeld, Austria; en los términos y condiciones establecidos en las cláusulas siguientes:

\section{PRIMERA: ANTECEDENTES}

1.1 LA COMITENTE es una persona juridica constituida conforme a las leyes peruanas, cuyo objeto principal es desarrollar actividades de generación de energia eléctrica. LA COMITENTE está desarrollando un proyecto de generación hidroeléctrico consistente en el aprovechamiento de las aguas turbinadas de su central hidroeléctrica Huampani mediante el uso de turbinas sumergibles (en adelante, "HER1 HUAMPANI").

1.2 EL CONTRATISTA es un consorcio sin contabilidad independiente, integrado por una empresa extranjera (KÖSSLER) y una empresa peruana (GCZ), debidamente conformado mediante documeno de fecha 29 de setiembre de 2016, que se adjunta como Anexo [2] de este Contrato. De acuerdo a dicho documento, KÖSSLER y GCZ se obligan solidariamente ante LA COMITENTE a cumplir con las obligaciones de EL CONTRATISTA en el presente Contrato, sin reserva ni limitación alguna.

1.3 Para la ejecución del HERI HUAMPANI, LA COMITENTE requiere contratar a EL CONTRATISTA para que 'lleve a cabo por su cuenta, costo, gasto y riesgo la obra consistente en el diseño, fabricación, pruebas y ensamble en fábrica, transporte y suministro en el canal de descarga y zonas aledañas dentro la central hidroeléctrica Huampani (en adelante, el "SITIO") de todos los equipos electromecánicos e hidromecánicos asociados al HER1 HUAMPANI, las obras civiles, bodegaje, montaje y puesta en servicio de dichos equipos electromecánicos e hidromecanicos en adelante, la "OBRA").

1.4 Para ello se llevo a cabo la licitación № G.1-42-2122/16, denominado Water to Wire HER1 Huampani, en el cual participó EL CONTRATISTA, resultando su propuesta la adjudicada.

1.5 EL CONTRATISTA cuenta con la experiencia y calificaciòn requerida, clientes a quienes brinda servicios, profesionales altamente calificados, infraestructura, equipos técnicos, herramientas y, en general, con todos colgys bienes y servicios necesarios para ejecutar la OBRA en forma autónoma e integral bajo su propia cuenta ק्रिए: 


\section{SEGUNDA: OBJETO DEL CONTRATO}

2.1 En virtud del presente instrumento, EL CONTRATISTA se obliga a ejecutar por su cuenta, costo, gasto y riesgo la OBRA, bajo la modalidad de contrato de obra, según lo dispone el articulo $1771^{\circ}$ y siguientes del Código Civil. Las caracteristicas de la OBRA se detallan en los documentos referidos más adelante.

2.2 Conforme a lo estipulado en el párrafo anterior, la naturaleza del presente contrato se rige estrictamente por lo señalado en el Codigo Civil; por lo que la presente no puede considerarse ni interpretarse en ningún sentido como un contrato de naturaleza laboral.

2.3 Por su parte, LA COMITENTE se obliga a pagar a EL CONTRATISTA, como contraprestación por la ejecución del OBRA, la retribución pactada en la cláusula quinta del Contrato, en la forma y oportunidad convenida.

\section{TERCERA: DOCUMENTOS DEL CONTRATO}

3.1 EL CONTRATISTA se obliga a ejecutar la OBRA de acuerdo con los siguientes documentos, los cuales forman parte del Contrato:

a) Texto del Contrato y sus Anexos.

b) Orden de proceder firmada con fecha 29 de setiembre de 2016 .

c) Memorandum de Entendimiento firmado el 19 de agosto de 2016.

d) Bases Administrativas Especiales de Licitación $N^{*}$ G.1-42-2122/16, modificadas el 28 de setiembre de 2016.

e) Propuesta técnica del Consoncio presentada por licitación web el 10 de junio de 2016 , y oferta económica final del 19 de agosto de 2016.

f) Aclaraciones técnicas del 22 de junio, 4 de julio y 15 de julio del 2016 incluyendo estudios topográficos actualizados al 9 de setiembre 2016 y rango de operación enviado el 10 de octubre de 2016.

g) Serie de Preguntas y flespuestas remitidas a los postores durante la licitación el 27 de mayo del 2016

h) Especificaciones Técnicas E.EC.HI.001 y anexos.

i) Especificaciones de Seguridad y Salud Laboral y Ambiental para Contratistas de Obras y Servicios E.S.-001 Rev. 2 .

j) Instrucciones a los proponentes.

k) Condiciones Generales de Contratación del Grupo Enel Rev. 5* y su Anexo V Perú.

1) Normas y procedimientos del Sistema de Seguridad y Salud Ocupacional OHSAS 18001.

m) Normas y procedimientos del Sistema de Gestión Ambiental ISO 14001.

n) Normas y procedimientos del Sistema de Calidad ISO 9001

o) Pacto Mundial por las Naciones Unidas.

p) Politica Stop Work. 


\section{CUARTA: RESPONSABILIDADES DE LAS PARTES}

\section{RESPONSABILDADES DEL CONTRATISTA:}

4.1 EL CONTRATISTA contara con el personal profesional, técnico, administrativo y auxiliar que crea conveniente para la ejecución de la OBRA, bajo su absoluta dirección y responsabilidad, garantizando su idoneidad y competencia y know how apropiado para la correcta ejecución de la OBRA.

4.2 EL CONTRATISTA, en su calidad de único y exclusivo empleador de los respectivos trabajadores que ocupe para la ejecución de LA OBRA, ejercerá completo control sobre su personal, dando estricto y oportuno cumplimiento a las disposiciones legales, reglamentarias y administrativas vigentes en materia laboral v previsional y cualquier otra que se derive de su condición de empleador.

4.3 EL CONTRATISTA ejecutarả la OBRA con total autonomia técnica, operativa y financiera, utilizando para tales efectos sus propios equipos, implementos, recursos y todo aquelio que sea necesario para ejecutar la OBRA de manera satisfactoria, sin estar sujeto a horarios u otras obligaciones distintas de las que emanan del Contrato. En tal sentido, EL CONTRATISTA asume plena y total responsabilidad por la idoneidad, calidad $y$ resultados de la OBRA contratada;

4.4 Como consecuencia de la independencia y autonomia con que EL CONTRATISTA ejecuta la OBRA pactada a través del presente Contrato, LA COMITENTE, en modo alguno y bajo ningún título juridico, tendrá responsabilidad laboral o de algún otro tipo con relación a las personas contratadas por EL CONTRATISTA. directa o indirectamente, ya que éstos, como se desprende del presente documento y principalmente de los hechos, no se encuentran subordinados de forma alguna a LA COMITENTE.

4.5 EL CONTRATISTA designará a un responsable que será el encargado de hacet seguimiento a las actividades y labores realizadas por su personal, asi como evaluarlo de forma permanente a efectos de asegurar una correcta ejecución de la OBRA (en adelante, el "Responsable de la OBRA"). Dicha designación deberá ser informada a LA COMTENTE y constará por escrito. El Responsable de la OBRA deberá estar en el lugar de la OBRA a tiempo completo y ser el único nexo entre EL CONTRATISTA y LA COMITENTE, por lo que deberă asegurarse de que su personal única $y$ exclusivamente se encuentre en contacto directo $y$ permanente con éste.

4.6 La OBRA no será ejecutada por personas contratadas por EL CONTRATISTA bajo las modalidades de locación de servicios, honorarios profesionales o figuras similares de contratación. Tampoco bajo la modalidad de prácticas o formación laboral juvenil. Es decir, EL CONTRATISTA deberá tener a todo su personal en planilla bajo el régimen de la actividad privada.

EL CONTRATISTA deberá exhibir, a sólo requerimiento de LA COMITENTE, lo que podrá ocurrir en cualquier momento, las planillas y demás documentos que acrediten fehacientemente el cumplimiento de las 9y ligaciones legales, laborales, tributarias, sociales, etc. que tiene a su cargo en calidad de empleador i. 7 pecto de todas las personas que participen en la ejecución de la OBRA. 
4.7 EL CONTRATISTA debera cumplir con el pago cabal y opontuno de las remuneraciones y beneficios sociales, aportaciones a la seguridad social, seguros, tributos, etc. a favor de sus trabajadores y presentar mensualmente o en cualquier momento a solicitud de LA COMITENTE, original y copia de los comprobantes de pago de las obligaciones sociales y el pago de las indemnizaciones y vacaciones, depósitos de la compensación por tiempo de servicios (CTS), aportaciones a la seguridad social, seguros, tributos y otros que permitan verificar el cumplimiento de las obligaciones laborales y sociales que correspondan, siempre y cuando la divulgación de dicho material sea permitida de acuerdo con la legislacion laboral de los paises en que fueran constituidos KOSSLER y GCZ y que no permita acceso, incluso indirecto, a información confidencial de los trabajadores (como monto de las remuneraciones, por ejemplo). La comprobación y verificación que realice LA COMITENTE no implica que ésta asuma responsabilidad directa o indirecta respecto a dichas obligaciones, que son de cargo exclusivo de EL CONTRATISTA.

4.8 EL CONTRATISTA defenderá, a su propio costo, cualquier reclamación o amenaza de reclamación formulada por sus trabajadores, por autoridades competentes o por terceros, contra LA COMITENTE, en la medida en que dicha reclamación se fundamente en un incumplimiento atribuible a EL CONTRATISTA de obligaciones en materia juridico-laboral, de seguridad social y de prevención de riesgos laborales vinculadas a personal empleado en LA OBRA.

En caso LA COMITENTE decida asumir su propia defensa, EL CONTRATISTA reembolsará todos los gastos legales, incluyendo pero sin limitarse a ellos las tasas, honorarios profesionales, etc. en que LA COMITENTE razonablemente incurra en virtud de la misma.

En cualquier caso, EL CONTRATISTA asumirá integramente todos los gastos, intereses, multas, deudas, costos, tasas, honorarios profesionales, etc., en los que tenga que incurrir LA COMITENTE con motivo de cualquier reclamación de los trabajadores o ex trabajadores de EL CONTRATISTA o proceso iniciado por alguna autoridad, siempre que se encuentre vinculado a un incumplimiento atribuible a EL CONTRATISTA y que se encuentre relacionado con LA OBRA.

EL CONTRATISTA reembolsará a LA COMITENTE todos los montos abonados por ésta al personal de EL CONTRATISTA y/o sus beneficiarios, alguna multa impuesta por las autoridades administrativas o judiciales, o algún pago a una oficina o dependencia del Estado o alguna administradora privada de pensiones u otra por concepto de primas, aportaciones y/o prestaciones, etc, que correspondan a EL CONTRATISTA por su personal empleado en LA OBRA y como consecuencia de un incumplimiento o infracción de EL CONTRATISTA, incluyendo sus respectivos intereses legales, costas y costos, y demás gastos que tales pagos le hubieren ocasionado a LA COMITENTE.

Es de aplicación lo indicado en este numeral a cualquier acción interpuesta por un sub-contratista de EL CONTRATISTA en caso de sub-locación autorizada conforme a la Cláusula Décimo Sexta, asumiendo EL CONTRATISTA las obligaciones antes referidas, en la medida que se trate de incumplimientos o infracciones atribuibles a estos sub-contratistas con relación a su personal destacado para la ejecución de la OBRA.

En caso EL CONTRATISTA no asuma los pagos indicados en los pärrafos anteriores, LA COMITENTE encuentra plenamente facultada a repetir dichos pagos contra EL CONTRATISTA en cualquiera de las forias previstas en el numeral 5.8 de la Clausula Quinta del Contrato.

4.9 Serd de exclusiva responsabilidad de EL CONTRATISTA asumir el costo economico por daños, lesiones u otro que pudiera derivarse como consecuencia del accidente o la muerte de alguno de sus trabajadores ocurridos a raiz de la ejecución de la OBRA, tanto dentro como fuera de las instalaciones de LA COMITENTE. 
4.10 EL CONTRATISTA deberá asegurar a todo el personal que intervenga en la ejecución de la OBRA, cubriéndolos contra todo riesgo en el cumplimiento de su trabajo, contratando pólizas de seguro por responsabilidad civil, deshonestidad, accidentes personales, la póliza de Seguro Complementario de Trabajo de Riesgo, cobertura de salud y pensión (invalidez, muerte y sepelio), entre otras, asi como tomar las medidas de precaución necesarias a fin de evitar y prevenir cualquier tipo de accidentes. Las pólizas de seguro deberán encontrarse vigentes hasta la terminación o resolución del Contrato.

4.11 EL CONTRATISTA ejecutará la OBRA de manera idónea y apropiada, tomando las medidas necesarias para garantizar la seguridad y salud laboral de sus trabajadores y personal del subcontratista. Asimismo, instruira a su personal en los procedimientos de seguridad establecidos en las normas del ámbito eléctrico vigentes.

4.12 EL CONTRATISTA deberá dar estricto cumplimiento a la legislación vigente en materia de Seguridad y Salud Laboral que resulte aplicable, asi como a las disposiciones administrativas y reglamentarias que deriven de dicha materia.

4.13 El CONTRATISTA, al ejecutar la OBRA de manera integral y autónoma, bajo su entera responsabilidad, cuenta y riespo, deberá cumplir con todas las obligaciones previstas en la Ley $\mathrm{N}^{*} 29245$, Ley que regula los servicios de tercerización, Decreto Legislativo $\mathrm{N}^{*} 1038$ y las demás normas legales y reglamentarias aplicables y las que se emitan con posterioridad.

Por consiguiente, El coNTRATISTA se obliga a presentar ante eventuales inspecciones de la Autoridad Administrativa de Trabajo, toda la documentación sustentatoria que sirva para validar el fiel cumplimiento de sus abligaciones laborales como empresa tercerizadora.

4.14 EL CONTRATISTA declara que cumplirá con los estándares, procedimientos y buenas prácticas de la industria asi como las establecidas en las normas siguientes:

a) 15014001

b) OHSAS 18001

c) 1509001

Queda establecido que tambien resultarán aplicables las normas que modifiquen, reemplacen o complementen las normas referidas en los literales anteriores y que sean notificados oportunamente a $\mathrm{EL}$ CONTRATISTA.

4.15 EL CONTRATISTA no tiene ninguna capacidad de representación de LA COMITENTE ni facultad alguna para concluir negocios o actos juridicos en su nombre y representación. EL CONTRATISTA no asumirá obligaciones de ninguin tipo en nombre de LA COMITENTE.

RESPONSABILIDADES DE LA COMITENTE:

ha El perjuicio de que EL CONTRATISTA esta obligado a preparar la documentación necesaria para la Vha Fiportación de los bienes que debe suministrar para la ejecución de la OBRA y llevar a cabo el procedimiento gije importación, LA COMITENTE será la importadora en Perú de dichos bienes $y$, en consecuencia, es 


\section{QUINTA: RETRIBUCIÓN, FORMA Y OPORTUNIDAD DE PAGO}

5.1 LA COMITENTE se oblipa a pagar a EL CONTRATISTA, como retribución por la ejecución de la OBRA, la suma total de US\$ 1999 349,00 (un millón novecientos noventa y nueve mil trescientos cuarenta y nueve y 00/100 Dólares de los Estados Unidos de Américal, suma que no incluye el Impuesto General a las Ventas que corresponda según la legislación vigente. Las partes acuerdan expresamente que la retribución acordada por la ejecución de la OBRA se facturara de la siguiente manera:

(i) GCZ emitirá y entregará a LA COMITENTE las facturas por la retribución correspondiente a los servicios y suministros efectuadas porGCZ de acuerdo con el Anexo 3 del Contrato, División de Responsabilidades de El CONTRATISTA (en adelante, "COMPONENTE LOCAL")

(ii) KOSSLER emitira y entregara a LA COMITENTE las facturas por la retribución correspondiente a los servicios y suministros efectuadas por KOSSLER de acuerdo con el Anexo 3 del Contrato, División De Responsabilidades de el contratista (en adelante, "COMPONENTE EXTRANIERO'), KÖSSLER acepta y reconoce que LA COMITENTE cancelară las facturas previa retención de los tributos aplicables de acuerdo a la legislación preruana vigente.

Las retribuciones se facturarán en función a valorizaciones de los hitos acordados y detallados en el Anexo $\mathrm{N}^{*} 4$, las que serán preparadas por El CONTRATISTA y en las que éste debe demostrar, mediante documentación de respaldo, los trabajos ejecutados y aprobados, además de considerar los precios descritos en el Anexo $\mathrm{N}^{\circ} 1$.

EI CONTRATISTA presentará al Responsable del Contrato de LA COMITENTE, la valorización, en la que incluirá los trabajos ejecutados para el cumplimiento del/los hito(s) comprometido(s) en el Anexo $\mathrm{N}^{*} 4$. El Responsable del Contrato de LA COMITENTE dispondrá de 10 (diez) dias hábiles para revisar la valorización y para comunicar a El CONTRATISTA la aceptación o rechazo. En caso de rechazo de la valorización por parte del Responsable del Contrato de LA COMITENTE, éste lo devolverá al EL CONTRATISTA para su corrección. luego de lo cual se procederá conforme a lo establecido en la presente cláusula.

5.2 La(s) factura(s) deberá(n) enviarse a Calle Teniente César López Rojas № 201, Urbanización Maranga, distrito de San Miguel, provincia y departamento de Lima, indicando el nùmero de conformidad generado en el sistema SAGA por el area usuaria de LA COMITENTE.

Transcurridos treinta (30) dias de haber sido correctamente presentada la factura ésta será cancelada en la fecha más cercana de pago masivo de LA COMITENTE.

5.3 Cuando corresponda, de conformidad con la legislación tributaria aplicable, las prestaciones realizadas en el marco de la ejecución de LA OBRA para ta componente local se sujetarản al Sistema de Pago de Obligaciones Tributarias (detracción), por lo que, la(s) factura(s) emitidas por GCZ deberä(n) ser remitidajath con la siguiente indicación "Operación Sujeto al Sistema de Pago de Obligacianes Tributarias con el Gogeino

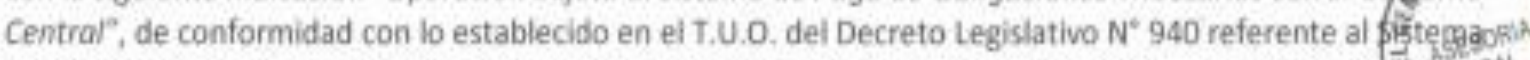
de Pago de Obligaciones Tributarlas con el Gobierno Centrat, la Resolución de Superintendencia $N^{*} 18$ f SUNAT y todas aquellas normas conexas, asi como las que las modifiquen o las sustituyan. En caso conteriprues 
5.4 EL CONTRATISTA deciara conocer y se compromete a cumplir con todas sus obligaciones legales, tanto de carácter formal como sustancial en materia tributaria. Tanto EL CONTRATISTA como LA COMITENTE se obligan mutuamente a cumplir con todos los requisitos y tramites exigidos por las normas tributarias pertinentes, debiendo aplicar la correspondiente retención de impuestos que proceda efectuar conforme a la normativa vigente en la jurisdicción respectiva. Asimismo, EL CONTRATISTA y LA COMITENTE se obligan a entregarse mutuamente toda la documentación que sea necesaria para la correcta liquidación de los impuestos.

5.5 Los pages se realizarán en Euros para la componente extranjera y en Soles para la componente local.

5.6 Sin perjuicio de lo establecido en la cláusula 3.4 , los precios convenidos para el COMPONENTE LOCAL serán reajustados de acuerdo a la formula siguiente:

Para todos los efectos de este Contrato se considerará que el nivel de precios inicial del Contrato corresponde al mes de presentación de las Ofertas.

a) Fórmula de Reajuste para la Componente en Moneda Local:

Los precios de la Componente en Moneda Local (Perú) del Cuadro de Precios estarán sujetos a reajustes mediante la aplicación de la siguiente fórmula:

$\mathrm{Pr}_{\mathrm{r}}=\mathrm{Po}_{\mathrm{O}}(0,50 \mathrm{IPC} / \mathrm{IPCo}+0,20 \mathrm{PE} / \mathrm{PEO}+0,20 \mathrm{~J} / \mathrm{/o}+0,10 \mathrm{D} / \mathrm{Do})$

En la Cual:

$P_{r}=$ Precio Reajustado

$P_{0}=$ Precio Base IPC = Índices de Precios al Consumidor publicado por el Instituto Nacional de Estadisticas e Informática de Peru (INEI) bajo el rubro $\mathrm{N}^{\circ} 39$, correspondiente al segundo mes anterior al mes de presentación del Estado de Pago.

IPCo - Corresponde a La definición del Indice IPC anterior, excepto la fecha de validez, siendo IPCo el indice correspondiente al mes de presentación de la oferta.

$P E=$ Precio base productor, excluido el impuesto General a las Ventas IGV, del $\mathrm{m} 3$ de petróleo diesel en Perú, puesto en refineria, utilizado por el INEI bajo el rubro $\mathrm{N}^{*}$ S3 "Petróleo Diesel", para determinar el Indice de Precios al por Mayor (IPM), correspondiente al segundo mes anterior al de presentación del Estado de Pago

PEo = Corresponde a la definición del precio PE anterior, excepto la fecha de validez, siendo PEo et precio correspondiente al mes de presentación de la oferta.

$I=$ Indice de Remuneraciones por Hora que publica en Perú el Instituto Nacional de Estadisticas e Informática (INEI) bajo el rubro $\mathrm{N}^{*} 47$, correspondiente al tercer mes anterior al de presentación del Estado de Pago.

Jo = Corresponde a la definición del indice anterior, exceptuando la fecha de validez, siendo to el indice correspondiente al mes de presentación de la oferta.

$\mathrm{D}=$ Tasa de Cambio del Sol con respecto del dólar de los Estados Unidos de América, expresado en Soles por dólar (S//US\$), determinado por el Banco Central de Perú para fines de pago de derechos de aduana, correspondiente al mes de presentación del Estado de Pago. 
Do $=$ Corresponde a la definición de la tasa $D$ anterior, excepto la fecha de validez, siendo Do la tasa correspondiente al mes de presentación de la oferta.

b) Fórmula de Reajuste para la Componente en Moneda Extranjera

La Moneda Extranjera no estará sujeta a reajuste.

Este reajuste afectará sólo a los precios de los servicios realizados con posterioridad a la fecha en que entre en vigencia el respectivo reajuste.

5.7 Las partes acuerdan que en caso LA COMITENTE realice alguin pago de cualquier indole que conforme a este Contrato sea obligación de EL CONTRATISTA o se derive de una obligación de EL CONTRATISTA, LA COMITENTE queda autorizada expresamente a repetir dichos pagos contra EL CONTRATISTA y recuperarlos mediante retención, descuento o compensación directa con cualquier monto pendiente de pago a EL CONTRATISTA por concepto de la ejecución de este Contrato u otro cualquier contrato que LA COMITENTE tenga con EL CONTRATISTA. En caso los importes pendientes no fueran suficientes, LA COMITENTE está facultada a ejecutar la Carta Fianza de Fiel Cumplimiento.

\section{SEXTA: VIGENCIA Y PLAZZO DE EJECUCIÓN}

6.1 LA COMITENTE se compromete a permitir el acceso al sitio a EL CONTRATISTA a más tardar el 1 de junio de 2017, para que éste inicie la ejecución de las obras civiles.

6.2 La OBRA deberá ejecutarse en un plazo de 14 (catorce) meses contados a partir de la firma de la Orden de Proceder ( 30 de setiembre de 2016) por lo que concluira sin necesidad de previo aviso el 30 de noviembre de 2017, fecha de la recepción definitiva de la OBRA sepun está definido en las Bases Administrativas Especiales. EL CONTRATISTA se obliga frente a LA COMITENTE a entregar la OBRA dentro del plazo de vigencia señalado. Dicho plazo podrá ser prorrogado de común acuerdo, para lo cual ambas partes suscribirán la modificación al Contrato correspondiente (adenda al Contrato). En caso que EL CONTRATISTA solicitase la variación del plazo señalado en el presente numeral, lo cual deberá hacer por escrito, y LA COMITENTE no se pronunciase al respecto en un plazo de quince (15) dias calendario se entenderá que la solicitud ha sido denegada.

Sin perjuicio de lo antes mencionado, no serán consideradas las solicitudes de ampliación de plazo presentadas con posterioridad al tèrmino del Contrato.

No obstante lo anterior, en el supuesto que por causa de fuerza mayor o imputable a LA COMITENTE no se pueda efectuar la recepción definitiva en el plazo previsto, se procederá a la recepción provisional de la OBRA a más tardar el 30 de noviembre de 2017. En este caso, la recepción definitiva se producirá una vez superada la causal de fuerza mayor o imputable a LA COMITENTE. En caso la demora se deba a causa imputable a LA COMITENTE, dicha causal deberá ser superada a más tardar a los 60 (sesenta) dias de la fecha de recepción provisional de la OBRA.

LA COMITENTE podrá resolver el Contrato en cualquier momento, parcial o totalmente, sin expresión décus causa, previo aviso por escrito a EL CONTRATISTA con una anticipación de por lo menos treinta (30) 198 
fianza bancaria de carảcter irrevocable, solidaria, incondicionada, de ejecución automática, y sin beneficio de excusión, por el mismo importe que el del adelanto (en adelante, la "Segunda Carta Fianza"), cuya valor máximo será de US\$ 299 902,35 (doscientos noventa y nueve mil novecientos dos con 35/100 Dólares de los Fstarlns Unidins de América) equivalente al quince por ciente (15\%) del impnrte total de la retribución del Contrato establecido en la cláusula quinta. Esta garantia deberá ser extendida a favor de LA COMITENTE a su entera satisfacción por un banco local de primer nivel que sea aceptable para LA COMITENTE, y deberá estar vigente desde su emision hasta que EL CONTRATISTA haya cumplido con ejecutar el 15\% (quince por ciento) de la valor de la OBRA.

8.2.2 LA COMITENTE se encuentra facultada para ejecutar la Segunda Carta fianza en caso que EL CONTRATISTA no destine el importe correspondiente al adelanto antes descrito, en el plazo y/o forma acordados, al fin para el cual le es entrepado. Para tal efecto, la Segunda Carta Fianza podrá ser emítida a solicitud de cualesquiera de las partes integrantes del Consorcio, es decir, EL CONTRATISTA.

8.2.4 Una vez que EL CONTRATISTA haya ejecutado la OBRA por un valor que exceda al adelanto recibido, LA COMITENTE le devolverá la Segunda Carta Fianza dentro de los 3 (tres) dias hábiles sipuientes de haber dado su conformidad respecto de las prestaciones debidamente ejecutadas.

\subsection{Garantía de Buen Funcionamiento}

Con el objeto de garantizar el buen funcionamiento de la OBRA a partir de la recepción definitiva de la OBRA de acuerdo a lo previsto en el nuumeral 6.1 de la cláusula sexta del Contrato, EL CONTRATISTA deberá entregar a LA COMITENTE, una carta fianza bancaria de carácter irrevocable, solidaria, incondicionada, de ejecución automática, y sin beneficio de excusión, por la suma de us\$ 99 967,45 (noventa y nueve mil novecientos sesenta y siete con 45/100 Dólares de los Estados Unidos de América), equivalente al cinco (5\%) del importe total de la retribución del Contrato establecido en la cláusula quinta (en adelante, la "Garantia de Buen Funcionamiento"). Esta garantia deberá ser extendida a favor de LA COMITENTE a su entera satisfacción por un banco local de primer nivel que sea aceptable para LA COMITENTE, con una vigencia anual y la última renovación será hasta los 24 (veinticuatro) meses de la recepción definitiva de la OBRA. Para tal efecto, la Garantia de Buen Funcionamiento podrá ser emitida a solicitud de cualesquiera de las partes integrantes del Consorcio, es decir, EL. CONTRATISTA.

EL CONTRATISTA deberá reemplazar la Garantia de Buen Funcionamiento quince (15) dias calendario antes de su vencimiento por otra de igual monto e iguales caracteristicas, Si EL. CONTRATISTA incumpliera con renovar la Garantía de Buen Funcionamiento quince (15) dias calendario antes de su vencimiento, LA COMITENTE quedará automáticamente facultada para ejecutarla.

8.4 EL CONTRATISTA renuncia a interponer cualquier acción o excepción que tienda a obstaculizar la ejecución de la Carta Fianza de Flel Cumplimiento, de la Segunda Carta Fianza o de la Garantia de Buen Funcionamiento por parte de LA COMITENTE.

8.5 Si el banco que otorga la Carta Fianza de Fiel Cumplimiento, la Segunda Carta Fianza o la Garantia de Buen Funcionamiento fuera declarado o deviniera en quiebra o en situación de concurso, o si el derecho de dicho

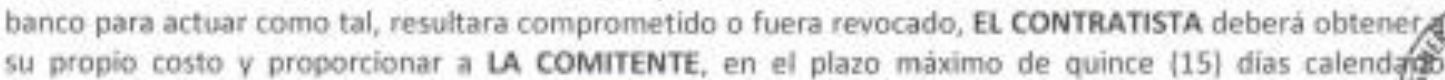
Su propio costo y proporcionar a LA COMITENTE, en el plazo maximo de quince (15) dias calend 7 y contenido que sean aceptados por LA COMITENTE, expedida también por un banco que sea aceptado LA COMITENTE, y con las mismas caracteristicas que la carta fianza materia de sustitución. 
NOVENA: SEGUROS

Durante todo el plazo de vigencia del presente Contrato asi como de las prórrogas que se acuerden, la actividad de EL CONTRATISTA deberá contar con los seguros especificados como Anexo 5:

\section{DÉCIMA: RESPONSABLES, COMUNICACIONES Y DOMICILIO}

LA COMITENTE designa como Responsable del Contrato (en adelante, el "Responsable del Contrato") a Raphael Huaman Marky, identificado con Documento Nacional de Identidad $\mathrm{N}^{\circ} 10305370$.

EL CONTRATISTA designa como Responsable de la OBRA (en adelante, el "Responsable de la OBRA") a Fernando Montero Machado, identificado con Documento Nacional de identidad $\mathrm{N}^{*} 09071072$.

El medio formal de comunicación entre las partes sera mediante cartas o correos electrónicos. De esta forma, todos aquellos hechos y eventos que tengan relación con algún punto del Contrato, así como el avance de la OBRA, deberán ser comunicados por los medios antes indicados.

Las comunicaciones deberán remitirse mediante cartas con cargo de recepción o mediante correos electrónicos con constancia de recepción a las siguientes direcciones:

\section{POr LA COMITENTE:}

Sr. Raphael Huamán Marky

Calle César López Rojas N²01, Urbanización Maranga, San Miguel, Lima

Correo electr' ponico: raphael.huaman@enel.com

\section{Por EL CONTRATISTA:}

Sr. Fernando Montero Machado

Calle Mártir Olaya, $\mathrm{N}^{\circ} 129$, oficina 1206, Miraflores, Lima

Correo electrónico: zzfernando.zzmontero@voith.com

Las partes se obligan a comunicar cualquier cambio del Responsable del Contrato o del Responsable de la OBRA, según corresponda, domicilios o direcciones electrónicas dentro de los cinco (5) días hábiles anteriores a la fecha en que se hará efectiva la modificación. En tanto los cambios no sean comunicados conforme a esta clausula. las comunicaciones y/o notificaciones realizadas a los anteriores coordinadores, domicilios o correos electrónicos se tendrán válidamente realizados.

\section{UNDÉCIMA: OBLIGACIONES DEL CONTRATISTA EN CASO DE DEFECTOS FALLAS O INCOMPATIBILIDADES}

En caso que se detecten defectos, fallas o incompatibilidades en la ejecución de la OBRA por parte de EL CONTRATISTA que determinen un incumplimiento de las especificaciones técnicas $/ / o$ documentos del Contrato, estas deberán ser subsanadas por EL CONTRATISTA a pedido de LA COMITENTE y a su entera satisfacción, en el plazo que sea acordado previamente y de común acuerdo entre las partes, el mismo que no podrá ser mayor a treinta (30) dias calendario. En caso que, transcurridos cinco (5) dias calendario desde que LA COMITENTE comuniquen la detección del defecto, falla o incompatibilidad, las partes no llegaran a un acuerdo respecto del plazo para subsanaria. correspondera a LA COMITENTE filar unilateralmente un 
La obtención oportuna de todas las autorizaciones, licencias y permisos necesarios para la ejecución de la OBRA y su puesta en operación de acuerdo a ley serán de cargo de las partes según se detalla en el Apéndice de este Contrato.

\section{DECIMOTERCERA: PENALIDADES Y BONO}

\section{PENALIDADES:}

13.1 LA COMITENTE evaluará mensualmente o con la periodicidad que determine, la ejecución de la OBRA por parte de EL CONTRATISTA, en forma total o parcial, aplicando, cuando corresponda, las siguientes penalidades:

13.1.1 Penalidad por desviaciones a los valores de eficiencia:

$0,5 \%$ de la retribución total pactada en el Contrato por cada $0,1 \%$ de desviación del valor garantizado 1700 $\mathrm{kw}$ ) con el límite de $10 \%$ (diez por ciento) de la retribución total del Contrato. En el supuesto que la desviación es mayor a $2 \%$ (dos por ciento) del valor garantizado, LA COMITENTE podra rechazar la OBRA hasta que ésta alcance el valor garantizado.

\subsubsection{Penalidades por retraso:}

En el supuesto que EL CONTRATISTA incumpla el plazo previsto en cronograma detallado en el Anexo 6 más 7 (siete) dias calendarios, se le aplicará las siguientes penalidades:

- Fin de la construcción del canal by-pass: $0,1 \%$ de la retribución total del contrato, por cada dia de atraso.

- Fin de la fabricación de los equipos principales (turbinas, valvulas shut-off, carriles guia, automatización: $0.1 \%$ de la retribución total del Contrato, por cada dia de atraso.

- Fin de las Obras Civiles (concreto, insertos, montajes de las turbinas): $0.2 \%$ de la retribución total del Contrato, por cada dia de atraso.

- Sincronización por Unidad (inicio de la producción): $0.1 \%$ por dia, del valor de la retribución total del Contrato, por cada unidad.

- POC - Puesta en Operación Comercial (= CAP - Certificación de Aceptación Provisional) para ambas unidaes: $0.2 \%$ de la retribución total del Contrato, por cada dia de atraso.

Limitado a $10 \%$ del total de los cinco items listados arriba.

13.2 Sin perjuicio de lo anterior, las partes acuerdan que, en caso de incumplimientos por parte de EL CONTRATISTA, LA COMITENTE queda facultada para suspender la ejecución de la OBRA y encargar el mismo a otra empresa. En este viltimo caso, El CONTRATISTA renuncia a exigir el pago o reembolso de cualquier dario y perjuicio, incluido lucro cesante, o pérdida que pudiera sufrir por la suspensión antes mencionada. Asimismo, EL CONTRATISTA, deberá pagar a LA COMITENTE por concepto de penalidad, la suma equivalente al costo en que incurra LA COMITENTE para restablecer la ejecución de la OBRA con otra empresa. 
13.3 LA COMITENTE queda autorizada a retener, compensar o descontar el importe de estas penalidades con cualquier monto adeudado a EL CONTRATISTA. En caso LA COMITENTE cobre las penalidades a través de la ejecución de la Carta Fianza de Fiel Cumplimiento otorgada por EL CONTRATISTA, este último se obliga a restituir de inmediato su monto originaL. No obstante lo indicado, LA COMITENTE también podrá exigir que EL CONTRATISTA pague directamente las penalidades, en curyo caso éste deberá proceder al pago en un plazo no mayor de quince (15) dias calendario, contados a partir del respectivo requerimiento, bajo penalidad de quedar constituido en mora en forma automática, de conformidad con lo dispuesto en el punto 7.4 .2 del Anexo V de las Condiciones Generales de Contratación, mencionadas en la cláusula tercera.

Se deja claramente establecido que para exigir el pago de las penalidades mencionadas, LA COMITENTE no tendrá que probar los daños sufridos ni su cuantia.

Si la penalidad acumulada superara el diez por ciento (10\%) del importe total de la retribución indicado en la clàusula quinta del Contrato, LA COMITENTE podra ejecutar la Carta Fianza de Fiel Cumplimientó, sin necesidad de previo aviso por parte de LA COMITENTE a EL CONTRATISTA. Asimismo, LA COMITENTE podrá solicitar la resolución de pleno derecho del presente Contrato.

En caso que la recepción definitiva de la OBRA se produzca el 30 de noviembre de 2017 , las penalidades generadas por el incumplimiento de hitos intermedios no serán cobradas al El CONTRATISTA o deberàn ser devueltas por LA COMITENTE, segün cporresponda.

EL CONTRATISTA autoriza a LA COMITENTE a descontar la penalidad descrita del monto que adeude a EL. CONTRATISTA por la ejecución de la OBRA, a la fecha indicada.

\section{BONO:}

13.4 En la eventualidad de que se alcance la recepción definitiva de la OBRA antes de trancurridos 180 (ciento achenta) dias después de la liberación dei sitio, EL CONTRATISTA tendrá derecho a recibir de LA COMITENTE un bono equivalente a US\$ 10 Do0 (diez mil Dólares de los Estados Unidos de América) por semana de adelanto (para periodos menores a una semana se calculará a prorrata).

\section{DECIMOCUARTA: PROTECCIÓN DE DATOS PERSONALES}

14.1. Debido a que para la ejecución de la OBRA, EL CONTRATISTA accederá a datos personales incluidos en bancos de datos de titularidad de LA COMITENTE, deberá cumplir lo dispuesto en la Ley $\mathbb{N}^{*} 29733$ - Ley de Protección de Datos Personales. En cualquier caso, será LA COMITENTE, como titular de los bancos de datos, quien decidirá sobre la finalidad, contenido y uso del tratamiento de los datos, limitándose EL CONTRATISTA a utilizar dichos datos, ùnica y exclusivamente, para los fines que se deriven de la prestación de servicios objeto de este Contrato.

14.2. Los bancos de datos que contengan datos personales a los que accederá El CONTRATISTA como consecuencia de la prestación de servicios, son de titularidad exclusiva de LA COMITENTE, extendiéndose tambièn esta titularidad a cuantas elaboraciones, evaluaciones, segmentaciones o procesos similares que, en relación con los mismos, pudiese realizar EL CONTRATISTA, conforme a los servicios que se pactan en el 
14.3. EL CONTRATISTA, en su calidad de encarpado de tratamiento, queda obligado al cumplimiento de lo establecido en lo Ley N* 29733 - Ley de Protección de Datos Personales y en su Reglamento aprobado por el Decreto Supremo 003-2013-JUS, y en particular, se compromete especificamente a:

I. Custodiar los datos personales a los que accederá como consecuencia de esta prestación de servicios, adoptando las medidas de indole juridica, técnica y organizativa necesarias, y en especial las establecidas en el Reglamento de la Ley $N^{*} 29733$ aprobado por el Decreto Supremo $N^{*}$ 003-2013-1U5, y demas disposiciones de desarrollo, para garantizar la seguridad de los datos personales y evitar su alteración, pérdida, tratamiento o acceso no autorizado, habida cuenta del estado de la tecnologia, la naturaleza de los datos suministrados y los riespos a que están expuestos, ya provengan de la acción humana o del medio fisico o natural.

II. Utilizar o aplicar los datos personales, exclusivamente, para la realización de los servicios que se pactan y, en su caso, de acuerdo con las instrucciones impartidas por LA COMITENTE, titular de los bancos de datos que contienen los datos personales.

III. No comunicarlos, ni siquiera para su conservación a otras personas, ni tampoco las elaboraciones, evaluaciones o procesos similares citados anteriormente, ni duplicar o reproducir toda o parte de la información, resultados o relaciones sobre los mismos.

IV. Asegurarse que losldatos personales a los que pudieran tener acceso sean tratados únicamente por aquelios empleados cuya intervención sea necesaria para realizar la prestación de servicios. EL CONTRATISTA comunicará a estos empleados las medidas de seguridad que han de aplicar y el deber de secreto $y$ confidencialidad que han de tener respecto a estos, incluso una vez finalizada la prestación de servicios.

V. Admitir controles y auditorias que, de forma razonable, pretenda realizar LA COMITENTE, a los efectos de cumplimiento de la prestación de servicios.

VL. Una vez finalizada la prestación de servicios, EL CONTRATISTA deberá devolver los datos personales a LA COMITENTE así como también los soportes o documentos en que consten, sin conservar copia alguna. En caso de que con los datos personales proporcionados por LA COMITENTE, EL CONTRATISTA haya creado un registro con la finalidad de cumplir con el objeto del presente Contrato, éste debe ser destruido.

En el supuesto de incumplimiento por EL CONTRATISTA, incluidos sus empleados, de sus obligaciones según lo establecido en este contrato o de las derivadas de la legislación aplicable en materia de protección de datos EL CONTRATISTA será considerado responsable del tratamiento, y de forma especifica asumirá la total responsabilidad que pudiera derivarse a LA COMITENTE, titular de los bancos de datos, como consecuencia de cualquier tipo de sanción administrativa impuesta por procedimientos judiciales o extrajudiciales contra LA COMITENTE.

\section{DECIMOQUINTA: CLÁUSULA DE CONFIDENCIALADAD DE DATOS PERSONALES}

15.1. Debido a que para la ejecución de la OBRA, EL CONTRATISTA y LA COMITENTE accederán a datos personales incluidos en bancos de datos de su respectiva titularidad, deberán cumplir lo dispuesto en la Ley N* 29733 - Ley de Protección de Datos Personales y en su Reglamento aprobado por el Decreto Supremo 003-2013-juS en lo respecta al deber de secreto y confidencialidad. Por tal razón, EL CONTRATISTA y LA 
la relación contractual y de manera indefinida; con excepción de aquelios supuestos en que la ley exige la revelación de los mismos."

Las partes se comprometen a respetar, cumplir y hacer cumplir los compromisos y obligaciones de confidencialidad estipulados con arreglo a la cláusula 22 de las Condiciones Generales de Contratación del Grupo Enel Rev. 5" (en adelante, la "Cláusula de Confidencialidad"). No obstante, EL CONTRATISTA consiente desde ya que KOSSLER y GCZ puedan compartir con terceros datos generales acerca este Contrato, de la OBRA y de su participación en la misma, a modo de referencia para participar o concursar en otros proyectos públicos y privados. Dicha autorización no se entendera extendida a datos o documentos (escritos o electrónicos) que contengan:

- Información personal relacionada a representantes o trabajadores de LA COMITENTE, incluyendo "datos personales" de cualquier tipo aludidos en la cláusula décimocuarta de este documento.

- Productos, muestras, o especificaciones técnicas de propiedad de LA COMITENTE o que sean desarrollados para LA COMITENTE.

Información comercial o financiera de LA COMITENTE, incluyendo toda clase de documentación técnica o financiera, planes estratégicos, procesos, patentes, licencias u otra propiedad industrial de LA COMITENTE.

\section{DECIMOSEXTA: SUBCONTRATACIÓN}

16.1 EL CONTRATISTA no podrá subcontratar, integra o parcialmente, los trabajos encomendados. En todo caso, la subcontratación debe ser autorizada por escrito por LA COMITENTE. Asimismo, LA COMITENTE deberá aprobar por escrito al subcontratista que EL CONTRATISTA desee subcontratar. De existir dicha autorización, EL CONTRATISTA y el subcontratista seràn solidariamente responsables frente a LA COMITENTE respecto de la materia del subcontrato, para cuyo efecto EL CONTRATISTA presentará a LA COMITENTE el documento correspondiente debidamente firmado por el subcontratista.

- En caso se autorice la subcontratación, EL CONTRATISTA no será responsable ante ningún subcontratista, ni ante su personal por cualquier reclamación derivada del Contrato. A tal efecto, cuando se autorice la subcontratación, EL CONTRATISTA deberá presentar la renuncia expresa y escrita a ejercer acciones legales en contra de LA COMITENTE.

- LA COMITENTE no será responsable ante ningùn sublocador, ni ante su personal por cualquier reclamación derivada del Contrato. A tal efecto, cuando se autorice la subcontratación, EL CONTRATISTA deberá presentar la renuncia expresa y escrita a ejercer acciones legales en contra de LA COMITENTE.

- el CONTRATISTA responderá, liberará y mantendrá indemne a La COMITENTE de cualquier daño o perjuicio, incumplimiento de cualquier indole ocasionado por el subcontratista, derivados de la ejecución del SERVICIO.

- EL CONTRATISTA se obliga a obtener del subcontratista la aceptación previa de las obligaciones que frente a LA COMITENTE se deriven para el de todas las condiciones contractuales, juridicas, laborales, de seguridad y medio ambiente, Guia de Subcontratación, siendo imprescindible la presentación de la documentación indicada en las Instrucciones a los Proponentes.

- Sin perjuicio de lo anterior, LA COMITENTE podrá en todo momento y sin previo aviso, inspeccionar

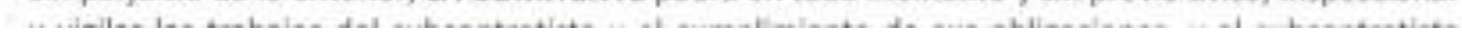


- LA COMITENTE se reserva el derecho de observación sobre aquellos subcontratistas que antes o durante la marcha de los trabajos, no considere conveniente subcontratar o mantener. Este derecho de observación deberá ser ejercitado por motivo justificado $y$ de forma razonable.

- El CONTRATISTA deberá efectuar un proceso de evaluación a los subcontratistas, debiendo presentar un informe detallado del mismo a LA COMITENTE.

16.2 EL CONTRATISTA no podrá aplicar para la ejecución de la OBRA el modelo de gestión denominado "Contratos de Gerenciamiento".

\section{DECIMOSÉTIMA: MORA}

Si EL CONTRATISTA no cumpliera con las obligaciones establecidas en el Contrato quedarà automáticamente constituido en mora, sin ser necesaria para el efecto la intimación de LA COMITENTE, de conformidad con lo dispuesto con el inciso 1 del artículo $1333^{\circ}$ del Código Civil. Si la obligación es pecuniaria, de conformidad con lo dispuesto por los articulos $1426^{\circ}$ y $1324^{\circ}$ del Código Civil, a partir de ese momento se devengarán los intereses.

\section{DECIMOCTAVA: RESOLUCIÓN DEL CONTRATO}

18.1 LA COMITENTE, de acuerdo con lo establecido en el artículo $1428^{\circ}$ del Código Civil, podrá resolver el presente Contrato en los casos que autoriza la ley.

Sin perjuicio de lo sehlalado en el párrafo precedente, las partes convienen expresamente que el Contrato se entenderá resuelto, sin necesidad de previa declaración judicial y con la sola notificación a la parte infractora, cuando se configure alguna de las siguientes causales de incumplimiento:

- Si El contratista no ejecuta la obra en los plazos pactados en el presente contrato.

- En caso El contratista no cumpla con ejecutar la OBRA con la calidad requerida.

- Si El CONTrAtista incumple lo establecido en las especificaciones técnicas, Bases integradas del Concurso del cual deriva el presente Contrato, y cualquier otra obligación o condición prevista en los documentos relacionados con el presente Contrato o lo dispuesto en las normas legales.

- Si El contratista acumula cuatro (4) atrasos en la fecha de entrega de los trabajos que comprende la OBRA.

- Si El CONTRATista usa material menudo, consumible y/o reembolsable que no cumpla con los estándares de calidad definidos por LA COMITENTE.

- Si El CONTRATISTA incumple las obligaciones, responsabilidades y declaraciones contempladas en el Contrato.

- Si El CONTRATISTA incumple la normativa y procedimientos legales y de LA COMITENTE en materia de salud, seguridad y medio ambiente.

- Si El contratista tiene un accidente fatal o grave bajo su responsabilidad.

- Si EL CONTRATISTA incumple con la responsabilidad de liberar y de mantener indemne a LA COMITENTE 
Tomando en consideración la calificación del EL CONTRATISTA como consorcio especializado en la ejecución de obras con caracteristicas similares a la OBRA, queda establecido que cualquier daño que se genere a las instalaciones de LA COMITENTE o de terceros asi como a la integridad fisica del personal de LA COMITENTE o de terceros derivada de la ejecución de la OBRA por parte del EL CONTRATISTA, sus subcontratistas o personal dependiente de cualquiera de ellos, será enteramente responsabilidad del EL CONTRATISTA Y deberá responder por la indemnización que corresponda en cada caso.

\section{VIGESSIMA: SOLUCIÓN DE CONTROVERSIAS}

Las partes harán sus mejores esfuerzos para que todos los conflictos y controversias feada una, una "Controversia") que pudieran surgir entre ellas sobre la interpretación, ejecución, cumplimiento y cualquier aspecto relativo a la existencia, validez o terminación del Contrato, sean resueltos en trato directo.

En el caso que las partes no resolvieran la Controversia en la via de trato directo, ésta será sometida a un arbitraje de derecho a través de un procedimiento tramitado de conformidad con lo estipulado en esta cláusula $\gamma$, en lo que no esté especificamente estipulado en la misma, en los Reglamentos Arbitrales del Centro de Arbitraje de la Cámara de Comercio de Lima (el "Centro"), siendo de aplicación supletoría el Decreto Legislativo $\mathrm{N}^{*} 1071$ que norma el arbitraje o la ley que lo sustituya. La aplicación del Reglamento del Centro no implica el sometimiento del asbitraje a la administración del Centro pues queda acordado que el arbitraje será ad-hoc, conducido por un tribunal arbitral integrado por tres (3) miembros (el "Tribunal Arbitral").

Cada parte designará a un (1) árbitro dentro de un plazo máximo de quince (15) dias contados desde la petición de arbitraje o su contestación, según corresponda. El tercer árbitro, quien a su vez se desempeñará como presidente del Tribunal Arbitral, será designado por acuerdo de los dos (2) árbitros designados por las partes dentro de un plazo de treinta (30) dias contados desde la designación del último de los árbitros. En caso que una parte no cumpla con designar el árbitro que le corresponde dentro del plazo estipulado en esta cláusula, dicho árbitro sera designado, a solicitud de cualquiera de las partes, por el Centro. En el caso que los dos árbitros designados por las partes no designaran al tercer árbitro dentro del plazo arriba indicado, el nombramiento será efectuado, a solicitud de cualquiera de las partes o de los árbitros designados, por el Centro.

El arbitraje tendrá lugar en la ciudad de Lima, Perú y será conducido en idioma español.

El laudo arbitral emitido y debidamente notificado sera definitivo, inapelable, tendra el valor de cosa juzgada y será eficaz y de obligatorio cumplimiento desde su notificación a las partes. Las partes, de la manera más amplia que permitan las leyes aplicables, renuncian a interponer cualquier recurso impugnatorio contra el laudo arbitral, quedando a sałvo únicamente el recurso de anulación del laudo previsto en el Decreto Legislativo $N^{\circ} 1071$ que norma el arbitraje o la ley que lo sustituya.

Constituye requisito para la admisibilidad del recurso de anulación y para la suspensión de los efectos del 
Para cualquier intervención de los jueces y tribunales ordinarios que fuera necesaria conforme al Decreto Legislativo $N^{*} 1071$, las partes se someten expresamente a la competencia de los jueces y tribunales del Distrito Judicial de Lima.

Los honorarios del Tribunal Arbitral y los gastos de secretaria serán fijados por el Tribunal Arbitral, teniendo como limite los establecidos por el Centro para los arbitrajes administrados por dicha institución, conforme a la Tabla de Aranceles aprobada por dicha institución vigente a la fecha de inicio del arbitraje.

Para efecto de determinar los honorarios y los gastos por secretaria, la cuantia de la Controversia se determinara tomando como base la valorización económica de la afectación invocada por el impugnante.

Cuando se trate de materias que no son cuantificables en dinero, el Tribunal Arbitral fijará sus honorarios según la complejidad de la materia, teniendo como limite los montos de honorarios y gastos administrativos previstos en la Tabla de Aranceles del Centro para cuantias de US\$ $5,000,000,00$ (cinco millones y 00/100 Dólares de los Estados Unidos de América).

Los gastos incurridos por las partes como consecuencia del arbitraje serán asumidos por la parte que resulte perdedora.

Sin perjuicio de lo expuesto, las partes someten la dirimencia de las Controversias que no fuesen arbitrables, a la jurisdicción y competencia de los jueces y tribunales del Distrito Judicial de Lima, renunciando de antemano a los fueros de sus domicilios.

Durante el proceso de solución de controversias conducido de conformidad con esta cláusula, las partes estarán obligadas a continuar cumpliendo con sus obligaciones respectivas en virtud del contrato en la medida que sea posible, inclusive con aquellas materia de disputa, salvo que exista medida cautelar arbitral o judicial que autorice lo contrario. 
En señal de conformidad y ratificación de lo acordado, se suscribe el presente Contrato en dos (2) ejemplares, quedando un (1) ejemplar en poder del EL CONTRATISTA y otro en poder de LA COMITENTE, en la ciudad de Lima a los 16 dias del mes de noviembre de 2016.

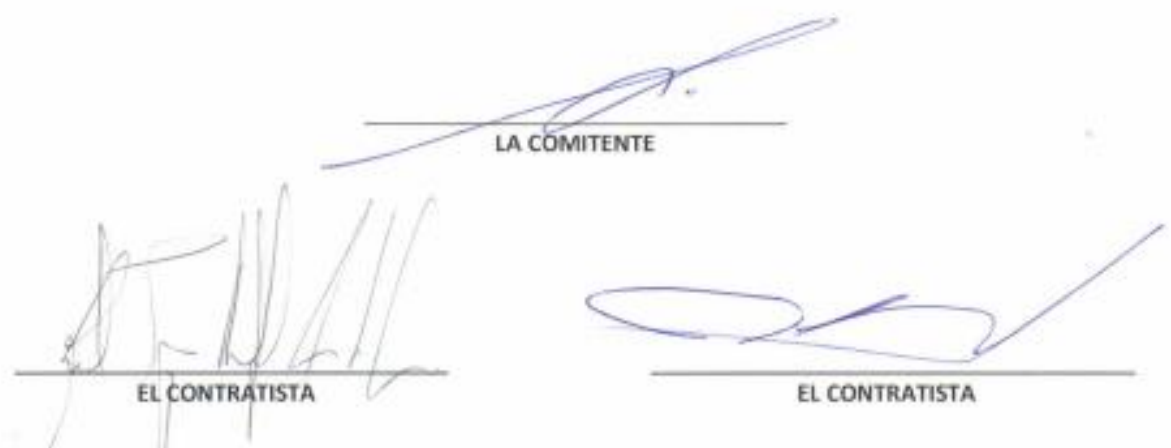


ANEXO $N^{*} 1$

CUADRO DE PRECIOS

Dólares de los Estados Unidos de América, sin impuestos

\begin{tabular}{|c|c|c|c|c|c|}
\hline $\mathbf{M}^{*}$ & Quantiy & Description & $\begin{array}{c}\text { Unit } \\
\text { Price ec? }\end{array}$ & $\begin{array}{c}\text { Unit } \\
\text { Price Köealer }\end{array}$ & $\begin{array}{l}\text { Tetal } \\
\text { Price }\end{array}$ \\
\hline 1 & 1 & Designa and tengintering & 15,000000 & 14.374 .14 & $29,374.14$ \\
\hline 2 & 1 & Temporary vite Gatilifes fiscluding fise: disposal and aite sleaningi & $11,438.61$ & $*$ & $15,430.61$ \\
\hline 3 & 1 & Hydrotiectric and hydromethanizal equipment & $184,570.65$ & 7eojost:D2 & $945,427,67$ \\
\hline It & 2 & Stream Diver Tiatines & * & 152,20030 & $305,460 \%$ \\
\hline 37 & 1 & Autunabon iCentrid Unt Spotronuzon, SCADA) & 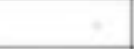 & t34. $x_{0} 88$ & 10450283 \\
\hline 33 & 2 & Pemarest Megnet Cenerdicrs & - & 112.342 .74 & $230,525,48$ \\
\hline 34 & 2 & shue oft Vaves & - & $35,391.00$ & 71.12365 \\
\hline 35 & 1 & Guding System (including LARS, Unserwater Caties] & + & 10.444 .26 & 18.4425 \\
\hline 35 & 1 & High Wotage Poser Iranstomet & 10.74230 & $=$ & $14,742.90$ \\
\hline 27 & 1 & $30 \mathrm{kV}$ Cuticles & 45.379 .65 & ? & 45,3965 \\
\hline 38 & 1 & Low Volape Cacies & 36.75620 & * & 35,76620 \\
\hline 39 & 1 & Flap Date & 83,58250 & + & 12,58,50 \\
\hline 4 & 1 & Tramaportation of equipments to the sile & $4,206.26$ & $23,396.09$ & $27,602.95$ \\
\hline 41 & 1 & Mos teight & - & 2139606 & $23 \times 5 \times 0 \%$ \\
\hline 42 & 1 & Iniand teght & 4.26685 & $=$ & 4.20688 \\
\hline 5 & 1 & Equipment asuembly & $76,194.64$ & $52,062.03$ & $128,206,67$ \\
\hline 51 & 1 & Fackory Assemely : Satan Dver unts & 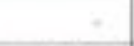 & 3206200 & $12,062.03$ \\
\hline 52.2 & 1 & Ste Assembly & 76,19464 & * & $76,194.64$ \\
\hline 5 & 1 & Clvil works & $464,107,94$ & , & $458,107,04$ \\
\hline 61 & 1 & Preimitiry wats & N. 500 os & - & 1050000 \\
\hline 62 & 1 & Phousional chumel & $63 \operatorname{sen} 23$ & + & 4380023 \\
\hline 63 & 1 & Wats ineg & 38,814 at & 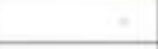 & $29.8+4.94$ \\
\hline 6.4 & 1 & Bndpe condboring & 76,86994 & " & 75.206 \\
\hline 6.5 & 1 & Tutine Housing conshuction & $201,132 \%$ & & 201,13290 \\
\hline
\end{tabular}

\begin{tabular}{|c|c|c|c|c|c|}
\hline 56 & 1 & 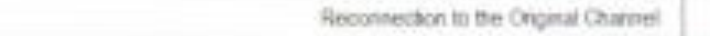 & 25.30632 & 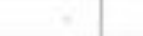 & $26308 \mathrm{n}$ \\
\hline & & & $2+1$ & & $-\ldots+\ldots-1$ \\
\hline & 1 & Sealng Kin (Flap gate, O-forngs, Seais of hydraulic servomotor) & 528.93 & . & 528.93 \\
\hline & 1 & Overthead & $104,285,14$ & $130,181.48$ & $234,466.62$ \\
\hline & 1 & Profits & $82,020,12$ & $41,966.40$ & $123,986.52$ \\
\hline & & Total cost of the service (without Taxes): & $970,744.00$ & $1,028,605.00$ & $1,999,349,00$ \\
\hline
\end{tabular}

№ Cesta: 2000224385

NN Expediente: LGPE11602646

Contrato SRM No: 8400104783 - 8400105046 